\title{
DIAGNÓSTICO DAS POPULAÇÕES DE AVES E MAMÍFEROS CINEGÉTICOS DO PARQUE ESTADUAL DA SERRA DO MAR, SP, BRASIL
}

\author{
Renato Matos Marques
}

\begin{abstract}
Dissertação apresentada à Escola Superior de Agricultura "Luiz de Queiroz", Universidade de São Paulo, para obtenção do título de Mestre em Ecologia de Agroecossistemas.
\end{abstract}

P I R A C I C A B A

Estado de São Paulo - Brasil

Novembro - 2004 


\title{
DIAGNÓSTICO DAS POPULAÇÕES DE AVES E MAMÍFEROS CINEGÉTICOS DO PARQUE ESTADUAL DA SERRA DO MAR, SP, BRASIL
}

\author{
Renato Matos Marques
}

Bacharel em Ciências Biológicas

Orientador: Prof. Dr. MAURO GALETTI RODRIGUES

P I R A C I C A B A

Estado de São Paulo - Brasil

Novembro - 2004 


\section{Dados Internacionais de Catalogação na Publicação (CIP) DIVISÃO DE BIBLIOTECA E DOCUMENTAÇÃO - ESALQ/USP}

\section{Marques, Renato Matos}

Diagnóstico das populações de aves e mamíferos cinegéticos do Parque Estadual da Serra do Mar, SP, Brasil / Renato Matos Marques. - - Piracicaba, 2004.

$145 \mathrm{p}$.

Dissertação (Mestrado) - - Escola Superior de Agricultura Luiz de Queiroz, 2004.

Bibliografia.

1. Área de conservação 2. Aves 3. Caça 4. Densidade populacional 5. Mamíferos 6. Mat Atlântica 7. Parques estaduais 8. Proteção ambiental 9. Serra do Mar I. Título

CDD 639.9 
De cada cem árvores antigas

Restam cinco testemunhas acusando

$O$ inflexivel carrasco secular.

Restam cinco, não mais. Resta o fantasma

Da orgulhosa floresta primitiva.

Carlos Drummond de Andrade

Muriqui, muriqui, tu estavas aqui

Bem antes do europeu, bem antes do progresso.

Teu alegre saltar entre ramos e ventos

Vai ficando tão longe. Onde estás, muriqui?

És apenas lembrança

De um tempo que eu não vi.

Carlos Drummond de Andrade 


\section{AGRADECIMENTOS}

Muito obrigado a toda minha família pela compreensão e apoio durante todo este tempo. Agradecimento especial a minha mãe Seuza, ao meu pai Fernando, minha irmã Paula e seu esposo Wesley, e a minha pequena sobrinha Bruna.

Agradeço ao meu orientador Mauro Galetti e aos professores Carlos A. Vettorazzi, Ariovaldo da Cruz-Neto, Wesley R. Silva pelas orientações, dicas e comentários que ajudaram muito para a elaboração desse trabalho, assim como as

críticas construtivas e opiniões de Denis Briani, Leandro Gumiero e Ângelo Gilberto Manzato. Agradeço também ao Giordano Automare e Marcos Nalon pelos mapas e dados fornecidos sobre uso do solo, tipos florestais e outros mais, além do auxílio na elaboração do banco de dados georreferenciado.

A todos os funcionários e estagiários dos Núcleos Cunha, Sta. Virgínia e Picinguaba do Parque Estadual da Serra do Mar, em especial aos que me ajudaram de uma forma ou outra nos trabalhos de campo e que além disso se tornaram grandes companheiros. Ao Instituto Florestal pela autorização em coletar dados nas áreas e aos responsáveis pelas administrações dos parques que, muitas vezes mesmo sem as condições ideais de trabalho, sempre me apoiaram nos longos períodos de campo, tornando a pesquisa viável.

Aos amigos e companheiros de campo que por muitas fezes tiveram que me aturar por longos períodos, dentre eles em especial ao André Teixeira (ganso), Paul François (franco-paraguaio) que tmbém me ajudaram posteriormente no planilhamento dos dados. Os muitos quilômetros percorridos nos censos e os milhares de dados de vegetação e frutos coletados somente foram possíveis graças ao apoio destas pessoas. $\mathrm{E}$ também ao Guima que me salvou quando eu precisei de um laptop pra trabalhar, além de 
sempre me incentivar a dar aquela pardinha e curtir uma festa...o que também é muito importante para a saúde mental de uma pessoa...

Agradeço também aos amigos de antes e àqueles que fiz durante o meu mestrado e que me ajudaram de uma maneira ou de outra, dando opiniões, fazendo críticas, participando de longas discussões ou que simplesmente me ouvindo quando eu precisava falar: Camila, Chris, Eliana, Paulo "miúdo", Saldanha, Omelete, Goiano, Sabrina, Ariane, Fadini, Julieta e muitos outros.

Agradeço a estrutura disponibilizada pelo Departamento de Ecologia da UnespRio Claro e por fim às instituições que forneceram apoios logísticos e financeiros ao projeto e à minha própria pessoa: Idea Wild, Fapesp (proc n. 01/00463-5, proc. N. 01/10545-3) e a Conservação Internacional do Brasil, principalmente a pessoa de Luiz Paulo Pinto, que acreditou na proposta de trabalho desde o seu início. 


\section{SUMÁRIO}

\begin{tabular}{|c|c|}
\hline & Página \\
\hline LISTA DE FIGURAS... & viii \\
\hline LISTA DE TABELAS.... & $\mathrm{xi}$ \\
\hline RESUMO... & $\mathrm{XV}$ \\
\hline SUMMARY................. & xvii \\
\hline 1 INTRODUÇÃO... & 1 \\
\hline 2 REVISÃO DE LITERATURA... & 6 \\
\hline 2.1 Abundância e Densidade da Fauna Silvestre................................................... & 6 \\
\hline 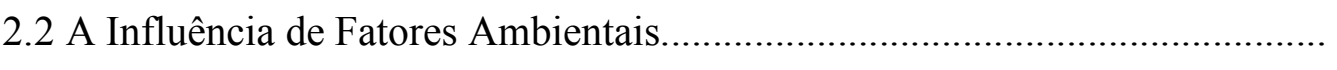 & 7 \\
\hline 2.3 Viabilidade de Populações...... & 10 \\
\hline 3 MATERIAL E MÉTODOS....... & 14 \\
\hline 3.1 Áreas de Estudo............ & 14 \\
\hline 3.2 Mapeamento de Trilhas e o Estabelecimento das Transecções......................... & 18 \\
\hline 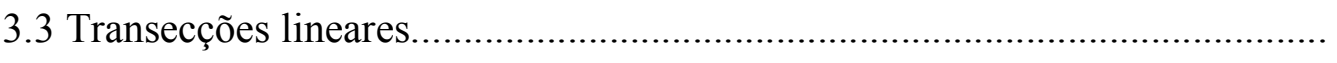 & 19 \\
\hline 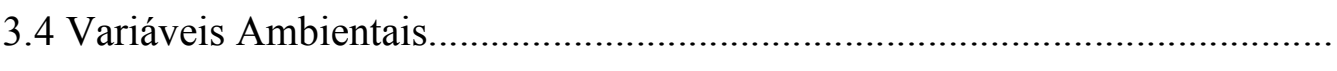 & 24 \\
\hline 3.4.1 Pressões Antrópicas: a caça e o turismo...... & 24 \\
\hline 3.4.2 Estrutura da Vegetação................................................ & 25 \\
\hline 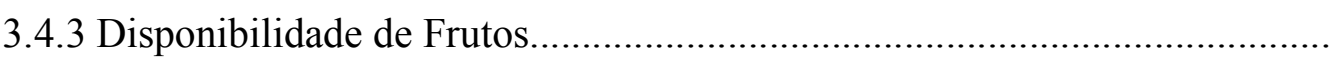 & 26 \\
\hline 3.5 Densidades e Estimativas Populacionais................................... & 27 \\
\hline 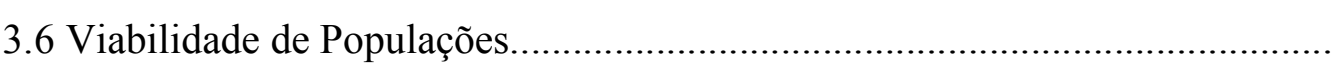 & 29 \\
\hline 3.7 Análise dos Dados.... & 30 \\
\hline
\end{tabular}




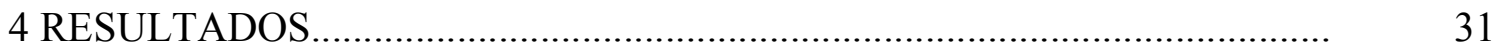

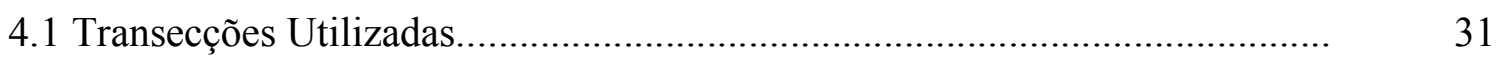

4.2 Distâncias de Detecção.......................................................................... 33

4.3 Padrões de Atividade............................................................................

4.4 Abundâncias das Espécies e Uso do Habitat................................................ 41

4.5 Variáveis Ambientais............................................................................. 45

4.5.1 Pressões Antrópicas: a caça e o turismo...................................................... 45

4.5.2 Estrutura da Vegetação.......................................................................... 47

4.5.3 Disponibilidade de Frutos.................................................................. 48

4.5.4 Comparação dos Resultados............................................................... 52

4.6 Influência das Variáveis Ambientais.......................................................... 58

4.6.1 Resultados da Análise de Correspondência Canônica (CCA)...................... 60

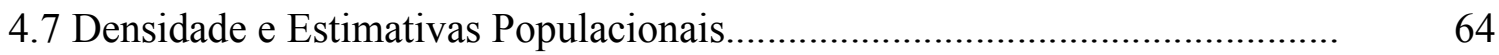

4.7.1 Comparação com Outras Áreas de Mata Atlântica..................................... 70

4.7.2 Influência do Tamanho da Área na Densidade das Espécies...................... 72

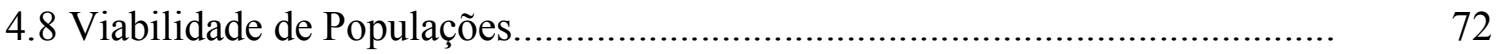

4.9 Ocorrência das Espécies.................................................................... 75

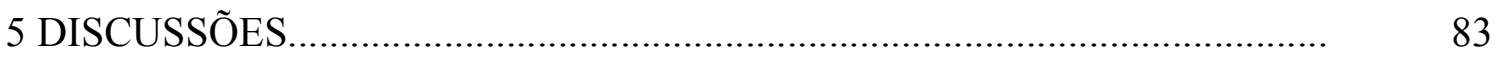

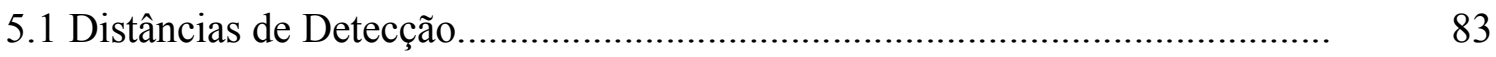

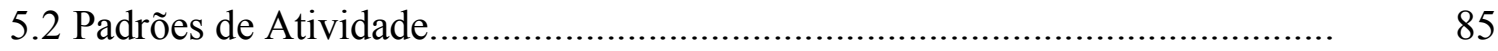

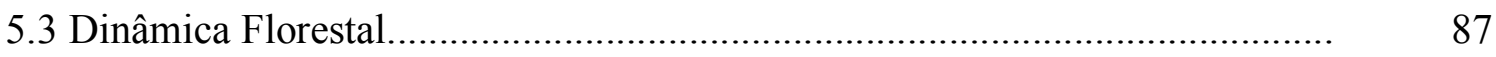

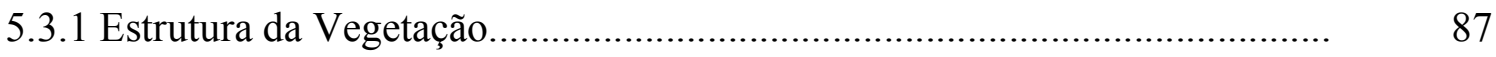

5.3.2 Disponibilidade de Frutos............................................................... 91

5.4 Fatores Ambientais e a Abundância e Distribuição das Espécies................... 93

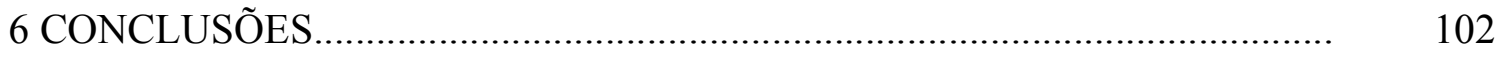

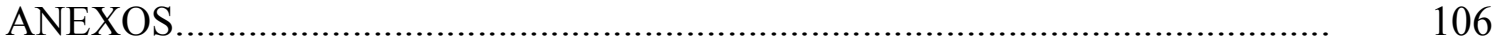

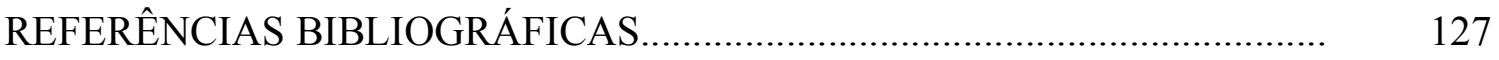




\section{LISTA DE FIGURAS}

Página

1 Localização dos corredores propostos para a Mata Atlântica no Brasil (extraído e modificado de MMA/SBF, 2000)....................................

2 Localização do PESM e suas unidades administrativas. Localização das três áreas alvo do presente estudo no setor norte do parque, próximo a divisa com o Estado do Rio de Janeiro (extraído de

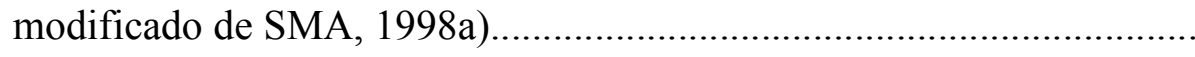

3 Setor norte do PESM, onde aparecem as trilhas utilizadas em cada uma das áreas amostradas (Mapa fonte: SIGMA).................................... 32

4 Distribuição dos horários das visualizações de mamíferos e aves nas áreas de estudo.

5 Distribuição dos horários das visualizações de mamíferos no inverno e verão.

6 Distribuição dos horários das visualizações de aves no inverno e verão.

7 Distribuição dos horários das visualizações de verão nas três áreas de estudo. 
8 Distribuição dos horários das visualizações de inverno nas três áreas de estudo

9 Freqüências de ocorrência das espécies de aves e mamíferos

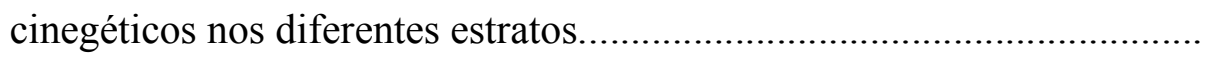

10 Porcentagem da biomassa total obtida para as principais espécies de frutos coletados.

11 Disponibilidades de frutos $\left(\mathrm{kg} / \mathrm{km}^{2}\right)$ obtidas durante o verão para as principais espécies nas três áreas do setor norte do PESM

12 Disponibilidades de frutos $\left(\mathrm{kg} / \mathrm{km}^{2}\right)$ obtidas durante o inverno para as principais espécies nas três áreas do setor norte do PESM.

13 Valores médios obtidos para cada uma das categorias de uso histórico avaliadas, referente às variáveis DABS (a), VOL (b) e DPA (c). Letras diferentes indicam diferenças significativas (Tukey-kramer, $\alpha=0,05$ ).

14 Valores médios obtidos para cada uma das categorias de uso histórico avaliadas, referente às variáveis $\operatorname{COBD}$ (a) e DPJ (b). Letras iguais indicam que não houve diferença significativa (Tukey-kramer , $\alpha=$ $0,05)$

15 Valores médios de DPP para cada uma das categorias de uso histórico avaliadas. Letras iguais indicam que não houve diferença significativa (Tukey-kramer, $\alpha=0,05$ ). 
16 Valores médios obtidos para cada uma das categorias de uso histórico avaliadas, referente às variáveis DISPO (a) e DISPP (b). Letras iguais indicam que não houve diferença significativa (Tukey-kramer, $\alpha 0,05$ )

17 Valores médios obtidos para cada uma das categorias de uso histórico avaliadas, referente às variáveis DEA (a), DEJ (b) e DEP (c). Letras iguais indicam que não houve diferença significativa para o teste

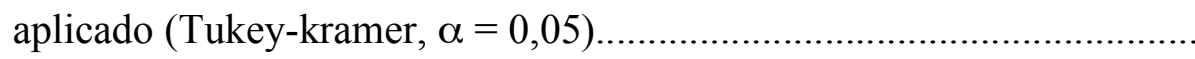

18 Diagrama de ordenação da Análise de Correspondência Canônica (CCA). O diagrama apresenta a distribuição das espécies/grupos e variáveis ambientais nos dois primeiros eixos de ordenação. As áreas amostrais, no caso as transecções, geralmente presentes no diagrama, não foram representadas para uma melhor visualização dos resultados. Variáveis ambientais representadas pelas setas, que indicam grandeza e sentido das variações (para melhor visualização os valores dos vetores foram multiplicados por 2). CACA = Caça, DISPP = Disponibilidade de frutos de palmito, DISPO = Disponibilidade de outros frutos, $\mathrm{COBD}=$ Cobertura de dossel, DABS, Densidade absoluta, DPA = Densidade de palmeiras adultas

19 Número de populações viáveis para cada um dos cenários propostos, com MVP mínimas de 500, 1.000, 2.000, 5.000 e 7.000 indivíduos....... 


\section{LISTA DE TABELAS}

Página

1 Núcleos amostrados do PESM com breve descrição de históricos de ocupação, uso do solo e pressões antrópicas atuais. Além do tamanho das áreas, porcentagem de cobertura dos principais tipos florestais e as estimativas populacionais nas principais cidades do entorno.

2 Trilhas utilizadas em cada um dos núcleos amostrados no PESM, as transecções estabelecidas, tipo florestal predominante e o comprimento total. Classificação da vegetação segundo SIGMA

3 Resultados da ANOVA e comparação através do teste de Tukey-Kramer dos valores transformados das distâncias perpendiculares médias ( $\log \mathrm{DPM})$, para as diferentes categorias avaliadas. Itens identificados pela mesma letra não apresentam diferença significativa

4 Número de visualizações de todas as espécies registradas durante os censos nas áreas de estudo.

5 Abundâncias em número de visualizações $/ 10 \mathrm{~km}$ (n. visual $/ 10 \mathrm{~km}$ ) das espécies de aves e mamíferos cinegéticos em cada um dos núcleos amostrados e abundância geral. Foram consideradas somente as espécies que obtiveram um número total mínimo de cinco registros 
6 Abundância das espécies de aves e mamíferos cinegéticos nos tipos florestais amostrados. Foram consideradas somente as espécies que obtiveram um número total mínimo de cinco visualizações.........................

$7 \quad$ Número total de registros de eventos de caça, taxa de intensidade desta atividade (número de eventos/10 km) e o número de turistas/ano para cada uma das transecções utilizadas no PESM.

8 Espécies e respectivas famílias de todos os frutos zoocóricos identificados no setor norte do PESM. Sub-síndrome, número de frutos coletados e o peso seco total obtido para cada uma delas

9 Disponibilidade de frutos $\left(\mathrm{kg} / \mathrm{km}^{2}\right)$ obtida no inverno, verão e numa avaliação anual para as principais espécies zoocóricas identificados no setor norte do PESM

10 Tabela dos Coeficientes de Correlação de Pearson obtidos para as diferentes variáveis ambientais avaliadas. Valores elevados dos coeficientes indicam colinearidade entre os fatores

11 Autovalores, variâncias relativas e correlações obtidas para cada um dos dois primeiros eixos de ordenação obtidos na Análise de Correspondência Canônica.

12 Coeficientes de correlação entre as variáveis ambientais e os dois primeiros eixos da Análise de Correspondência Canônica 
13 Resultados do Teste de Monte-Carlo indicando as correlações da matriz de variáveis ambientais e os dois primeiros eixos de ordenação da Análise de Correspondência Canônica.

14 Tamanho médio do grupo (TMG e variação) e largura efetiva de trilha (ESW) calculada pelo programa DISTANCE 4.1 para espécies de mamíferos e aves cinegéticas com número (n) mínimo de cinco visualizações. S.E. = erro padrão, C.V. = coeficiente de variação e C.I. = intervalo de confiança a 95\%, que são utilizados para o cálculo dos valores máximos e mínimos das densidades.

15 Densidades $\left(\mathrm{D}_{\text {média }}=\right.$ indivíduos $\left./ \mathrm{km}^{2}\right)$ das espécies de mamíferos e aves cinegéticas com mais de cinco visualizações, calculadas a partir das ESW e TMG fornecidos pelo programa DISTANCE 4.1. Valores entre parênteses representam Densidade Mínima $\left(\mathrm{D}_{\text {mínima }}\right)$ e Densidade Máxima $\left(\mathrm{D}_{\text {máxima }}\right)$, respectivamente, calculadas a partir do C.I. presente na Tabela 11. Densidades calculadas para cada tipo florestal avaliado $(F O D=$ floresta ombrófila densa e VS = vegetação secundária), em cada uma das áreas.......

16 População estimada (Pop média $=$ indivíduos) das espécies de mamíferos e aves cinegéticas com mais de cinco visualizações. Valores entre parênteses

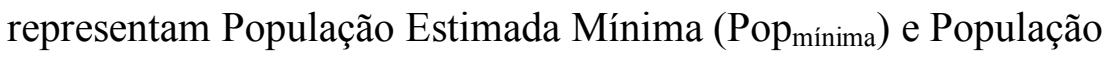

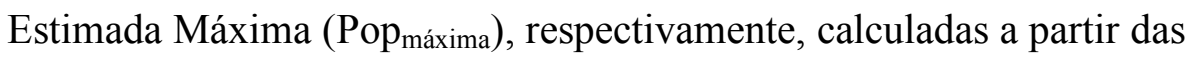
$\mathrm{D}_{\text {mínima }}$ e $\mathrm{D}_{\text {máxima }}$ presentes na Tabela 12. Populações estimadas para cada tipo florestal avaliado (FOD = floresta ombrófila densa e VS = vegetação secundária), em cada uma das áreas de estudo. 
17 Densidades das espécies de mamíferos e aves cinegéticas no presente estudo e em outras áreas de estudo na Mata Atlântica. Referência (Ref.).....

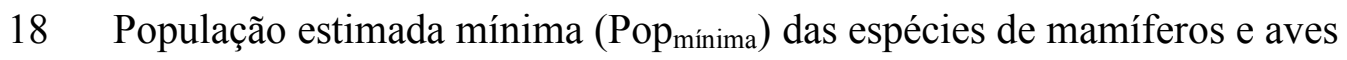
cinegéticas para os diferentes cenários a serem avaliados. Área total $\left(\mathrm{km}^{2}\right)$ considerada em cada um dos cenários. Número total de populações viáveis (Pop.V), sendo a MVP considerada na primeira análise como de 500 indivíduos e de 1.000, 2.000, 5.000 e 7.000 indivíduos nas seguintes............ 


\section{DIAGNÓSTICO DAS POPULAÇÕES DE AVES E MAMÍFEROS CINEGÉTICOS DO PARQUE ESTADUAL DA SERRA DO MAR, SP, BRASIL}

Autor: RENATO MATOS MARQUES

Orientador: Prof. Dr. MAURO GALETTI

RESUMO

O presente trabalho avaliou não somente a abundância e densidade de mamíferos e aves cinegéticas na área do Parque Estadual da Serra do Mar (PESM), mas também identificou fatores que influenciaram a ocorrência e distribuição destas espécies. $O$ PESM tem ao todo $3.150 \mathrm{~km}^{2}$ e é o maior remanescente de florestas contínuas de Mata Atlântica no Brasil. Foram percorridos $633,55 \mathrm{~km}$ em 15 trilhas distribuídas em três núcleos do setor norte do PESM. Foram obtidas 184 visualizações, tendo sido registradas 11 espécies de mamíferos e 6 espécies de aves cinegéticas durante os censos, num total de 77 encontros com mamíferos e 107 com aves. Dentre as aves cinegéticas com maior abundância destaca-se o jacu Penelope sp. (0,99 visualizações/10 km) e dentre os mamíferos o esquilo Sciurus aestuans (0,48 visualizações/10 km). As espécies apresentaram padrões diferenciados de uso do habitat, padrão de atividades e ocorrência nas áreas avaliadas. Através da análise de correspondência canônica (CCA) dos fatores ambientais foi possível determinar que de maneira geral as espécies de aves apresentamse correlacionadas com uma maior disponibilidade de frutos carnosos, enquanto que as espécies de mamíferos apresentam-se correlacionadas com parâmetros de estrutura física da floresta tais como cobertura de dossel, densidade arbórea e densidade de outras 
palmeiras que não o palmito, este último principalmente para o queixada (Tayassu pecari). A caça se mostrou um fator que afeta negativamente a maioria das espécies sendo que seu efeito somente não foi observado para $S$. aestuans e Penelope sp. que, ao que tudo indica, não são espécies intensamente caçadas nas áreas avaliadas. A partir das densidades obtidas foram realizadas estimativas populacionais para as áreas de estudo e extrapolações para todo o PESM. Considerando-se apenas 500 indivíduos como o número mínimo necessário de indivíduos para garantir a viabilidade destas populações foi possível perceber que as áreas estudadas, avaliadas separadamente, não seriam capazes de garantir a manutenção de boa parte das espécies. Quadro este agravado quando considerados valores ainda maiores de população mínima viável necessária. Contudo, para todos os cenários avaliados dados indicam que maiores seriam as chances de manutenção das espécies quando considerado todo o setor norte do parque, área formada pelos três núcleos avaliados, e principalmente o PESM como um todo. Este fat reforça a importância da conectividade entre estas áreas e a manutenção de grandes blocos de matas contínuas. O PESM pode ser considerado uma das mais importantes áreas para a preservação de espécies cinegéticas, sendo a área estratégica no contexto de criação de um corredor ecológico na região, devido principalmente a sua riqueza faunística, qualidade dos remanescentes existentes, presença de espécies raras e ameaçadas de extinção, localização biogeográfica e também por seu gradiente altitudinal. 


\title{
DIAGNOSTIC OF GAME BIRDS AND MAMMALS POPULATIONS OF SERRA DO MAR STATE PARK, SP, BRAZIL
}

\author{
Author: RENATO MATOS MARQUES \\ Adviser: Prof. Dr. MAURO GALETTI
}

\section{SUMMARY}

The aim of this work was to estimate the abundance, diversity and population size of game birds and mammals from the rain forest at Serra do Mar State Park (Parque Estadual da Serra do Mar - PESM), and to identify the variables which influence the ocurrence and distribution of those species. The PESM has $3.150 \mathrm{~km}^{2}$ and is the major continuous remaining of Atlantic Forest in Brazil. A total of 633,55 km census using line transect method, distributed on 15 trails on the north-sector of PESM, resulted in 184 observations, which 77 of those were encounters with game mammals and 107 with birds. Eleven species of mammals and six of birds were recorded during the census. Among game birds the most abundant was the guan, Penelope spp. (0,99 encounters/10 $\mathrm{km})$, and among the game mammals was the squirrel, Sciurus aestuans $(0,48$ encounters $/ 10 \mathrm{~km}$ ). The species presented different habitat uses, activity and ocurrence patterns, but when analysing the environmental variables with canonical correspondence analysis (CCA) we detected that the birds were correlated with fruit aviability, while mammals were more correlated to the vegetation structure, such as canopy cover, arboreal density and palms (not palmito) density, this last one specially to the whitelipped-peccaries (Tayassu pecari). The hunting pressure affected negatively most of the species, except for S. aestuans and Penelope spp., which seems to not be intensively hunted at the study areas. Using the densities obtained we estimated the remaining 
population to the study areas and also to the different scenarios proposed. Even considering only 500 as a minimum number of individuals necessary to guarantee the viability of those populations, the study areas, when analyzed separally, could not maintain most of the game species. It does get worst when considering higher numbers of minimum viable population. Moreover, the results indicate better chances of maintaining populations of the species when considering the area of the north-sector and higher chances when considering the entire park. This fact regards the importance of the connectivity between these areas and the necessity of maintaining large continuous block of forests. PESM can be considered one of the most important areas for the conservation of game species and it's a strategic area in a context of an ecological corridor, due to it's richness, quality of forest remains, presence of rare and threatened species, biogeographic localization and also by the altitudinal gradient. 


\section{INTRODUÇÃO}

Quando os primeiros portugueses chegaram no Brasil em 1.500, pesquisadores estimam que a Mata Atlântica cobria cerca de 1,3 milhão de $\mathrm{km}^{2}$ (Myers et al., 2000; SOS Mata Atlântica \& INPE, 1992), embora provavelmente as populações humanas nativas pré-cambrianas tenham reduzido e modificado parte dessa área original (Dean, 1996). Esta vegetação contínua de norte a sul do país era uma das maiores florestas tropicais do mundo, ocorrendo desde o Rio Grande do Norte $\left(6^{\circ} \mathrm{S}\right)$ ao Rio Grande do Sul $\left(30^{\circ} \mathrm{S}\right)$. Atualmente, esse bioma está reduzido a menos de $8 \%$ de sua extensão original, ou cerca de $100.000 \mathrm{~km}^{2}$, espalhados em vários fragmentos e poucas matas contínuas (Myers et al., 2000; SOS Mata Atlântica \& INPE, 1992). Após a exploração madeireira pelos colonizadores, quando foram retiradas muitas espécies, a floresta foi devastada para as plantações de cana-de-açúcar e café e, se não bastasse tais impactos, nas últimas décadas a Mata Atlântica vem sofrendo também com uma enorme pressão devido ao crescimento urbano, e por isso, já é considerado um dos ecossistemas mais ameaçados do planeta (Brown Jr. \& Brown, 1992; Myers et al., 2000).

Vertebrados de grande porte e frugívoros especialistas como aves e mamíferos de médio porte, são particularmente mais vulneráveis a diminuição de suas populações frente as diferentes pressões no ambiente, tais como perda de habitat, competição por recursos com o homem ou caça e tráfico de animais (Chiarello, 1999; Chiarello, 2000a; Estrada et al., 1993; Galetti \& Fernandez, 1998; Redford, 1992). A perda de habitat, através de desflorestamento ou fragmentação, afeta principalmente animais de médio e grande porte, pois necessitam geralmente de uma extensa área de vida e a redução da área faz com que os indivíduos remanescentes não sejam capazes de encontrar recursos 
suficientes, o que pode levar à migração ou à extinção local de tais espécies (Chiarello, 2000b; Newmark, 1991; Newmark, 1993; Newmark, 1995; Newmark, 1996).

Redford e Robinson (1991) constataram que, após avaliarem diversas Unidades de Conservação (UCs) brasileiras, áreas menores que $316 \mathrm{~km}^{2}$ podem não ser capazes de abrigar populações geneticamente viáveis de grandes mamíferos, especialmente de predadores estritamente carnívoros. Mesmo nos bem equipados parques norteamericanos tem sido registrado um grande número de extinções de mamíferos, principalmente os de grande porte, que requerem em torno de $1.000 \mathrm{~km}^{2}$ (Newmark, 1995).

Outra forma de pressão atualmente existente sobre a fauna da Mata Atlântica é a competição por recursos com o homem e a retirada de produtos não madeireiros, como por exemplo, bromélias, frutos ou partes vegetativas de diversas plantas (Vasquez \& Gentry, 1989). Na Mata Atlântica brasileira um desses produtos largamente utilizado é o palmito-juçara (Euterpe edulis), que vem sendo explorado antes mesmo da chegada dos primeiros portugueses (Galetti \& Fernandez, 1998). Como a grande maioria de mamíferos e aves em áreas de floresta são espécies frugívoras (Robinson \& Redford, 1986; Terborgh, 1986) e o palmito-juçara é uma importante fonte de frutos na Mata Atlântica para boa parte da fauna (Galetti \& Peres, 1999; Ziparro et al., dados não publicados), é possível que a retirada de palmito afete não somente a estrutura vegetal da floresta, pela perda de milhares de indivíduos e destruição causada às outras espécies vegetais próximas e ou associadas, como também afete toda estrutura da fauna local, que se alimenta dos frutos do palmito-juçara (Galetti \& Aleixo, 1998; Galetti et al., 1997). Estudos relacionando a abundância das espécies animais com características da vegetação demonstram que a estrutura da vegetação e principalmente a disponibilidade de alimento são determinantes da ocorrência e abundância das espécies (Peres, 1997; Spironelo, 1991; Stevenson, 2001).

Além de afetar diretamente a ocorrência das espécies, a perda de habitat e a retirada ilegal de palmito-juçara geralmente levam ao aumento da exploração comercial e/ou da caça nestas áreas (Tabarelli et al., 2004). Isto se deve ao fato de que na maioria 
das vezes ocorre um aumento significativo no número de pessoas vivendo ou transitando pela área afetada ou no entorno dela e que praticam tais atividades, ou até mesmo facilitando a entrada de caçadores de áreas adjacentes através de trilhas, estradas ou acessos antes não existentes ou desconhecidos (Peres, 1999).

A caça, apesar de ilegal no Brasil desde 1967 (Lei 5.197/67), continua sendo praticada de maneira esportiva, recreacional e até mesmo profissional na maioria das áreas de Mata Atlântica (Chiarello, 2000a; Olmos \& Galetti, 2004; Olmos et al., 2002; Pardini \& Develey, 2004) e diversos estudos demonstraram mudanças na abundância de espécies e até mesmo alterações comportamentais de alguns animais devido `a pressão da caça (Bodmer et al., 1997; Cullen Jr. et al., 1999; Cullen Jr. et al., 2000; Peres, 1990; Peres, 1996; Peres, 2000; Wright et al., 2000).

Apesar das diversas pressões existentes sobre os remanescentes de Mata Atlântica, este bioma ainda abriga cerca de 250 espécies de mamíferos, 55 endêmicos, e 1.020 espécies de aves, das quais 188 endêmicas, além de muitas outras espécies de anfíbios, répteis e peixes que somam um total de cerca de 1.810 espécies de vertebrados sendo que pelo menos 389 são endêmicas (Ministério do Meio Ambiente/Secretaria de Biodiversidade e Florestas (MMA/SBF), 2000; Secretaria do Meio Ambiente (SMA), 1998). Myers compilou informações sobre a riqueza biológica de cada ecossistema no mundo, a importância destas áreas para seus respectivos países ou regiões, as crescentes pressões antrópicas nestes locais e o quanto desses ambientes se encontra protegido, definindo o termo "hotspot" ou áreas quentes (Myers et al., 2000).

No ano de 1996 a Conservation International realizou reuniões onde mais de 20 especialistas, incluindo Myers, re-avaliaram os conceitos para a determinação dessas áreas e decidiram que um dos principais fatores que deveriam influenciar nestas escolhas seria o nível de endemismo, uma vez que estas espécies, segundo especialistas seriam as primeiras a desaparecerem frente aos impactos antrópicos (Myers et al., 2000). Destes trabalhos, um total de 25 áreas foram definidas como sendo "hotspots" e dentre elas a Mata Atlântica, em grande parte devido ao seu alto nível de endemismo, sendo considerada como uma das áreas mais importantes para a manutenção da biodiversidade 
mundial, mas que por outro lado necessita de esforços conservacionistas imediatos devido ao rápido avanço das pressões antrópicas à sua volta (Myers et al., 2000).

O Brasil possui atualmente um Sistema de Unidades de Conservação abrangendo aproximadamente $700.000 \mathrm{~km}^{2}$ (ou menos de $10 \%$ do território nacional) de áreas protegidas, representados por reservas federais, estaduais e particulares que visam a conservação dos diferentes biomas brasileiros (MMA, 1998). Considerando-se somente as UCs de uso indireto este número diminui para aproximadamente $220.000 \mathrm{~km}^{2}$, cerca de $3 \%$ do território brasileiro (MMA, 1998).

A Mata Atlântica, um dos biomas mais ameaçados do planeta, abriga quase a metade do número total de Unidades de Conservação no país, mas é responsável por apenas $17.600 \mathrm{~km}^{2}$ das áreas protegidas (cerca de 2,5\%). Isto se deve em muito ao pequeno tamanho médio das áreas protegidas neste bioma, enquanto na Amazônia este valor é de $3.560 \mathrm{~km}^{2}$, na Mata Atlântica esta média é de apenas $145 \mathrm{~km}^{2}$ (Ayres et al., 1997; Fonseca et al., 1997).

A maior parte dos grandes remanescentes deste bioma encontra-se no sudeste brasileiro, onde vive cerca de $70 \%$ da população brasileira sendo que a Serra do Mar situa-se entre as duas maiores cidades do país, São Paulo e Rio de Janeiro (MMA, 1998). O Parque Estadual da Serra do Mar (PESM) ocupa uma área total de cerca de $3.150 \mathrm{~km}^{2}$ e é o maior bloco contínuo remanescente desse bioma (SMA, 1999).

Apesar de estar inserida numa das mais importantes bacias hidrográficas do sudeste brasileiro, a Bacia do Rio Paraíba do Sul, as encostas e as bases dos morros da região da Serra do Mar foram extremamente desflorestadas, prevalecendo atualmente áreas fragmentadas de crescimento secundário ou até mesmo terra nua (Fonseca, 1989; Silva, 1982). Não bastasse, nos últimos anos, devido a sua localização, esta área tem sofrido uma enorme pressão devido a expansão de cidades vizinhas, incremento da malha rodoviária, construção de gasodutos e também do crescimento desordenado do chamado "ecoturismo" (SMA, 1999; MMA, 1998). Agravando essa situação, nos últimos anos populações tradicionais, especialmente indígenas, invadiram diversas UCs 
reclamando direitos ancestrais sobre a terra (Olmos \& Galetti, 2002; Olmos et al., 2002; São Bernardo \& Galetti, no prelo).

O conceito de corredores ecológicos, muitas vezes chamados de corredores de conservação ou simplesmente corredores, é de que sub-regiões, biológica e estrategicamente definidas, sejam selecionadas para implementação de propostas e ações de planejamento, visando conservação em larga-escala, onde se pretende manter a biodiversidade através de uma dinâmica que permita a coexistência das atividades humanas, ecológicas e evolucionárias (CABS, 2003). Trabalhos recentes vêm demonstrando o efetivo papel desses corredores na ampliação de importantes áreas e no estabelecimento de conectividade de ambientes antes isolados, favorecendo o fluxo de indivíduos e as interações tais como polinização e dispersão de sementes (Fahrig \& Merriam, 1994; Haas, 1995; Dunning et al. 1995; Rosenberg et al., 1997 in CABS, 2003). Portanto, para a Mata Atlântica brasileira, visando à conservação deste bioma, foram estabelecidos dois corredores de conservação; o Corredor Central ou Corredor do Descobrimento, que engloba áreas do sul de Bahia e todo o Espírito Santo, e o Corredor da Serra do Mar, que cobre as áreas do Estado do Rio de Janeiro e do Estado de São Paulo, incluindo a Serra do Mar (Figura 1).

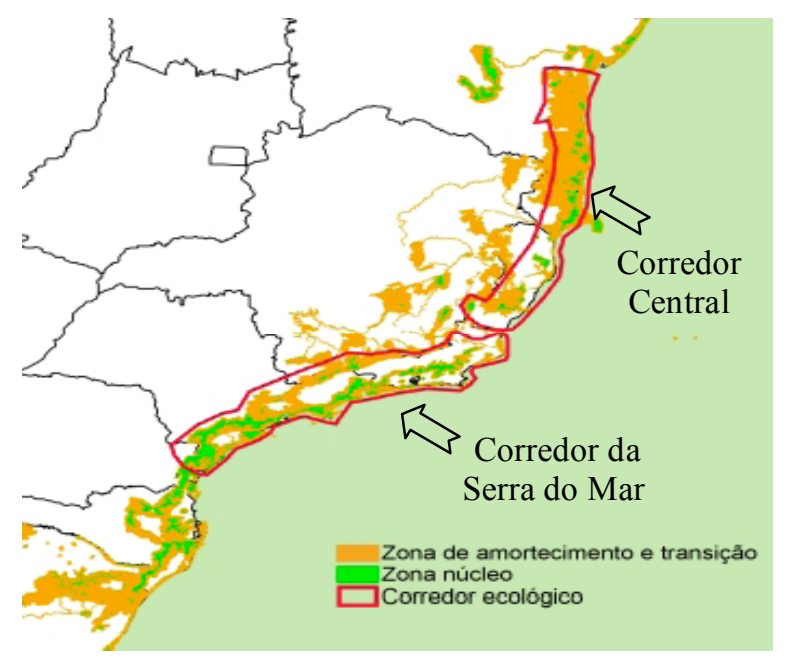

Figura 1- Localização dos corredores propostos para a Mata Atlântica no Brasil (extraído e modificado de MMA/SBF, 2000) 


\section{REVISÃO DE LITERATURA}

\subsection{Abundância e Densidade da Fauna Silvestre}

Estimativas de abundância e densidade são cruciais para os estudos de biologia da população e monitoramento da vida silvestre. Além disso, a abundância das espécies permite a comparação entre diferentes regiões onde já foram realizados censos e a realização de censos periódicos nestas áreas, possibilita o monitoramento dessas espécies, avaliando se há aumento, declínio ou estabilidade da população a longo prazo (Glanz, 1996; Soulé, 1986).

A maior parte dos estudos recentes relativos aos diferentes grupos de mamíferos nas áreas de Mata Atlântica apenas descreve a ocorrência das espécies, destacando a riqueza e a diversidade local, freqüência de utilização dos tipos florestais, distribuição geográfica ou mudanças na dieta (Ávila-Pires \& Gouvêa, 1977; Cerqueira et al., 1998; Ferrari, 1988; Martins \& Setz, 2000; Paschoal \& Galetti, 1995; Passamani et al., 2000). Em relação às aves de grande porte, a maior parte dos estudos apenas descreve a distribuição e a ocorrência das espécies, dietas, ou possuem abordagem naturalista (Aleixo \& Galetti, 1997; Collar et al., 1992; Galetti et al., 2000; Guix, 1997).

São pouco freqüentes os estudos que fornecem dados sobre a abundância e principalmente densidade de mamíferos não-primatas e aves de grande porte nas áreas remanescentes de Mata Atlântica (Chiarello, 1997; Cullen Jr. 1997; Galetti, 1996; Galetti \& Aleixo, 1998; Guix et al., 1997; Hernández et al., 2002; Martin, 2000; Sánchez-Alonso et al., 2002). No entanto, para os primatas existe uma grande quantidade de trabalhos realizados neste bioma, porém a maioria deles em áreas fragmentadas ou em florestas semidecíduas do interior do Estado de São Paulo 
(Chiarello, 1993; Cosenza \& Melo, 1998; Gonzáles-Solis et al., 2001; González-Solis et al., 2002; Kierulff \& Rylands, 2003; Martuscelli \& Olmos, 1997; Price et al., 2002; Pinto et al., 1993; São Bernardo \& Galetti, in press; Stallings et al., 1991; Strier, 1993; Torres de Assumpção, 1983).

Não obstante o baixo número de estudos com a maioria das espécies em regiões contínuas de Mata Atlântica, a falta de padronização na coleta e até mesmo na análise e apresentação dos dados inviabiliza ou dificulta a comparação de grande parte desses estudos (Chiarello \& de Melo, 2001).

As abundâncias, ou taxas de visualização, têm sido utilizadas por diversos autores, inclusive para comparação entre ambientes distintos (Peres, 1999; Price et al., 2002). Apesar das diferenças entre estudos quanto ao horário de realização de censos, análise da densidade, ausência de intervalos de confiança e até mesmo diferenças nas condições de observação entre as áreas, alguns autores afirmaram ser possível comparar as estimativas populacionais em diferentes locais através da simples comparação de suas abundâncias (Chiarello, 1999; Gonzáles- Sóliz et al., 2001; Pinto et al., 1993). A relação entre taxas de abundância e valores de densidade populacional foi alvo de um recente trabalho realizado por Chiarello (2003) onde este verificou que as abundâncias apresentaram uma correlação altamente significativa com as estimativas de densidades em diversas áreas de Mata Atlântica.

\subsection{A Influência de Fatores Ambientais}

Apesar de existir um número elevado de estudos avaliando as comunidades de mamíferos ou aves nos neotrópicos, grande parte deles apenas descreve as comunidades, informando as abundâncias, densidades, estimativas populacionais, dietas ou áreas de vida, e em alguns casos destacando o uso preferencial de tipos florestais por estas espécies ou a relação entre suas densidade e o tamanho dos fragmentos amostrados (Ávila-Pires \& Gouvêa, 1977; Brandão \& Develey, 1998; Cerqueira et al., 1998; Ferrari et al. 1996; Galleti \& Aleixo, 1997; Gargaglioni et al., 1998; Guix, 1997; Guix et al., 
1997; Hernández et al., 2002; Lemos de Sá, 1988; Martín, 2000; Martins \& Setz, 2000; Paschoal \& Galetti, 1995; Passamani et al., 2000; Rylands, 1982; Sanchéz et al., 2002; Torres de Assumpção, 1983).

Estudos avaliando a influência de fatores ambientais sobre as comunidades de mamíferos ainda não são comuns nos neotrópicos, apesar de que em se tratando de estudos com comunidades de primatas, principalmente em áreas da Amazônia, eles sejam bem mais freqüentes (Altrichter, 2001; Galetti \& Aleixo, 1998; Peres, 1990; Peres, 1996; Peres, 1999; Peres, 2001; Peres \& Dolman, 2000; Pontes, 1999), especialmente quando comparados com os poucos trabalhos disponíveis para áreas de Mata Atlântica (Chiarello, 1999; Chiarello, 2003; Cullen Jr. et al., 2000; Keirulff \& Rylands, 2003).

Os frutos são a alimentação básica de muitos dos animais presentes numa floresta, e estudos anteriores demonstraram existir uma forte relação entre a diversidade de frutos e a ocorrência de algumas espécies (Blake et al., 1990; Stevenson, 2001). Muitos fatores podem afetar o tamanho das populações, a riqueza de espécies e até mesmo as interações entre elas (Stevenson, 2001). Alguns autores consideram a existência de uma relação direta entre a estrutura da vegetação e a disponibilidade de recursos com o tamanho da população, principalmente de frugívoros, dessas comunidades (Asquish et al., 1997; Castro, 2003; Stevenson, 2001).

Sabemos ainda que na Mata Atlântica entre $80 \%$ e $90 \%$ das espécies vegetais produzem frutos adaptados à dispersão animal (Campassi, 2002; Galetti, 1996), contudo poucos são os estudos faunísticos que levam em consideração a produtividade ou disponibilidade de recursos no ambiente como fator importante na variação de densidade entre os diferentes sítios amostrais (Chiarello, 2000a; Heiduck, 2002; Peres, 1997; Peres \& Dolman, 2000; Stevenson, 2001; Spironelo, 1991).

O palmito-juçara (Euterpe edulis) é uma importante fonte de frutos nas florestas, sendo considerada uma espécie-chave para os frugívoros, já que fornece uma enorme quantidade de frutos, geralmente coincidindo com períodos de escassez dos demais, além de ser um dos frutos mais ricos em energia na Mata Atlântica (Galetti, 1996; 
Galetti \& Aleixo, 1998; Galetti et al., 1993). Por isso, a retirada ilegal de palmito-juçara, pelos chamados "palmiteiros", afeta não somente a estrutura vegetal da mata, pela perda de milhares de indivíduos e destruição causada às outras espécies vegetais próximas ou associadas, como também pode afetar a estrutura da fauna local, que se alimenta deste recurso (Galetti \& Aleixo, 1998; Galeti et al., 1999).

Outro fator que pode influenciar a distribuição e ocorrência, além de ocasionar mudanças comportamentais, reduções populacionais e até mesmo extinções locais das espécies nativas é a caça ilegal (Hodges et al., 2000; Kilgo et al., 1998). Ainda hoje, para muitas comunidades humanas, essa atividade compreende uma fonte essencial de obtenção de proteína e gordura animal (Peres, 1990; Redford \& Robinson, 1987). Os impactos desta prática extrativista, uma das mais antigas em utilização pelo homem desde os primórdios da evolução dos hominídeos modernos, sobre as comunidades de fauna, vem sendo observados até mesmo em vastas áreas de mata contínua na região Amazônica (Peres, 1990; Peres, 1996). Estudos recentes demonstram que nos dias de hoje, e praticamente em toda a extensão da Mata Atlântica, onde essa atividade sempre existiu, ainda ocorre caça de maneira generalizada, sendo responsável pela redução e ameaça de extinção de muitas espécies de mamíferos e aves (Chiarello, 2000b; Cullen Jr., 1997). Galetti et al. (1997) consideram a prática desta atividade como a provável causa da drástica redução populacional de jacutingas (Pipile jacutinga) na Mata Atlântica, espécie hoje considerada ameaçada de extinção e considerada extinta em alguns locais.

Não menos grave que o impacto dessas atividades ilegais, retirada de palmito e caça, é o possível impacto de uma outra atividade humana legalizada e bem recente, o chamado "ecoturismo". Esta atividade tem sido apontada por alguns pesquisadores como responsável por graves mudanças no ambiente natural (Claar et al., 1999; De La Torre et al., 2000). Nos últimos tempos, este tipo de turismo vem se expandindo rapidamente e, apesar de ter sido inicialmente proposto como uma alternativa para uso "sustentável" de algumas áreas de proteção ambiental, pouco se sabe sobre o impacto dessa atividade sobre o habitat e populações animais (De La Torre et al., 2000; MMA/SBF, 2000). 


\subsection{Viabilidade de Populações}

Atualmente existe muita controvérsia sobre a maneira mais eficiente para a conservação de ecossistemas tropicais, e em particular, sobre o papel que áreas protegidas desempenham, ou deveriam desempenhar, para atingir esse objetivo. Porém, é de comum acordo que parques e outras categorias de áreas protegidas são necessários para proteger uma amostra representativa de pelo menos dez por cento de todos os ecossistemas ao redor do mundo (Robinson \& Bennett, 2000). Em muitos ecossistemas essa meta ainda não foi atingida, além de que muitos destes parques criados não conseguem efetivamente proteger a sua biodiversidade (Bennett \& Robinson 2000). Exemplo disso são os Parques Nacionais nos Estados Unidos, onde Newmark (1986; 1987; 1995) mostrou que haviam sido registradas 42 extinções locais de mamíferos depois da implantação dos mesmos, provavelmente devido ao isolamento e perda de viabilidade das populações.

Existe um consenso entre os pesquisadores que a chance de sobrevivência de uma espécie ameaçada aumenta quando ela abrange grandes unidades da paisagem (MMA, 1998). Shaffer (1981) propôs uma definição simplificada para o conceito de população mínima viável como "a menor população isolada que possui $99 \%$ de chance de permanecer por 1000 anos em uma área, mesmo frente a catástrofes naturais e efeitos demográficos, ambientais e estocásticos". Há controvérsias sobre qual seria o tamanho mínimo de uma população que garantiria a sobrevivência da espécie a longo prazo, especialmente porque os valores devem variar consideravelmente entre os organismos e não há consenso sobre qual período de tempo pode ser considerado como "longo prazo" (Gilpin \& Soulé, 1986).

Lynch e Lande (1998) sugerem que o tamanho populacional mínimo de 500 indivíduos é necessário para que a diversidade genética seja mantida e a população seja assegurada contra efeitos ambientais e estocásticos. Muitos autores questionam este valor, sugerindo $2.000,5.000$ e até 7.000 indivíduos como população mínima necessária para manutenção da variabilidade genética, garantindo assim a sobrevivência de tais 
populações por longos prazos e a salvo de efeitos estocásticos (Brito \& Figueiredo, 2003; Frankham, 1995; Ralls et al., 1986). Contudo, esse número ainda tem sido amplamente utilizado por diversos autores para a avaliação da viabilidade de populações em áreas de Mata Atlântica (Chiarello, 1997; Chiarello \& Melo, 2001; Robinson \& Redford, 1986; Redford \& Robinson, 1991).

Reed et al (2003), num recente estudo, a partir da análise das populações mínimas viáveis (MVP) de 102 espécies de vertebrados, verificaram que essas espécies precisaram, em média, de 7.316 indivíduos para garantirem a manutenção de suas populações. Ainda segundo este autor, a espécie de felino Puma concolor (onça-parda ou suçuarana) teria uma MVP de aproximadamente 5.160 indivíduos, enquanto que para o primata Brachyteles arachnoides (mono-carvoeiro), o valor seria de 1.664 indivíduos.

Hacourt (2002), a partir da análise das espécies em ilhas do sudeste asiático, verificou que aquelas com tamanho corporal maior apresentaram MVPs significativamente maiores que as de tamanho reduzido. Contudo, diversos estudos demonstram que o resultado observado por Hacourt não pode ser considerado como padrão, uma vez que para um pequeno roedor com ocorrência nas áreas de Mata Atlântica, Trynomis eliasi, a MVP estimada foi de cerca de 2.000 indivíduos (Brito \& Figueiredo, 2003), enquanto que para o mico-leão-dourado, Leontopithecus rosalia, este valor foi de 6.587 indivíduos e para um pequeno fasianídeo europeu, Tetrao terix, de 5.846 indivíduos (Reed et al., 2003). Portanto, ao que tudo indica, a MVP é específica para cada táxon e depende das características ecológicas e de história natural de cada uma delas (Reed et al., 2003; Shaffer \& Samson, 1985; Shaffer et al. 2002; Tear et al., 1993).

Estudos no Brasil demonstraram que seriam necessárias reservas maiores que $160 \mathrm{~km}^{2}$ ou $200 \mathrm{~km}^{2}$ para manutenção de populações viáveis de primatas nas áreas de Mata Atlântica (Chiarello \& de Melo, 2001; São Bernardo \& Galetti, 2004). Outros estudos indicam ainda que muitas das UCs brasileiras possuem áreas insuficientes, aumentando assim o efeito de borda, o que leva à diminuição da diversidade genética 
das populações remanescentes, sendo desta maneira, incapazes de suportar populações viáveis de muitas outras espécies, principalmente de grande porte (Pires et al., 2000).

Um dos principais desafios na Mata Atlântica é propiciar a efetiva proteção da biodiversidade nas UCs já estabelecidas. Muitas delas ainda não estão devidamente regulamentadas ou encontram-se mal estruturadas, com número de funcionários insuficientes, onde inexistem planos de manejo ou informações sobre a fauna existente (WORLD WILDLIFE FUNDATION, 1999). Apesar dos mamíferos e aves serem os grupos taxonômicos mais bem conhecidos quando comparados aos demais grupos de vertebrados, a grande maioria das UCs carece de informações precisas quanto a ocorrência, abundância e principalmente densidade populacionais de espécies muitas vezes comuns, quanto mais em relação às ameaçadas de extinção (Pires et al., 2000).

Quantos animais existem atualmente nas florestas brasileiras? Desde o artigo clássico de Redford (1992), denominado de The Empty Forest, ou "A Floresta Vazia", estudos sobre a densidade de espécies vem sendo realizados nas áreas de Mata Atlântica, porém, a grande maioria deles, em áreas fragmentadas (Aleixo \& Galetti, 1997; Chiarello, 1993; Chiarello, 1997; Collar et al., 1992; Cullen Jr., 1997; Galetti \& Aleixo, 1998; Galetti, 1996; Galetti et al., 2000; Guix et al., 1997; Kierulff \& Rylands, 2003; Martin, 2000; Martuscelli 1995; Pinto et al., 1993; Price et al., 2002; São Bernardo \& Galetti, 2004; Stallings et al., 1991; Strier, 1993).

Um dos aspectos mais alarmantes é que não há dados disponíveis sobre a densidade, nem mesmo abundância, de grande maioria de espécies de mamíferos e aves nas UCs da Mata Atlântica do sudeste brasileiro. Boa parte delas conta apenas com listas de fauna, geralmente elaboradas a partir de levantamentos indiretos de dados e geralmente desatualizadas, tendo sido realizadas no período de implantação dessas unidades. Portanto, não sabemos se as UCs estão efetivamente protegendo as espécies em seus interiores, diminuindo assim o risco de extinções, além de não termos informações sobre o estado de preservação e conservação dessas áreas. 
O PESM não foge a regra da maioria das UCs brasileiras. Para a área do parque não existe praticamente nenhuma informação disponível sobre o status populacional e, muitas vezes, nem mesmo uma listagem confiável de ocorrência de espécies.

Um dos objetivos deste projeto é o de avaliar o status populacional de aves e mamíferos cinegéticos no norte do PESM, região que possui cidades com elevado crescimento populacional nos últimos anos, com mais de 1,6 milhão de habitantes no Vale do Paraíba e outros 200 mil nas cidades do litoral (IBGE, 2004). Cortada por rodovias que cada vez mais recebem um número maior de veículos, devido em muito ao crescimento do turismo, esta UC está entre as mais ameaçadas na Mata Atlântica. Apesar de tudo isso, ainda é uma das áreas mais representativas de contínuo desse bioma, fazendo divisa ao norte com uma outra grande importante área protegida, o Parque Nacional da Serra da Bocaina, com cerca de $90 \mathrm{~km}^{2}$, no Estado do Rio de Janeiro, e ao sul, no Estado de São Paulo, a Serra de Paranapiacaba, com aproximadamente $120 \mathrm{~km}^{2}$.

Ao final deste estudo espera-se contribuir para o conhecimento sobre a ocorrência, abundância e até mesmo sobre a densidade e o status de conservação de algumas destas espécies nestes locais, buscando também avaliar a viabilidade destas populações remanescentes. Contudo, sabemos que muitos outros fatores podem e devem afetar não somente a riqueza de espécies como também o tamanho das populações em um determinado local, entre eles características da própria população, estrutura da vegetação e disponibilidade de recursos no ambiente (Asquith et al., 1997; Castro, 2003; Stevenson, 2001). Portanto, um segundo objetivo do projeto é o de tentar identificar quais e, principalmente, como e onde os fatores bióticos e abióticos podem estar influenciando a ocorrência destas espécies, buscando assim identificar possíveis padrões que expliquem a distribuição destas populações nas áreas avaliadas.

Desta forma, com este trabalho espera-se gerar subsídios técnicos que permitiriam uma melhor avaliação da importância destas áreas para a conservação deste bioma, indicando também as potencialidades e fragilidades de cada uma delas. 


\section{MATERIAL E MÉTODOS}

\section{1 Áreas de Estudo}

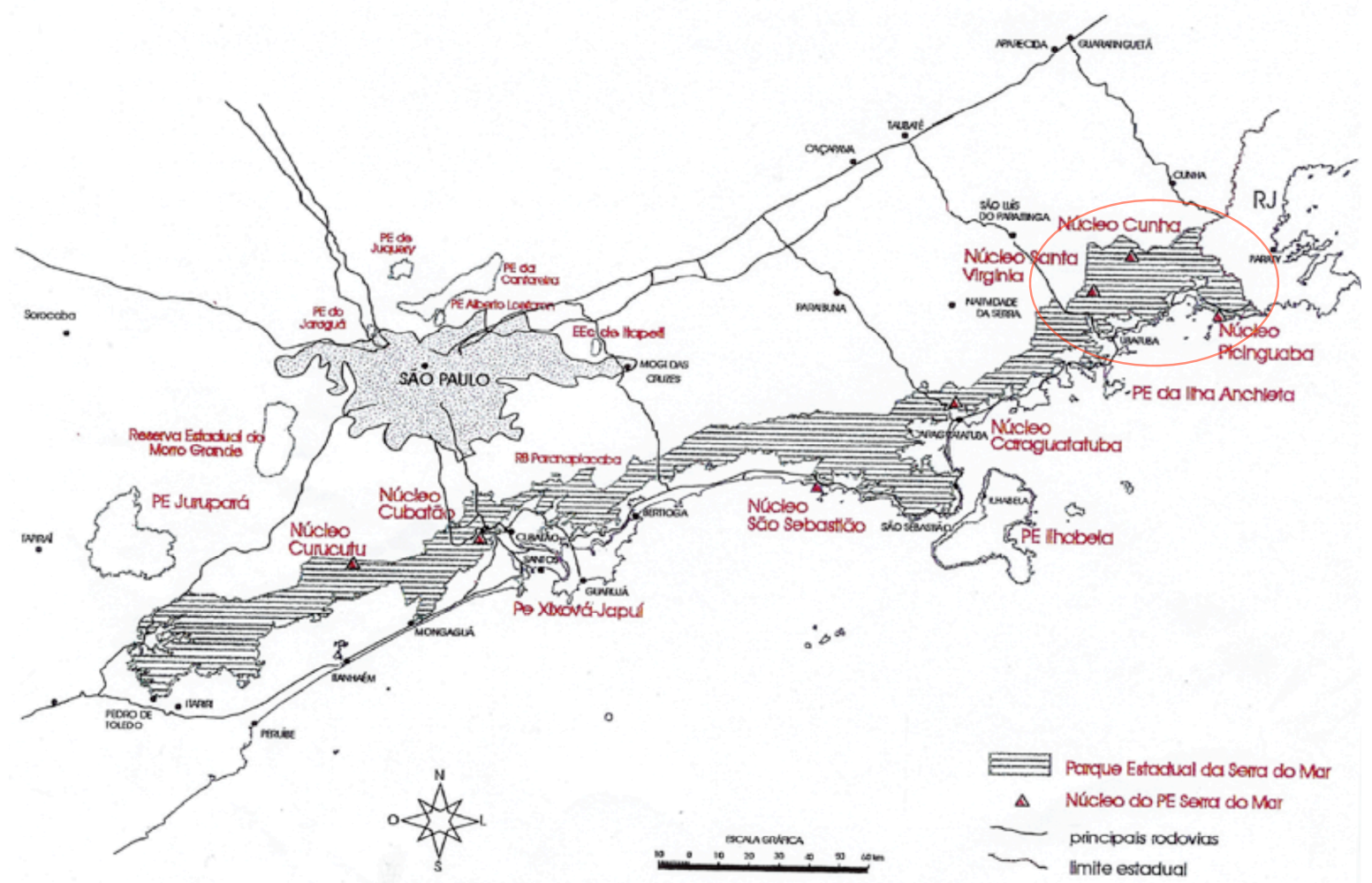

Figura 2 - Localização do PESM e suas unidades administrativas. Localização das três áreas alvo do presente estudo no setor norte do parque, próximo a divisa com o Estado do Rio de Janeiro (extraído de modificado de SMA, 1998a)

O PESM foi criado em 1977 e é a maior UC do Estado de São Paulo, abrangendo 26 municípios e cerca de $3.190 \mathrm{~km}^{2}$ de Mata Atlântica. O Parque é dividido em várias regiões administrativas, chamados núcleos (Figura 2). O presente estudo foi desenvolvido em três deles, localizados na porção norte do parque: Núcleo Cunha/Indaiá 
(NC/I), Núcleo Santa Virgínia/Natividade da Serra (NSV/NS) e Núcleo Picinguaba (NP). Administrado pelo Instituto Florestal do Estado de São Paulo e com a área pertencendo à Secretaria Estadual do Meio Ambiente, o parque, na sua porção mais ao norte, próximo a divisa com o Estado do Rio de Janeiro, sobrepõe-se parcialmente ao Parque Nacional da Bocaina (SMA, 1998a).

As áreas fazem divisas entre si, existindo, portanto, elevada conectividade entre elas, e correspondem ao setor do PESM onde ele se apresenta com sua maior extensão longitudinal, estendendo-se da área costeira ao reverso imediato às escarpas da Serra do Mar, abrangendo áreas desde a planície costeira ao planalto atlântico. Detém assim, a maior parte das nascentes dos rios que vertem para o Atlântico, responsáveis pelo abastecimento de água das populações urbanas do litoral, que hoje chegam em torno de mais de 200.000 habitantes (SMA, 1998a; IBGE, 2004). Toda essa área é considerada área chave para a proteção da vida silvestre, além do fato de que provavelmente funciona como corredor entre as grandes áreas de vegetação presentes mais ao sul em São Paulo (P.E. de Jacupiranga, P.E. de Carlos Botelho, E. E. Juréia-Itatins) e ao norte no Rio de Janeiro (Parque Nacional da Bocaina e APA Cairuçu) (SMA, 1999).

O presente estudo foi desenvolvido nas unidades administrativas do setor norte do PESM, Núcleo Santa Virgínia/Natividade da Serra (NSV/NS), Núcleo Cunha/Indaiá (NC/I) e Núcleo Picinguaba (NP), áreas que, juntas, abrangem mais de $760 \mathrm{~km}^{2}$. Uma avaliação recente das áreas, através de análise de fotografias aéreas, permitiu a elaboração de mapas digitalizados das coberturas florestais e usos do solo disponíveis no Sistema de Informação Georreferenciada da Mata Atlântica (SIGMA), Departamento de Dasonomia do Instituto Florestal do Estado de São Paulo. Estas avaliações permitiram, com maior precisão, determinar a superfície de cada uma das unidades avaliadas, bem como da cobertura dos diferentes tipos florestais em cada uma das áreas e no PESM.

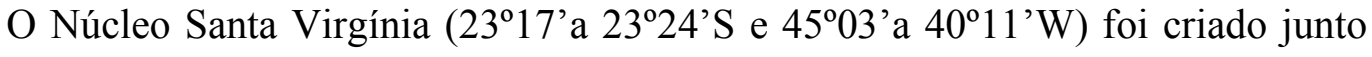
com o PESM em 1977, sendo que recentemente a área do antigo Núcleo Natividade da Serra também passou a ser administrada pelo mesmo. Com cerca de $170,00 \mathrm{~km}^{2} \mathrm{o}$ NSV/NS apresenta 57,80 \% de sua área com cobertura de Florestas Ombrófilas Densas, 
29,70 \% de Vegetação Secundária e os 10,80 \% restantes de áreas antropizadas e reflorestamentos de eucalipto (Fonte: SIGMA). Abrange principalmente os municípios de Ubatuba, São Luis do Paraitinga e Natividade da Serra. O clima da região é do tipo tropical, sem estação seca definida, relevo com altitudes variando de $860 \mathrm{~m}$ a $1200 \mathrm{~m}$. A precipitação anual média é de $1.850 \mathrm{~mm}$, sendo freqüentes as chuvas orográficas e a formação de nevoeiros.

O Núcleo Cunha (231' a $23^{\circ} 16^{\prime}$ 'S e $45^{\circ} 02^{\prime}$ a $\left.45^{\circ} 05^{\prime} \mathrm{W}\right)$ foi criado em 1974 e se tornou parte do PESM em 1977. Atualmente a área do antigo Núcleo Indaiá, área adjacente, também está sob administração desta unidade. O NC/I abrange os municípios de Ubatuba e Cunha sendo que a altitude média é de $1.050 \mathrm{~m}$, variando de aproximadamente $900 \mathrm{~m}$ a $1.200 \mathrm{~m}$ e a precipitação média anual é de $2.250 \mathrm{~mm}$. O relevo é montanhoso e favorece a formação de nevoeiros e chuva orográfica (SMA, 1999). A área, calculada em 116,60 km², apresenta 66,50\% de Florestas Ombrófilas Densas, 20,60 \% de Vegetações Secundárias e os demais 12,90 \% entre solos expostos e campos antrópicos (Fonte: SIGMA).

O NP $\left(23^{\circ} 17^{\prime}\right.$ a $23^{\circ} 24^{\prime}$ S e $45^{\circ} 03^{\prime}$ a $\left.45^{\circ} 05^{\prime} \mathrm{W}\right)$ foi anexado ao PESM em 1979 e, segundo recentes avaliações, tem cerca de $474,40 \mathrm{~km}^{2}$, sendo que deste total cerca de 77,10 \% são de Florestas Ombrófilas Densas, 25,50 \% de Vegetações Secundárias e cerca de 15,20\% entre campos antrópicos, agricultura cíclica, solos expostos e áreas de vegetação Arbóreo/Herbácea/Arbustiva (Fonte: SIGMA). Localiza-se inteiramente no município de Ubatuba. O clima é tropical, sem estação seca definida e suas altitudes variam de $0 \mathrm{~m}$ a $1.670 \mathrm{~m}$. A precipitação média anual é de $2.450 \mathrm{~mm}$ e a vegetação predominante é de Mata Atlântica de encosta e de planície, abrangendo também ecossistemas costeiros (SMA, 1998a).

A partir da análise dos Planos de Manejo destas áreas, dados de censos populacionais da região, e da realização de um levantamento de informações atualizadas junto aos administradores dessas unidades ${ }^{1}$, além de observações em campo, foi possível

\footnotetext{
${ }^{1}$ Entrevistas não padronizadas com administradores, funcionários e moradores das unidades amostradas, incluindo ex-caçadores locais, além de moradores do entorno. Comunicação pessoal, 2003.
} 
elaborar um quadro resumo, contendo informações do histórico e das principais pressões existentes atualmente em cada uma das áreas (Tabela 1).

Tabela 1. Núcleos amostrados do PESM com breve descrição de históricos de ocupação, uso do solo e pressões antrópicas atuais. Além do tamanho das áreas, porcentagem de cobertura dos principais tipos florestais e as estimativas populacionais nas principais cidades do entorno

\begin{tabular}{|c|c|c|}
\hline Núcleo & Descrição Geral & Informações Gerais \\
\hline $\mathrm{NSV} / \mathrm{NS}$ & $\begin{array}{l}\text { Áreas alteradas, utilizadas para pastagem e } \\
\text { atualmente em regeneração, áreas } \\
\text { moderadamente alteradas devido à retirada } \\
\text { de madeira e palmito ou plantio de } \\
\text { eucalipto, atualmente com vegetação } \\
\text { secundária e remanescentes de floresta } \\
\text { ombrófila densa ainda "virgem". Rodovia } \\
\text { Oswaldo Cruz corta a área do núcleo. Caça } \\
\text { de moderada a baixa e impacto de turismo } \\
\text { ausente, baixo a elevado nas trilhas. }\end{array}$ & $\begin{array}{l}\text { Localização: } 23^{\circ} 17^{\prime} \text { a } 23^{\circ} 24^{\prime} \mathrm{S} \text { e } 45^{\circ} 03^{\prime} \text { 'a } \\
40^{\circ} 11^{\prime} \mathrm{W} \\
\text { Área: } 170,00 \mathrm{~km}^{2} \\
\text { Cobertura: } 57,8 \% \text { Florestas Ombrófilas } \\
\text { Densas e } 29,7 \% \text { Vegetações Secundárias } \\
\text { Municípios: Ubatuba, São Luis do } \\
\text { Paraitinga, Lagoinha e Natividade da Serra } \\
\text { Pop. 1976: } 45.616 \text { hab.* } \\
\text { Pop. 2000: } 88.767 \text { hab.* } \\
\text { Turistas/ano: } 5.000^{* *}\end{array}$ \\
\hline $\mathrm{NC} / \mathrm{I}$ & $\begin{array}{c}\text { Áreas pouco alteradas devido a corte } \\
\text { seletivo de madeira, retirada de palmito e } \\
\text { plantio de araucárias. Grandes } \\
\text { remanescentes de áreas de mata ainda } \\
\text { "virgem", praticamente não alterada. Caça } \\
\text { de baixa a praticamente ausente na área e } \\
\text { impacto de turismo ausente ou de baixo a } \\
\text { elevado nas trilhas. }\end{array}$ & $\begin{array}{l}\text { Localização: } 23^{\circ} 13^{\prime} \text { a } 23^{\circ} 16^{\prime} \mathrm{S} \text { e } 45^{\circ} 02^{\prime} \text { a } \\
45^{\circ} 05^{\prime} \mathrm{W} \\
\text { Área: } 116,60 \mathrm{~km}^{2} \\
\text { Cobertura: } 66,5 \% \text { Florestas Ombrófilas } \\
\text { Densas e } 20,6 \% \text { Vegetações Secundárias } \\
\text { Municípios: Cunha e Lagoinha } \\
\text { Pop. 1976: } 28.419 \text { hab.* } \\
\text { Pop. 2000: } 28.020 \text { hab.* } \\
\text { Turistas/ano: } 6.200^{* *}\end{array}$ \\
\hline NP & $\begin{array}{l}\text { Área altamente alterada devido ao uso para } \\
\text { agricultura e uso urbano, áreas } \\
\text { moderadamente alteradas com corte de } \\
\text { madeira e retirada de palmito. Áreas de } \\
\text { remanescentes de mata madura } \\
\text { principalmente nas encostas da serra. } \\
\text { Rodovia Rio-Santos corta a área do núcleo. } \\
\text { Existe um grande número de comunidades } \\
\text { no interior na unidade. Caça elevada e } \\
\text { impacto de turismo de baixo a moderado. }\end{array}$ & $\begin{array}{l}\text { Localização: } 23^{\circ} 17^{\prime} \text { a } 23^{\circ} 24^{\prime} \mathrm{S} \text { e } 45^{\circ} 03^{\prime} \text { a } \\
45^{\circ} 05^{\prime} \mathrm{W} \\
\text { Área: } 474,40 \mathrm{~km}^{2} \\
\text { Cobertura: } 77,1 \% \text { Florestas Ombrófilas } \\
\text { Densas e } 25,5 \% \text { Vegetações Secundárias } \\
\text { Municípios: Ubatuba População 1976: } \\
\text { 18.249 hab.* } \\
\text { População 2000: } 66.448 \text { hab.* } \\
\text { Turistas/ano: } 3.500^{* *}\end{array}$ \\
\hline
\end{tabular}




\subsection{Mapeamento de Trilhas e o Estabelecimento das Transecções}

Foram utilizadas trilhas e antigas estradas pré-existentes nas unidades amostradas, sendo que em alguns casos trilhas que estavam fechadas ou abandonadas foram reabertas. No NC uma trilha nova foi aberta visando amostrar uma região do núcleo que não possuía nenhuma trilha pré-existente. Todas as trilhas que permitiram a realização de amostragens padronizadas através da técnica de transecções lineares (Line Transect - Buckland et al., 1993) foram marcadas de $50 \mathrm{em} 50 \mathrm{~m}$ com fitas numeradas. Tais marcações foram utilizadas para a identificação do local de visualização dos animais durante os censos, encontro dos rastros e também para a coleta dos dados das variáveis ambientais, no intuito de elaboração futura de um banco de dados georreferenciados para as áreas avaliadas.

Utilizando-se de técnicas básicas de mapeamento em campo, com o auxílio de bússola e trena, associada ao uso de equipamento de posicionamento global via satélite (receptor GPS - marca Garmin, modelo e-trex, datum Córrego Alegre, coordenadas em UTM), foi possível traçar os trajetos de cada uma das trilhas utilizadas. Posteriormente, utilizando-se de programas específicos (AutoCAD 2000 e ArcView 8.2), estes trajetos foram inseridos em mapas digitalizados, produzidos a partir de fotografias aéreas recentes, cedidos pelo programa SIGMA do Departamento de Dasonomia do Instituto Florestal do Estado de São Paulo (Anexos B, C e D).

A partir de verificações em campo foi possível a confirmação dos mosaicos florestais observados nos mapas e com o auxílio de ferramentas do programa ArcView 8.2 foi possível identificar o tipo florestal predominante em diferentes trechos das trilhas utilizadas para o levantamento de dados. Com base nestas classificações dos tipos florestais algumas trilhas foram então divididas em trechos menores, considerados no presente estudo como sendo as unidades básicas de amostragem, ou seja, as transecções utilizadas.

Os mapas temáticos originais para as áreas de estudo, produzidos a partir de fotografias aéreas digitalizadas, seguem uma classificação para a vegetação e uso do 
solo onde aparecem 12 categorias diferentes, sendo quatro delas para as áreas de floresta ombrófila densa: Alto Montana, Densa Montana, Montana de Terras Baixas e Submontana, estas duas últimas com ocorrência somente na área do NP. No presente estudo todos estes tipos florestais foram agrupados e considerados como Floresta Ombrófila Densa.

Já a classificação de Vegetação Secundária utilizada no presente trabalho é um agrupamento de três categorias originalmente descritas nos mapas fontes utilizados, são elas: Vegetação Secundária de Floresta Ombrófila Submontana, Vegetação Secundária da Floresta Ombrófila Densa Montana e Vegetação Secundária da Floresta Ombrófila de Terras Baixas, esta última ocorrendo somente no NP.

Os demais tipos florestais não foram avaliados, uma vez que não existiam trilhas suficientes para uma amostragem satisfatória destes ambientes ou, para alguns deles, representam uma pequena parcela da superfície do parque. De maneira geral estas áreas podem ser classificadas como de não utilização potencial para a fauna avaliada. Estão inclusas neste grupo as vegetações mais simples, classificadas como Vegetação Arbórea /Herbácea /Arbustiva de Terras Marinhas e Vegetação Arbórea/Herbácea /Arbustiva de Várzea, ambas com ocorrência somente no NP, e também áreas severamente alteradas identificadas como Solo Exposto, Agricultura Cíclica, Campo Antrópico e Reflorestamento de Eucaliptos.

\subsection{Transecções Lineares}

Para estimar a abundância e a densidade das aves e mamíferos cinegéticos do PESM foi utilizado o método de transecções lineares, geralmente empregado para a obtenção de estimativas populacionais (Buckland et al., 1993; Burham et al., 1980; Laake et al., 1994; Peres, 1999), e que vem sendo empregado na maioria dos estudos de censo nos neotrópicos (Cullen Jr., 1997; Cullen Jr. \& Rudran, 2003; Lourival \& Fonseca, 1997; Peres, 2000; Peres \& Dolman, 2000). Este método está incluso na categoria de métodos amostrais `a distância e que utilizam a função de detecção $g(y)$, 
que representa a probabilidade de deteç̧ão do objeto (grupo ou indivíduo) a uma distância $y$ da linha da transecção (Buckland et al., 1993).

Entre os diversos pesquisadores que se utilizam desta técnica, não existe um consenso quanto a qual seria o melhor delineamento experimental para garantir a obtenção de resultados confiáveis e estimativas populacionais da fauna silvestre. $\mathrm{O}$ comprimento ideal das trilhas, geralmente consideradas como as unidades amostrais básicas, a disposição delas nas áreas de estudo e a independência entre as amostras (Ferrari, 2002; Magnusson, 2001; Peres, 1999).

Magnusson (2001) argumentou que uma única trilha, de preferência reta e de no mínimo 100 km seria o ideal para a realização de censos, enquanto que Ferrari (2002) defendeu o uso de trilhas de pequeno comprimento uma vez que, principalmente em áreas com relevo acidentado ou devido a problemas de logística, é praticamente impossível a abertura de trilhas extensas (Ferrari, 2002).

Para as áreas do presente trabalho foi utilizado o maior número de trilhas existentes, distribuídas da melhor maneira dentro destas áreas, a fim de se amostrar o maior número de ambientes possíveis. As trilhas utilizadas tinham em média 3,3 km, variando de $1,2 \mathrm{~km}$ a $8,4 \mathrm{~km}$. Segundo Janson e Terborgh (1980), num delineamento experimental com diversas trilhas menores, há uma maior probabilidade de se amostrar satisfatoriamente áreas heterogêneas.

Para o uso da técnica de transecções lineares deve-se assumir a priori cinco premissas básicas para satisfazer as exigências implícitas na metodologia, garantindo assim que o resultado seja o mais acurado possível: $(a)$ as distâncias perpendiculares devem ser medidas de maneira precisa; $(b)$ todos os animais sobre a trilha $(y=0)$ devem ser detectados, ou seja, $g(0)=1 ;(c)$ um mesmo animal não deve ser contado duas vezes ou mais em uma mesma amostragem; (d) os animais devem ser detectados em sua localização inicial, antes de qualquer movimento em resposta ao observador; $(e)$ os visualizações devem representar eventos independentes (Buckland et al., 1993; Cullen Jr., 1997; McArdle et al., 1990; Peres 1999). 
Os dados foram coletados numa mesma transecção, tanto para mamíferos quanto para aves. As trilhas foram percorridas do início da manhã (6:30 h) até o fim da tarde $(18: 00 \mathrm{~h})$ a uma velocidade de aproximadamente $1 \mathrm{~km} / \mathrm{h}$, com eventuais paradas para detecção de ruídos que pudessem indicar a presença de animais na mata.

Para cada amostragem realizada foi registrado o horário de início e final do censo e a quilometragem percorrida, sendo que para cada visualização de mamífero ou ave foram anotados: (1) número de indivíduos; (2) espécie visualizada; (3) distância perpendicular entre o animal e a trilha; (4) horário de visualização do animal; (5) estrato da vegetação utilizado pelo animal e (6) ponto de referencia onde o animal foi visualizado, utilizando-se das marcações com fitas a cada $50 \mathrm{~m}$ presentes nas trilhas (Buckland et al., 1993; Cullen Jr., 1997; Peres, 1999).

A velocidade do pesquisador nos censos foi verificada constantemente durante o percorrer das transecções, o que era possível devido às marcações existentes nas trilhas de $50 \mathrm{~m}$ em $50 \mathrm{~m}$, onde o pesquisador realizava eventuais paradas para verificação da velocidade média, mas que também ajudavam na detecção de ruídos na mata. Estes procedimentos, juntamente com a manutenção e limpeza das trilhas visavam garantir o cumprimento das premissas $b$ e $d$, ou seja, de que $g(0)=1$ e de que os animais devem ser detectados em sua localização inicial, respectivamente. Eventuais trilhas ou mesmo trechos destas, onde a locomoção do pesquisador era dificultada, com inclinação elevada, por exemplo, foram descartadas das análises, bem como aquelas em meio a áreas altamente antropizadas, tais como vilas de comunidades tradicionais. Os censos também não foram realizados, ou foram interrompidos imediatamente, quando as condições climáticas apresentavam-se de maneira a prejudicar a coleta de dados como, por exemplo, em dias chuvosos, de ventos fortes ou até mesmo com trovoadas, condições essas que poderiam prejudicar a acuidade do observador devido ao aumento de ruídos no ambiente natural.

Para evitar que um mesmo animal fosse contado duas vezes ou mais em uma mesma amostragem, premissa (c), e garantir que as visualizações representassem eventos independentes, premissa $(d)$, as trilhas situadas próximas umas das outras foram 
percorridas num mesmo dia ou em dias subseqüentes, o que permitiria a exclusão de eventuais visualizações suspeitas de serem recontagens de um mesmo indivíduo ou grupo. Alguns autores estipulam intervalos de uma a duas horas entre as amostragens numa mesma trilha e consideram que este tempo seja o suficiente para evitar encontros com o mesmo indivíduo ou grupo de animais e, dessa maneira, seja garantida a independência das amostras (Ferrari, 2002; Peres, 1999). Este desenho experimental permite aos pesquisadores realizar os censos tanto na ida como na volta das trilhas, otimizando assim o tempo gasto, permitindo um aumento no esforço amostral. Contudo, para o presente estudo, não foi considerado como amostragens de censo o trajeto da volta realizada numa mesma trilha ainda num mesmo dia, buscando assim garantir a independência das amostras realizadas. Além disso, para uma mesma trilha ou grupo de trilhas próximas, foi mantido um intervalo de pelo menos dois dias entre as amostragens de censo, tempo este considerado pelo pesquisador como suficiente para o rearranjo da fauna na área amostrada. Este procedimento foi adotado uma vez que nas áreas de estudo são conhecidas as ocorrências de diversas espécies de primatas, grupo de animais que geralmente apresentam características territorialistas, sendo muitas vezes visualizados num mesmo local em dias subseqüentes, o que poderia levar a uma superestimativa de suas abundâncias.

Ainda visando garantir uma amostragem não viciada dos censos, as trilhas foram percorridas em seqüências aleatórias e também em direções alternadas, ou seja, ora iniciando-se pelo primeiro e ora pelo último ponto de marcação.

Para a obtenção das distâncias perpendiculares de maneira acurada foi utilizada uma técnica onde esta distância perpendicular foi obtida através de medidas indiretas, ou seja, triangulação com o uso de bússola e, quando necessário, estimativa visual da distância (Chiarello, 1997; Wilson et al., 1996). Para a utilização do método de triangulação o pesquisador deve registrar, com o auxílio de uma bússola, o ângulo existente entre a transecção e o primeiro animal visualizado. Em seguida, deve-se obter o valor da distância percorrida ao longo da trilha entre o ponto inicial de visualização do animal e o ponto de interseção de uma linha imaginária perpendicular (ângulo de $90^{\circ}$ ) à 
transecção. Através de trigonometria básica, ou seja, multiplicando-se essa distância percorrida na trilha pelo valor da tangente do ângulo obtido, obtém-se a distância perpendicular de cada visualização. $\mathrm{O}$ uso desta técnica permite ao pesquisador permanecer na trilha evitando ao máximo a perturbação do ambiente, o que poderia afugentar os animais ao longo dos censos. Porém, esta técnica possui uma limitação, já que para os ângulos máximos de visualizações, ou seja, quando o animal ou grupo é visualizado a $90^{\circ}$, não é possível obter-se a distância perpendicular de visualização através do uso de trigonometria, sendo necessário realizar estimativas visuais. Buscando garantir a acuracidade dos dados, foram realizadas calibragens constantes das estimativas visuais através de exercícios práticos em campo, onde eram estimadas visualmente distâncias de pontos na mata (árvores, arbustos, frutos e fitas de marcação) e, em seguida, comparadas com a distância real obtida com o uso de trena. Este procedimento foi realizado nos primeiros dias de campo de cada viagem e se mostrou extremamente importante, uma vez que geralmente nas primeiras estimativas, após longo período sem prática, o pesquisador obtinha erros maiores, que diminuíam de acordo com a realização destes exercícios, chegando a não representar diferença significativa, garantindo assim uma menor chance de erro nestas estimativas durante a coleta de dados em campo.

É importante salientar que tais medidas foram adotadas visando garantir o cumprimento das premissas básicas da metodologia adotada. Esta preocupação é freqüentemente abordada em trabalhos e livros textos que discutem o uso da técnica de transecções lineares para o cálculo de estimativas populacionais (Buckland et al., 1993; Buckland et al., 2001; Burham et al., 1980; Laake et al., 1994; Peres, 1999).

Os dados obtidos nos censos realizados em cada uma das áreas foram transformados em taxas de abundâncias (número de visualizações/ $10 \mathrm{~km}$ ) ou foram utilizados para cálculo de valores de densidade (número de indivíduos $/ \mathrm{km}^{2}$ ), através do programa DISTANCE 4.1 (http://www.ruwpa.st-and.ac.uk/distance). 


\subsection{Variáveis Ambientais}

Buscando identificar quais fatores poderiam estar influenciando a ocorrência e distribuição das espécies nas áreas de estudo, foram tomadas diversas medidas de variáveis ambientais, com o objetivo de melhor caracterizar os locais amostrados, são elas;

1- intensidade de caça (CAÇA)

2- atividade de turismo (TUR);

3- cobertura de dossel (COBD);

4- distância (Dist.) ao ponto central, altura (Alt.) e diâmetro (dap) das quatro maiores árvores;

5- número de palmeiras (exceto E. edulis) adultas (NPA);

6- número de palmeiras (exceto E. edulis) jovens (NPJ);

7- número de plântulas de palmeiras (exceto E. edulis) (NPP);

8- número de Euterpe edulis (palmitos) adultos (NEA);

9- número de Euterpe edulis (palmitos) jovens ( $\mathrm{N} E \mathrm{~J})$;

10- número de plântulas de Euterpe edulis (palmitos) (NEP);

11- disponibilidade de frutos (DISPF);

\subsubsection{Pressões Antrópicas: a caça e o turismo}

A intensidade da caça foi avaliada a partir do número de registros de caçadores ou do encontro de evidências (cães, tiros, etc.) desta atividade durante o período de estudo, sendo que estes valores foram transformados em índices (eventos de caça/10 km) para cada transecção utilizada (extraído e modificado de: Chiarello, 1999; Chiarello, 2000a; Cullen, 1997; Cullen et al., 1999; Cullen et al., 2001; Wright et al., 2000).

Já a atividade de turismo foi avaliada a partir do número de turistas/ano que utilizaram cada uma dessas transecções. Estes valores são aproximações fornecidas pelas administrações das unidades, tendo sido extraídos dede livros de registros internos de 
visitação turística presentes em cada uma das áreas (extraído e modificado de Wright et al., 2000). Em alguns casos, estimativas complementares de visitação turística tiveram que ser realizadas para complementação dos registros oficiais, principalmente na área do NP onde, devido à localização das trilhas, o controle do número de acessos na maioria delas é impraticável.

\subsubsection{Estrutura da Vegetação}

Para as medidas de estrutura da vegetação as medidas foram obtidas em pontos de amostragem dispostos ao longo das trilhas utilizadas, distantes $100 \mathrm{~m}$ um do outro, utilizando-se de metodologias específicas (extraídas e modificadas de Cerqueira \& Freitas, 1999; Henriques \& Alho, 1991), descritas a seguir.

Os parâmetros obtidos no estudo da vegetação foram realizados utilizando-se o método de quadrantes (Gibbs et al, 1980; Mueller-Dombois \& Ellemberg, 1974). Como critério de inclusão foram selecionados os indivíduos arbustivos e arbóreos com fuste igual ou superior a $10 \mathrm{~cm}$. Não foram incluídos nesta amostragem indivíduos da família Arecaceae (palmeiras), que foram amostrados através de outra metodologia, descrita adiante. Todos os indivíduos amostrados foram numerados com plaquetas de metal e medidos a sua distância do ponto central, seu DAP e estimado sua altura com o auxílio de um clinômetro. Este equipamento fornece o ângulo formado entre o olho do observador e o topo da árvore a ser mensurada. A partir destes valores, da distância do observador à árvore e da altura do observador, até o nível dos olhos, é calculada a altura estimada através de trigonometria básica.

Buscando ainda caracterizar a estrutura da vegetação foram tomadas medidas de cobertura de dossel (COBD), que foram obtidas com o auxílio de um densiômetro, que forneceu essa variável em valores percentuais para cada um dos pontos amostrados no método de quadrantes.

Sabendo-se que as palmeiras em geral (Arecaceae), e principalmente o palmito (Euterpe edulis), são importantes produtores de frutos para a fauna em áreas de Mata 
Atlântica, a densidade desses indivíduos foi estimada com o uso de metodologia específica. Em cada um dos pontos amostrados foi contado o número de indivíduos de palmitos (E. edulis) e, numa outra contagem, o número de indivíduos de outras espécies de palmeiras. Para ambas amostragens foi contado o número de indivíduos em cada seus diferentes estágios de crescimento, adultos, jovens e plântulas, presentes num raio de 5 m em relação ao ponto central, sendo que para a diferenciação destas espécies bem como de seus diferentes estágios de crescimento foi utilizada bibliografia específica (Lorenzi et al., 1996).

\subsubsection{Disponibilidade de Frutos}

A disponibilidade de frutos e sementes foi avaliada através da coleta destes no solo da floresta, tendo sido também mensurada para as duas estações mais distintas do ano, coincidindo com os períodos de amostragem de censos nas áreas. Portanto, tanto no inverno quanto no verão, foi aplicado um esforço amostral de $20 \mathrm{~m}^{2}(2 \times 10 \mathrm{~m})$ por ponto de coleta, dispostos de 100 em 100 metros ao longo das transecções utilizadas (extraído e modificado de Blake et al, 1990; Chapman et al, 1992, Stevenson, 2001).

Todos os frutos e sementes encontrados foram coletados e o material foi seco em estufa a $60^{\circ} \mathrm{C}$, por um período que variou de 2 a 5 dias, dependendo do grau de umidade das amostras. Posteriormente todo este material foi triado e identificado em laboratório com base em bibliografia especializada (Barroso et al., 1999; Lorenzi, 1992; Lorenzi et al., 1996; Lorenzi, 1998) e também a partir de comparações com material existente na carpoteca do Herbário Rioclarense na UNESP - Rio Claro, que conta inclusive com material coletado e identificado de duas das três áreas de estudo avaliadas no presente trabalho, NSV/NS e NP. Este material foi triado conforme síndromes de dispersão sendo que para a avaliação da disponibilidade nas áreas (peso seco $/ \mathrm{km}^{2}$ ), foram consideradas somente as espécies reconhecidamente zoocóricas, mais especificamente aquelas com dispersão por aves, mamíferos ou que são dispersas por ambos, classificadas como de dispersão mista (Campassi, 2002). 


\subsection{Densidades e Estimativas Populacionais}

Muitos pesquisadores apresentam seus dados somente em forma de abundâncias, uma vez que esta abordagem é muito mais simples e o número de premissas é bem menor. Comparações entre estes dados de abundâncias para áreas diferentes só é possível se assumirmos que a detecção é igual nestes ambientes (Buckland et al., 1993; Janson \& Emmons, 1990; Malcon, 1990), o que é difícil de testar para a maioria dos casos. Nestas situações devemos utilizar as comparações dos valores de densidade obtidos em cada uma destas áreas para permitir as comparações propostas.

O problema principal dos trabalhos que buscam estimar densidades acuradas das espécies consiste em determinar a largura da área amostral (Chiarello, 1997). No presente estudo, para o cálculo desta largura da área amostral foi utilizado o programa DISTANCE 4.1 (Buckland et al., 1993). As visualizações para uma mesma espécie realizadas em todas as áreas foram utilizadas para o cálculo da largura efetiva de trilha de cada uma delas (ESW - "effective strip width").

Foram consideradas apenas as espécies que obtiveram mais de 5 registros no total para o cálculo das densidades. Este critério foi utilizado, pois para obter-se uma estimativa precisa e acurada da densidade, é recomendado o maior conjunto de dados possível, uma vez que pequenas amostras podem levar a distorções nas curvas de detecção, resultando em estimativas irreais segundo diversos autores (Cassey \& Mcardle, 1999; Cullen, 1997; Laake et al., 1994; Peres, 1999).

O programa DISTANCE 4.1 utiliza-se das distâncias perpendiculares animaltrilha para estimar a largura efetiva da trilha, modelando a função matemática que melhor se adequa à probabilidade de detecção de um animal numa dada distância da trilha (Buckland et al., 1993; Laake et al., 1994).

Na maioria dos trabalhos os valores obtidos de densidade são calculados para as áreas de estudo como um todo, não levando em consideração possíveis diferenças dentro destas áreas, inclusive de áreas não utilizadas pela fauna (Chiarello, 1997; Chiarello, 1999; Cullen Jr., 1997; Cullen Jr. et al., 1999). No presente trabalho foram calculadas as 
densidades médias, máximas e mínimas, para cada um dos tipos florestais amostrados em cada uma dos núcleos avaliados, utilizando-se da fórmula acima descrita e das visualizações de cada uma das espécies nestes diferentes ambientes. Os valores obtidos representam o número de visualizações $/ \mathrm{km}^{2}$, sendo que para as espécies sociais, que geralmente ocorrem em grupo, estes valores foram multiplicados pelos tamanhos médios dos grupos, obtidos no presente trabalho ou disponíveis na literatura, para obtenção da densidade de indivíduos nas áreas (indivíduos $/ \mathrm{km}^{2}$ ).

Para o cálculo de estimativas populacionais nas áreas amostradas, multiplicou-se o valor de densidade, calculados para cada um dos tipos florestais, pelas áreas de cobertura, em quilômetros quadrados, destas vegetações em cada um dos núcleos avaliados. As áreas de cobertura de cada um dos tipos florestais foram calculadas a partir da análise de mapas digitalizados (Fonte: SIGMA), através do programa ArcView 8.2.

As estimativas populacionais calculadas a partir de dados analisados pelo DISTANCE 4.1 devem ser avaliadas com ressalvas, considerando-as apenas como aproximações dos valores reais, até que técnicas melhores permitam corrigí-las (Chiarello \& de Melo, 2001). Apesar disso, os valores obtidos permitem aos conservacionistas terem uma idéia das populações naturais remanescentes, bem como de avaliarem a viabilidade destas populações sob diferentes cenários imagináveis e, sobretudo, o efetivo papel destas áreas na conservação deste bioma, o que pode auxiliar a tomada de decisões e a adoção de estratégias para garantir o cumprimento dos objetivos e metas propostas para estas áreas. 


\subsection{Viabilidade de Populações}

Uma maneira de se avaliar a efetividade de uma UC é avaliando a viabilidade das populações remanescentes em seu interior. Quanto maior o número de espécies com populações viáveis dentro de uma determinada área, maior a importância deste local para a conservação do bioma como um todo.

Apesar de saber que MVP é específica para cada táxon e que depende das características ecológicas e de história natural de cada uma delas, as análises de viabilidade de população, mesmo que realizadas com dados incompletos ou de espécies similares podem permitir conclusões quanto aos riscos de extinção, o que pode ser muito útil para o manejo destas espécies, sendo que inclusive, o sistema da Lista Vermelha da União para a Conservação Mundial (IUCN “Red List”), baseia-se neste princípio (Reed et al., 2003; Shaffer \& Samson, 1985; Shaffer et al. 2002; Tear et al., 1993).

Portanto, foi buscando avaliar o sucesso na manutenção de populações mínimas viáveis e demonstrar a importância da conectividade entre as áreas de Mata Atlântica, que os valores de densidade obtidos nas áreas de estudo foram utilizados para realizar extrapolações tanto para o setor norte do parque como para as demais áreas do PESM. Portanto, três cenários foram avaliados para cada uma das espécies. No primeiro, foi avaliada a viabilidade das populações em cada um dos núcleos separadamente, supondo uma situação de elevado índice de fragmentação do ambiente, onde as populações remanescentes nestas áreas estariam isoladas umas das outras. Num segundo cenário, foram avaliadas as viabilidades das populações totais estimadas para o conjunto das três áreas amostradas no presente estudo e que representam o setor norte do parque. Finalmente, no terceiro e último cenário, foi avaliada a viabilidade de cada uma das populações totais estimadas na área total do PESM.

O número de indivíduos necessários para manutenção destas populações, ou seja, a população mínima viável ("Minimun Viable Population" - MVP) considerada no presente estudo foi de 500 indivíduos, para uma primeira abordagem, assim como realizado por outros autores em outras áreas de Mata Atlântica (Chiarello \& de Melo, 
2001; Cullen Jr., 1997). Contudo, sabendo-se do avanço recente nas pesquisas de viabilidade de populações e de que os resultados vêm demonstrando que são necessários números superiores a este valor, abordaremos também a viabilidade destas populações com base em valores maiores até um limite de 7.000 indivíduos, similar ao registrado como sendo a MVP média para cerca de 102 espécies de vertebrados analisadas por Reed et al. (2003).

Para verificação da viabilidade das populações remanescentes nestas áreas foram utilizados os valores de populações mínimas estimadas, uma vez que o elevado número de visualizações a uma curta distância, como obtido no presente estudo, pode levar a complicações no cálculo da função de detecção para cada uma das espécies, afetando também a estimativa da ESW, e nestes casos, a estimativa de densidades mínimas podem e devem ser utilizadas (Buckland et al., 1993; Buckland et al., 2001; Marsden, 1999).

\subsection{Análise dos Dados}

Devido à diversidade de análises utilizadas bem como de padronizações utilizadas e programas específicos requeridos, cada um dos procedimentos realizados no presente trabalho serão abordados antes de cada resultado apresentado. Contudo, vale ressaltar que a escolha dos testes estatísticos, a avaliação de suas premissas, as limitações de suas análises e a interpretação dos resultados obtidos foram realizados seguindo ampla bibliografia especializada disponível sobre estes temas, como Sokal e Rolf (1995), Ter Braak (1986; 1988) e Zar (1996), dentre outros. 


\section{RESULTADOS}

\subsection{Transecções Utilizadas}

A partir de mapeamento em campo foi possível traçar os trajetos das trilhas utilizadas em mapas digitalizados da região (Figura 3). Utilizando-se também das classificações da vegetação disponíveis nestes mapas foi possível a determinação das transecções, consideradas no presente estudo como sendo as unidades básicas de amostragem, e suas respectivas coberturas florestais predominante, comprimento total e disposição nas áreas de estudo (Tabela 2).

A partir da elaboração destes mapas no programa ArcView 8.2, foi possível identificar e avaliar a cobertura total dos diferentes tipos florestais utilizados para as análises propostas. Além disso, uma série de fatores tais como a proximidade de comunidades tradicionais, distância destas transecções à sede administrativa da unidade, proximidade a rodovias, estradas ou bairros também puderam ser melhores visualizados ou até mesmo mensurados utilizando-se de ferramentas disponíveis no programa, permitindo a visualização de todos esses componentes que integram a região e conseqüentemente uma melhor discussão dos resultados. 


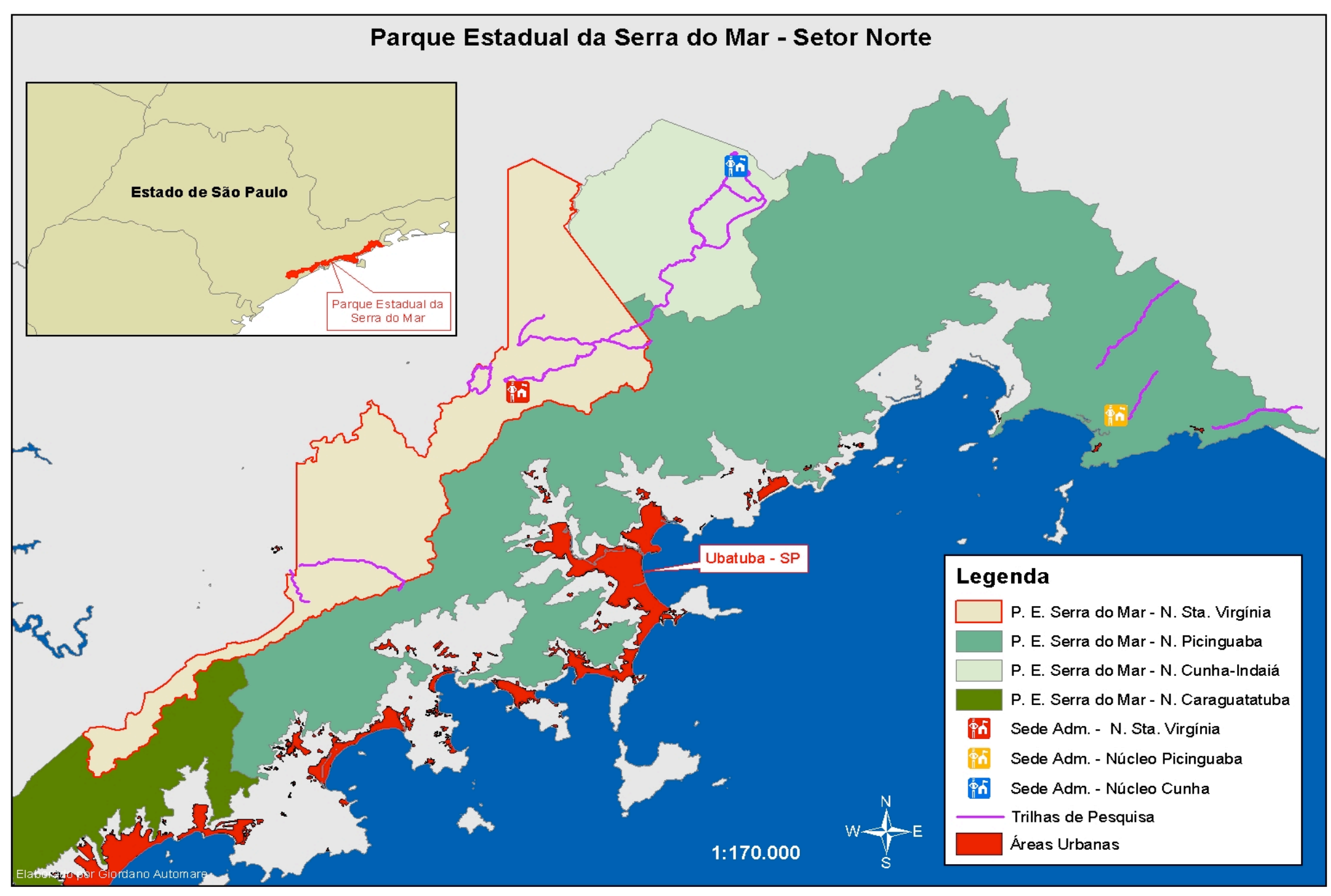

Figura 3 - Setor norte do PESM, onde aparecem as trilhas utilizadas em cada uma das áreas amostradas (Mapa fonte: SIGMA) 
Tabela 2. Trilhas utilizadas em cada um dos núcleos amostrados no PESM, as transecções estabelecidas, tipo florestal predominante e o comprimento total. Classificação da vegetação segundo SIGMA

\begin{tabular}{|c|c|c|c|c|}
\hline Núcleos & Trilhas & $\begin{array}{l}\text { Transecções } \\
\text { Siglas }\end{array}$ & Vegetação Predominante & $\begin{array}{c}\text { Comprimento } \\
(\mathrm{m})\end{array}$ \\
\hline \multirow{8}{*}{$\mathrm{NC} / \mathrm{I}$} & Estrada NSV-NC & NSV-NC A & Floresta Ombrófila Densa & 1.750 \\
\hline & & NSV-NC B & Vegetação Secundária & 2.750 \\
\hline & Cachoeiras & Cacho & Vegetação Secundária & 1.100 \\
\hline & Rio Bonito & RiBoA & Vegetação Secundária & 1.050 \\
\hline & & RiBoB & Floresta Ombrófila Densa & 3.550 \\
\hline & & $\mathrm{RiBoC}$ & Vegetação Secundária & 1.400 \\
\hline & Grotão-dos-Mono & GrMo & Floresta Ombrófila Densa & 8.450 \\
\hline & Paraibuna & Para & Vegetação Secundária & 1.500 \\
\hline \multirow{11}{*}{$\mathrm{NSV} / \mathrm{NS}$} & Pau-de-Bala & $\mathrm{PaBaA}$ & Floresta Ombrófila Densa & 2.450 \\
\hline & & $\mathrm{PaBaB}$ & Vegetação Secundária & 2.950 \\
\hline & Poço-do-Pito & PoPi & Vegetação Secundária & 2.450 \\
\hline & Itamambuca & Itam & Floresta Ombrófila Densa & 2.800 \\
\hline & Pirapitinga & Pira & Vegetação Secundária & 5.300 \\
\hline & Garcês & Garc & Floresta Ombrófila Densa & 3.000 \\
\hline & Corcovado & CorcA & Vegetação Secundária & 3.600 \\
\hline & & CorcB & Floresta Ombrófila Densa & 1.250 \\
\hline & Ipiranga & IpirA & Reflorestamento & 2.250 \\
\hline & & IpirB & Vegetação Secundária & 1.800 \\
\hline & & IpirC & Floresta Ombrófila Densa & 6.300 \\
\hline \multirow{3}{*}{ NP } & Casa da Farinha & $\mathrm{CaFa}$ & Floresta Ombrófila Densa & 8.000 \\
\hline & Cubatã & Cuba & Floresta Ombrófila Densa & 1.250 \\
\hline & Cambury & $\mathrm{Camb}$ & Floresta Ombrófila Densa & 4.000 \\
\hline
\end{tabular}

\subsection{Distância de Detecção}

Cerca de $630 \mathrm{~km}$ de censos foram percorridos nas três áreas amostradas do PESM. Foram obtidos um total de 184 visualizações, tendo sido registradas 11 espécies de mamíferos e 6 espécies de aves durante estes censos. Houve um total de 77 encontros com mamíferos e 107 com aves, obtendo-se abundâncias, ou taxas de encontro, de 1,22 visualizações $/ 10 \mathrm{~km}$ e de 1,70 visualizações $/ 10 \mathrm{~km}$, respectivamente.

Os valores de abundância não consideram as possíveis diferenças na distância de detecção destes locais, ou seja, o quão distante da trilha o pesquisador pode avistar um animal devido simplesmente às características do ambiente até mesmo a características 
das próprias espécies avaliadas. As abundâncias não consideram a área amostrada e valores muito próximos podem na verdade significar densidades totalmente discrepantes. Por isso, interpretações baseadas em comparações diretas destas taxas podem levar um pesquisador desatento a conclusões errôneas no caso de ambientes muito diferentes. Para a realização de comparações diretas desses valores, um procedimento simples que pode auxiliar os pesquisadores é a análise estatística das distâncias perpendiculares médias obtidas para as espécies e entre as áreas a serem comparadas. Não havendo diferenças significativas entre estas distâncias perpendiculares o pesquisador pode considerar, com menores chances de erro, que eventuais diferenças observadas entre as abundâncias refletem diferenças populacionais, ou seja, das densidades das espécies avaliadas nestes ambientes.

Assim sendo, os valores das distâncias perpendiculares obtidos para cada uma das espécies visualizadas, grupos de espécies, diferentes tipos florestais, núcleos amostrados ou tipos de transecções utilizadas, foram comparados através da aplicação de testes estatísticos específicos, buscando identificar possíveis diferenças na distância de detecção entre estes.

Os dados originais não apresentaram as premissas de normalidade e homoceidasticidade. Devido as características dos dados foi possível a transformação $\left(\log _{10}\right)$ para permitir a utilização de testes paramétricos. Foram utilizadas análises de variância (ANOVA One-way) seguidas do teste Tukey-Kramer, com $\alpha=0,05$, para a maioria das comparações e Teste-t (“t-student”) quando apenas dois valores foram comparados, todos procedimentos seguindo Zar (1996).

Não foram identificadas diferenças significativas entre as distâncias perpendiculares médias de todas as espécies amostradas. A maior distância perpendicular média observada foi para o mono-carvoeiro Brachytheles arachnoides $(12,36 \mathrm{~m})$ enquanto que a menor foi para o uru Odontophorus capueira $(3,06 \mathrm{~m})$.

Também não foi observada nenhuma diferença significativa entre os valores médios dos grupos analisados. Os Primatas, que incluem as espécies B. arachnoides, Alouatta guariba, Cebus nigritus e Callithrix aurita, apresentaram a distância 
perpendicular média mais elevada $(7,25 \mathrm{~m})$, enquanto que Sciurus aestuans, que foi analisado como um grupo à parte, obteve a menor média $(4,15 \mathrm{~m})$ (Tabela 3$)$.

Não foi observada nenhuma diferença significativa entre as observações realizadas nos diferentes tipos florestais amostrados. Para as áreas de floresta ombrófila densa as visualizações apresentaram uma distância média perpendicular de 4,96 m enquanto que na vegetação secundária este valor foi pouco menor, $4.38 \mathrm{~m}$ (Tabela 3).

Tabela 3. Resultados da ANOVA e comparação através do teste de Tukey-Kramer dos valores transformados das distâncias perpendiculares médias (LogDPM), para as diferentes categorias avaliadas. Itens identificados pela mesma letra não apresentam diferença significativa

\begin{tabular}{|c|c|c|c|c|c|}
\hline Categorias & $Q^{*}$ & Itens Comparados & Letras & $\operatorname{LogDPM}$ & DPM \\
\hline \multirow{16}{*}{ Espécies } & \multirow{16}{*}{3,50} & B. arachnoides & $\mathrm{A}$ & 1,39 & 12,36 \\
\hline & & R. vitellinus & $\mathrm{A}$ & 1 & 11,25 \\
\hline & & C. nigritus & A & 0,87 & 9,54 \\
\hline & & B. variegatus & A & 0,87 & 7,5 \\
\hline & & A. guarida & A & 0,87 & 7,44 \\
\hline & & N. nasua & $\mathrm{A}$ & 0,82 & 6,75 \\
\hline & & C. aurita & A & 0,77 & 5,67 \\
\hline & & S. brasiliensis & A & 0,74 & 5,5 \\
\hline & & P. tajacu & A & 0,69 & 5,02 \\
\hline & & Penelope spp. & $\mathrm{A}$ & 0,77 & 4,94 \\
\hline & & T. pecari & A & 0,81 & 4,64 \\
\hline & & T. solitarius & A & 0,82 & 4,26 \\
\hline & & S. aestuans & A & 0,64 & 4,15 \\
\hline & & D. azarae & A & 0,65 & 3,48 \\
\hline & & P. jacutinga & A & 0,51 & 3,25 \\
\hline & & O. capueira & A & 0,55 & 3,06 \\
\hline \multirow{4}{*}{ Grupos } & \multirow{4}{*}{2,60} & Primatas & $\mathrm{A}$ & 0,84 & 7,25 \\
\hline & & Aves & A & 0,73 & 4,49 \\
\hline & & Mam. Terrestres & A & 0,77 & 4,33 \\
\hline & & S. aestuans & $\mathrm{A}$ & 0,64 & 4,15 \\
\hline \multirow[t]{2}{*}{ Tipos Florestais** } & \multirow[t]{2}{*}{1,98} & Flor. Ombrófia Densa & $\mathrm{A}$ & 0,76 & 4,96 \\
\hline & & Vegetação Secundária & A & 0,67 & 4,38 \\
\hline \multirow{3}{*}{ Núcleos } & \multirow{3}{*}{2,37} & $\mathrm{NC} / \mathrm{I}$ & A & 0,81 & 5,33 \\
\hline & & NSV/NS & A & 0,69 & 4,31 \\
\hline & & NP & A & 0,69 & 4,01 \\
\hline \multirow{3}{*}{ Transecções } & \multirow{3}{*}{2,46} & Estrada & A & 0,77 & 5,86 \\
\hline & & Trilha & A & 0,76 & 4,96 \\
\hline & & Picada & $\mathrm{A}$ & 0,82 & 4,26 \\
\hline
\end{tabular}

$*$ alfa $=0,05$

** Para estas comparações o teste utilizado foi o Teste-t ( $t$-student). 
Nenhuma diferença significativa foi obtida entre as distâncias perpendiculares médias nos três núcleos amostrados. Para as áreas do NC/I as visualizações apresentaram uma distância média perpendicular de $5,33 \mathrm{~m}$, pouco maior que o observado no NSV/NS e no NP, 4,38 m e 4,01 m, respectivamente (Tabela 3)

Quanto ao tipo das transecções utilizadas também não foi possível observar nenhuma diferença significativa, sendo que as estradas obtiveram as maiores distâncias perpendiculares médias (5,86 m) e as “picadas", as menores (4,26 m) (Tabela 3)

Analisando a distribuição dos valores das distâncias perpendiculares de todas as visualizações realizadas durante os censos verificou-se que $90 \%$ foram registrados a uma distância menor que 10,39 $\mathrm{m}$ (média $=4,03 \mathrm{~m}, \mathrm{n}=182 *$ ), sendo que os mamíferos apresentaram média de 4,65 $\mathrm{m}$ e as aves de 4,49 $\mathrm{m}$. (*excluídas 2 visualizações $>20 \mathrm{~m}$ ).

\subsection{Padrões de Atividade}

Em cada uma das áreas foram percorridos cerca de $200 \mathrm{~km}$, sendo que metade destes no verão e o restante no inverno. Foram realizadas 206 amostragens, totalizando 630,55 km de censos e 184 visualizações de aves e mamíferos cinegéticos (Tabela 4).

Tabela 4. Número de visualizações de todas as espécies registradas durante os censos nas áreas de estudo

\begin{tabular}{|c|c|c|c|c|}
\hline Espécies avistadas & $\begin{array}{c}\text { NC/I } \\
(218,40 \mathrm{~km}) \\
\end{array}$ & $\begin{array}{c}\text { NP } \\
(202,20 \mathrm{~km}) \\
\end{array}$ & $\begin{array}{c}\text { NSV/NS } \\
(209,95 \mathrm{~km}) \\
\end{array}$ & Total \\
\hline Bradypus variegatus & $?$ & 1 & $*$ & 1 \\
\hline Callithrix aurita & 6 & * & 8 & 14 \\
\hline Alouatta guariba & 3 & * & $*$ & 3 \\
\hline Brachyteles arachnoides & 2 & * & $*$ & 2 \\
\hline Cebus nigritus & 4 & $*$ & 1 & 5 \\
\hline Nasua nasua & 1 & 1 & $*$ & 2 \\
\hline Procyon cancrivorus & $*$ & $*$ & 1 & 1 \\
\hline Tayassu pecari & 8 & 1 & 5 & 14 \\
\hline Pecari tajacu & 1 & $*$ & 1 & 2 \\
\hline Sciurus aestuans & 2 & 3 & 24 & 29 \\
\hline Dasyprocta spp. & $*$ & 3 & $*$ & 3 \\
\hline Silvilagus brasiliensis & $?$ & 1 & $*$ & 1 \\
\hline Total Mamíferos & 27 & 10 & 40 & 77 \\
\hline
\end{tabular}


Tabela 4. Número de visualizações de todas as espécies registradas durante os censos nas áreas de estudo

\begin{tabular}{lcccc}
\hline Espécies avistadas & $\begin{array}{c}\text { NC/I } \\
(218,40 \mathrm{~km})\end{array}$ & $\begin{array}{c}\text { NP } \\
(202,20 \mathrm{~km})\end{array}$ & $\begin{array}{c}\text { NSV/NS } \\
(209,95 \mathrm{~km})\end{array}$ & Total \\
\hline P. jacutinga & 1 & $?$ & $*$ & 1 \\
Penelope spp. & 21 & 17 & 23 & 61 \\
Odontophorus capueira & 7 & 6 & 12 & 25 \\
Tinamus solitarius & 7 & 6 & 5 & 18 \\
Ramphastos vitellinus & $?$ & $*$ & 1 & 1 \\
Ramphastos toco & $*$ & 1 & $*$ & 1 \\
Total Aves & $\mathbf{3 6}$ & $\mathbf{3 0}$ & $\mathbf{4 1}$ & $\mathbf{1 0 7}$ \\
Total Geral & $\mathbf{6 3}$ & $\mathbf{4 0}$ & $\mathbf{8 1}$ & $\mathbf{1 8 4}$ \\
\hline
\end{tabular}

* Indica que a espécie ocorre na área de estudo, porém não foi registrada durante os censos.

? Não foi possível confirmar a ocorrência da espécie para a área de estudo.

Para cada ave ou mamífero cinegético registrado durante o censo foi anotado o horário de visualização. Para uma melhor visualização dos resultados estes horários foram distribuídos em intervalos iguais que permitiram a identificação de um padrão de atividade comum para aves e mamíferos (Figura 4).

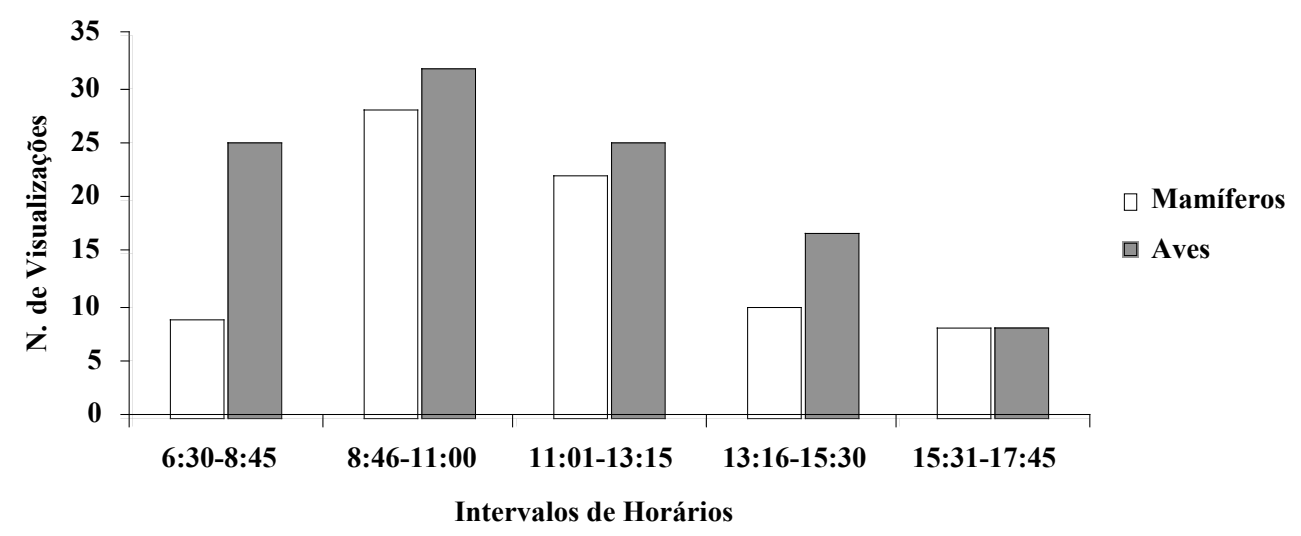

Figura 4 - Distribuição dos horários das visualizações de mamíferos e aves nas áreas de estudo

Ambos os grupos apresentam um padrão similar onde uma grande parte das visualizações ocorreu no período da manhã sendo cerca de $48 \%$ dos mamíferos $(\mathrm{n}=37)$ e $53 \%$ das aves $(n=57)$. Aproximadamente $23 \%$ das visualizações de ambos os grupos foram realizadas durante a tarde $(\mathrm{n}=18$, mamíferos e $\mathrm{n}=25$, aves $)$, enquanto que os 
demais registros foram obtidos durante o período próximo ao meio do dia, compreendido das $11: 01 \mathrm{~h}$ às $13: 15 \mathrm{~h}$, ou seja, $29 \%$ dos mamíferos $(\mathrm{n}=22)$ e $24 \%$ das aves $(\mathrm{n}=25)$. Buscando identificar diferenças estacionais nos padrões de atividade destes grupos que os dados foram analisados separadamente para cada uma das estações amostradas ao longo dos anos, ou seja, verão e inverno (Figuras 5 e 6).

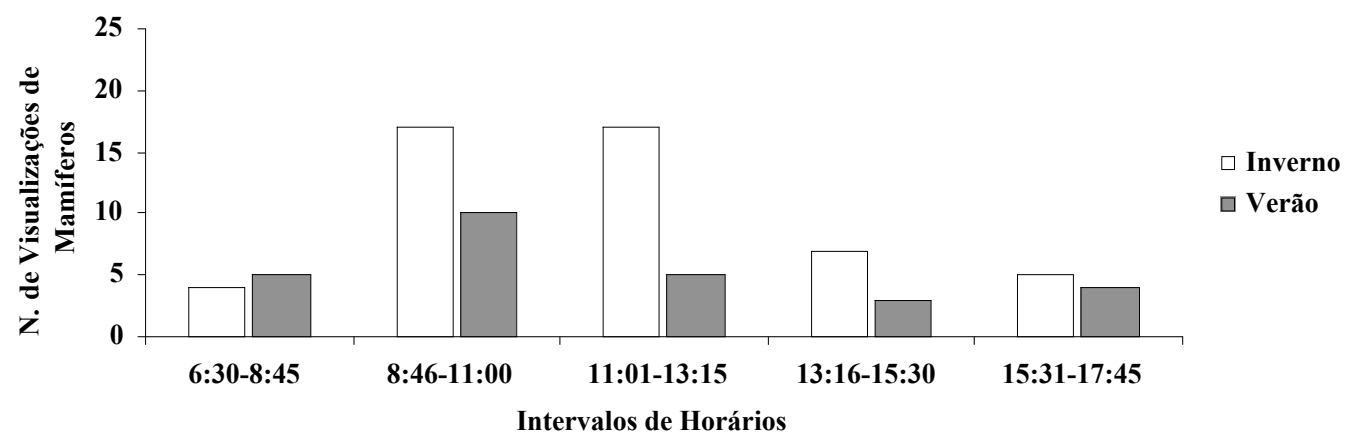

Figura 5 - Distribuição dos horários das visualizações de mamíferos no inverno e verão

Em ambas as estações os mamíferos apresentaram um padrão similar ao observado na análise anterior, com um maior número de registros durante o período da manhã ( $42 \%$ no inverno e $55 \%$ no verão). Contudo, é interessante notar que no inverno, apesar de apresentar um maior número de visualizações que no verão, os mamíferos obtiveram somente quatro (4) registros, ou seja, apenas $8 \%$, nas primeiras horas do dia.

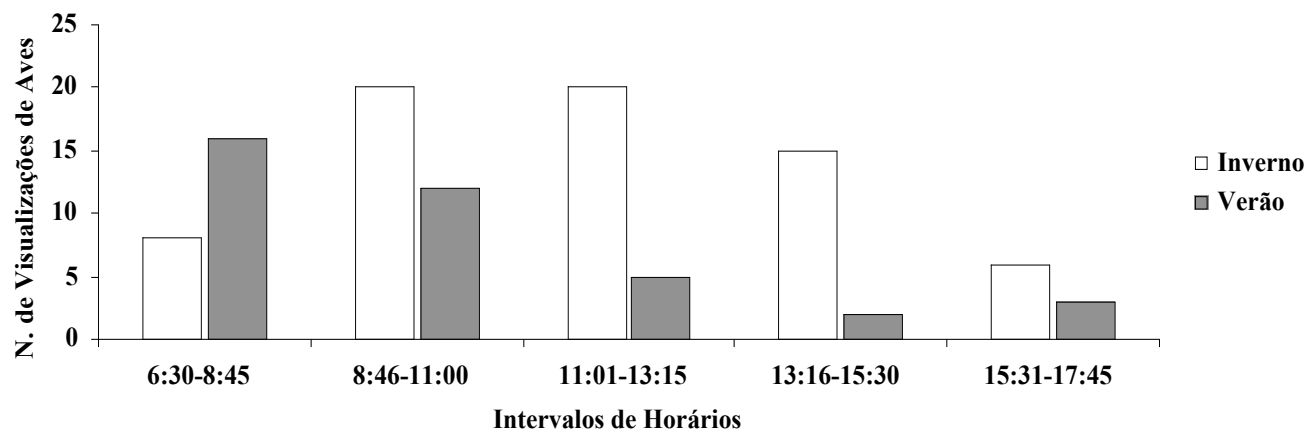

Figura 6 - Distribuição dos horários das visualizações de aves no inverno e verão 
As aves apresentaram padrões bem distintos entre as estações avaliadas. Durante o verão as visualizações foram na sua grande maioria no período da manhã, correspondendo a aproximadamente $74 \%$ dos registros $(n=28)$, sendo que o intervalo de horário com maior número de visualizações foi o das $6: 30$ h às 8:45 h. No inverno o padrão observado foi o oposto, onde um pequeno número de eventos $(\mathrm{n}=8,11 \%)$ foi registrado neste horário, enquanto um total de 55 visualizações, aproximadamente $80 \%$, foi realizado das $8: 45 \mathrm{~h}$ às $15: 30 \mathrm{~h}$.

Buscando identificar possíveis diferenças destes padrões entre as áreas amostradas foram realizadas comparações entre os resultados em cada um dos núcleos (Figura 7 e 8).

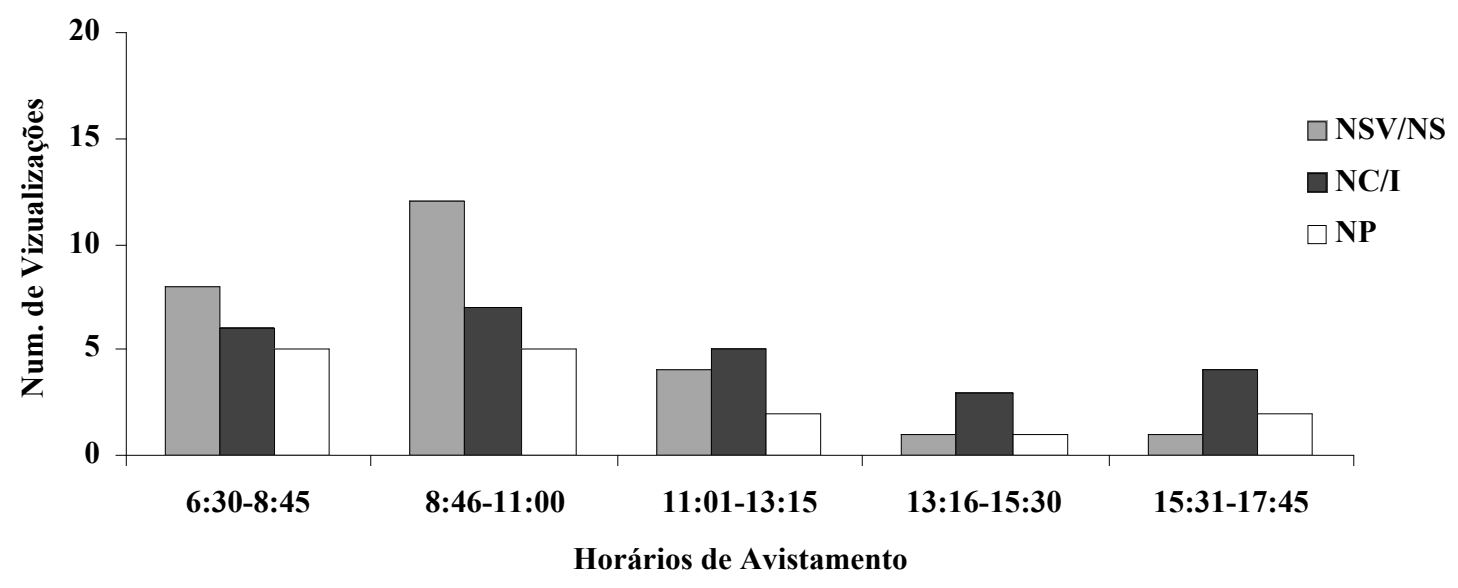

Figura 7 - Distribuição dos horários das visualizações de verão nas três áreas de estudo

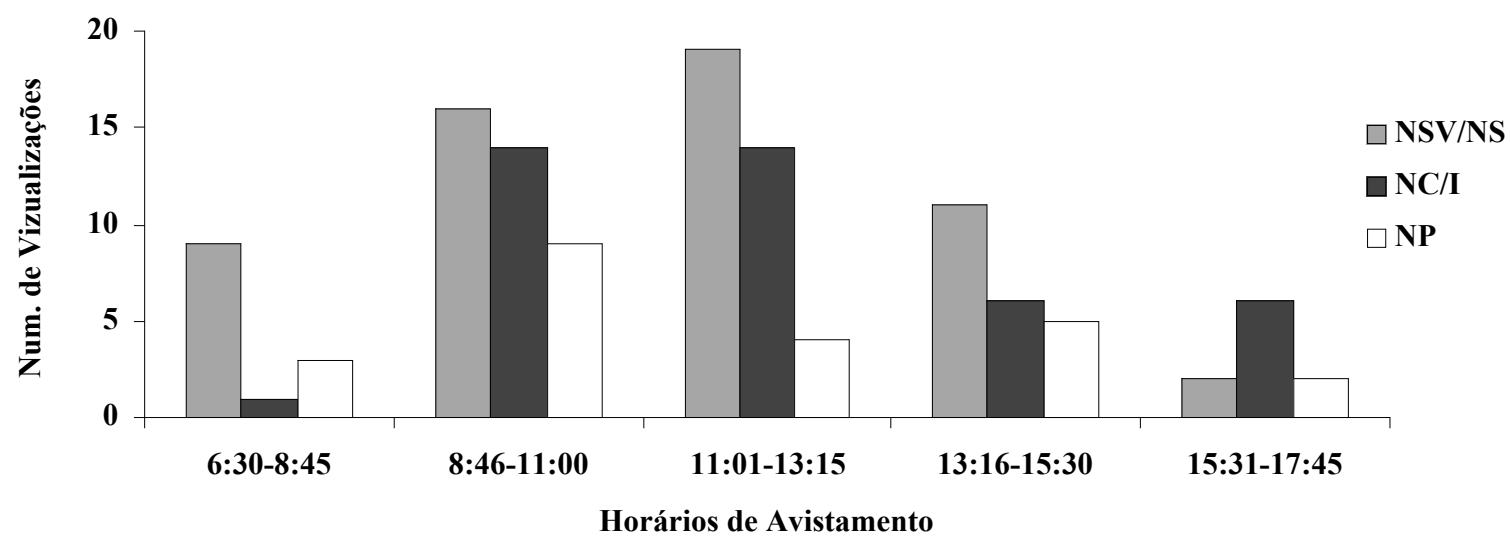

Figura 8 - Distribuição dos horários das visualizações de inverno nas três áreas de estudo 
Para as visualizações realizadas no verão o padrão obtido nas três áreas de estudo é similar, ou seja, um maior número de registros no período da manhã e uma queda nestes valores ao longo do dia. Já no inverno é possível observar dois padrões distintos onde na área do NP podemos visualizar um maior número de registros no meio do período da manhã em relação aos demais horários do dia, padrão muito parecido ao observado durante o verão em todas as áreas. Enquanto que nas áreas do NC/I e NSV/NS podemos verificar um maior número de visualizações durante o meio do dia, ou seja, compreendido entre as 11:01 h e 13:15 h. Contudo, é interessante perceber que embora tenha ocorrido um aumento médio no número de visualizações realizadas no inverno em relação ao obtido no verão na maioria dos horários, das 08:46 h às 11:00 h, das 11:01 h às 13:15 h e das 11:16 h às 15:30h, podemos notar que um número muito pequeno destes registros ocorreu nas primeiras horas do dia (intervalo 6:30 - 8:45), ocorrendo inclusive uma diminuição, em média de 36\%, no número de registros neste intervalo de horário, enquanto que nas horas mais próximas do final do dia (intervalo 15:31 - 17:45) ocorreu um aumento, porém em média de apenas 50\%.

As áreas do NC/I e NSV/NS ficam na porção mais elevada da Serra do Mar, com altitudes que variam de $800 \mathrm{~m}$ a $1.200 \mathrm{~m}$, , portanto, a menor atividade dos animais no início da manhã e final da tarde durante o inverno nestas áreas deve-se, provavelmente, as temperaturas médias mais baixas nesta estação do ano (Anexo E). É provável que as baixas temperaturas possam estar afetando o ritmo de atividade destes animais, principalmente das aves, diminuindo assim consideravelmente as chances de detecção.

Segundo dados da estação meteorológica localizada no NC/I, as temperaturas durante o inverno, tomadas as $9 \mathrm{~h}$ e as $18 \mathrm{~h}$, apresentaram médias próximas aos $14{ }^{\circ} \mathrm{C}$, tendo chegado às mínimas de até mesmo $4,7{ }^{\circ} \mathrm{C}$ e $4,6{ }^{\circ} \mathrm{C}$ nos meses de junho e julho durante o ano de 2003, respectivamente. No verão apresentaram médias acima dos $20^{\circ} \mathrm{C}$ e mínimas de no máximo $15,5{ }^{\circ} \mathrm{C}$ (ver Anexo E). Enquanto que, segundo dados do Instituto Nacional de Meteorologia, as temperaturas durante o mesmo período, em Ubatuba, onde está inserido o NP, apresentaram médias próximas aos $18{ }^{\circ} \mathrm{C}$, nunca inferiores a $10^{\circ} \mathrm{C}$, sendo que em janeiro ainda maiores, próximas aos $25^{\circ} \mathrm{C}$ (Anexo $\mathrm{F}$ ). 
Para cada registro realizado durante os censos foi anotado o estrato da mata utilizado pela espécie avistada, o que também permitiu, ao final do trabalho, estabelecer a freqüência de uso dos diferentes estratos de mata por estas espécies (Figura 9).

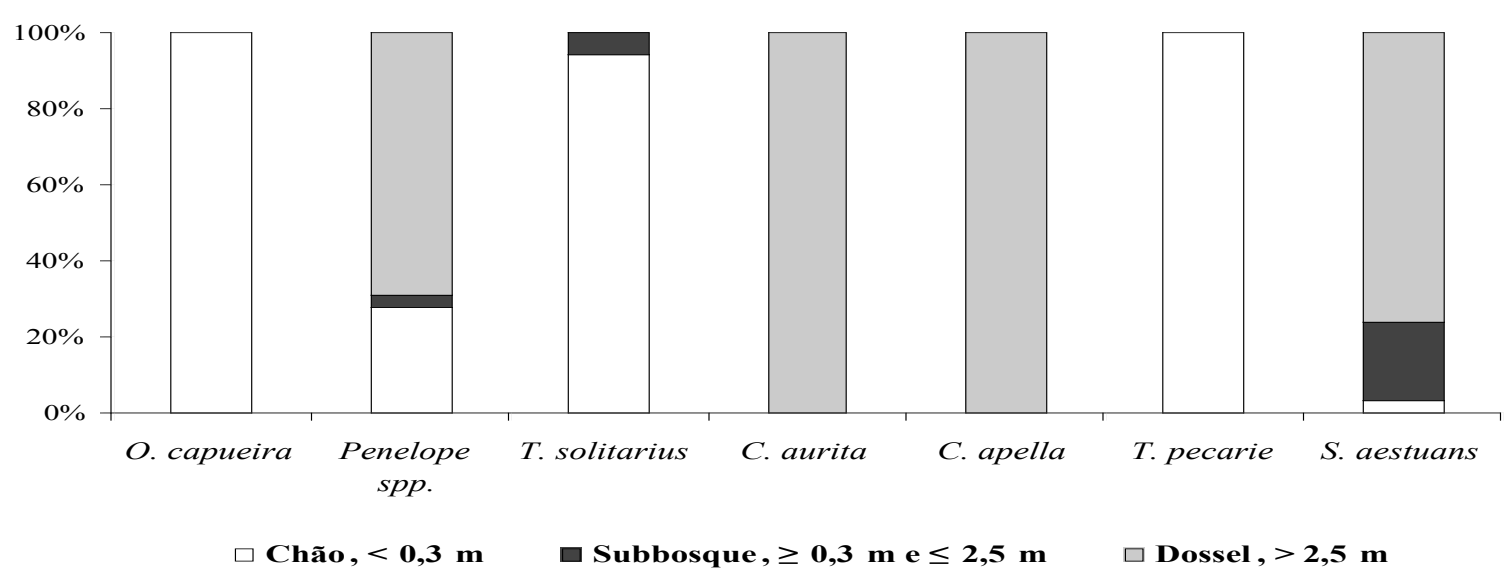

Figura 9 - Freqüências de ocorrência das espécies de aves e mamíferos cinegéticos nos diferentes estratos

As duas espécies de primatas (sagui-da-serra-escuro, C. aurita e macaco-prego, C. nigritus) obtiveram $100 \%$ de suas visualizações registradas acima dos 2,5 m, ou seja, no dossel da mata. Já o queixada, $T$. pecari e o uru, O. capueira, foram avistados exclusivamente no chão da mata. O macuco, T. solitarius obteve a maioria de suas visualizações no chão, porém, uma pequena parte delas, cerca de 5,5\% $(\mathrm{n}=1)$, foi registrada no sub-bosque da mata. Já o esquilo, $S$. aestuans foi observado aproximadamente $72,5 \%(\mathrm{n}=21)$ das vezes no dossel, cerca de $24 \%(\mathrm{n}=7)$ no subbosque e apenas 3,5\% $(\mathrm{n}=1)$ no chão da mata. Enquanto que Penelope spp. obteve 68,8 $\%(\mathrm{n}=42)$ das visualizações no dossel, apenas 3,4 \% $(\mathrm{n}=2)$ no sub-bosque e aproximadamente $27,8 \%(\mathrm{n}=17)$ no chão da mata.

\subsection{Abundâncias das Espécies e Uso do Habitat}

Para a identificação de possíveis diferenças quanto ao uso das áreas de estudo e também dos diferentes tipos florestais estudados, foram comparadas estatisticamente as 
abundâncias das espécies nestes ambientes. As espécies registradas durante os censos que obtiveram um total de cinco ou mais registros nas áreas amostradas tiveram suas visualizações transformados em taxas de abundância (n. de visualizações/10 km) para permitir as análises propostas. Os valores de abundância foram transformados para permitirem as comparações propostas. Os valores transformados correspondem a abundâncias obtidas projetadas para um total de $1.000 \mathrm{~km}$ percorridos.

Para as análises propostas foi utilizado o teste de Chi-quadrado $\left(\chi^{2}\right)$ onde foi fixado o nível de significância $(\alpha)$ de $5 \%$, sendo que nas comparações onde o grau de liberdade foi igual a 1, aplicou-se uma correção de continuidade conhecida como Correção de Yates. Todos os procedimentos seguem Zar (1996).

Tabela 5. Abundâncias originais em número de visualizações $/ 10 \mathrm{~km}$ (n. visual $/ 10 \mathrm{~km}$ ) das espécies de aves e mamíferos cinegéticos em cada um dos núcleos amostrados e abundância geral. Foram consideradas somente as espécies que obtiveram um número total mínimo de cinco registros

\begin{tabular}{lcccc}
\hline Núcleo & $\begin{array}{c}\text { NC/I } \\
\text { n. visual./10km }\end{array}$ & $\begin{array}{c}\text { NP } \\
\text { n. visual./10km }\end{array}$ & $\begin{array}{c}\text { NSV/NS } \\
\text { n. visual./10km }\end{array}$ & $\begin{array}{c}\text { Média Geral } \\
\text { n. visual./10km }\end{array}$ \\
\hline C. aurita $*$ & 0,27 & & 0,40 & 0,23 \\
C. nigritus* & 0,18 & & 0,05 & 0,08 \\
T. pecari* & 0,37 & 0,05 & 0,25 & 0,22 \\
S. aestuans & 0,09 & 0,15 & 1,21 & 0,48 \\
Mamíferos & 0,92 & 0,20 & 1,91 & 1,00 \\
Penelope spp. & 0,96 & 0,84 & 1,15 & 0,99 \\
O. capueira & 0,32 & 0,30 & 0,60 & 0,41 \\
T. solitarius & 0,32 & 0,30 & 0,25 & 0,29 \\
Aves & 1,60 & 1,43 & 2,01 & 1,68 \\
Abundância Geral & $\mathbf{2 , 5 2}$ & $\mathbf{1 , 6 3}$ & $\mathbf{3 , 9 2}$ & $\mathbf{2 , 6 9}$ \\
\hline
\end{tabular}

* Espécies que ocorrem em bandos. Valores indicam grupos/10 km.

As espécies mais abundantes de maneira geral nas áreas de estudo foram $S$. aestuans (0,48 visual./10km), entre os mamíferos, e Penelope spp. (0,99 visual./10km), entre as aves. Para as duas espécies de primatas (C. aurita e C. nigritus) não foi possível obter valores de abundância para o NP já que elas não foram visualizadas durante os censos. As aves, de maneira geral, apresentaram valores maiores de abundância que os mamíferos enquanto que o NSV/NS foi o que apresentou a maior abundância geral $(3,92$ visual./10km), cerca de duas vezes e meia o valor observado no NP (1,63 visual./10km). 
Tabela 6. Abundância das espécies de aves e mamíferos cinegéticos nos tipos florestais amostrados. Foram consideradas somente as espécies que obtiveram um número total mínimo de cinco visualizações

\begin{tabular}{lcc}
\hline Tipo de Floresta & $\begin{array}{c}\text { F. Omb. Densa } \\
\text { (n. visual./10km) }\end{array}$ & $\begin{array}{c}\text { Veg.Sec } \\
\text { (n. visual. } / 10 \mathrm{~km})\end{array}$ \\
\hline Mamíferos & 0,20 & \\
C. aurita** & 0,09 & 0,23 \\
C. nigritus** & 0,32 & 0,06 \\
T. pecari** & 0,41 & - \\
S. aestuans & & 0,63 \\
Aves & 0,92 & \\
Penelope spp.** & 0,36 & 1,15 \\
O. capueira** & 0,38 & 0,52 \\
T. solitarius & $\mathbf{2 , 6 8}$ & 0,06 \\
Abundância Geral & $\mathbf{2 , 6 5}$ \\
\hline
\end{tabular}

** Espécies não solitárias. Valores de grupos $/ 10 \mathrm{~km}$.

A espécie de mamífero mais abundante nos dois tipos florestais foi $S$. aestuans (0,41 indivíduos $/ 10 \mathrm{~km}$ e 0,63 indivíduos/10 km), sendo que entre as aves Penelope spp. foi a mais abundante também em ambos os ambientes amostrados $(0,92$ grupos $/ 10 \mathrm{~km} \mathrm{e}$ 1,15 grupos/10km).

A partir da comparação dos resultados obtidos foi possível verificar que tanto o grupo de mamíferos apresentou diferença significativa $\left(\chi^{2}=146,45, \mathrm{p}<0,05\right)$ entre os núcleos quanto as aves $\left(\chi^{2}=10,36, \mathrm{p}<0,05\right)$. A diferença observada para mamíferos e aves ocorre devido ao menor número de visualizações destes grupos na área do NP. O mesmo acontece quando se compara a abundância geral entre as áreas de estudo, ou seja, a diferença significativa observada $\left(\chi^{2}=98,67, \mathrm{p}<0,05\right)$, também se deve ao baixo número de registros em geral na área deste núcleo, principalmente para os mamíferos.

Entre os mamíferos, o $C$. aurita não apresentou diferença significativa $\left(\chi^{2}=2,39\right.$, p > 0,05) para os valores de abundância entre o NC e NSV/NS e nem mesmo para os diferentes tipos florestais $\left(\chi^{2}=0,19, \mathrm{p}>0,05\right)$. A ocorrência desta espécie na área do NP foi citada em outro trabalho realizado na área, porém nenhum registro ocorreu no presente estudo, nem mesmo durante as demais atividades de campo ao longo de três anos. 
C. nigritus não apresentou diferença significativa quanto ao tipo florestal $\left(\chi^{2}=\right.$ $0,79, p>0,05)$, porém apresentou diferença significativa $\left(\chi^{2}=7,61, p<0,05\right)$ entre as duas áreas em que ocorreu, tendo sido mais abundante na área do NC $(0,09$ grupos $/ 10 \mathrm{~km})$ que na do NSV (0,05 grupos/10km). Esta espécie, assim como C. aurita, apesar de ter sua ocorrência para NP citada em outro trabalho, também não foi registrada neste estudo.

T. pecari apresentou diferença entre as áreas amostradas $\left(\chi^{2}=23,14, \mathrm{p}<0,05\right)$ sendo que esta espécie ocorreu somente em áreas de floresta ombrófila densa, não tendo sido registrado durante os censos nas área de vegetação secundária. Suas abundâncias são muito maiores nas áreas do NSV/NS $(0,25$ grupos/10 km) e NC/I (0,37 grupos/10 $\mathrm{km})$, quando comparadas a obtida na área do NP $(0,05$ grupos $/ 10 \mathrm{~km})$.

S. aestuans apresentou uma diferença significativa entre os tipos florestais $\left(\chi^{2}=\right.$ 4,97, $\mathrm{p}<0,05)$ e também entre as áreas amostradas $\left(\chi^{2}=163,31, \mathrm{p}<0,05\right)$. Esta espécie ocorreu de maneira bem mais abundante na área do NSV/NS (1,21 indivíduos/10 km) quando comparado ao NC/I (0,09 indivíduos/10 km) ou NP (0,15 indivíduos/10 km). Sendo que sua abundância foi maior nas áreas de vegetação secundária $(0,63$ indivíduos $/ 10 \mathrm{~km})$ que nas áreas de floresta ombrófila densa (0,41 indivíduos $/ 10 \mathrm{~km})$.

Dentre as espécies de aves avaliadas neste trabalho somente $T$. solitarius apresentou diferença significativa quanto ao tipo florestal utilizado, enquanto que $O$. capueira foi a única espécie que apresentou diferença entre os núcleos amostrados. Penelope spp. não apresentou diferença significativa nem entre os tipos florestais $\left(\chi^{2}=\right.$ $2,46, \mathrm{p}>0,05)$ e nem entre os núcleos $\left(\chi^{2}=5,09, \mathrm{p}>0,05\right)$.

T. solitarius, como dito anteriormente, não apresentou diferença significativa entre os tipos florestais $\left(\chi^{2}=2,81, p>0,05\right)$, mas sim entre as áreas estudadas $\left(\chi^{2}=\right.$ 14,23, p < 0,05), apresentando sua maior abundância na área do NSV/NS $(0,60$ indivíduos $/ 10 \mathrm{~km})$ quando comparada ao NC/I $(0,32$ indivíduos/10 km) ou NP $(0,30$ indivíduos $/ 10 \mathrm{~km})$.

O. capueira, apesar de não apresentar diferença significativa entre as áreas avaliadas $\left(\chi^{2}=0,86, p>0,05\right)$, apresentou diferença significativa entre os tipos florestais 
avaliados $\left(\chi^{2}=24,10, \mathrm{p}<0,05\right)$, sendo mais abundante nas áreas de floresta ombrófila densa $(0,38$ grupos/10 km) que nas áreas de vegetação secundária $(0,06$ grupos/10 km).

\subsection{Variáveis Ambientais}

\subsubsection{Pressões Antrópicas: a caça e o turismo}

$\mathrm{O}$ registro de eventos de caça nas áreas de estudo permitiu determinar a intensidade desta variável (CAÇA) para cada uma das transecções utilizadas, assim como o turismo (TUR), que foi avaliado a partir das informações fornecidas pelas administrações das unidades e transformados em número de turistas/ano que freqüentaram as transeccções durante o período de estudo (Tabela 7).

Foi encontrado um total de 57 evidências de caça nas áreas de estudo, sendo que mais da metade delas na área do NP $(n=32)$. Visando avaliar a intensidade em cada uma das trilhas amostradas estes registros foram transformados em taxas de encontro de evidências $/ 10 \mathrm{~km}$, retirando assim também as possíveis diferenças no número de registros devido às diferenças de esforço amostral ( $\mathrm{km}$ percorridos) em cada uma delas. Os eventos de caça mais freqüentes foram tiros escutados $(n=15)$, seguidos de encontro com caçadores $(n=10)$ e cães de caça $(n=10)$ no interior da mata. Armadilhas de captura, geralmente chamadas de "arapucas", o encontro de "poleiros" ou "esperas", que consistem em uma plataforma posicionada sobre as árvores, onde o caçador geralmente permanece durante a noite para a caça de pacas (Agouti paca), foram menos freqüentes nestas áreas, registrados sete (7) vezes cada um deles.

Também foram encontrados cartuchos e outras munições deflagradas, geralmente de pequeno calibre, o que pode ser um indício, que confirmaria o levantado nas entrevistas realizadas, ou seja, de que as espécies mais caçadas atualmente seriam as aves de médio e grande porte, uma vez que os mamíferos, principalmente os porcos-do- 
mato (T. pecari e T. tajacu), alvos de preferência local, encontram-se em locais de maior difícil acesso, sendo caçados somente pelos chamados "caçadores-profissionais" 1 .

As aves por sua vez, por apresentarem uma distribuição geralmente mais ampla, são alvo tanto da caça "profissional", da de subsistência, geralmente praticada por populações tradicionais que vivem em áreas próximas, como também da caça recreativa/esportiva, além da cultural, geralmente praticadas por jovens destas comunidades ou caçadores esporádicos. É freqüente o encontro dos chamados "pios" com a população local, muitas vezes produzidos artesanalmente, e que auxiliam na caça destas aves. Segundo informações obtidas a espécie preferida na região é o macuco $T$. solitarius, geralmente caçada no final do dia, quando os indivíduos desta espécie estão se preparando para empoleirar-se, facilitando a sua visualização e abate ${ }^{1}$.

Uma atividade que foi registrada três vezes durante o trabalho de campo, todas elas na região de Picinguaba, e que, segundo os moradores locais, vem se desenvolvendo nestas áreas, é o chamado turismo da caça. Caçadores locais estariam sendo pagos para levarem os "caçadores-clientes" até os melhores pontos de caça na região, ficando incumbidos muitas vezes de toda a logística da caçada. Segundo informações, algumas “cevas", onde são colocadas iscas compostas geralmente por frutos e grãos (e.g. milho), estariam sendo mantidas em locais estratégicos para garantir o sucesso da caçada ${ }^{1}$.

O turismo nas áreas do NC/I e NSV/NS ocorre de maneira controlada e direcionada para algumas poucas trilhas. Já no NP, devido à localização das trilhas e a facilidade de acesso à maioria delas pela Rodovia Rio-Santos (BR 101) ou bairros da cidade de Ubatuba, favorece o turismo descontrolado sendo comum o encontro de turistas em meio à mata sem o agendamento prévio ou acompanhamento de guias, o que pode afetar não somente a manutenção destas trilhas como também pesquisas em andamento na área, vindo até mesmo a atrapalhar as ações de fiscalização (Observação pessoal).

\footnotetext{
${ }^{1}$ Entrevistas não padronizadas com administradores, funcionários e moradores das unidades amostradas, incluindo ex-caçadores locais, além de moradores do entorno. Comunicação pessoal, 2003.
} 
Tabela 7. Número total de registros de eventos de caça, taxa de intensidade desta atividade (número de eventos $/ 10 \mathrm{~km}$ ) e o número de turistas/ano para cada uma das transecções utilizadas no PESM

\begin{tabular}{lccc}
\hline Transecçóes/Núcleos & Total Eventos de Caça & Caça (eventos/10 km) & Turismo** (turistas/ano) \\
\hline NSV-NC A & $\mathbf{0}$ & 0,00 & 1.200 \\
Cacho & $\mathbf{1}$ & 1,01 & 1.200 \\
RiBoA & $\mathbf{0}$ & 0,00 & 3.600 \\
RiBoB & $\mathbf{0}$ & 0,00 & 3.600 \\
RiBoC & $\mathbf{0}$ & 0,00 & 3.600 \\
GroMo & $\mathbf{5}$ & 0,59 & 0 \\
Parai & $\mathbf{0}$ & 0,00 & 4.200 \\
NC/I Geral* & $\mathbf{7}$ & $\mathbf{0 , 3 2}$ & $\mathbf{6 . 2 0 0}$ \\
& & & \\
PaBaA & $\mathbf{3}$ & 2,65 & 0 \\
PaBaB & $\mathbf{0}$ & 0,00 & 0 \\
PoPit & $\mathbf{0}$ & 0,00 & 750 \\
Itama & $\mathbf{3}$ & 1,34 & 0 \\
Pirap & $\mathbf{0}$ & 0,00 & 3.500 \\
Corça & $\mathbf{1}$ & 0,39 & 380 \\
CorcB & $\mathbf{4}$ & 5,06 & 380 \\
NSV/NS Geral* & $\mathbf{1 8}$ & $\mathbf{0 , 8 6}$ & $\mathbf{5 . 0 0 0}$ \\
CaFar & $\mathbf{1 6}$ & 1,38 & $800^{(1)}$ \\
Cubat & $\mathbf{6}$ & 2,82 & 0 \\
Cambu & $\mathbf{1 0}$ & 1,55 & $1.200^{(2)}$ \\
NP Geral* & $\mathbf{3 2}$ & $\mathbf{1 , 5 8}$ & $\mathbf{3 . 6 0 0}$ \\
\hline * Os va & & &
\end{tabular}

* Os valores gerais não representam a soma dos valores apresentados nas linhas acima, uma vez que para a determinação da intensidade destas atividades nos núcleos foram utilizados todos os registros dentro destas unidades, alguns em trilhas não descritas acima.

** Valores aproximados fornecidos pelas administrações das unidades. NP representa somente visitas em área de floresta, não incluindo praias e restingas. ${ }^{1}$ No NP muitos turistas visitam a Casa da Farinha porém a maioria realiza caminhadas somente na parte inicial desta trilha e por isso o valor considerado é uma estimativa de utilização completa da trilha. ${ }^{2}$ Este valor é uma estimativa a partir de informações obtidas na comunidade da Vila Cambury.

\subsubsection{Estrutura da Vegetação}

Um total de 1.976 indivíduos arbóreos (DAP $>10 \mathrm{~cm}$ ) foram mensurados, distribuídos em 494 pontos quadrantes, número este igual ao de pontos utilizados para a amostragem de indivíduos de palmitos e palmeiras, o que gerou um esforço de 38.000 $\mathrm{m}^{2}$ de área amostrada, sendo que para a amostragem de frutos este valor foi de cerca de $19.700 \mathrm{~m}^{2}$, considerando-se as amostragens em ambas as estações (Anexo $\mathrm{G}$ ). 
Os parâmetros empregados na caracterização da estrutura da vegetação, com o uso da técnica de ponto quadrante, foram computados através do programa FITOPAC 2.0 (Shephard, 1995). Os parâmetros considerados foram os normalmente utilizados em estudos dessa natureza. Estes parâmetros foram agrupados para cada uma das transecções utilizadas e a análise dos valores de DAP, altura e distância das quatro maiores árvores próximas ao ponto central permitiram a obtenção da Densidade Absoluta (DABS) de indivíduos arbóreos e também do Volume (VOL) de madeira estimado (Anexo G). Para cada uma das transecções foram determinados também os valores médios de Cobertura de Dossel (COBD) e de Densidade de Palmitos e outras Palmeiras (DPA, DPJ, DPP, DEA, DEJ e DEP)(Anexo G).

\subsubsection{Disponibilidade de Frutos}

Um total de aproximadamente 40.000 frutos foi coletado, sendo que destes, cerca de $94 \%$ foram devidamente identificados, distribuídos num total de 23 espécies (Tabela 8). A partir do peso seco obtido para cada uma destas espécies foi possível determinar a porcentagem que cada uma delas contribuiu para o peso seco total obtido. Esta análise revelou que o palmito (E. edulis) é responsável em média por cerca de $61 \%$ de toda a biomassa, seguido pela canela (Cryptocaria moschata, Lauraceae) com 10\%, e pelo indaiá (Attalea dubia, Arecaceae) com 9 \% (Anexo F). As demais espécies identificadas $(n=20)$ corresponderam a $18 \%$ da biomassa e as não identificadas a $2 \%$ (Figura 10).

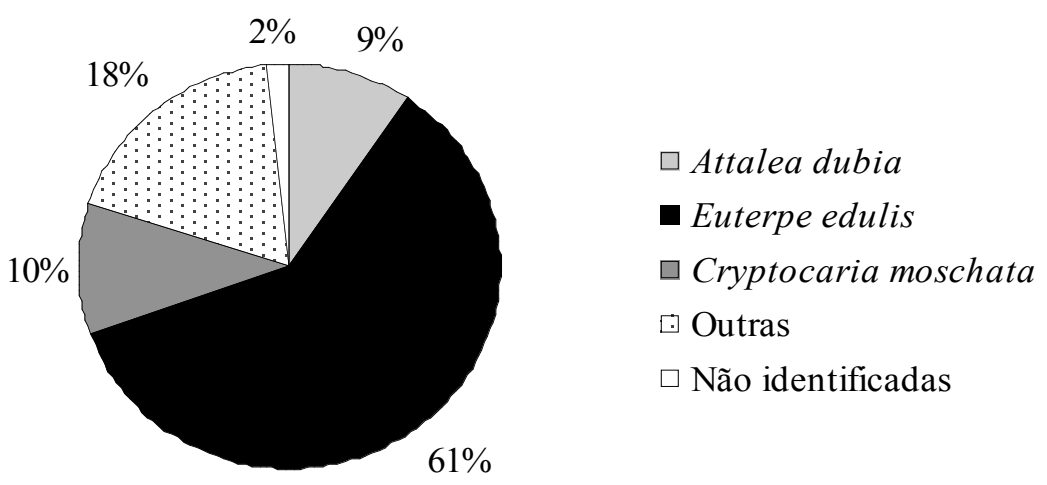

Figura 10 - Porcentagem da biomassa total obtida para as principais espécies de frutos coletados 
Devido à elevada participação (61\%) de frutos de palmito (E. edulis) na biomassa total, optou-se pela análise em separado dos frutos desta espécie. Assim sendo, a variável DISPF ora existente, foi substituída por duas novas, a disponibilidade de frutos de palmito (DISPP) e a de outros frutos em geral (DISPO).

Tabela 8. Espécies e respectivas famílias de todos os frutos zoocóricos identificados no setor norte do PESM. Sub-síndrome, número de frutos coletados e peso seco total obtido para cada uma delas

\begin{tabular}{|c|c|c|c|c|}
\hline Famílias & Espécies & Sub-síndrome $^{T}$ & $\mathbf{N}^{\mathbf{0}}$ Frutos & Peso seco (g) \\
\hline Annonaceae & Rollinia mucosa (Jacquin) Baillon & Mamíferos & 31 & 100,90 \\
\hline \multirow[t]{3}{*}{ Arecaceae } & Attalea dubia (Mart.) Burret & Mamíferos & 241 & 2345,30 \\
\hline & Euterpe edulis Mart. & Mista & 28.835 & $15.144,50$ \\
\hline & Syagrus pseudococos (Radi) Glassman & Mamíferos & 74 & 660,50 \\
\hline Cecropiaceae & Cecropia sp & Mista & 11 & 126,60 \\
\hline Ebenaceae & Diospyros sp & Mamíferos & 23 & 360,00 \\
\hline Elaeocarpaceae & Sloanea c.f. guianensis K.Schum & Aves & 46 & 91,40 \\
\hline Euphorbiaceae & Alchornea glandulosa (Sprengel) Müll.. & Aves & 2.127 & 176,15 \\
\hline \multirow[t]{3}{*}{ Fabaceae } & Hymeneae courbaril L. & Mamíferos & 1 & 8,60 \\
\hline & Inga sessilis (Vell.) Mart. & Mamíferos & 51 & 614,20 \\
\hline & Zollernia glabra (Sprengel) Yakovlev & Mamíferos & 147 & 221,80 \\
\hline \multirow[t]{2}{*}{ Lauraceae } & Cryptocaria moschata Nees \& Mart. & Mista & 2.049 & $2.545,00$ \\
\hline & Ocotea sp. & Aves & 44 & 298,80 \\
\hline Magnoliaceae & Talauma ovata A.St.-Hill. & Aves & 1 & 22,70 \\
\hline Malpighiaceae & Byrsonima lancifolia A.Juss. & Aves & 555 & 639,20 \\
\hline Meliaceae & Cabralea canjerana (Vell.) Mart. & Aves & 44 & 19,80 \\
\hline Myristicaceae & Virola oleifera (Schott.) A.C.Sm. & Mista & 677 & 325,40 \\
\hline Myrtaceae & Campomanesia sp & Mamíferos/Aves & 144 & 66,90 \\
\hline Passifloraceae & Passiflora sp. & Mamíferos & 35 & 38,80 \\
\hline Rosaceae & Prunus myrtifolia (L.) Urban & Mamíferos & 105 & 14,70 \\
\hline Sapindaceae & Matayba eleagnoides Radlk. & Aves & 936 & 581,80 \\
\hline Sapotaceae & Pouteria c.f. psammophylla Radlk. & Mamíferos & 2 & 67,80 \\
\hline Solanaceae & Solanum sp. & Aves/Mamíferos & 642 & 125,20 \\
\hline
\end{tabular}

${ }^{1}$ Segundo Campassi, 2002.

A disponibilidade de frutos total apresentou uma grande variação sazonal e também entre os núcleos (Figura 11 e 12), Grande parte desta variação geral se deve a variação na disponibilidade de E. edulis que, assim como a maioria dos frutos, apresentou uma diminuição no inverno (Tabela 9). Contrário a este padrão somente $C$. moschata, que durante os meses de inverno apresentou uma disponibilidade cerca de duas vezes maior que a observada durante o verão. 
Tabela 9. Disponibilidade de frutos $\left(\mathrm{kg} / \mathrm{km}^{2}\right)$ obtida no inverno, verão e numa avaliação anual para as principais espécies zoocóricas identificados no setor norte do PESM

\begin{tabular}{|c|c|c|c|c|}
\hline Espécies & Nome comum & $\operatorname{Verão}^{1}\left(\mathrm{~kg} / \mathrm{km}^{2}\right)$ & $\operatorname{Inverno}^{2}\left(\mathrm{~kg} / \mathrm{km}^{2}\right)$ & Anual $\left(\mathrm{kg} / \mathrm{km}^{2}\right)$ \\
\hline E. edulis & palmito & $17.416,02$ & $7.699,74$ & $12.557,88$ \\
\hline C. moschata & canela & 813,18 & $1.885,80$ & $1.621,28$ \\
\hline A. dúbia & indaía & $2.971,31$ & $2.253,22$ & $2.612,26$ \\
\hline Outros & & $7.775,13$ & $4.780,86$ & $6.006,20$ \\
\hline Total & & $28.975,64$ & $16.619,61$ & $22.797,63$ \\
\hline
\end{tabular}

${ }^{1}$ dezembro a fevereiro ${ }^{2}$ de junho a agosto

A área do NSV/I apresentou a mais elevada disponibilidade total de frutos durante o verão $\left(21.055,52 \mathrm{~kg} / \mathrm{km}^{2}\right)$, sendo que neste período o palmito obteve uma produtividade de $16.687,39 \mathrm{~kg} / \mathrm{km}^{2}$, contribuindo com cerca de 79,25\% de toda a biomassa coletada. Durante esta mesma época na área dos NP e NC/I o palmito apresentou produtividade bem mais baixas, de apenas $179,40 \mathrm{~kg} / \mathrm{km}^{2}$ e $549,23 \mathrm{~kg} / \mathrm{km}^{2}$, contribuindo com cerca de $3,31 \%$ e $21,95 \%$ da biomassa observada, respectivamente.

Verão

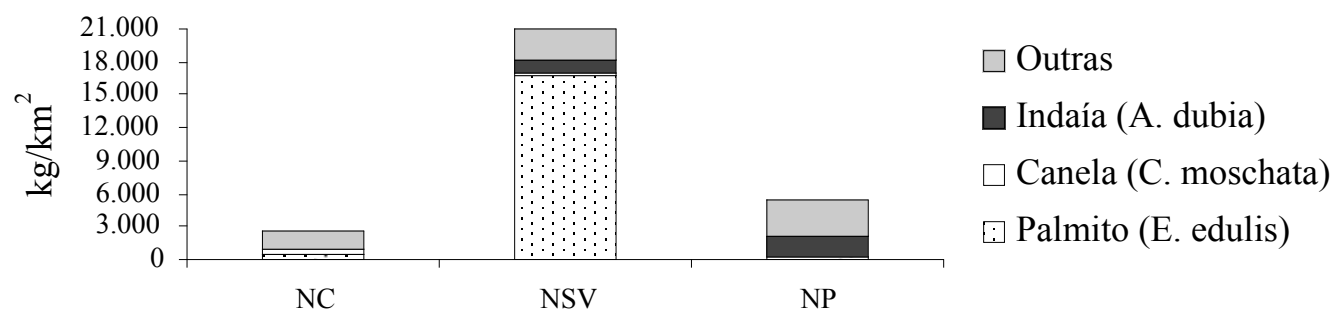

Figura 11 - Disponibilidades de frutos $\left(\mathrm{kg} / \mathrm{km}^{2}\right)$ obtidas durante o verão para as principais espécies nas três áreas do setor norte do PESM

As demais áreas apresentaram produtividades totais $\left(\mathrm{NC} / \mathrm{I}=2.501,82 \mathrm{~kg} / \mathrm{km}^{2} \mathrm{e}\right.$ $\mathrm{NP}=5.418,30 \mathrm{~kg} / \mathrm{km}^{2}$ ) bem mais baixas que a observada para a área do NSV/NS, sendo que nestas áreas os frutos de outras espécies foram responsáveis por cerca de 63,37 \% e $61,03 \%$ de toda a biomassa disponível. A produtividade de outros frutos obtidos na área do $\mathrm{NC} / \mathrm{I}$ foi de $1.585,03 \mathrm{~kg} / \mathrm{km}^{2}$ e de $3.305,80 \mathrm{~kg} / \mathrm{km}^{2}$ para a área do NP. A 
disponibilidade de outros frutos na área do NSV/NS, $2.884,30 \mathrm{~kg} / \mathrm{km}^{2}$, contudo, devido a disponibilidade do palmito, estes frutos contribuíram com apenas 13,69 \% da biomassa.

Inverno

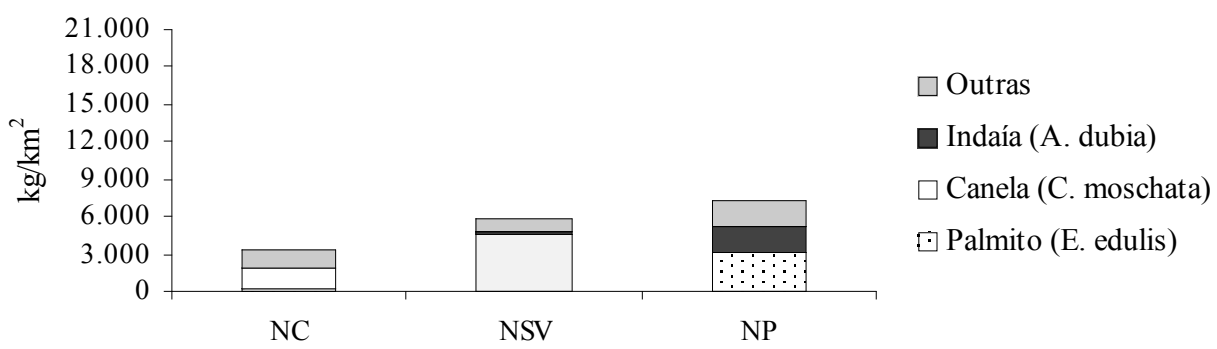

Figura 12 - Disponibilidades de frutos $\left(\mathrm{kg} / \mathrm{km}^{2}\right)$ obtidas durante o inverno para as principais espécies nas três áreas do setor norte do PESM

Durante o inverno a área do NSV/I apresentou uma diminuição de cerca de três vezes em relação a sua disponibilidade obtida no verão, mas mesmo com esta queda ainda foi a segunda área mais produtiva durante os meses mais frios com um total de $5.906,06 \mathrm{~kg} / \mathrm{km}^{2}$. Parte desta redução deveu-se pela diminuição da disponibilidade do palmito nesta área, que apresentou uma redução para aproximadamente $4.510 \mathrm{~kg} / \mathrm{km}^{2}$, porém, mesmo com redução esta espécie ainda representa boa parte dos frutos disponíveis para a fauna, correspondendo a cerca de $76,37 \%$ da biomassa de frutos na área.

$\mathrm{Na}$ área do $\mathrm{NC}$ foi observado um aumento na disponibilidade total de frutos $\left(3.368,34 \mathrm{~kg} / \mathrm{km}^{2}\right)$, cerca de $34 \%$, sendo que boa parte deste aumento se deve a uma maior disponibilidade de frutos de canela $\left(1.757,10 \mathrm{~kg} / \mathrm{km}^{2}\right)$, que passou a contribuir com cerca de $52 \%$ da biomassa de frutos na área, enquanto que o palmito com 4,48 \%.

Por outro lado, na área do NP, onde também foi observado um crescimento de cerca de $35 \%$ na disponibilidade total de frutos, total de $7.344 \mathrm{~kg} / \mathrm{km}^{2}$, observou-se que boa parte deste aumento ocorreu devido a uma maior disponibilidade de frutos de palmito $\left(3.037 \mathrm{~kg} / \mathrm{km}^{2}\right)$, que passaram a contribuir com $41 \%$ da biomassa na área, além 
de frutos de outra palmeira, o indaiá (A. dubia), que passou a contribuir com $28,44 \%$ da biomassa.

Devido à extensão e ao grande número de trilhas utilizadas para os censos, não foi possível realizar as amostragens de estrutura da vegetação, disponibilidade de frutos e densidade de palmitos e palmeiras nas seguintes transecções; NSV-NC B na área do NC/I, e IpirA, IpirB, IpirC e Garc na área do NSV/NS.

\subsubsection{Comparação dos Resultados}

Comparações dos parâmetros de estrutura da vegetação e disponibilidade de frutos foram realizadas entre os diferentes tipos florestais amostrados. Para a comparação de cada um dos parâmetros mensurados; densidade arbórea (DABS), volume (VOL), cobertura de dossel (COBD), densidade de palmeiras adultas (DPA), jovens (DPJ), e plântulas (DPP), densidade de palmito adultos (DEA), jovens (DEJ), plântulas (DEP), disponibilidade de frutos de palmitos (DISPP) e outros frutos (DISPO), foram utilizadas análises de variância (ANOVA One way). Todos os dados foram checados quanto à normalidade e homocedasticidade através dos testes de Shapiro-Wilk e Barlett (Sokal \& Rohlf, 1995). O único parâmetro que não cumpriu com estas premissas foi COBD e por isso teve seus valores transformados em $\log _{10}\left(\log _{10} \mathrm{COBD}\right)$, para permitir o uso de testes paramétricos. Era esperado que esta medida não apresentasse distribuição normal devido ao fato de que somente tipos florestais mais bem estruturados foram alvo do presente levantamento, o que fez com que os resultados tivessem uma variância muito baixa e valores muito próximos (de 79,65 a 96,8 \%).

Após análises de variância (ANOVA One way), para a comparação dos valores médios obtidos entre a floresta ombrófila densa (FOD) e vegetação secundária (VS) foi utilizado o Teste-t ("t-student"), $\alpha=0,05$, seguindo Zar (1996).

Os dois tipos florestais amostrados apresentaram diferença significativa para as densidades em todos os estágios de crescimento de outras palmeiras (DPA, DPJ e DPP), sendo que nas áreas de floresta ombrófila densa os valores observados foram maiores 
que os observados na vegetação secundária. DPA nas áreas de floresta ombrófila densa foi $6.532,86 \mathrm{ind} / \mathrm{km}^{2}$ e de apenas $1.266,88 \mathrm{ind} / \mathrm{km}^{2}$ na vegetação secundária $(\mathrm{t}=2,13, p$ $<0,05$ ). DPJ na floresta ombrófila densa foi de $41.491,87 \mathrm{ind} / \mathrm{km}^{2}$ e na vegetação secundária de 11.289,9 ind $/ \mathrm{km}^{2}(\mathrm{t}=2,13, p<0,05)$. DPP na floresta ombrófila densa é $56.458,40 \mathrm{ind} / \mathrm{km}^{2}$ e na vegetação secundária de $18.720 \mathrm{ind} / \mathrm{km}^{2}(\mathrm{t}=2,13, p<0,05)$.

Apesar de não apresentar diferenças significativas para todas as variáveis comparadas é importante ressaltar que as áreas de floresta ombrófila densa apresentaram as maiores médias para todos os demais parâmetros comparados.

Sabendo-se que na área do NP foram amostradas somente áreas de FOD era de se esperar valores médios para este núcleo superiores ao demais, uma vez que as áreas de FOD apresentaram médias superiores as áreas de VS para todos os parâmetros avaliados. Contudo, quando analisada a COBD entre as áreas de estudo foi constatada a diferença significativa do valor apresentado pelas áreas do NP e NSV/NS, 84,98 \% e $89,72 \%$, respectivamente, quando comparadas às médias do NC/I, 93,12\%.

Sabe-se que dentre as áreas avaliadas a do NC/I é a que apresenta o histórico de menor perturbação, tendo sido alvo de ações de corte seletivo, mas apresentando ainda boa parte da vegetação em seu estado praticamente intacto. Por outro lado, a área do NP sofreu historicamente com uma maior exploração de seus recursos florestais, principalmente durante e após a construção da Rodovia Rio-Santos (BR 101). Além disso, desde os primórdios da ocupação humana nas áreas do litoral brasileiro, a área do núcleo sempre esteve ocupada por vilas, comunidades tradicionais e/ou aldeias indígenas, que fizeram uso diretamente da floresta para retirada de madeira para construção de casas, lenha, uso medicinal ou da derrubada dela para dar lugar a roças, cultivos e até mesmo novas vilas e aldeias (SMA, 1998b). Segundo moradores locais ${ }^{1}$, durante a abertura e construção da rodovia Rio-Santos (BR 101) muita madeira foi cortada e retirada das áreas baixas da Serra do Mar, tanto para dar lugar à rodovia como

\footnotetext{
${ }^{1}$ Entrevistas não padronizadas com administradores, funcionários e moradores das unidades amostradas, incluindo ex-caçadores locais, além de moradores do entorno. Comunicação pessoal, 2003.
} 
para uso na própria construção, além da comercialização e uso na construção civil nos municípios da região, principalmente na cidade de Ubatuba.

Portanto, era possível que um fator determinante para a estrutura de vegetação atualmente encontrada nestes núcleos fosse o uso histórico das áreas. Buscando-se avaliar a influência desse fator na estrutura da vegetação, foi elaborada uma nova matriz onde, além dos parâmetros já descritos anteriormente, foi acrescentada uma nova variável categórica, o uso histórico de cada uma das transecções utilizadas (Anexo H). A partir da análise de planos de manejo (SMA, 1998a; SMA, 1998b) e de informações obtidas junto a moradores e administradores destas unidades foi possível determinar três diferentes tipos de uso histórico e, desta maneira classificá-las como;

- preservada - onde nenhuma ou praticamente nenhuma atividade humana foi registrada, consideradas como remanescentes praticamente intactos;

. corte seletivo - onde foi registrada atividade madeireira moderada, corte seletivo de espécies de maior porte e importância econômica;

. uso intenso - onde o corte de madeira ocorreu de maneira mais intensa, áreas foram alteradas para estabelecimento de roças e/ou com o corte também de espécies de menor porte para uso como lenha e outras aplicações; e finalmente,

. pastagem - áreas que foram drasticamente alteradas com derrubada de praticamente toda a vegetação, utilizadas como pastagens no passado.

As áreas da Serra do Mar, de maneira geral, foram exploradas intensamente durante nos anos 60, principalmente para a produção madeireira ou para uso como pastagens (SMA, 1998b), contudo, é importante salientar que desde a implantação do parque em 1977, todas estas áreas foram deixadas para regeneração natural, processo que vem acontecendo a pelo menos 25-35 anos na maioria delas.

Após a realização de análises de variância para cada um dos parâmetros mensurados (ANOVA One way), a comparação dos valores médios obtidos em cada uma das categorias de uso histórico foi realizada utilizando-se o teste de Tukey-kramer, com $\alpha=0,05$, seguindo Zar (1996). 
As áreas preservadas apresentaram diferença significativa $(\mathrm{q}=2,93, p<0,05)$ principalmente para os valores representantes de estrutura física da floresta, DABS e VOL, e DPA quando comparada com as demais categorias de uso. A DABS nas áreas preservadas foi de $9.940,13 \mathrm{ind} / \mathrm{km}^{2}$ enquanto que nas demais áreas estes valores foram inferiores a 3.300,00 ind $/ \mathrm{km}^{2}$ (Figura 13 - a). O mesmo foi observado para o VOL, que apresentou um total de $304.558,30 \mathrm{~m}^{3} / \mathrm{km}^{2}$ enquanto que as demais áreas estes valores não atingiram $100.000,00 \mathrm{~m}^{3} / \mathrm{km}^{2}$ (Figura 13 - b). Já para a DPA a diferença observada foi ainda maior, onde nas áreas preservadas este valor foi de $20.700,15 \mathrm{ind} / \mathrm{km}^{2}$, e nas demais áreas, inferiores a 4.200,00 ind $/ \mathrm{km}^{2}$ (Figura 13 - c).

a) DABS (ind $/ \mathrm{km} 2)$

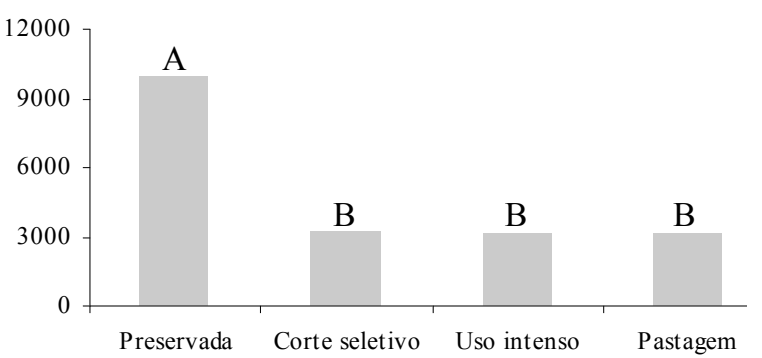

c) b) $\quad \operatorname{VOL}\left(\mathrm{m}^{3} / \mathrm{km}^{2}\right)$

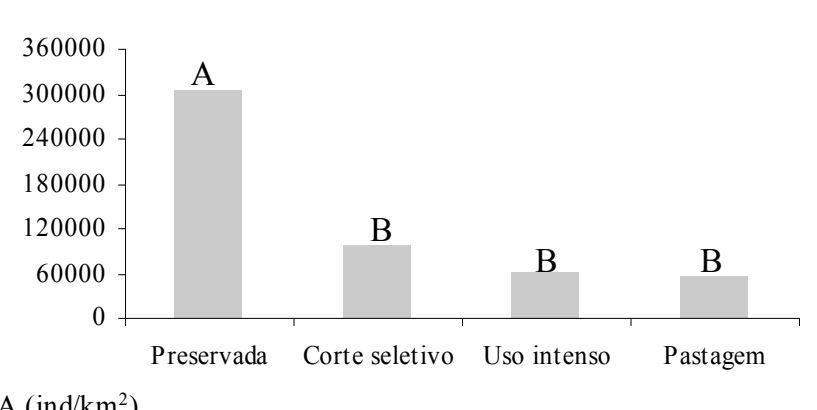

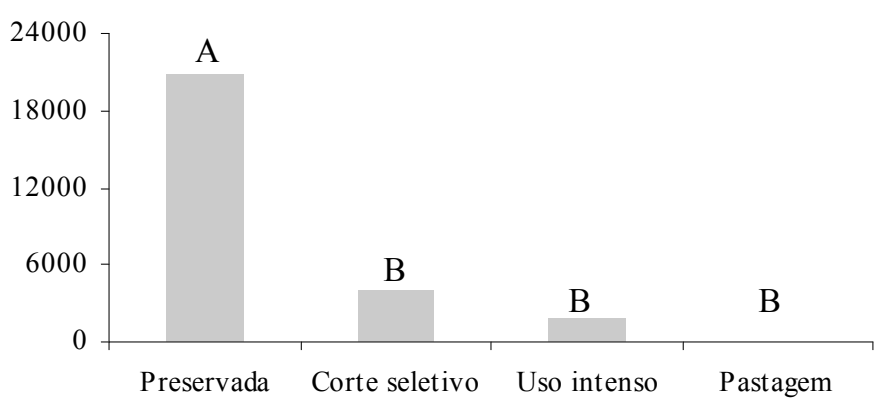

Figura 13 - Valores médios obtidos para cada uma das categorias de uso histórico avaliadas, referente às variáveis DABS (a), VOL (b) e DPA (c). Letras diferentes indicam diferenças significativas (Tukey-kramer, $\alpha=0,05$ )

Apesar de não apresentarem diferença significativa, os valores médios observados de COBD, DPJ e DPP também foram maiores para as áreas preservadas quando comparadas com as demais categorias de uso (Figura 14 - a, b e Figura 15). 


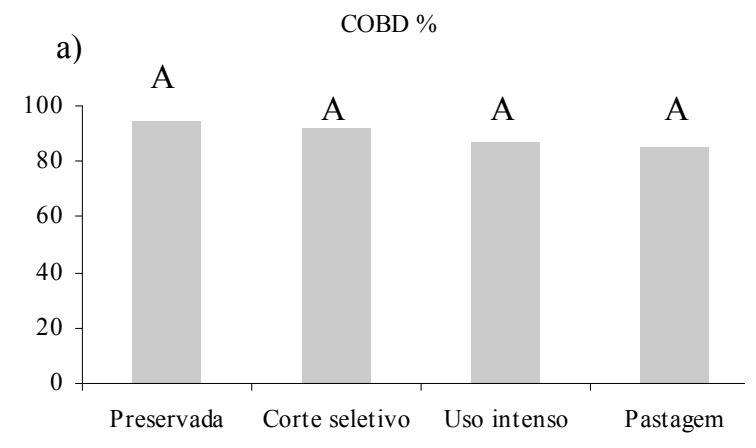

b) DPJ (ind./km2)

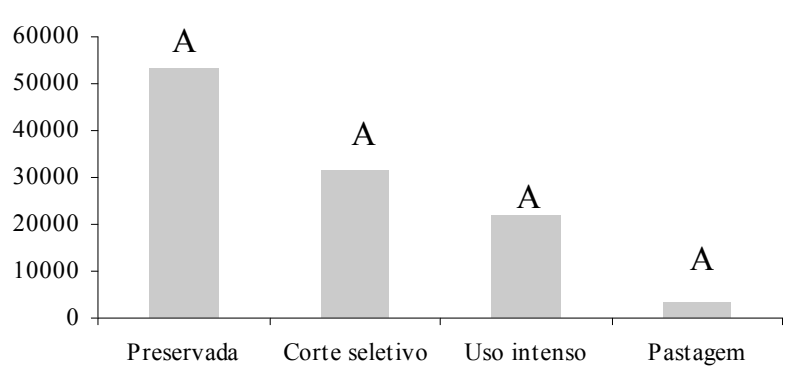

Figura 14 - Valores médios obtidos para cada uma das categorias de uso histórico avaliadas, referente às variáveis COBD (a) e DPJ (b). Letras iguais indicam que não houve diferença significativa (Tukey-kramer, $\alpha=0,05$ )

$$
\text { DPP (ind } \left./ \mathrm{km}^{2}\right)
$$

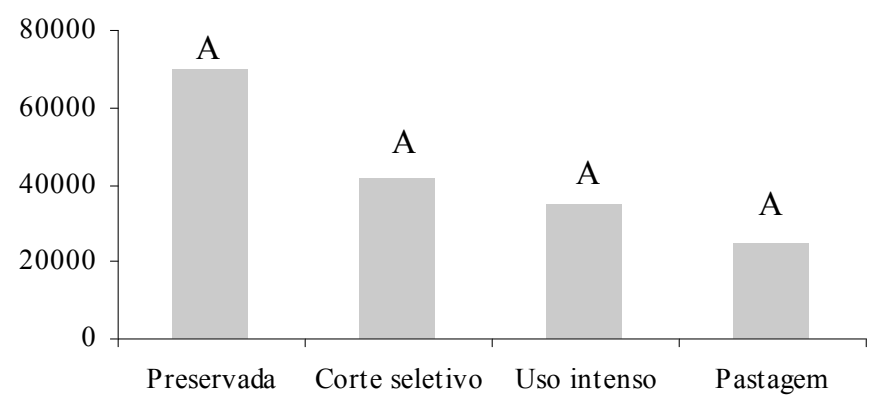

Figura 15 - Valores médios de DPP para cada uma das categorias de uso histórico avaliadas. Letras iguais indicam que não houve diferença significativa (Tukey-kramer , $\alpha=0,05$ )

DISPO e DISPP, bem como as densidades de palmito, DEA, DEJ e DEP, apresentaram padrão diferenciado, com valores geralmente maiores, apesar de não significativamente diferentes, para áreas de corte seletivo (Figura 16 - a, b e Figura 17 $\mathrm{a}, \mathrm{b}, \mathrm{c})$. DISPO não somente apresentou uma média muito superior nas áreas de corte seletivo $\left(310,10 \mathrm{~kg} / \mathrm{km}^{2}\right)$ como também elevado para as áreas de uso intenso $(170,00$ $\mathrm{kg} / \mathrm{km}^{2}$ ). É interessante notar que as áreas de ex-pastagem também apresentaram valores muito baixos de DISPO $\left(18,05 \mathrm{~kg} / \mathrm{km}^{2}\right)$ e ainda mais baixos de DISPP $\left(0,45 \mathrm{~kg} / \mathrm{km}^{2}\right)$, difíceis até mesmo de serem visualizados nos gráficos abaixo (Figura 17 - a e b). 
a)

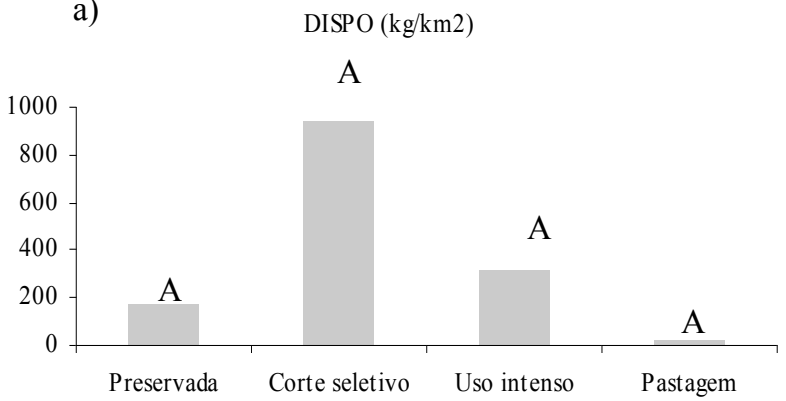

b)

$\operatorname{DISPP}\left(\mathrm{kg} / \mathrm{km}^{2}\right)$

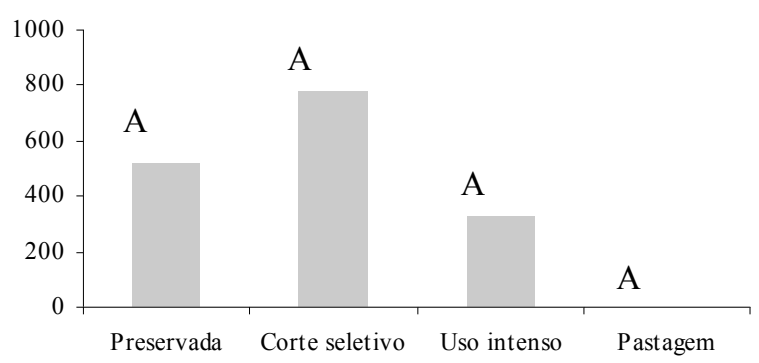

Figura 16 - Valores médios obtidos para cada uma das categorias de uso histórico avaliadas, referente às variáveis DISPO (a) e DISPP (b). Letras iguais indicam que não houve diferença significativa (Tukey-kramer, $\alpha=0,05$ )

a)

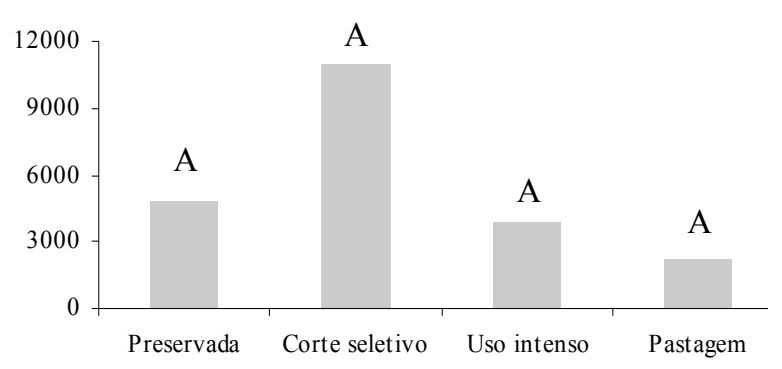

b)

DEJ (ind./km2)

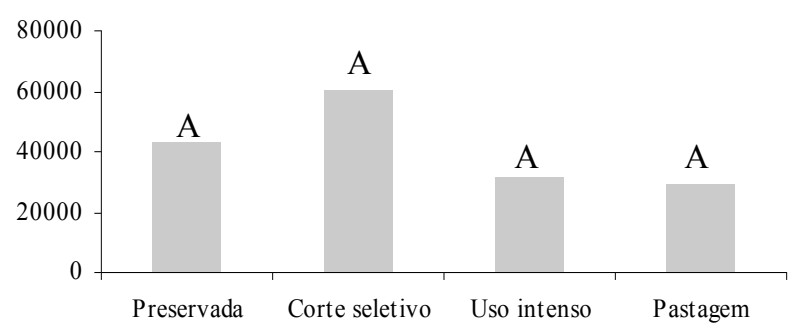

c)

DEP (ind/km2)

A

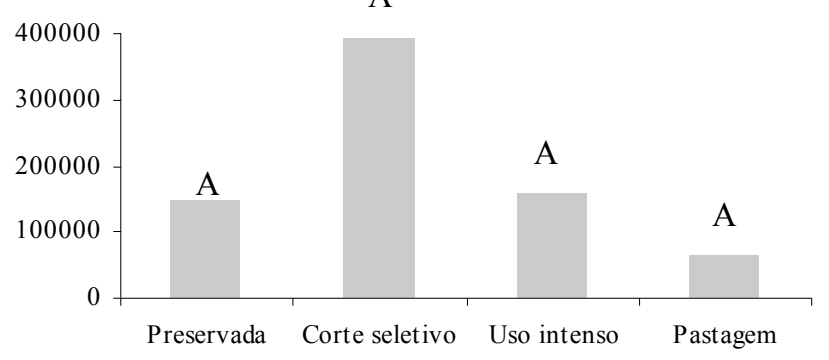

Figura 17 - Valores médios obtidos para cada uma das categorias de uso histórico avaliadas, referente às variáveis DEA (a), DEJ (b) e DEP (c). Letras iguais indicam que não houve diferença significativa (Tukey-kramer, $\alpha=0,05$ )

Todos os resultados indicam que as áreas de FOD apresentam-se melhor estruturadas e que geralmente apresentam densidades de indivíduos arbóreos (dap $>10$ 
$\mathrm{cm})$, palmeiras e também de palmitos, maiores que as formações secundárias. Por outro lado, dependendo do histórico de uso, principalmente as áreas de corte seletivo, podem apresentar maiores densidades de plântulas, jovens e adultos de palmito (DEP, DEJ e DEA), e conseqüentemente uma maior disponibilidade de frutos desta espécie (DISPP).

\subsection{Influência das Variáveis Ambientais}

Existe uma multiplicidade de técnicas de análise multivariada disponível para análise dos padrões de variação das comunidades em função de fatores ambientais (Kent \& Coker, 1992). Para avaliar a hipótese da existência de correlação entre a ocorrência das espécies de mamíferos e aves cinegéticas e variáveis ambientais foi utilizada a análise de correspondência canônica (CCA - “canonical correspondence analysis")(Ter Braak, 1987), por meio do programa PC - ORD versão 4.0.

A CCA permite a ordenação concomitante das espécies, áreas amostrais e variáveis ambientais. Essa técnica realiza a análise direta (ordenação forçada) dos gradientes pressupondo respostas unimodais baseadas na média ponderada dos dados. Ao contrário de outras técnicas de ordenação, na CCA, os eixos de ordenação das espécies e áreas amostrais, são definidos em combinação com as variáveis ambientais produzindo diagramas (biplots) onde se apresentam conjuntamente espécies, áreas amostrais e fatores ambientais (Ter Braak, 1986; 1987; 1988).

$\mathrm{Na} \mathrm{CCA}$, as espécies e áreas amostrais, aparecem no diagrama de ordenação como pontos correspondentes a seus ótimos aproximados no espaço bidimensional. Variáveis ambientais contínuas aparecem como setas indicando a direção de seu aumento no espaço de ordenação, sendo que o comprimento da seta é proporcional à sua importância na explicação da variância projetada em cada eixo (Ter Braak, 1986).

A CCA também identifica para cada eixo de ordenação as variáveis ambientais mais fortemente correlacionadas com a distribuição das espécies. Essa análise permite ainda testar a probabilidade de acerto nas relações encontradas por meio do teste de permutação de Monte Carlo (Ter Braak, 1988). Essa técnica combina princípios de 
ordenação e regressão múltipla, buscando assim detectar os padrões de variação das espécies mais bem explicados pelas variáveis ambientais.

Quando as variáveis ambientais são fortemente correlacionadas uma com as outras os efeitos destas sobre a composição da comunidade avaliada não podem ser diferenciados, e conseqüentemente os coeficientes canônicos se tornam instáveis. Este problema, a multi-colinearidade, ocorre com freqüência nas análises de regressão múltipla (Ter Braak, 1986). Contudo, estratégias podem ser adotadas para minimizar ou evitar que este problema aconteça, como por exemplo, a manutenção de apenas uma dentre o grupo de variáveis que apresentarem uma elevada correlação entre si (Ter Braak, 1986). Em contraste às análises de correlação canônica, a CCA (análise de correspondência canônica), não é influenciada pela colinearidade entre as espécies analisadas, sendo também aceito nestas análises que elas excedam o número de áreas (Ter Braak, 1986).

Portanto, para executar a CCA foram utilizadas as variáveis ambientais que não apresentaram elevadas correlações entre si, enquanto que para os dados de fauna, que compõem a matriz principal, foram consideradas as abundâncias das espécies com mais de dez visualizações no total ou de diversas espécies em grupos (indiv./10 km) obtidos para cada uma das transecções, ou seja, um total de 8 "espécies" e 17 unidades amostrais. C. nigritus foi visualizado um total de apenas cinco vezes e por isso apresentou valores de abundância nulos para a grande maioria das transecções. Esta espécie não foi avaliada separadamente, tendo sido considerada no grupo mamíferos geral (Anexo I).

Para a escolha das variáveis que comporiam a matriz secundária da análise de CCA foram calculados os coeficientes de correlação de Pearson para os pares de variáveis que poderia apresentar colinearidade tais como as densidades dos diferentes estágios de palmeiras, de palmitos, dados de estrutura física da floresta, etc (Tabela 10). 
Tabela 10. Tabela dos Coeficientes de Correlação de Pearson obtidos para as diferentes variáveis ambientais avaliadas. Valores elevados dos coeficientes indicam colinearidade entre os fatores

\begin{tabular}{rlc}
\hline Variáveis Ambientais & $\begin{array}{c}\text { Coeficientes de } \\
\text { Correlação de Pearson }\end{array}$ \\
\hline Densidade arbórea - DABS X VOL & 0,87 \\
Cobertura de dossel - COBD X DABS & 0,02 \\
Volume de madeira - VOL X COBD & 0,10 \\
Densidade de palmeiras adultas - DPA X DPJ & 0,40 \\
Densidade de plântulas de palmeiras - DPP X DPA & 0,48 \\
Densidade de palmeiras jovens - DPJ X DPP & 0,48 \\
Densidade de palmitos adultos - DEA X DEJ & 0,69 \\
Densidade de plântulas de palmitos - DEP X DEA & 0,94 \\
Densidade de palmitos jovens - DEJ X DEP & 0,56 \\
Disponibilidade de frutos de palmito - DISPP X DISPO & 0,22 \\
Densidade de palmitos adultos - DEA X DISPP & 0,71 \\
Disponibilidade de outros frutos - DISPO X DPA & 0,25 \\
\hline
\end{tabular}

A partir da análise dos resultados obtidos na tabela acima foi escolhido um total de sete variáveis que não apresentaram valores elevados de correlação, garantindo assim que não fosse observado o efeito de colinearidade na análise proposta. As selecionadas foram DABS, COBD $\left(\log _{10}\right)$, DPA, DISPO, DISPP, CAÇA e TUR (Anexo J).

\subsubsection{Resultados da Análise de Correspondência Canônica (CCA)}

Os autovalores ("eigenvalues") dos dois primeiros eixos, cujos valores expressam a contribuição de cada um para a variação total dos dados, foram 0,29 e 0,18, respectivamente. As variâncias relativas acumuladas para os dois primeiros eixos foram de $32,2 \%$ e $52,3 \%$, respectivamente (Tabela 11 ).

Tabela 11. Autovalores, variâncias relativas e correlações obtidas para cada um dos dois primeiros eixos de ordenação obtidos na Análise de Correspondência Canônica

\begin{tabular}{ccc}
\hline & Eixo 1 & Eixo 2 \\
\hline Autovalores "Eigenvalues" & 0,29 & 0,18 \\
\% da variância explicada por eixo & 32,20 & 20,10 \\
\% de variância acumulada & 32,20 & 52,30 \\
Correlação de Pearson & 0,87 & 0,92 \\
\hline
\end{tabular}


Analisando as correlações das variáveis ambientais com os eixos estabelecidos é possível observar a importância das variáveis de disponibilidade de frutos (DISPP e DISPO), e das de estrutura da vegetação (DPA e DABS) para a ordenação no primeiro eixo, e das variáveis CACA e COBD, para o segundo eixo (Tabela 12).

Tabela 12. Coeficientes de correlação entre as variáveis ambientais e os dois primeiros eixos da Análise de Correspondência Canônica

\begin{tabular}{lcc}
\hline Variáveis Ambientais & Eixo 1 & Eixo 2 \\
\hline Densidade Absoluta (DABS) & 0,18 & 0,19 \\
Cobertura de Dossel (COBD) $\log _{10}$ & 0,16 & 0,43 \\
Densidade de Palmeiras Adultas (DPA) & 0,28 & 0,28 \\
Disponibilidade de Outros Frutos (DISPO) & $-0,41$ & 0,11 \\
Disponibilidade de Frutos de Palmito (DISPP) & $-0,49$ & $-0,21$ \\
Caça (CACA) & $-0,26$ & $-0,46$ \\
Turismo (TUR) & $-0,09$ & 0,05 \\
\hline
\end{tabular}

Os resultados da CCA encontram-se espacializados num diagrama ('biplot") (Figura 18). Para melhor visualização do diagrama não foram representadas as áreas amostrais, bem como a variável TUR, que apresentou valor muito baixo de correlação, não representando influência sobre as espécies ou grupos avaliados (Tabela 12). 
Eixo 2

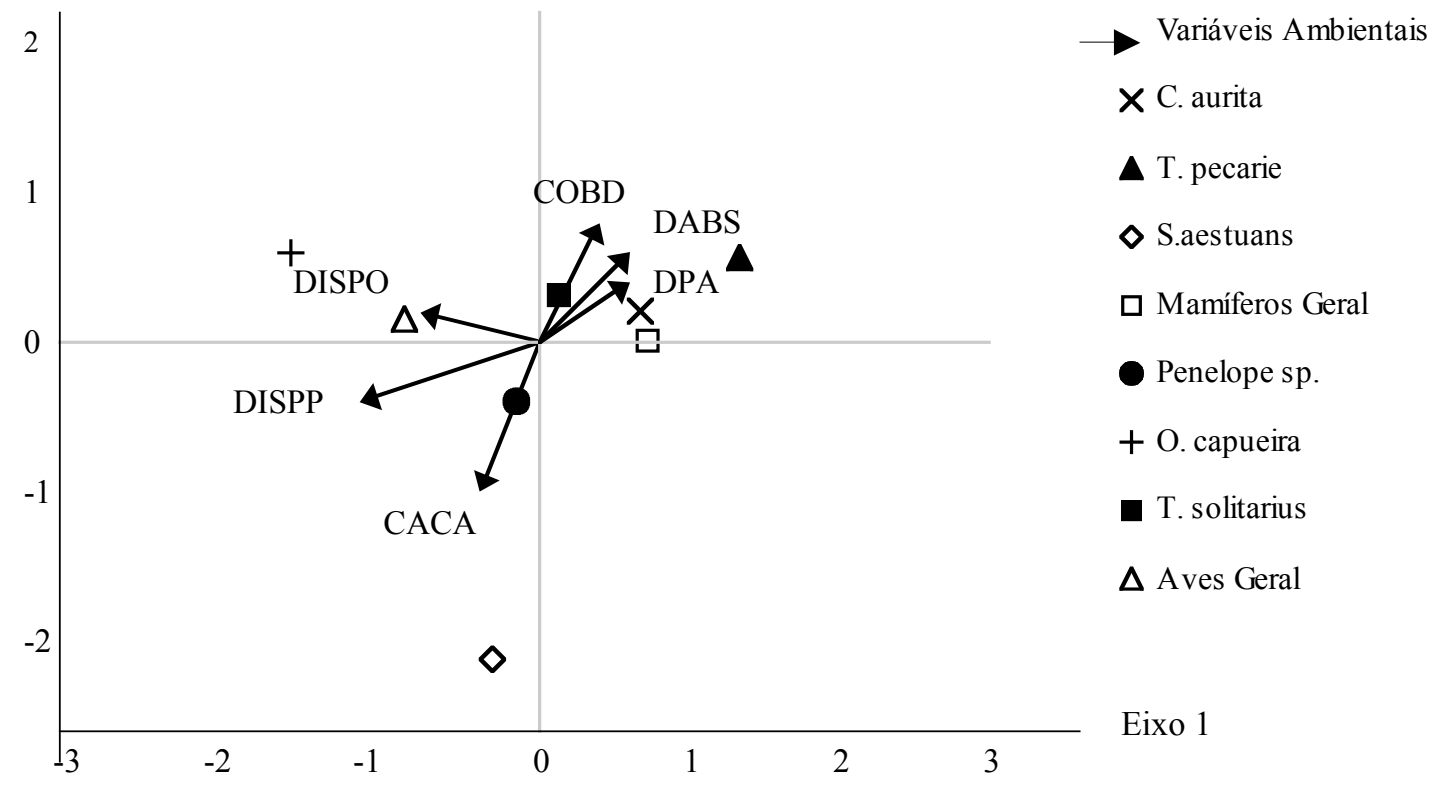

Figura 18 - Diagrama de ordenação da Análise de Correspondência Canônica (CCA). O diagrama apresenta a distribuição das espécies/grupos e variáveis ambientais nos dois primeiros eixos de ordenação. As áreas amostrais, no caso as transecções, geralmente presentes no diagrama, não foram representadas para uma melhor visualização dos resultados. Variáveis ambientais representadas pelas setas, que indicam grandeza e sentido das variações (para melhor visualização os valores dos vetores foram multiplicados por 2). CACA $=$ Caça, DISPP $=$ Disponibilidade de frutos de palmito, DISPO $=$ Disponibilidade de outros frutos, $\mathrm{COBD}=$ Cobertura de dossel, DABS, Densidade absoluta, DPA = Densidade de palmeiras adultas. Espécies ou grupos de fauna representados por símbolos identificados na legenda

A fim de testar a significância dos resultados obtidos foi utilizado a posteriori o teste de Monte Carlo que, não somente indicou o valor da correlação existente entre a matriz de variáveis ambientais utilizada e as abundâncias das espécies como também avaliou se estas correlações foram estatisticamente significativas (Tabela 13).

Tabela 13. Resultados do teste de Monte-Carlo indicando as correlações da matriz de variáveis ambientais e os dois primeiros eixos de ordenação da Análise de Correspondência Canônica

\begin{tabular}{lccccc}
\hline Eixos & Correlação & Média & Minimo & Máximo & $\boldsymbol{P}$ \\
\hline 1 & 0,87 & 0,83 & 0,53 & 0,965 & 0,333 \\
2 & 0,92 & 0,77 & 0,42 & 0,972 & 0,054 \\
\hline
\end{tabular}


Os resultados obtidos indicam que, apesar de valores elevados de correlação, nenhum deles foi estatisticamente significativo. Porém, estes valores de correlações indicam que, apesar de não significativos, a matriz de variáveis ambientais pode representar importante fonte de influência no padrão das abundâncias das espécies, principalmente quando avaliada sob os componentes do segundo eixo de ordenação. Desta forma, as interpretações destes resultados podem e devem ser consideradas como fortes tendências no ambiente natural e, por isso, serão melhor descritas a seguir.

As espécies C. aurita e T. pecari estão dispostas no primeiro quadrante do diagrama apresentado, o que indica que as suas abundâncias estão relacionadas ao aumento das variáveis DABS, DPA e principalmente COBD, esta última com maior importância para T. pecari, devido ao maior deslocamento desta espécie sobre o segundo eixo. Esta espécie, dentre todos os mamíferos, também foi a que apresentou maior correlação negativa com o aumento do fator CAÇA.

O grupo "Mamíferos Geral", apesar de também apresentar correlação com as variáveis DPA e DABS, não indica nenhuma correlação com as variáveis COBD ou CAÇA. De maneira geral, para todos os mamíferos, a disponibilidade de frutos (DISPO e DISPP) parece não ser um fator tão importante para a explicação de suas abundâncias.

S. aestuans foi a única espécie, dentre os mamíferos, que apresentou correlação positiva com o aumento da variável CAÇA e, negativamente, para com as variáveis de estrutura da vegetação.

Para as aves em geral, o padrão observado é o oposto, onde as disponibilidades de frutos (DISPP e DISPO) são as variáveis que melhor explicam as abundâncias. Exceto para os indivíduos de $T$. solitarius, que apresentaram uma certa correlação com as variáveis de estrutura da vegetação (DABS e DPA), mas principalmente com o aumento da variável COBD. Dentre as espécies de aves Penelope sp. foi a única que apresentou correlação positiva com o fator CAÇA enquanto que as demais espécies, principalmente $T$. solitarius, este fator apresentou-se negativamente correlacionado com os valores de abundância observados. 


\subsection{Densidade e Estimativas Populacionais}

Um total de 206 amostragens de censo foram realizadas nas áreas de estudo, distribuídas em 20 trilhas, totalizando-se 630,55 km percorridos. Ao final dos censos foi obtido um total de 184 visualizações que permitiu, com o auxílio do programa DISTANCE 4.1 (Buckland et al., 1993), o cálculo da largura efetiva de trilha (ESW), o intervalo de confiança (C.I.) e o tamanho médio do grupo (TMG), para 4 espécies de mamíferos e 3 espécies de aves, todas elas com um número mínimo de cinco visualizações (Tabela 14). Este procedimento foi possível devido ao fato de que não foram apresentadas diferenças significativas entre as distâncias médias perpendiculares obtidas nas áreas amostradas (item 4.2 Distâncias de Detecção).

Tabela 14. Tamanho médio do grupo (TMG e variação) e largura efetiva de trilha (ESW) calculada pelo programa DISTANCE 4.1 para espécies de mamíferos e aves cinegéticas com número (n) mínimo de cinco visualizações. S.E. = erro padrão, C.V. = coeficiente de variação e C.I. = intervalo de confiança a 95\%, que são utilizados para o cálculo dos valores máximos e mínimos das densidades

\begin{tabular}{lcccccc}
\hline Espécies & n & TMG (variação) & ESW (m) & S.E. & C.V. (\%) & C.I. (95\%) \\
\hline C. aurita & 14 & $4,07(3-6)$ & 10,39 & 2,90 & 27,91 & $5,72-18,87$ \\
C. nigritus & 5 & $6,80(6-16)$ & 18,13 & 5,83 & 32,18 & $7,58-43,35$ \\
T. pecari & 14 & $12,00(8-16)$ & 9,70 & 2,06 & 21,23 & $6,16-15,28$ \\
S. aestuans & 29 & $1,00^{*}$ & 7,49 & 0,87 & 11,60 & $5,91-9,50$ \\
Penelope sp. & 61 & $1,52(1-2)$ & 6,68 & 0,77 & 11,55 & $5,31-8,41$ \\
O. capueira & 25 & $3,20(3-5)$ & 5,41 & 0,65 & 12,05 & $4,22-6,94$ \\
T. solitarius & 18 & $1,00^{* *}$ & 8,59 & 1,89 & 22,02 & $5,42-13,49$ \\
\hline
\end{tabular}

* Uma única visualização de 4 ind. para esta espécie não foi considerada para cálculo do TMG.

** Uma única visualização de 2.ind. para esta espécie não foi considerada para cálculo do TMG..

Alguns valores de coeficiente de variação foram maiores que 20\%, o máximo recomendado por Buckland et al. (1993), contudo as estimativas de densidade 
apresentadas servem como ponto de partida para comparações com outros locais bem como comparações futuras nestas mesmas áreas.

Assim sendo, as densidades destas espécies foram estimadas através da seguinte fórmula: $D=$ Número Total de Visualizações $/ 2 *(E S W) * \mathrm{~L}$, onde $D=$ densidade em indivíduos ou grupos $/ \mathrm{km}^{2}, E S W=$ largura efetiva de trilha $(\mathrm{km})$ calculada pelo programa DISTANCE 4.1 e $L=$ quilometragem percorrida.

Foram calculadas as densidades $\left(\mathrm{D}_{\text {média }}, \mathrm{D}_{\text {mínima }}\right.$ e $\mathrm{D}_{\text {máxima }}$ - ind. $/ \mathrm{km}^{2}$ ) para cada um dos tipos florestais amostrados (Tabela 14). Utilizando-se destes valores das densidades das espécies e da cobertura total $\left(\mathrm{km}^{2}\right)$ destes tipos florestais, foram

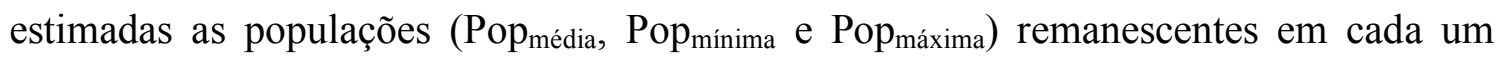
desses ambientais (Tabela 16).

Para as espécies que não obtiveram nenhum registro num determinado tipo florestal em alguma(s) (das) área(s) amostrada(s), o valor calculado das densidades é, obviamente, igual a zero. Porém, devemos lembrar que não foram realizadas amostragens nas áreas de VS do NP $\left(120,97 \mathrm{~km}^{2}\right)$ e a desconsideração de possíveis populações existentes nesta área poderiam levar a estimativas gerais, interpretações e avaliações inequívocas para a região.

A determinação de valores aproximados de densidade e populações destas espécies, mesmo que baseada em extrapolações, é valiosa e deve ser aplicada para permitirem assim uma melhor avaliação da viabilidade destas populações sob os diferentes contextos abordados, principalmente para avaliações no PESM como um todo.

Embora C. nigritus e C. aurita tenham ocorrência comprovada para a área do NP, uma vez que existem exemplares coletados na área, identificados e depositados no Museu Nacional de História Natural (MNHN) no Rio de Janeiro segundo Pinheiro e Geise (2003), estas espécies não obtiveram nenhum registro em áreas de FOD do NP, apesar do grande esforço realizado $(202 \mathrm{~km})$ neste ambiente.

C. aurita é uma espécie que não ocorre naturalmente em áreas abaixo de 150-200 m de altitude (Vivo, 1991; Auricchio, 1995; Cerqueira et al., 1998). Contudo, esta não 
poderia ser a causa da não visualização desta espécie nas áreas do NP uma vez que as trilhas utilizadas iam além deste limite, chegando muitas vezes a altitudes superiores a 400 m e até mesmo a 600 m (e.g. Trilha Casa da Farinha).

Além disso, estes primatas não apresentaram diferenças quanto ao uso dos tipos florestais nos demais núcleos amostrados (item 4.4 Abundâncias das Espécies e Uso do Habitat), portanto, a ausência de qualquer registro destas espécies nas áreas de FOD do NP, frente aos registros realizados por Pinheiro e Geise (2003) para a área do núcleo, pode ser interpretada como ocorrência eventual de bandos destas espécies, mas que não constituem população fixa na área, ou ainda como uma possível evidência de extinção no NP, caso o material depositado no MNHN tenha sido coletado há alguns anos.

Sendo assim a densidade calculada de zero ind $/ \mathrm{km}^{2}$ para as áreas de FOD no NP serão também consideradas para as áreas de VS do mesmo núcleo para ambas as espécies. Para as demais espécies serão considerados os valores de densidade obtidos a partir de uma média dos valores obtidos na VS nos demais núcleos amostrados.

As áreas do PESM, apesar de terem sido amostradas separadamente constituem um único bloco de remanescente de Mata Atlântica, havendo inclusive divisa de limites e continuidade da vegetação entre as três unidades, por isso as densidades destas áreas foram consideradas como um único valor para todo o Setor Norte (SN/PESM =

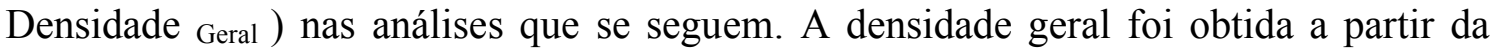
média dos valores de densidade nos núcleos amostrados, ponderadas por suas áreas, para cada uma das espécies analisadas. 
Tabela 15. Densidades $\left(\mathrm{D}_{\text {média }}=\right.$ indivíduos $\left./ \mathrm{km}^{2}\right)$ das espécies de mamíferos e aves cinegéticas com mais de cinco visualizações, calculadas a partir das ESW e TMG fornecidos pelo programa DISTANCE 4.1. Valores entre parênteses representam Densidade Mínima ( $\mathrm{D}_{\text {mínima}}$ ) e Densidade Máxima $\left(\mathrm{D}_{\text {máxima }}\right)$, respectivamente, calculadas a partir do C.I. presente na Tabela 11. Densidades calculadas para cada tipo florestal avaliado (FOD = floresta ombrófila densa e VS = vegetação secundária), em cada uma das áreas de estudo

\begin{tabular}{|c|c|c|c|c|c|c|}
\hline Área de Estudo & NC & & $\mathbf{N}$ & & $\mathrm{NSV} / \mathrm{I}$ & \\
\hline Tipo florestal & FOD & VS & FOD & VS & FOD & VS \\
\hline km percorrida & 144,0 & 74,4 & 202,2 & - & 99,4 & $\mathbf{9 7 , 1}$ \\
\hline C. aurita & $\begin{array}{c}6,80 \\
(3,74-12,35)\end{array}$ & $\begin{array}{c}5,26 \\
(2,89-9,56)\end{array}$ & $\begin{array}{c}0,00 \\
\text { (nenhum registro) }\end{array}$ & $\begin{array}{c}0,00 * * \\
(0,00-0,00)\end{array}$ & $\begin{array}{c}7,88 \\
(4,33-14,31)\end{array}$ & $\begin{array}{c}6,05 \\
(3,33-10,99)\end{array}$ \\
\hline C. nigritus & $\begin{array}{c}6,81 \\
(3,75-12,38)\end{array}$ & $\begin{array}{c}4,39 \\
(2,42-7,99)\end{array}$ & $\begin{array}{c}0,00 \\
\text { (nenhum registro) }\end{array}$ & $\begin{array}{c}0,00 * * \\
(0,00-0,00)\end{array}$ & $\begin{array}{c}3,29 \\
(1,81-5,98)\end{array}$ & $\begin{array}{c}0,00 \\
\text { (nenhum registro) }\end{array}$ \\
\hline T. pecari & $\begin{array}{c}32,08 \\
(17,66-58,27)\end{array}$ & $\begin{array}{c}0,00 \\
\text { (nenhum registro) }\end{array}$ & $\begin{array}{c}2,85 \\
(1,57-5,18)\end{array}$ & $\begin{array}{c}0,0 * \\
(0,00-0,00)\end{array}$ & $\begin{array}{c}29,04 \\
(15,99-52,76)\end{array}$ & $\begin{array}{c}0,00 \\
\text { (nenhum registro) }\end{array}$ \\
\hline S. aestuans & $\begin{array}{c}0,33 \\
(0,18-0,60)\end{array}$ & $\begin{array}{c}0,64 \\
(0,35-1,17)\end{array}$ & $\begin{array}{c}0,71 \\
(0,39-1,29)\end{array}$ & $\begin{array}{c}2,55^{*} \\
(1,40-4,03)\end{array}$ & $\begin{array}{c}7,26 \\
(3,99-13,19)\end{array}$ & $\begin{array}{c}4,46 \\
(2,45-8,10)\end{array}$ \\
\hline Penelope spp. & $\begin{array}{c}4,57 \\
(2,51-8,30)\end{array}$ & $\begin{array}{c}11,79 \\
(6,49-21,42)\end{array}$ & $\begin{array}{c}6,15 \\
(3,38-2,59)\end{array}$ & $\begin{array}{c}8,53 * \\
(4,69-15,50)\end{array}$ & $\begin{array}{c}11,77 \\
(6,48-21,38)\end{array}$ & $\begin{array}{c}5,27 \\
(2,90-9,58)\end{array}$ \\
\hline O. capueira & $\begin{array}{c}4,27 \\
(2,35-7,77)\end{array}$ & $\begin{array}{c}6,20 \\
(3,41-6,20)\end{array}$ & $\begin{array}{c}4,56 \\
(2,51-8,30)\end{array}$ & $\begin{array}{c}7,06^{*} \\
(3,88-10,30)\end{array}$ & $\begin{array}{c}10,84 \\
(5,97-19,69)\end{array}$ & $\begin{array}{c}7,93 \\
(4,36-14,40)\end{array}$ \\
\hline T. solitarius & $\begin{array}{c}2,01 \\
(1,10-3,64) \\
\end{array}$ & $\begin{array}{c}0,64 \\
(0,35-1,17) \\
\end{array}$ & $\begin{array}{c}1,42 \\
(0,78-2,59) \\
\end{array}$ & $\begin{array}{c}0,32 * \\
(0,17-0,58) \\
\end{array}$ & $\begin{array}{c}2,42 \\
(1,33-4,39) \\
\end{array}$ & $\begin{array}{c}0,00 \\
\text { (nenhum registro) }\end{array}$ \\
\hline
\end{tabular}

* Não foram realizadas amostragens na VS, densidades obtidas a partir da média dos valores observados neste tipo florestal nos demais núcleos.

** Espécies não registradas nos censos realizados na FOD do NP, sendo as densidades encontradas neste tipo florestal também consideradas para VS. 
Tabela 16. População estimada ( Pop $_{\text {média }}=$ indivíduos) das espécies de mamíferos e aves cinegéticas com mais de cinco visualizações. Valores entre

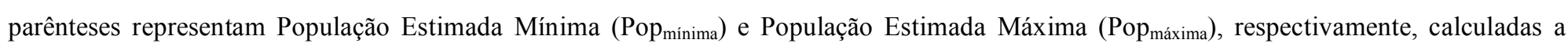
partir das $\mathrm{D}_{\text {mínima }}$ e $\mathrm{D}_{\text {máxima }}$ presentes na Tabela 12. Populações estimadas para cada tipo florestal avaliado (FOD = floresta ombrófila densa e VS = vegetação secundária), em cada uma das áreas de estudo

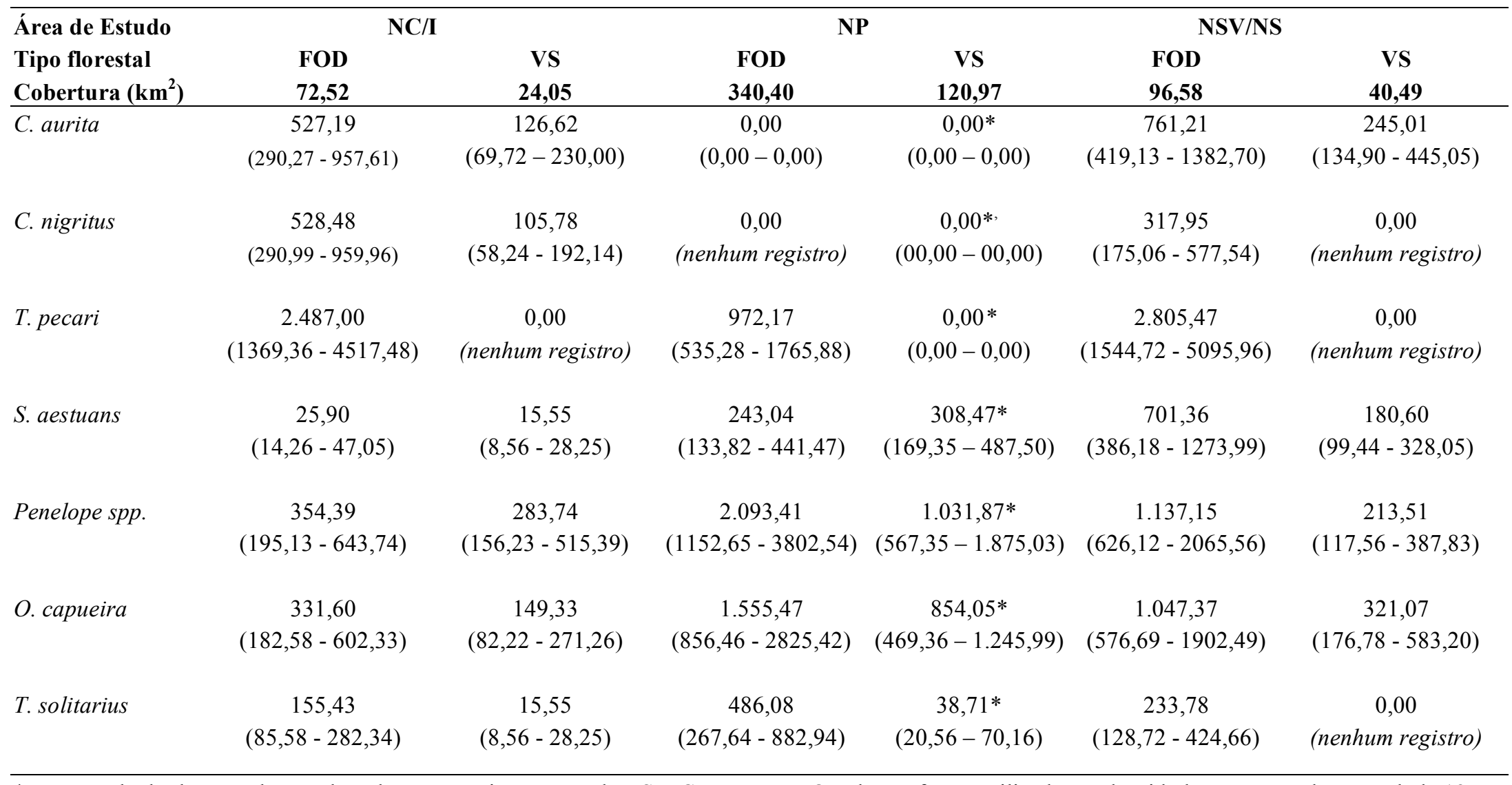

* Para o cálculo das populações de todas as espécies na área de VS e C. aurita na FOD do NP foram utilizadas as densidades apresentadas na Tabela 12. 
Os resultados do presente estudo foram comparados com os de outros censos de mamíferos e aves na Mata Atlântica que se utilizaram de transecções lineares para determinação das densidade (Tabela 17 e Anexo K). Para a maioria das espécies de aves cinegéticas pouca ou nenhuma informação está disponível, excetuando-se Penelope spp.

Tabela 17. Densidades das espécies de mamíferos e aves cinegéticas no presente estudo e em outras áreas de estudo na Mata Atlântica. Referências (Ref.)

\begin{tabular}{|c|c|c|c|c|c|c|c|c|}
\hline $\begin{array}{l}\text { Áreas de } \\
\text { Estudo } \\
\end{array}$ & $\begin{array}{l}\text { Tipo de } \\
\text { Floresta } \\
\end{array}$ & $\begin{array}{c}\text { Tamanho } \\
\left(\mathrm{km}^{2}\right)\end{array}$ & $\begin{array}{l}\text { C. aurita } \\
\left(\mathrm{ind} / \mathrm{km}^{2}\right)\end{array}$ & $\begin{array}{l}\text { C. nigritu } \\
\left(\mathrm{ind} / \mathrm{km}^{2}\right) s\end{array}$ & $\begin{array}{l}\text { T. pecari } \\
\text { (ind } / \mathrm{km}^{2} \text { ) }\end{array}$ & $\begin{array}{l}\text { S. aestuans } \\
\left.\text { (ind } / \mathrm{km}^{2}\right)\end{array}$ & $\begin{array}{c}\text { Penelope sp } \\
\left(\text { ind } / \mathrm{km}^{2}\right) .\end{array}$ & $\underset{1}{\text { Ref. }}$ \\
\hline $\mathrm{PESM}^{* * *}$ & Ombrófila & 761,0 & 2,87 & 1,64 & 10,81 & 2,01 & 7,05 & 1 \\
\hline MDSP** & Semidecídua & 350,0 & & 9,90 & 6,94 & 0,37 & 24,87 & 2 \\
\hline CES** & Semidecídua & 21,0 & & 17,64 & 6,30 & 11,31 & 6,33 & 2 \\
\hline FM & Semidecídua & 21,0 & & 8,31 & 3,60 & 20,20 & & 2 \\
\hline $\mathrm{FT}^{* *}$ & Semidecídua & 20,0 & & 8,57 & & 3,91 & 14,50 & 2 \\
\hline FRC** & Semidecídua & 17,0 & & 10,18 & & 2,71 & 5,60 & 2 \\
\hline LFR* & Tabuleiro & 218,0 & 37,50 & 25,79 & & 23,00 & & 3 \\
\hline SBR* & Tabuleiro & 242,5 & 32,00 & 15,75 & & 24,60 & & 3 \\
\hline CVBR* & Tabuleiro & 24,0 & 18,50 & 11,32 & & 41,20 & & 3 \\
\hline CGBR* & Tabuleiro & 15,0 & 2,50 & 6,29 & & 31,30 & & 3 \\
\hline M7 & Tabuleiro & 2,6 & & 22,64 & & 9,40 & & 3 \\
\hline Putiri* & Tabuleiro & 2,1 & 3,50 & 10,69 & & 12,20 & & 3 \\
\hline $\mathrm{RBAR}^{*}, 1$ & Tabuleiro & 40,0 & 7,10 & 10,20 & & & & 4 \\
\hline MSL* & Tabuleiro & 5,0 & 3,6 & 4,00 & & & & 4 \\
\hline M. Sta. Lúcia* & Tabuleiro & 4,4 & 5,68 & 4,5 & & & & 4 \\
\hline $\mathrm{EBC}$ & Semidecídua & 8,8 & 40,00 & & & & & 5 \\
\hline SB & Semidecídua & 132,0 & 10,06 & & & & & 5 \\
\hline MSJ & Semidecídua & 2,3 & 3,5 & 24,50 & & 41,27 & & 6 \\
\hline FBR/AS & Semidecídua & 2,4 & & 22,0 & & & & 7 \\
\hline FBR/S & Semidecídua & 5,0 & 6,38 & 15,34 & & & & 7 \\
\hline $\mathrm{FBR} / \mathrm{V}$ & Semidecídua & 14,5 & 6,80 & 47,92 & & & & 7 \\
\hline FBR/M & Semidecídua & 3,7 & & 43,98 & & & & 7 \\
\hline PEI $* *, 2$ & Ombrófila & 490,0 & & & & & 1,79 & 8 \\
\hline PEI $* *, 2$ & Ombrófila & 383,0 & & & & & 3,53 & 9 \\
\hline $\mathrm{SPP} * *, 2$ & Ombrófila & $1.000,0$ & & & & & 3,52 & 9 \\
\hline PEIC & Ombrófila & 151,0 & & & & 1,60 & 3,20 & 10 \\
\hline
\end{tabular}

* Para estas as áreas a comparação foi realizada com C. geoffroyi ou ${ }^{1}$ C. flaviceps .

** Para estas áreas a comparação foi realizada com $P$. superciliares ou ${ }^{2} P$. obscura.

*** Os valores são médias das densidades, ponderadas pelas áreas, de cada um dos núcleos amostrados.

${ }^{1} 1$ = presente estudo; 2 = Cullen Jr., 1997; 3 = Chiarello, 1997; 4 = Chiarello, 2000b; 5 = Chiarello \& de Melo, 2001; 6 = São Bernardo \& Galetti, 2004; 7 = Martins, dados não publicados; 8 = Guix et al., 1997;

9 = Sanchés-Alonso et al., 2002; e 10 = São Bernardo, 2004 
Apesar de divergências quanto aos limites da Mata Atlântica (Atlantic forest) e as diferentes classificações adotadas por diversos autores, pode-se considerar que este bioma é composto basicamente por dois tipos de floresta, a floresta ombrófila (Atlantic rain forest) e a floresta semi-decídua (Semi-deciduous forest) (Morellato \& Haddad, 2000). Contudo, ainda mesmo dentro destes grupos pode-se encontrar diferenças principalmente quando avaliadas ao longo do gradiente latitudinal ou longitudinal em que ocorrem. Para as áreas de floresta ombrófila é possível verificar diferenças entre as formações dispostas mais ao norte e ao sul na zona costeira, sendo que o fator temperatura média é provavelmente o determinante na diferenciação ao longo deste eixo. Ao norte deste gradiente, a diminuição das altitudes médias e o distanciamento das cadeias montanhosas da costa permitem o aparecimento de florestas de terras baixas com características bem diferenciadas, geralmente conhecidas como tabuleiros (Northern atlantic low altitude rain forest), que se estendem do norte do Estado do Rio de Janeiro ao nordeste brasileiro (Oliveira-filho \& Fontes, 2000).

Seguindo esta classificação foi determinado o tipo de Mata Atlântica predominante para cada uma das áreas dos estudos compilados para as comparações propostas, sendo considerados três os tipos de florestas; semidecídua, ombrófila e, para aquelas mais ao norte, tabuleiro (Anexo K). Comparações foram realizadas para cada uma das espécies buscando verificar possíveis influências destes tipos de floresta nos valores de densidade observados.

Buscando ainda identificar possíveis influências de fatores não bióticos sobre as densidades observadas, foi avaliada a possível existência de relação entre a densidade (indivíduos $/ \mathrm{km}^{2}$ ) e o tamanho das áreas de estudo.

\subsubsection{Comparação com Outras Áreas de Mata Atlântica}

As densidades obtidas para cada uma das espécies foram verificadas quanto a normalidade e homocedasticidade, sendo que somente as densidades de $S$. aestuans não cumpriram com estas premissas e por isso foram transformadas $\left(\log _{10}\right)$ para permitirem 
a utilização de testes paramétricos nas análises propostas. Foi utilizado o Teste-t (" $t$ student”), uma vez que somente comparações entre dois tipos florestais foram possíveis, devido principalmente à escassez de dados disponíveis para áreas de floresta ombrófila.

Somente o presente trabalho avaliou a densidade de $C$. aurita em área de floresta ombrófila através de transecções lineares e por isso não foi possível realizar nenhuma comparação estatística para este tipo florestal. Não foi possível verificar diferença significativa entre as médias obtidas nas áreas de tabuleiro $\left(13,79 \mathrm{ind} / \mathrm{km}^{2}\right)$ e nas de floresta semidecídua $\left(13,34 \mathrm{ind} / \mathrm{km}^{2}\right)(\mathrm{t}=2,20, \mathrm{p}>0,05)$. Contudo, é interessante notar que a densidade $C$. aurita no PESM foi uma das menores densidades observadas, sendo somente maior que a de um pequeno fragmento $\left(15 \mathrm{~km}^{2}\right)$ nas áreas de tabuleiro.

Para C. nigritus a única avaliação de densidade disponível para uma área de floresta ombrófila também foi a obtida no presente trabalho e, assim como observado para $C$. aurita, esta espécie também não apresentou diferença significativa entre as densidades nas florestas semidecídua e tabuleiro, 20,83 ind $/ \mathrm{km}^{2}$ e 12,35 ind $/ \mathrm{km}^{2}$ respectivamente $(\mathrm{t}=2,10, \mathrm{p}>0,05)$. Mais uma vez, o valor observado da densidade para o PESM foi baixo, sendo que para esta espécie, foi o menor observado entre as demais áreas de Mata Atlântica com dados disponíveis para esta espécie.

T. pecari teve sua densidade avaliada somente em quatro áreas ao todo, três delas de floresta semidecídua e somente uma de floresta ombrófila, o PESM. Devido a este baixo número amostral nenhuma análise estatística pode ser realizada. Contudo, é interessante observar que o valor de densidade obtido no PESM, ao contrário dos observados para os primatas acima descritos, foi o maior já observado para uma área de Mata Atlântica, inclusive superior ao observado por Cullen Jr. (1997) em uma grande área $\left(350 \mathrm{~km}^{2}\right)$ no interior de São Paulo, o Parque Estadual do Morro do Diabo (MDSP).

S. aestuans teve sua densidade avaliada somente duas vezes em áreas de floresta ombrófila, uma pelo presente trabalho e outra num recente estudo na área da Ilha do Cardoso, por São Bernardo (2004), onde foi observado um valor próximo ao obtido no PESM. Comparando-se estes poucos resultados de áreas de floresta ombrófila $\left(\log _{10}=\right.$ $\left.0,25=1,78 \mathrm{ind} / \mathrm{km}^{2}\right)$ com as médias das áreas de tabuleiro $\left(\log _{10}=1,32=21,10\right.$ 
ind $\left./ \mathrm{km}^{2}\right)$ foi possível perceber diferença significativa $(\mathrm{t}=2,20, \mathrm{p}<0,05)$, enquanto que a comparação destas com as áreas de semidecídua $\left(\log _{10}=0,76=5,76 \mathrm{ind} / \mathrm{km}^{2}\right)$ não apresentaram nenhuma diferença $(t=2,20, p>0,05)$.

A espécie mais estudada dentre as aves é com certeza as do gênero Penelope, apesar disso, nenhum trabalho foi encontrado sobre estimativas de densidade para estas espécies em área de tabuleiro. Portanto, para Penelope sp. as comparações foram realizadas entre os demais tipos de floresta, que apresentaram médias de densidade significativamente diferentes $(\mathrm{t}=2,36, \mathrm{p}<0,05)$, sendo menores nas áreas de floresta ombrófila $\left(3,90 \mathrm{ind} / \mathrm{km}^{2}\right)$ quando comparadas as obtidas na semidecídua $(20,83$ ind $/ \mathrm{km}^{2}$ ). Vale lembrar que, segundo Guix (1997), para as áreas de semidecídua geralmente a espécie presente é $P$. superciliares, enquanto que nas áreas de floresta ombrófila podem ser encontradas ambas as espécies, sendo que para as áreas altas, topos de morros da Serra do Mar, é prevista a ocorrência exclusiva de P. obscura.

\subsubsection{Influência do Tamanho da Área na Densidade das Espécies}

Foram aplicadas regressões lineares simples aos valores transformados $\left(\log _{10}\right)$ seguindo Sokal e Rohlf (1995). Transformação recomendada com o objetivo de melhorar o ajuste dos dados a modelos lineares. Nenhuma das espécies apresentou resultados significativos $(\mathrm{p}<0,05)$ para as regressões realizadas, porém, $S$. aestuans apresentou uma tendência de diminuição de suas densidade com o aumento da área $\left(\mathrm{r}^{2}=\right.$ $\left.0,22, \mathrm{t}_{\text {ratio }}=-1,85, \mathrm{p}=0,08\right)$, padrão este, inverso ao apresentado por $T$. Pecari, que tende a aumentar suas densidades $\left(\mathrm{r}^{2}=0,70, \mathrm{t}_{\text {ratio }}=2,20, \mathrm{p}=0,11\right)$.

\subsection{Viabilidade de Populações}

A partir das populações estimadas para as espécies foi avaliado o número de populações viáveis considerando-se MVPs de 500, 1.000, 2.000, 5.000 e 7.000 indivíduos. Foram criados três cenários como base para estas avaliações onde num 
primeiro momento as populações de cada um dos núcleos foram avaliadas separadamente, depois estas populações foram somadas e avaliadas como parte de um bloco maior chamado de setor norte e, por último, foram também avaliadas as populações de todo o PESM (Tabela 18).

Para a estimativa das populações da maioria das espécies para todo a área do PESM foi considerada a área total do parque coberta por FOD e VS, calculadas com o uso do programa ArcView 8.2 e mapas digitalizados da vegetação das áreas (SIGMA).

Portanto, para a maioria das espécies, foi considerada a soma de FOD $=2.168,03$ $\mathrm{km}^{2}$ e VS $=648,35 \mathrm{~km}^{2}$ como sendo a área total para cálculo das populações remanescentes. Já para o cálculo das populações de $C$. aurita foram consideradas somente as áreas totais dos tipos florestais dispostas acima dos $150 \mathrm{~m}$ de altitude, uma vez que este primata não ocorre naturalmente abaixo deste limite (Vivo, 1991; Auricchio, 1995; Cerqueira et al., 1998), ou seja, FOD C.aurita $=2.093,70 \mathrm{~km}^{2}$ e VS C.aurita $=597,17 \mathrm{~km}^{2}$.

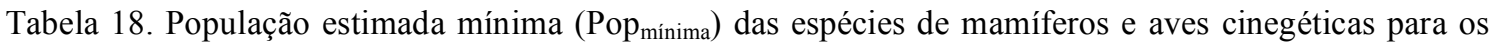
diferentes cenários a serem avaliados. Área total $\left(\mathrm{km}^{2}\right)$ considerada em cada um dos cenários. Número total de populações viáveis (Pop.V), sendo a MVP considerada na primeira análise como de 500 indivíduos e de 1.000, 2.000, 5.000 e 7.000 indivíduos nas seguintes

\begin{tabular}{|c|c|c|c|c|c|}
\hline $\begin{array}{l}\text { Cenários avaliados } \\
\text { Área total }\left(\mathbf{k m}^{2}\right)^{*}\end{array}$ & $\begin{array}{c}\mathrm{NC} / \mathrm{I} \\
101,57\end{array}$ & $\begin{array}{c}\text { NP } \\
461,37\end{array}$ & $\begin{array}{c}\text { NSV } \\
137,07\end{array}$ & $\begin{array}{c}\text { Setor Norte } \\
\mathbf{7 0 0 , 0 1} \\
\end{array}$ & $\begin{array}{c}\text { PESM } \\
2.816,38\end{array}$ \\
\hline C. aurita** & 360 & 0 & 554 & 914 & 6.870 \\
\hline C. nigritus & 349 & 0 & 175 & 524 & 4.541 \\
\hline T. pecari & 1.369 & 535 & 1.545 & 3.449 & 25.453 \\
\hline S. aestuans & 23 & 303 & 486 & 812 & 4.203 \\
\hline Penelope spp. & 351 & 1.720 & 744 & 2.815 & 11.982 \\
\hline O. capueira & 265 & 1.326 & 753 & 2.344 & 10.344 \\
\hline T. solitarius & 94 & 288 & 129 & 511 & 2.432 \\
\hline Pop. $V_{(M V P}=500$ indiv.) & 1 & 3 & 4 & 7 & 7 \\
\hline Pop. V (MVP $=1.000$ indiv.) & 1 & 2 & 1 & 3 & 7 \\
\hline Pop. V. (MVP $=2.000$ indiv. $)$ & 0 & 0 & 0 & 3 & 7 \\
\hline Pop. V (MVP $=5.000$ indiv. $)$ & 0 & 0 & 0 & 0 & 4 \\
\hline 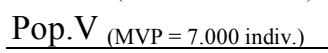 & 0 & 0 & 0 & 0 & 3 \\
\hline
\end{tabular}

* Foram consideradas somente as áreas de FOD e VS para cálculo das áreas totais das unidades avaliadas. ** Para esta espécie foram consideradas somente as áreas de FOD e VS acima dos 150 m de altitude. 
Mesmo considerando-se o valor hipotético de MVP de 500 indivíduos, assim como realizado por outros autores na Mata Atlântica (Chiarello e De Melo, 2001; Cullen Jr., 1997) pode-se observar que a muitas das espécies não apresentariam populações mínimas viáveis para as áreas dos núcleos quando avaliados separadamente, principalmente na área do NC/I, a menor das unidades avaliadas. Contudo, considerando-se essas áreas como um bloco contínuo de Mata Atlântica, cenário Setor Norte, o número de populações viáveis aumentaria sendo que a área como um todo seria capaz de garantir a manutenção de todas as sete espécies avaliadas.

Contudo, se a tendência observada nos recentes estudos de MVP (Brito \& Figueiredo, 2003; Brito \& Grelle, 2003; Horino \& Miura, 2000; Maehr et al., 2002; Reed et al., 2003; Sommer et al., 2002; Tiepolo et al., 2004) onde geralmente números muito superiores a 500 indivíduos foram constatados como sendo necessários para garantir a viabilidade das populações, podemos prever uma situação mais alarmante para as espécies avaliadas.

Com o aumento da MVP considerada para apenas 1.000 indivíduos, a situação das espécies nos núcleos quando avaliados separadamente seria pior ao observado anteriormente, com um número ainda maior de espécies que não possuiriam populações viáveis nos seus interiores. Mesmo o bloco maior formado por estas três áreas, o chamado Setor Norte, que na avaliação anterior garantiria a sobrevivência de todas as espécies, seria capaz de manter nestas condições um total de apenas três espécies. Para esta MVP considerada, seria necessária a área do PESM como um todo para garantir a sobrevivência de todas as espécies avaliadas. Enquanto que na avaliação considerandose a MVP de 5.000 ou 7.000 indivíduos, nem mesmo a área total do PESM seria capaz de manter todas as populações, garantindo somente a sobrevivência de quatro espécies (Figura 19). 


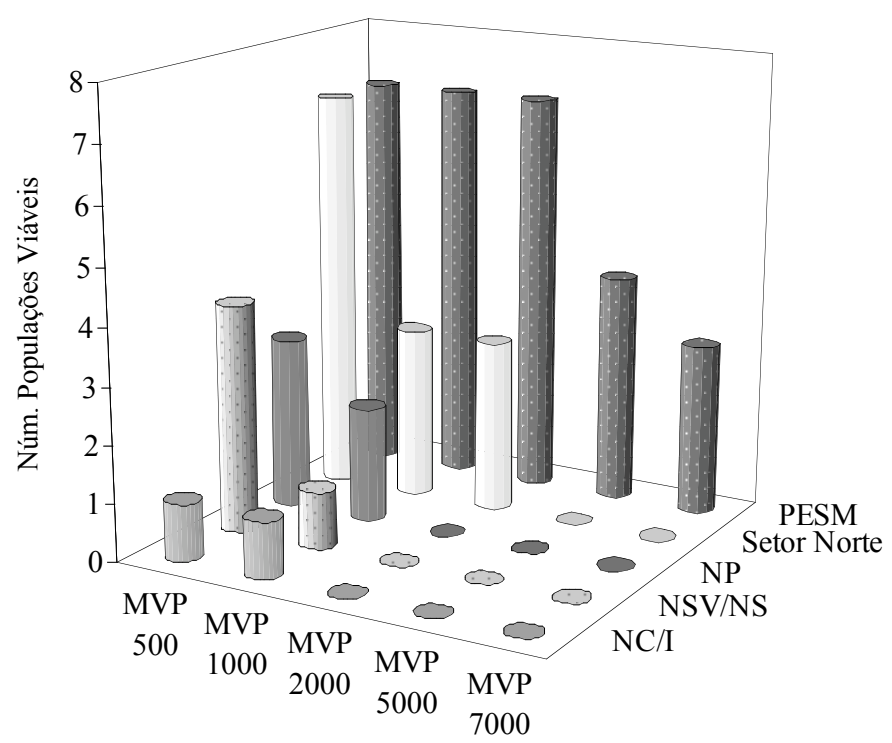

Figura 19 - Número de populações viáveis para cada um dos cenários propostos, com MVP mínimas de $500,1.000,2.000,5.000$ e 7.000 indivíduos

\subsection{Ocorrência das Espécies}

Para cálculo das taxas de abundância ou densidades foram considerados somente aqueles eventos onde foi possível o contato visual com os indivíduos das espécies avaliadas, ou seja, eventuais vocalizações, encontro de carcaças ou até mesmo encontro de sinais indiretos como rastros, fezes e pênas, não foram computados. Contudo, o encontro destes sinais e eventualmente a visualização de animais fora dos períodos de censo, foram utilizados para a elaboração de uma Lista de Ocorrência de Espécies (Anexo M).

Para a elaboração desta lista também foi realizado um trabalho de revisão bibliográfica além de um levantamento junto a pesquisadores e instituições que desenvolvem ou já desenvolveram atividade nas áreas dos três núcleos amostrados. $\mathrm{O}$ intuito deste esforço é o de elaborar uma lista atualizada de ocorrência de fauna, principalmente mastofauna, para a região e a partir de análises simples destes resultados ressaltar a importância delas no contexto de conservação do bioma Mata Atlântica e a necessidade de um maior número de trabalhos básicos de levantamento ou específicos visando esclarecer dúvidas quanto a ocorrência de algumas espécies nas áreas. 
Para a verificação quanto a categoria de ameaça foi utilizada a Lista de Fauna Silvestre Ameaçada do Estado de São Paulo (Decreto N. 42.838 - de 04 de fevereiro de 1998 - SMA/CED, 1998). Serão consideradas as espécies com ocorrência confirmada para as áreas e também aquelas com ocorrência provável. As espécies com classificação como provável foram assim consideradas quando foram registradas em duas das três áreas avaliadas e que não puderam ser confirmadas para a terceira área, devido principalmente a problemas de amostragem. Devido a conectividade existente entre os núcleos e o fato de que todos eles são áreas de floresta atlântica consideramos como provável a ocorrência destas espécies na área não devidamente avaliada.

Informações obtidas em entrevistas são uma fonte essencial de informações, principalmente para aqueles mamíferos facilmente identificáveis por características externas, tais como edentatos, carnívoros, primatas e ungulados (Voss \& Emmons, 1996) e que apesar de não possuírem nenhum caráter quantitativo e de não terem sido consideradas no presente estudo aquelas espécies somente registradas por esta metodologia, permitiram uma discussão mais ampla dos resultados obtidos, indicando a possível ocorrência de algumas espécies nas áreas de estudo, que serão melhores discutidas ao longo do texto.

Assim sendo, foram registrados um total de 70 espécies, com ocorrência confirmada ou na categoria provável, para a área do NSV/NS, 60 para o NP e 43 para o NC/I. Para as áreas do NSV/NS e NC/I foram registradas sete espécies de aves, duas delas presentes da lista de fauna ameaçada do estado, são elas: Pipile jacutinga (jacutinga) e Tinamous solitarius (macuco).

A área do NP também apresentou um total de sete espécies de aves, contudo, difere-se das demais áreas por apresentar P. jacutinga como provavelmente extinta na região. Isto se deve ao fato de que esta espécie não foi avistada em nenhum momento durante os trabalhos de campo e também por nenhum pesquisador ou funcionário nestes últimos cinco anos na área do núcleo. Esta é uma espécie facilmente distinguível dos jacus (Penelope spp.) por apresentarem uma típica mancha branca na asa e que pode ser facilmente visualizada mesmo com a ave em vôo (Sick, 1993). Portanto, a ausência de 
registros desta espécie na área pode ser considerada como uma provável extinção local destes indivíduos, porém uma investigação mais detalhada sobre esta espécie seria necessária para a confirmação deste quadro.

Ainda na área do NP é provável a ocorrência de $P$. superciliares, contudo a confirmação desta espécie não foi possível devido à dificuldade de diferenciação dos indivíduos em campo, uma vez que na área também ocorre P. obscura. Segundo Guix (1997) a área do NP seria um local previsto para a ocorrência de ambas as espécies, assim como no planalto voltado para o interior do estado, no outro lado das escarpas da Serra do Mar. Segundo este autor, nas partes altas dessa serra é prevista a ocorrência somente de P. obscura. Sabe-se que a área do NSV/NS é um dos locais utilizados pelo Programa de Re-introdução de Cracídeos na natureza, desenvolvido pela Companhia Energética do Estado de São Paulo (CESP), e que promove a soltura de indivíduos reproduzidos em cativeiro em algumas áreas de Mata Atlântica (Villani, J. P. ${ }^{2}$ ), sendo inclusive o único registro obtido de $P$. jacutinga, um casal sobrevoando a Rodovia Oswaldo Cruz (SP 125), suspeita de ser de indivíduos re-introduzidos.

Porém, na área do NSV/NS também foram avistados indivíduos com características de $P$. superciliares geralmente em meio à vegetação secundária, tipo de vegetação geralmente utilizada por esta espécie, enquanto que $P$. obscura prefere áreas de vegetação de floresta mais bem estruturadas (Sick, 1993; Willis \& Oniki, 2003). Sabe-se que o programa da CESP possui indivíduos de ambas as espécies deste gênero, apesar de muito mais freqüentes os indivíduos de $P$. obscura, devido a maior facilidade de reprodução em cativeiro desta espécie (Azeredo, R.M.A ${ }^{3}$ ). Portanto, é possível que indivíduos de $P$. superciliares realmente estejam ocorrendo na área do NSV/NS, devido a elevada proporção de áreas de vegetação secundária existente nesta unidade, cerca de 29,7 \%, e que poderia estar favorecendo a ocorrência destes indivíduos na área ou ainda, devido a introdução dos mesmos por meio de solturas realizadas pelo programa da CESP

\footnotetext{
${ }^{2}$ Villani, J. P. (Instituto Florestal do Estado de São Paulo. Responsável pela administração da unidade). Comunicação pessoal, 2003.

${ }^{3}$ Azeredo, R. M.A. (ONG Crax - Wild Fauna Research Society, Belo Horizonte - MG). Comunicação pessoal, 2004.
} 
na área do NSV/NS. São necessários estudos mais detalhados sobre a possível ocorrência desta espécie na área do NSV/NS e também uma verificação junto ao programa desenvolvido pela CESP a fim de suspender as atividades até uma melhor avaliação das conseqüências deste processo ou da distribuição natural destas espécies na região, caso seja confirmada a suspeita de re-introdução eventual de indivíduos de $P$. superciliares.

Para a avaliação da mastofauna, podemos considerar o total de 63 espécies registradas para o NSV/NS, 53 para o NP e de apenas 36 para NC/I. Estas diferenças devem-se principalmente a diferenças de esforço amostral entre as áreas avaliadas. $\mathrm{Na}$ área do NSV/NS, por exemplo, foi possível confirmar a existência de um total de 11 espécies de morcegos (Ordem Chiroptera), enquanto que nenhum levantamento disponível foi obtido para as demais áreas. Sabe-se que existe uma pesquisa em desenvolvimento na área do NP sobre este grupo de mamíferos voadores, porém não foi possível obter nenhum dado quanto às espécies registradas.

Já o pequeno número de espécies observado na área do $\mathrm{NC}$ deve-se principalmente a inexistência de trabalhos sobre a comunidade de pequenos mamíferos. O grupo dos pequenos mamíferos não voadores é formado por marsupiais e roedores, pertencentes às ordens Didelphiomorphia e Rodentia, respectivamente, cuja massa corporal não ultrapassa os dois quilogramas (sensu Nowak, 1999). Para as áreas do NSV/NS este grupo de mamíferos contribuiu com um total de 24 espécies, sendo 10 marsupiais e 14 pequenos roedores. Na área do NP foram registradas 20 espécies de pequenos mamíferos, 7 de marsupiais e 13 pequenos roedores. Para a área do NC/I foram possíveis somente as confirmações de três espécies deste grupo, Didelphis aurita, Kannabateomys amblyonyx e Sciurus aestuans, enquanto que as demais foram registradas como sendo de ocorrência provável para a área deste núcleo.

Fonseca et al. (1996) listaram 23 espécies de marsupiais e 64 espécies de roedores ocorrendo no bioma Mata Atlântica. Este grupo compõe uma grande parte da biomassa de mamíferos das florestas tropicais e têm grande importância nas cadeias tróficas de todos os ambientes tropicais, como alimento de pequenos e médios 
predadores dentre répteis, aves e outros mamíferos (Emmons, 1990; Sick, 1997). Embora de pequeno porte, esses mamíferos podem atuar também como polinizadores de várias espécies de flores (Vieira, 1993), dispersores (Marinho-filho \& Reis, 1989) e predadores de sementes (Galetti et al., 1992), influenciando dessa forma na distribuição e dinâmica da vegetação.

Nos últimos vinte anos muitos estudos avaliaram essas comunidades de pequenos mamíferos em florestas do Domínio Atlântico, sendo que na maioria deles as amostragens foram realizadas somente no chão da floresta (Bergallo et al., 1998). Contudo, mais recentemente os estudos têm contemplado os outros estratos da floresta, como o sub-bosque, entre 1,5 e 2 metros, e dossel, acima de 8 metros de altura (Passamani et al., 2000; Vieira, 1993), que permitiram avaliar as relações entre diversidade de espécies e complexidade do habitat. Os resultados dos estudos "tridimensionais" na floresta Atlântica mostraram que, de forma semelhante ao observado na floresta Amazônica, as espécies exploram o ambiente de formas diferentes, sendo que a complexidade vertical oferece um maior número de potenciais nichos e sua utilização permite a coexistência de um maior número de espécies (August, 1983). Dada a complexidade e a organização espacial das comunidades de pequenos mamíferos nas florestas tropicais é fundamental que estudos que visem a conservação desses ecossistemas avaliem de forma conjunta a riqueza, diversidade, abundância e uso do espaço.

Estudos mais recentes sobre estes pequenos mamíferos, têm relatado a ocorrência de novas espécies ou ampliaram a distribuição de espécies em áreas de floresta, principalmente para os roedores, cuja riqueza de espécies e a dificuldade de identificação em campo são grandes, com o incremento dos estudos sistemáticos e genéticos que tem ocorrido nos últimos anos, espera-se um crescimento importante no número de espécies e até de gêneros (Vieira, 1999).

A pequena riqueza de espécies registradas deste grupo para as áreas em geral e sabendo-se que a amostragem na maioria delas foi realizada somente sobre o chão da floresta, indicam a necessidade do aumento no número de levantamentos sobre a fauna 
destes pequenos mamíferos nas áreas como um todo, com o incremento de levantamentos de espécies de sub-bosque e dossel, e principalmente para as áreas do $\mathrm{NC} / \mathrm{I}$ onde praticamente nenhuma informação está disponível.

Ao todo, 11 espécies representantes da Ordem Carnivora foram registradas nas três áreas avaliadas, sendo que a diferenciação de muitas delas só foi possível devido ao uso de câmeras automáticas (Camtrakker e TrailMaster), que permitiram também a diferenciação de alguns indivíduos nas áreas de estudo.

Nos últimos anos o uso de câmeras automáticas para o levantamento ou censo de animais crípticos ou noturnos tem sido amplamente utilizado, principalmente em regiões tropicais (Carbone et al., 2001; Cullen Jr., 1999; Cullen Jr. \& Valladares-Pádua, 1999; Griffiths \& Schaik, 1993; Jones \& Raphael, 1993; Karanth \& Nichols, 2000).

Geralmente os carnívoros possuem um território amplo e ocorrem de maneira dispersa no ambiente com densidades geralmente baixas, sendo que muitas vezes são estritamente noturnos ou se locomovem somente em áreas com cobertura vegetal densa, o que torna os métodos de observação direta impróprios. Por isso, métodos indiretos como o uso de câmeras automáticas e o reconhecimento de rastros devem ser utilizados para o estudo desses animais.

Guardas-parque relatam a visualização, em pelo menos duas ocasiões, de indivíduos de Panthera onca (onça-pintada) nas áreas do NSV/NS. Segundo Villani, J. $\mathrm{P} .{ }^{2}$ outras visualizações desta espécie já foram descritas no passado por funcionários, palmiteiros ou caçadores, e também por motoristas que utilizavam-se da Rodovia Oswaldo Cruz, que corta a área do núcleo. Segundo ele, carcaças e peles deste felino já foram encontrados em "ranchos" de caçadores na região, durante ações de fiscalização em conjunto com a Polícia Ambiental, o que reforçaria a provável ocorrência desta espécie na região a menos de 10 anos. Contudo, durante o ano de 1997 Wang (1999) também não obteve nenhum registro desta espécie, embora tenha encontrado um total de 88 fezes e regurgitados de todas as outras espécies de felino com ocorrência na área.

\footnotetext{
${ }^{2}$ Villani, J. P. (Instituto Florestal do Estado de São Paulo. Responsável pela administração da unidade). Comunicação pessoal, 2003.
} 
Para área do NC/I as entrevistas com ex-caçadores e funcionários do parque indicaram a possível ocorrência de Speothos venaticus (cachorro-vinagre) nas áreas mais remotas deste núcleo. A descrição dos indivíduos avistados por algumas destas pessoas coincide com a descrição desta espécie e, devido às características peculiares deste carnívoro que facilitam a sua diferenciação dos demais canídeos, coloração avermelhada, presença de cauda curta e viverem em bandos (Emmons, 1990; Eisenberg \& Redford, 1999), devem ser consideradas como indícios importantes de uma possível ocorrência desta espécie na região.

Contudo, apesar de um esforço de mais de $3.600 \mathrm{~h}$ de uso de câmeras automáticas e da procura de rastros ao longo dos últimos quatro anos na região, nenhum registro confiável foi obtido para nenhuma destas espécies. Para a $P$. onca, a ausência de registros confiáveis nos últimos anos pode indicar que esta espécie esteja localmente extinta, ou pelo menos com um número drasticamente reduzido de indivíduos.

Situação semelhante é a observada para $C$. aurita que apesar de ter a sua ocorrência confirmada para o NP, através de material depositado em museu (Pinheiro \& Geise, 2003), não foi observada ao longo destes últimos três anos de estudos nas áreas deste núcleo, inclusive não tendo sido avistada também por nenhum dos pesquisadores que atuaram na região nos últimos anos.

Ambas as espécies de carnívoros são pouco conhecidos e considerados raros, e todas elas são consideradas espécies ameaçadas de extinção no Estado de São Paulo, portanto esforços específicos são necessários para a confirmação da ocorrência de indivíduos de $S$. venaticus e também uma melhor avaliação do status das populações de P. onca e C. aurita nestas áreas do PESM.

Dentre os primatas, quatro espécies foram registradas nas áreas de estudo. Além da ocorrência do C. aurita, já discutida anteriormente, é importante citar a ocorrência de Brachyteles arachnoides (mono-carvoeiro), uma espécie ameaçada de extinção e que possui atualmente um número estimado de 1.200 indivíduos distribuídos em apenas 19 populações (Strier, 2002). Este importante primata foi confirmado nas áreas do NC/I e NP pela visualização de indivíduos desta espécie, contudo é provável que os indivíduos 
avistados em duas ocasiões na área do NC/I, alimentando-se de frutos de Byrsonima lancifolia, durante os censos, e uma outra vez na área do NP, acima dos $400 \mathrm{~m}$ de altitude, façam parte de um mesmo bando. Os locais onde estes indivíduos foram avistados são relativamente próximos e, devido ao tamanho de área de vida, que pode chegar a 168 ha (Strier, 1993), poderiam estar sendo utilizados por um único bando.

Para Alouatta guariba (bugio) os registros foram geralmente realizados por reconhecimento de sua vocalização típica (Auricchio, 1995), que pode ser ouvida até mesmo nas baixadas do NP, exceto para a área NSV/NS onde os indivíduos desta espécie foram avistados na região próxima a Trilha do Itamambuca. Em uma das ocasiões um bando foi seguido e um dos indivíduos, aparentemente o macho dominante, foi avistado descendo das árvores e em seguida locomovendo-se no chão da floresta, sendo que ao perceber o observador retornou rapidamente a copa das árvores. As áreas onde este primata foi avistado eram geralmente altitudes elevadas, entre $950 \mathrm{~m}$ e 1050 $\mathrm{m}$, sendo que mesmo na área do NP onde a vocalização desta espécie pode ser freqüentemente escutada, até mesmo da base administrativa da unidade, situada próximo à Rodovia Rio-Santos (BR 101), estimasse que os indivíduos ocorram acima do limite de $750 \mathrm{~m}$ de altitude.

Dentre os ungulados em geral foram registradas as mesmas quatro espécies em todas as áreas de estudo, sendo importante ressaltar que três delas são consideradas como ameaçadas no Estado de São Paulo, Pecarie tajacu (cateto), Tayassu pecarie (queixada) (Ordem Artiodactyla) e Tapirus terrestris (anta) (Ordem Perissodactyla), esta última considerada o maior mamífero das Américas, podendo atingir cerca de $260 \mathrm{~kg}$ de peso (Emmons, 1990; Eisenberg \& Redford, 1999). É importante ainda dizer que todas estas espécies, apesar de serem registradas para a área do NP, ocorreram geralmente acima dos $400 \mathrm{~m}$ de altitude, áreas essas de maior dificuldade de acesso e onde a vegetação apresentava-se com as suas melhores características.

Dentre os mamíferos em geral as áreas do PESM apresentaram números elevados de espécies consideradas ameaçadas de extinção no Estado de São Paulo, 18 ao todo para o NSV/NS, 17 para o NP e 16 para as áreas do NC/I. 


\section{DISCUSSÕES}

\subsection{Distâncias de Detecção}

Dentre outras características que devem afetar a distância de detecção dessas espécies em campo, as diferenças quanto à própria densidade, às estratégias de fuga e aos padrões de movimentação e vigilância são aquelas que se diferem entre si e também entre diferentes habitats (Bodmer, 1990; Bodmer et al., 1988; McCoy et al., 1990; Dubost \& Sabatier, 1994; Paschoal \& Galetti, 1995).

Para o presente estudo as visualizações das espécies amostradas não apresentaram diferenças significativas entre suas distâncias perpendiculares médias, nem mesmo quando agrupados por tipo florestal, grupos ecológicos, núcleos e tipos de transecções utilizadas. Isto permitiu a comparação direta destes valores entre os diferentes tratamentos propostos, bem como o uso desses valores de abundância para avaliação direta de possíveis influências de fatores bióticos ou abióticos sobre estas populações nas áreas estudadas.

Apesar da diferença não ter sido significativa, os primatas apresentaram distância perpendicular média mais elevada que dos demais grupos e isso provavelmente se deve ao fato que estes animais são arborícolas, forragearem em bandos e geralmente são muito barulhentos quando ativos (Auricchio, 1995; Fonseca et al., 1996), o que facilita a visualização destas espécies na mata mesmo a uma maior distância, principalmente aqueles com maior peso corporal, tais como B. arachnoides (mono-carvoiero) e $A$. guariba (bugio). Já o uru, O. capueira, que apresentou a menor das distâncias médias, apesar de andar em bando, é uma ave de pequeno porte que se locomove exclusivamente no chão da mata, geralmente vocalizando durante o dia somente quando se sente 
ameaçada ou em perigo (Sick, 1993; Willis \& Oniki, 2003; Develey \& Endrigo, 2004), e por isso, foi geralmente avistado a curtas distâncias da trilha.

É interessante observar que a estrutura da vegetação também pode influenciar na distância de detecção das espécies. Podemos supor isto uma vez que as áreas de floresta ombrófila apresentaram, apesar de não serem significativamente diferentes, as maiores médias de distâncias perpendiculares quando comparadas às áreas de vegetação secundária.

Num estudo realizado por Tabarelli \& Mantovani (1999) sobre o processo de sucessão ecológica da floresta atlântica na área do NSV/NS foi verificado que, assim como em todas as florestas tropicais conhecidas, os estádios mais avançados apresentam uma diminuição da densidade dos indivíduos em geral, com aumento de biomassa e volume de madeira, ou seja, ocorre uma predominância de árvores com maior diâmetro, mais distantes entre si e com maior altura média, principalmente no sub-bosque. Tais características do sub-bosque podem estar favorecendo a uma melhora nas condições de observação nestes ambientes, aumentando assim a distância perpendicular média obtida nas áreas de floresta ombrófila densa quando comparadas as de vegetação secundária.

A criação abrupta de ambientes abertos em áreas de floresta pode gerar alterações nas condições micro-climáticas, promovendo assim o estabelecimento de espécies não florestais, principalmente com o aumento de espécies resistentes à insolação, tais como bambus, lianas e cipós (Tabarelli et al., 1999). Este processo, chamado de efeito de borda, é comumente observado nas laterais de estradas, geralmente alterando a composição e a estrutura da vegetação em suas margens, o que poderia influenciar as condições de observação, levando a uma diminuição da distância perpendicular média de visualização nestes locais. Porém, para as áreas de estudo não foram observadas diferenças significativas nas distâncias perpendiculares médias obtidas nos três tipos de transecção avaliados, tendo inclusive as estradas apresentado valores médios um pouco maiores que o observado para os demais tipos de transecções utilizadas. 
Este resultado pode estar refletindo o fato de que a maioria das estradas utilizada nestas áreas não sofre o típico efeito de borda esperado (Observação pessoal, 2003; Assis, M. ${ }^{4}$ ). Provavelmente isto se deve ao fato de que o banco de sementes de espécies não-florestais encontra-se muito distante destas áreas e por isso, a estrutura e composição da vegetação se mantêm praticamente inalteradas em suas margens quando comparadas com o ambiente no interior dessas matas.

Desta maneira, a exposição destes ambientes presentes nas margens da estrada a uma maior luminosidade, devido a menor ou ausência de cobertura de dossel sobre esta, pode estar favorecendo as condições de observação do pesquisador e, conseqüentemente, aumentando as distâncias perpendiculares médias obtidas nestes locais.

De maneira geral as áreas avaliadas no presente estudo apresentaram valores muito baixos de distâncias perpendiculares médias (DPM), menores que o observado para diversas localidades, mesmo quando comparadas somente com outras áreas de Mata Atlântica (Anexo L). Este fato indica que para as áreas do presente estudo a estrutura da vegetação pode estar sendo um fator limitante no número de visualizações obtidas, já que é necessário um esforço muito maior ( $\mathrm{km}$ percorrida) para se obter uma mesma área amostrada quando comparado com outras áreas de estudo (Área amostrada $=2 * \mathrm{ESW}^{*} \mathrm{~km}$ percorridos, sendo que o cálculo da ESW depende das distâncias perpendiculares obtidas nas visualizações).

\subsection{Padrões de Atividade}

A grande maioria dos trabalhos já desenvolvidos nos neotrópicos realizou as atividades de censos durante o período da manhã já que, conforme os autores, este é geralmente o período de maior atividade das espécies, o que otimizaria a coleta de dados nestas regiões (Peres, 1990; Peres, 1996; Peres, 1997; Chiarello, 1999; Chiarello, 2000b;

\footnotetext{
${ }^{4}$ Assis, M. (UNESP. Instituto de Biociências. Depto. de Botânica. Rio Claro, SP. Realizou diversas coletas na área do NSV/NS, inclusive nas margens da Trilha do Ipiranga, antiga estrada que liga a área deste núcleo com NC/I). Comunicação pessoal, 2003.
} 
Peres, 2000; Peres \& Dolman, 2000; Chiarello \& de Melo, 2001; Peres, 2001). Alguns autores realizaram amostragens durante todo o período da manhã e retomaram os trabalhos somente nos períodos próximos ao final da tarde, evitando desta maneira realizar censos durante as horas próximas ao meio do dia (Guix et al., 1997; Cullen Jr. et al., 1999; Martin, 2000; González-Solís et al., 2001; Marsden et al., 2001; SanchésAlonso et al., 2002; Hernández et al., 2002; Timock \& Vaughan, 2002). Poucos são os trabalhos como os realizados por Pontes (1999) numa área da Amazônia, onde censos foram realizados desde as primeiras horas do dia até o entardecer, e muitos são aqueles em que os horários dos levantamentos não estão descritos de forma clara na metodologia.

Os resultados obtidos ressaltam a importância da realização de censos ao longo de todo o dia em algumas situações, pelo menos durante o projeto piloto, para permitir a identificação de padrões de atividade locais das espécies alvo, principalmente como os observados para as áreas mais elevadas do presente estudo, NSV/NS e NC/I.

Quanto ao uso dos diferentes estratos da mata pelas espécies de aves e mamíferos cinegéticos amostrados não foi observado nenhum padrão além dos já esperados. $T$. pecari e $O$. capueira, que são espécies que andam em bandos e consideradas de hábitos estritamente terrestres (Sick, 1993; Willis \& Oniki, 2003; Eisenberg \& Redford, 1992; Fonseca et al., 1996; Develey \& Endrigo, 2004), foram avistados somente no chão da mata. Enquanto que $C$. aurita e $C$. nigritus, espécies de primatas tipicamente arborícolas (Eisenberg \& Redford, 1992; Fonseca et al., 1996), mas que ocasionalmente podem ser vistos no solo, geralmente atravessando descampados entre manchas de mata (Becker \& Dalponte, 1991), foram registradas somente no estrato do dossel.

T. solitarius obteve a maioria de suas visualizações no chão da mata e um único registro no sub-bosque na área do NP, realizado no final da tarde. Esta é uma espécie que geralmente vive no chão da mata, mas que pode se empoleirar em galhos baixos das árvores, principalmente no final do dia quando se prepara para dormir (Sick, 1993; Willis \& Oniki, 2003; Develey \& Endrigo, 2004). 
Na maioria das vezes $S$. aestuans foi avistada no sub-bosque ou dossel das matas avaliadas, tendo sido avistada no chão da mata coletando um fruto maduro de Attalea dubia, conhecida localmente como palmeira-indaiá, o que não é nnehuma surpresa uma vez que os indivíduos desta espécie apesar de possuírem hábitos escansoriais, ou seja, adaptados a vida nas árvores (Eisenberg \& Redford, 1992; Fonseca et al., 1996), também podem ser vistos no solo forrageando, sendo que costumam visitar também taquarais nativos e agrupamentos de palmeiras (Galetti et al., 1992; Paschoal \& Galleti, 1995).

No presente trabalho os indivíduos de Penelope sp. foram geralmente viualizados no dossel das matas, tendo sido avistados 17 vezes no chão. Ambas as espécies de jacu, P. obscura e P. superciliares, habitam geralmente das copas das árvores até o chão da mata (Sick, 1997; Willis \& Oniki, 2003), onde muitas vezes, segundo Willis (1979), são vistas espojando-se em banho de areia.

\subsection{Dinâmica Florestal}

\subsubsection{Estrutura da Vegetação}

Comparando-se os valores de estrutura (DABS e VOL) dos dois tipos florestais avaliados, pode-se observar valores médios superiores nas áreas de floresta ombrófila densa quando comparadas as de vegetação secundária. Estes resultados estão de acordo com Brown e Lugo (1990) e Vandermeer et al. (1997) que concluíram que independente do tipo de floresta, formações secundárias com idades ao redor de 80 anos podem apresentar riquezas e diversidades de espécies similares às observadas nas florestas maduras, contudo, são necessários entre 100 e 200 anos para que as mesmas atinjam os valores de biomassa e volume similares aos destas florestas.

Porém, um fator que pode alterar toda a dinâmica florestal é a intervenção humana, através de ações como corte e/ou queima. A regeneração, processo pelo qual a floresta perturbada atinge novamente as características de floresta madura, pode levar a 
modificações nas características da comunidade e na composição de espécies (Guariguata \& Dupuy, 1997).

Num estudo realizado na área do NSV/NS sobre a regeneração da floresta atlântica montana após corte ou queima, Tabarelli e Mantovani (1999) verificaram que durante os processos de regeneração de maneira geral ocorreu um aumento além da riqueza, da diversidade de espécies, do percentual de espécies zoocóricas, de espécies de sub-bosque e daquelas tolerantes à sombra, e também, o aumento nos atributos físicos da floresta (área basal e volume), com exceção da densidade de indivíduos. Estes autores encontraram valores de densidade de indivíduos para as áreas de floresta com 18 anos de regeneração superiores aos observados para as áreas com 40 anos, e ambos maiores que os observados para as áreas de floresta madura.

No presente estudo foram avaliadas áreas que sofreram perturbações de intensidade diferente, contudo, todas elas a um mesmo período de tempo, à aproximadamente 25-30 anos. Contudo, diferenças na composição e abundância podem ser observadas devido não somente ao tempo de regeneração, mas também ao tipo de uso antrópico pela qual elas passaram, o que pode acelerar ou retardar estes processos (Tabarelli \& Mantovani,1999).

Segundo o observado por estes autores, as áreas consideradas preservadas no presente estudo (= floresta madura) deveriam apresentar valores de densidade menores que as áreas em estágios avançados de regeneração (= floresta com 40 anos). O observado no presente estudo difere do esperado uma vez que as áreas de floresta preservada apresentaram as maiores médias tanto do volume como de densidade de indivíduos, diferentes significativamente, quando comparadas com as demais categorias.

Contudo, devemos lembrar que estes autores realizaram levantamentos de todos os indivíduos com $D A P$ superior a $3,2 \mathrm{~cm}$ enquanto que no presente estudo o critério de inclusão foi $D A P>10 \mathrm{~cm}$. Segundo Gentry e Dodson (1987) as árvores constituem entre 15 e $22 \%$ das espécies nas florestais neotropicais onde há floras conhecidas, enquanto que o restante são lianas, epífitas, ervas, arbustos e pequenas árvores que nunca atingem $10 \mathrm{~cm}$ de DAP. Por isso podemos considerar que a diminuição da densidade observada 
por estes autores entre floresta com 40 anos e floresta madura tenha ocorrido devido a uma diminuição de indivíduos de menor porte $(3 \mathrm{~cm} \leq D A P \geq 10 \mathrm{~cm})$, o que é de se esperar devido ao crescimento dos indivíduos estabelecidos.

Estes indivíduos (3 $\mathrm{cm} \leq D A P \geq 10 \mathrm{~cm}$ ) não foram amostrados no presente estudo, por isso o aumento da densidade média de indivíduos observado par as áreas preservadas estaria refletindo na verdade o aumento no número de indivíduos de maior porte (DAP $>10 \mathrm{~cm})$. Um forte indício desta substituição por indivíduos de maior porte para as áreas de floresta madura é o fato de apesar da diminuição na densidade arbóreoarbustiva, estes autores verificaram um aumento no volume de madeira para estas áreas.

Ao que parece, o uso histórico destas áreas afeta não somente a dinâmica florestal no que se refere aos atributos físicos da floresta, mas também na composição de sua comunidade, afetando principalmente a densidade de palmitos.

O palmito é uma das palmeiras mais abundantes e amplamente distribuídas na Mata Atlântica, penetrando para o interior das matas pelas redes de drenagem fluviais (Mantovani, 1993). Segundo Reis et al. (2000), os fundos de vale são ambientes propícios para o desenvolvimento vegetativo desta espécie, sendo o que recrutamento para a fase reprodutiva deve estar associado a condições de maior luminosidade.

$\mathrm{Na}$ estrutura das florestas tropicais úmidas apenas $0,5 \%$ a $4 \%$ da luz alcança o solo da floresta e como conseqüência, o crescimento de muitas plântulas no interior destas florestas é limitado por esta escassez luminosa, sendo que qualquer variação, mesmo que pequena, pode ter grande influência na fotossíntese, crescimento e regeneração destes indivíduos (Chazdon, 1986).

Estudos sobre a influência da luminosidade no crescimento de espécies vegetais de florestas tropicais vêm demonstrando que a melhor capacidade de adaptação a mudanças na luminosidade é variável de espécie para espécie, sendo que geralmente espécies que aparecem num estágio sucessional mais inicial parecem ter maior flexibilidade fisiológica que espécies de estágios sucessionais mais tardios, embora haja casos em que estas espécies mostrem maior potencial de adaptação à variação de luz (Bazzaz, 1979; Turnbull, 1991). 
Algumas espécies regeneraram-se exclusivamente na baixa luminosidade que ocorre no nível do chão da floresta, neste caso um aumento na radiação, mesmo que pequeno, pode ser prejudicial, resultando em foto-inibição da fotossíntese nestes indivíduos, entretanto, muitas outras espécies, cujas plântulas geralmente crescem sob o dossel fechado de uma floresta, podem se beneficiar de uma pequena abertura na copa das árvores (Pickett, 1983; Whitmore, 1990).

Estudos realizados com E. edulis revelaram que o crescimento desta espécie é limitado pela baixa quantidade de radiação que chega ao chão da floresta, podendo sua regeneração ser beneficiada pelo aparecimento de clareiras que favoreçam o aumento da luz solar em até $20 \%$, valor este que parece ser o limite para que o crescimento de plântulas seja favorecido (Paulilo, 2000). Valores superiores a este parecem não causar nenhum favorecimento para as plântulas, sendo que acima de $70 \%$ podem até mesmo levar a inibição do crescimento neste estágio, devido à exposição excessiva à luz solar (Paulilo, 2000).

Sabe-se que pequenas alterações na estrutura da vegetação, como a queda de uma árvore, podem aumentar de $2 \%$ a $20 \%$ a incidência de luz nestes ambientes (Chazdon \& Fetcher, 1984). A pequena diferença observada entre a cobertura de dossel das áreas preservadas e das de corte seletivo, 94,5 \% e 91,4\% respectivamente, deve-se provavelmente à extração num passado próximo, nas áreas de corte seletivo, de indivíduos de maior porte da vegetação, geralmente de maior valor econômico, mas que demoram um maior tempo para se regenerarem, conforme descrito no item anterior.

Portanto, é possível que esta pequena diminuição na cobertura do dossel nas áreas de corte seletivo esteja levando a um aumento na radiação que chega ao solo da floresta, aumento este suficiente para acelerar o crescimento e conseqüentemente favorecer o estabelecimento de plântulas de E. edulis, o que poderia explicar um aumento na densidade dos indivíduos desta espécie ao longo destes últimos 30-40 anos.

Entre as formações de floresta ombrófila densa e vegetação secundária praticamente nenhuma diferença foi observada na cobertura de dossel $(90,01 \%$ e 89,58 $\%$ respectivamente), porém uma maior densidade de palmitos e também de palmeiras foi 
observada nestas áreas. Sabe-se que espécies florestais necessitam de condições ideais de micro-hábitat para garantirem a sobrevivência de sementes, contudo, uma vez que estas sementes sobrevivam, as propriedades abióticas, como luminosidade, irão definir a velocidade de crescimento de plântulas, sendo que o sucesso no estabelecimento destas poderá influenciar a estrutura de toda a comunidade (Malcon, 1990). Portanto, podemos concluir que áreas de floresta ombrófila densa apresentam naturalmente melhores condições gerais para o estabelecimento de palmeiras e palmitos, assim como o observado por Conte et al. (2000) ao longo dos anos em áreas de Mata Atlântica em Santa Catarina, onde, apesar de ambos os ambientes terem apresentado alguns anos de elevada produtividade ("masting years"), de maneira geral, estas florestas apresentaram médias no número de plântulas da palmito/ha superiores ao observado para as áreas de vegetação secundária.

Contudo, os dados obtidos no presente etudo indicam que e em alguns locais, pequenas alterações na cobertura do dossel, tais como as que ocorrem em áreas de corte seletivo, possam favorecer ao crescimento das plântulas de palmito, aumentando as chances de estabelecimento destas e conseqüentemente levando a alterações na densidade de indivíduos desta espécie.

Esta alteração na dinâmica da comunidade de palmito nestas áreas de corte seletivo poderia explicar o elevado número de indivíduos desta espécie na área do NSV/NS, uma vez que estas elevadas densidades foram encontradas em trilhas que sofreram corte seletivo antes da implantação do parque na região (ver Anexo G), e que desde então estão protegidas da ação de palmiteiros e sujeitas aos processos naturais de regeneração da floresta.

\subsubsection{Disponibilidade de Frutos}

O aumento na disponibilidade de frutos de palmito nas áreas de corte seletivo, avaliada através da biomassa coletada de frutos nas áreas $\left(\mathrm{kg} / \mathrm{km}^{2}\right)$, está diretamente 
relacionada ao aumento observado de indivíduos adultos desta espécie. Contudo, foi possível observar também um aumento na biomassa de frutos de outras espécies.

Geralmente durante os processos de regeneração de uma floresta ocorre o aparecimento de um maior número de espécies de Myrtaceae e Lauraceae nos estágios mais avançados (Tabarelli \& Mantovani, 1999). Estas famílias são compostas, em sua maioria, por espécies zoocóricas e, no caso de Myrtaceae, principalmente espécies típicas de sub-bosque (Tabarelli \& Mantovani, 1999). Contudo, diferenças na composição e abundância destas espécies podem ser observadas devido não somente ao tempo de regeneração mas também ao tipo de uso antrópico pela qual elas passaram.

Para as áreas de corte seletivo, hoje em estágio avançado de regeneração, mas que porem nunca foram pastos podemos esperar um sub-bosque semelhante ao observado nas áreas de floresta madura, sendo que nestas áreas pode ainda ocorrer um aumento na densidade de indivíduos de menor porte $(3 \mathrm{~cm} \leq D A P \geq 10 \mathrm{~cm})$, típicos de sub-bosque, principalmente Myrtaceae, como já discutido anteriormente, enquanto que nas áreas de floresta madura ocorreria um crescimento dos indivíduos já estabelecidos, geralmente espécies de maior porte, as Lauraceae (Tabarelli \& Mantovani, 1999).

Para diversos estudos realizados na Mata Atlântica, a família Myrtaceae apresentou um maior número de espécies, podendo chegar a $23 \%$ do total de espécies presentes nestas áreas de floresta, enquanto que as Lauraceae contribuem com um número muito menor de espécies, variando de 0 a $9 \%$ (Sánchez et al., 1999). Portanto, a maior disponibilidade de frutos de outras espécies encontrada nas áreas de corte seletivo deve-se provavelmente a maior densidade e diversidade de espécies de Myrtaceae de sub-bosque nestas áreas, quando comparadas com as áreas preservadas.

Para as áreas de ex-pastagens, durante os estágios iniciais de regeneração, Tabarelli \& Mantovani (1999) observaram a formação de florestas de espécies geralmente anemocóricas tais como as dos gêneros Tibouchina e Baccharis, e que puderam ainda nos dias de hoje ser observadas ocorrendo em grandes manchas nestas áreas, mesmo em estágios já mais avançados de regeneração (Observação pessoal, 
2003). Portanto, a menor produtividade destas áreas deva-se provavelmente a ocorrência de espécies anemocóricas e também da pequena densidade de Myrtaceae no sub-bosque.

Apesar da alta produtividade de frutos nas regiões tropicais, a fenologia é altamente sazonal, podendo ocorrer períodos de escassez de recursos e alta produtividade no mesmo ano (Van Schaik et al., 1993), por isso, espécies que frutificam fora do período de maior produtividade da comunidade são importantes para a manutenção dos frugívoros e denominadas de “espécies-chaves” (Terborgh, 1986).

Por isso, as palmeiras em geral são consideradas, apesar de algumas discordâncias, espécies-chaves, já que seus frutos, apresentam pouca sincronia de frutificação quando comparado com outras espécies da comunidade e ocorrem geralmente em épocas de escassez de alimento (Terborgh, 1986; Peres, 1994; Galetti \& Fernandez, 1998; Peres, 2000).

Nas áreas do presente estudo, as palmeiras representaram cerca de $75 \%$ de todos os frutos coletados o que correspondeu a 72,5\% de toda a biomassa disponível, o que reforça a importância destas espécies para a comunidade da fauna em geral. Contudo vale ressaltar também a importância de $C$. moschata, principalmente para a área do NC/I, onde, durante o inverno esta espécie passou a representar cerca de metade da biomassa disponível de frutos, num período quando o palmito era praticamente escasso na área, tendo sido registrado o consumo destas por primatas tais como B. arachnoides e C. nigritus e também encontradas em meio às fezes de porcos (T. pecari e $P$. tajacu) e antas (Tapirus terrestris) (Observação pessoal; Galetti, M $^{5}$; Nobre, R.A. ${ }^{6}$ ).

\subsection{Fatores Ambientais e a Abundância e Distribuição das Espécies}

C. aurita apresentou uma maior correlação com os atributos físicos da floresta, principalmente com a cobertura do dossel. Provavelmente esta espécie esteja utilizando-

\footnotetext{
${ }^{5}$ Galetti, M. UNESP. Instituto de Biociências. Depto. de Ecologia. Em visita recente á área de estudo. Comunicação pessoal, 2003.

${ }^{6}$ Nobre, R.A. Mestrando no PPGI-EA, ESALQ. Desenvolve atualmente projeto nas áreas do NC/I, NSV/NS e NP. Comunicação pessoal, 2004.
} 
se de áreas com maior densidade de indivíduos arbóreos e maior cobertura de dossel devido ao fato de nestes ambientes a sua locomoção seja facilitada, uma vez que a conectividade do dossel, estrato preferencialmente utilizado por estes indivíduos, é maior nestes locais. A maior cobertura de dossel deve favorecer ao estabelecimento de maiores quantidades de fungos e principalmente epífitas, o que poderia também favorecer esta espécie uma vez que ela pode consumir não somente uma grande quantidade destes fungos e partes vegetativas destas plantas, como também invertebrados que geralmente proliferam nesse ambiente (Corrêa et al., 2000; Lovejoy et al., 1986; Morelatto, 1991; Ferrari, 1988).

O gênero Callithrix possui espécies com hábitos alimentares mais variados, preferencialmente gomívoras, mas alimentando-se também de insetos, pequenos vertebrados e até mesmo partes reprodutivas de plantas, sendo que estas espécies possuem uma excelente capacidade de se adaptar ao ambiente, podendo inclusive modificar a composição de sua dieta dependendo da disponibilidade dos recursos (Eisenberg \& Redford, 1992; Ferrari et al., 1996). C. aurita é endêmico do sudeste do Brasil e, segundo alguns autores, naturalmente raro e típico de áreas de maior altitude, sendo até mesmo considerado como ausente em áreas mais baixas, principalmente abaixo dos 150-200 m (Auricchio, 1995; Cerqueira et al., 1998; Olmos \& Martuscelli, 1995; Brandão \& Develey, 1998). Essa espécie em particular é predominantemente insetívora, sendo menos gomívora que as outras espécies do mesmo gênero (Muskin, 1984, Ferrari et al., 1996). A sua persistência em fragmentos florestais tem sido associada a esta dieta diferenciada, já que segundo alguns autores, ocorreria a proliferam de insetos nos emaranhados de cipós e lianas, que geralmente dominam estas áreas, levando assim a um aumento na disponibilidade de alimento para estes primatas (Muskin, 1984; Brandão \& Develey, 1998). Num estudo realizado na área do NC/I Corrêa et al. (2000) verificou que esta espécie modificou totalmente sua dieta provavelmente de acordo com a disponibilidade dos recursos no ambiente. Durante o ano de 1993 o grupo avaliado por esta autora consumiu cerca de 62,2\% de frutos enquanto que no ano seguinte somente $20,7 \%$ enquanto que exudatos passaram de 18,8 
$\%$ para cerca de $64 \%$ da dieta, provavelmente por causa da escassez de frutos naquele ano devido a mudanças nos padrões pluviométricos da área, o que comprova a elevada capacidade desta espécie em se adaptar as condições do ambiente, diminuindo assim a sua dependência na ocorrência de frutos.

C. nigritus foi analisada juntamente com outras espécies no grupo "mamíferos geral", e este grupo como um todo também apresentou maior correlação com cobertura de dossel e maior densidade de indivíduos arbóreos. Provavelmente esta espécie utilizase mais destes ambientes devido a facilidade de locomoção ou também a uma maior oferta de alimento nestes locais, como já discutido para C. aurita. C. nigritus, assim como as demais espécies do gênero, apresenta uma dieta generalista (Spironelo, 1991; Galetti \& Pedroni, 1994; Eisenberg \& Redford, 1999), sendo um dos fatores responsáveis pela alta densidade populacional em fragmentos florestais de pequeno porte, tanto em áreas de semidecídua como em florestas de tabuleiro, tendo sido observado inclusive alimentando-se de cana-de-açucar ou milho das plantações no entorno destas áreas (Brown et al., 1984; Brown \& Zunino, 1990; Cullen Jr. et al., 2001; Chiarello \& de Melo, 2001; Galetti \& Pedroni, 1994; São Bernardo \& Galetti, 2004).

Apesar destas duas espécies de pequenos primatas $C$. aurita e $C$. nigritus apresentarem uma elevada plasticidade, sendo capazes de se adaptarem a áreas alteradas e até mesmo fragmentadas, apresentaram densidades muito inferiores $(C$. aurita $=2,87$ ind $/ \mathrm{km}^{2}$ e $C$. apella $=1,64 \mathrm{ind} / \mathrm{km}^{2}$ ) às médias observadas para as áreas de tabuleiro $\left(13,79 \mathrm{ind} / \mathrm{km}^{2}\right.$ e $12,35 \mathrm{ind} / \mathrm{km}^{2}$, respectivamente) e semidecídua $\left(13,34 \mathrm{ind} / \mathrm{km}^{2}\right.$ e 20,83 ind $/ \mathrm{km}^{2}$, respectivamente).

Chiarello (2000a) sugeriu que a eventual baixa abundância de pequenos primatas em fragmentos florestais, principalmente Callithriquídeos, poderia ser explicada devido a alta predação por felinos de menor porte nestes locais. Nas áreas do NC/I e NSV/NS, onde ocorreram C. aurita e C. nigitus, também foi possível confirmar a ocorrência de três espécies de pequenos felinos, Leopardus pardalis, L. tigrinus e L. wiedii (ver Anexo M). Além disso, nestas áreas também foi possível identificar um outro potencial predador destas espécies de primatas, o gavião-pega-macaco (Spizaetus tyrannus). 
Portanto, é possível que as populações destes primatas estejam sendo controladas nas áreas destes núcleos pela predação por estas espécies.

T. pecari também apresentou uma maior correlação positiva com cobertura de dossel, densidade de palmeiras e densidade de indivíduos arbóreos, enquanto que por outro lado negativamente com o fator caça. Esta espécie ocorreu exclusivamente nas áreas de floresta ombrófila densa e provavelmente esta associação deve-se ao fato de que nestas áreas, a densidade de palmeiras em geral é muito superior ao observado nas áreas de vegetação secundária.

Estes animais são de grande porte e pesam em média $33,5 \mathrm{~kg}$, sendo que a onçapintada (Panthera onca) é considerada como predador natural típico desta espécie, enquanto que a onça-parda (Puma concolor) pode atacar eventualmente indivíduos mais jovens (Oliveira, 1994). Com dieta que pode variar de invertebrados, frutos, partes vegetativas ou reprodutivas de plantas, e até mesmo pequenos vertebrados, esta espécie consome preferencialmente frutos e sementes grandes (Eisenberg \& Redford, 1999; Fonseca et al., 1996). A análise do estômago de trinta e quatro indivíduos de $T$. pecari num estudo no Peru revelou que $61 \%$ do conteúdo consumido era de sementes de palmeiras e cerca de $39 \%$ de partes vegetativas de plantas (Eisenberg \& Redford, 1999). Contudo, apesar de consumirem muitas sementes e frutos, geralmente as espécies de porcos-do-mato, T. pecari e $P$. tajacu, raramente atuam como dispersores, uma vez que poucas destas sementes podem ser encontradas intactas (Kiltie, 1981a; 1981b). Num recente estudo realizado numa área de Mata Atlântica, estes animais não somente consumiram grandes quantidades de frutos como também apresentaram padrões de migração relacionados à disponibilidade destes recursos no ambiente (Keuroghlian et al., 2004). T. pecari apresenta sua distribuição e abundâncias altamente correlacionadas com a oferta de frutos de palmeiras, porém, nas áreas do NP, apesar da elevada disponibilidade desses frutos, esta espécie apresentou o menor densidade. Este fato confirma que, por outro lado, a caça afeta negativamente estes mamíferos. A presença ou ausência de predadores, bem como os efeitos da caça são reconhecidamente fatores que podem influenciar na densidade e eventualmente até mesmo nos padrões 
comportamentais desta espécie (Peres, 1990; Peres, 1996; Bodmer et al., 1988; Bodmer et al., 1997; Kilgo et al., 1998; Cullen Jr. et al., 2000). Portanto, a menor densidade desta espécie na área do NP deve-se provavelmente ao histórico de caça da região, enquanto que a elevada densidade nas áreas do NC/I e NSV/NS pode ser explicada pela maior dificuldade de acesso aos caçadores, devido ao isolamento geográfico de boa parte destas áreas, principalmente do NC/I, e também pela provável ausência de predadores naturais desta espécie nas áreas avaliadas.

As populações de espécies animais preferencialmente caçadas podem responder de formas diferentes a uma mesma pressão de caça, sendo geralmente mais sensíveis aquelas espécies que apresentam uma baixa taxa de crescimento populacional e alta longevidade, tais como a anta, veados e primatas de grande porte, enquanto que ungulados e roedores, apesar de geralmente serem os mais caçados, podem ser menos sensíveis, uma vez que apresentam baixa longevidade e altas taxas de crescimento populacional (Wright, 2003). Por isso, apesar de toda a região do PESM ser muito caçada, T. pecari ainda é capaz de apresentar populações com altas densidades em algumas dessas áreas, e que, segundo observações de moradores e administradores das unidades $^{1}$, vêm crescendo nos últimos anos. Ou seja, devido a ausência de predadores naturais e as elevadas taxas naturais de crescimento desta espécie, é possível que, mesmo sob uma pressão de caça moderada, como a observada nas áreas do NC/I e NSV/NS, as populações destas espécies continuem a crescer nestes últimos anos.

Em contraste as elevadas densidades apresentadas por estes ungulados nas áreas do NSV/NS e NC/I, a espécie $P$. tajacu foi avistada uma única vez em cada uma destas áreas, o que poderia indicar que esta espécie esteja sofrendo fortes pressões devido a competição por recurso com $T$. pecari, similares até certo ponto para ambas as espécies (Eisenberg \& Redford, 1999; Keuroghlian et al., 2004).

Os mamíferos em geral parecem estar correlacionados positivamente aos atributos físicos da floresta e menos associados à disponibilidade de frutos no geral.

\footnotetext{
${ }^{1}$ Entrevistas não padronizadas com administradores, funcionários e moradores das unidades amostradas, incluindo ex-caçadores locais, além de moradores do entorno. Comunicação pessoal, 2003.
} 
Provavelmente isto se deva ao fato de que as espécies de mamíferos avaliadas no presente estudo (C. aurita, A.guariba, B. arachnoides, C. nigritus, $N$. nasua, $P$. cancrivorus, T. pecari, P. tajacu, S. aestuans, Dasyprocta sp. e S. brasiliensis) geralmente apresentam dieta mais diversificada e menos especializada em frutos (Eisenberg \& Redford, 1999), enquanto que por outro lado, indicam também que suas abundâncias são negativamente influenciadas pelo fator caça, principalmente aquelas espécies de maior porte ou reconhecidamente cinegéticas tais como T. pecari, P. tajacu e Dasyprocta sp..

Vale ainda lembrar que Dasyprocta spp. foi raramente avistada nas áreas, principalmente do NSV/NS e NC/I, mesmo tendo estas áreas menores índices de caça que o NP. Apesar de ter sido relatada por muitos dos moradores como sendo mais freqüente nestas áreas a cerca de 10 anos, num estudo realizado nas áreas do NSV/NS em 1997 que investigou a dieta de diversos felinos, a autora não registro nenhuma ocorrência desta espécie em meio às presas identificadas (Wang, 1999). Portanto, é difícil dizer se esta espécie já ocorria naturalmente em baixas densidades nestas áreas ou se isso poderia ser efeito de um histórico de caça em toda região, uma vez que esta espécie é reconhecidamente cinegética em toda a Mata Atlântica (Chiarello, 1997; Cullen Jr., 1997)

S. aestuans foi a única espécie de mamífero que apresentou correlação positiva com as áreas de elevada intensidade de caça. Os indivíduos desta espécie são geralmente de pequeno porte, solitários e possuem hábitos escansoriais, apresentando uma dieta que pode variar de acordo com a disponibilidade de frutos e grandes sementes, seu principal alimento, principalmente as de palmeiras (Gentry \& Emmons, 1987; Eisenberg \& Redford, 1992; Paschoal \& Galetti, 1995). Portanto, provavelmente devido ao seu pequeno peso $(<300 \mathrm{~g})$ esta espécie não é localmente apreciada para a caça, tendo sido uma das poucas espécies ainda avistadas em áreas altamente caçadas, sendo a mais abundante dentre os mamíferos, o que gerou a correlação observada no diagrama da análise de correspondência canônica. Vale ainda ressaltar que a elevada abundância deste pequeno roedor pode representar uma resposta do ambiente às baixas abundãncias 
ou ausência de Dasyprocta sp. nestas áreas, fenômeno este conhecido como "density compensation", ou seja, compensação de densidades, onde a abundância de algumas espécies aumenta em função do declínio, extinção ou ausência de outras espécies potencialmente competidoras, neste caso, relacionadas ao consumo de grandes sementes de palmeiras (Macarthur et al., 1972; Peres \& Dolman, 2000). Evidência de compensação de densidade entre estas espécies também podem ser vistas em trabalhos realizados em outras áreas de Mata Atlântica. Num recente estudo na Ilha do Cardoso, São Bernardo (2004) verificou uma maior densidade de Dasyprocta leporina (3,4 ind $/ \mathrm{km}^{2}$ ) que nas áreas avaliadas no presente estudo, contudo a densidade obtida para $S$. aestuans foi menor $\left(1,6 \mathrm{ind} / \mathrm{km}^{2}\right)$. $\mathrm{O}$ mesmo padrão foi observado para as áreas de Cullen Jr. (1997) onde no MDSP, área com a maior densidade de Dasyprocta azarae $\left(26,80 \mathrm{ind} / \mathrm{km}^{2}\right), S$. aestuans apresentou a menor densidade $\left(0,37 \mathrm{ind} / \mathrm{km}^{2}\right)$, enquanto que nos demais fragmentos avaliados, onde D. azarae apresentou menores densidades, provavelmente devido a pressão de caça, esta espécie obteve seus maiores valores de densidade, chegando a $20,20 \mathrm{ind} / \mathrm{km}^{2}$ onde $D$. azarae por sua vez apresentou a sua menor densidade $\left(0,39 \mathrm{ind} / \mathrm{km}^{2}\right)$.

Já $T$. solitarius foi, dentre as aves, a espécie que apresentou a maior correlação negativa com a caça. Esta ave é uma das preferidas localmente, sendo considerada altamente cinegética também por outros autores, que consideram esta prática ilegal como a principal ameaça a conservação desta espécie (Develey \& Endrigo, 2004; Sick, 1997; Willis \& Oniki, 2003). Este tinamídeo solitário é considerado típico de matas limpas e com dieta frugívora/granívora, incluindo principalmente sementes, pequenos artrópodes e eventualmente moluscos (Redford, 1993; Sick, 1997; Willis \& Oniki, 2003). Esta espécie apresentou suas maiores abundâncias em áreas pouco caçadas e geralmente com maiores valores de estrutura física da floresta. A maior cobertura do dossel e a maior densidade de árvores de grande porte indicam matas mais bem estruturadas e que, provavelmente, apresentam sub-bosque mais esparso, o que cria o ambiente típico preferido por esta espécie. Vale lembrar ainda que este tinamídeo foi a espécie de ave que apresentou os valores mais baixos de densidade para todas as áreas 
avaliadas, o que pode ser um indicativo de uma população já muito reduzida devido a histórico de caça em toda a região, contudo, devido a escassez de dados desta espécies em outras áreas de Mata Atlântica poucas inferências podem ser realizadas sobre o real status de conservação destas populações. $\mathrm{Na}$ Ilha do Cardoso, esta espécie também foi a que apresentou a menor densidade dentre as espécies avaliadas na área, com cerca de 1,2 ind $/ \mathrm{km}^{2}$, sendo que a caça e também a disponibilidade de frutos foram os fatores que afetaram a distribuição desta espécie nesta área. Vale dizer ainda que num estudo realizado no Parque Estadual de Intervales, Aleixo \& Galetti (1997) consideraram esta espécie como sendo de ocorrência comum nas áreas, contudo, assim como no presente trabalho, preferencialmente em florestas mais bem estruturadas, principalmente em matas primárias ou florestas com corte seletivo, e também menos abundante em áreas de maior intensidade de caça.

O. capueira, apesar de não apresentar uma correlação tão significativa com os atributos físicos da floresta, foi de certa forma influenciado por estes fatores, assim como pela caça, geralmente ocorrendo em maior abundância em áreas menos caçadas e com maiores atributos físicos da floresta. Contudo, o principal determinante para suas abundâncias foi a disponibilidade de frutos no ambiente. Este fasianídeo é típico de chão da mata, normalmente andando em pequenos bandos, de dieta frugívora/granívora, incluindo desde sementes, frutos, larvas, até insetos (Redford, 1993; Sick, 1997; Willis \& Oniki, 2003) Esta espécie ocorreu preferencialmente em áreas de floresta ombrófila densa, provavelmente devido a maior disponibilidade de frutos e sementes em geral, apresentada por este tipo florestal quando comparado à vegetação secundária.

Penelope sp. foi a única espécie de ave que apresentou correlação positiva com as áreas de elevada intensidade de caça. Os indivíduos desta espécie, assim como $S$. aestuans, não são considerados como alvo preferencial dos caçadores na região, porém, diferentemente deste mamífero, podem eventualmente ser caçados na falta de outras espécies. Portanto, devido a estas características que esta espécie ainda pode ser avistada em áreas caçadas, o que acabou gerando a associação na análise de correspondência 
canônica, contudo, pode-se perceber que mesmo sendo menos caçada que T. solitarius esta ave apresentou densidades maiores em áreas menos caçadas, NSV/NS e NC/I.

As aves de maneira geral, o contrário dos mamíferos, parecem estar mais relacionadas à disponibilidade de frutos que aos atributos físicos da floresta. Provavelmente isto se deva ao fato de que as espécies de aves avaliadas ( $P$. jacutinga, Penelope sp., O. capueira, T. solitarius, R. vitellinus e $R$. toco) são, na sua maioria, espécies frugívoras que apresentam dieta mais especializada (Develey \& Endrigo, 2004; Sick, 1997; Willis \& Oniki, 2003).

Alguns estudos na Amazônia e mais recentemente na Mata Atlântica também relacionam a abundância, densidade, ocorrência e riqueza das espécies com alguns fatores ambientais tais como o tamanho do fragmento e pressão de caça, mas poucos são aqueles que exploram os efeitos da estrutura da vegetação e qualidade do habitat (Chiarello, 1999; Cullen Jr et al, 2001; Heiduck, 2002; Peres, 1999; Peres, 2001; Schwarzkopf \& Rylands, 1989).

Em pequenos fragmentos na região amazônica houve, assim como observado no presente trabalho, relação entre a distribuição e número de primatas com a estrutura do habitat (Schwarzkopf \& Rylands, 1989), sendo que os resultados nestas áreas sugeriram também que ambientes estruturalmente mais complexos (maior número de árvores de grande porte, baixo número de lianas, etc.) abrigam maior número de espécies de primatas. Outros estudos com primatas vêm demonstrando que não só a estrutura da vegetação é importante para a locomoção e proteção contra predadores, mas também a disponibilidade de alimento, que pode ser fator determinante para a ocorrência destas espécies (Heiduck, 2002; Peres, 1996; Stevenson, 2001; Spironelo, 1991). 


\section{CONCLUSÕES}

Os dados apresentados demonstram que mesmo áreas de floresta contínua na Mata Atlântica sofrem do grave problema de defaunação, até então observado e amplamente estudado em áreas fragmentadas, sendo pouquíssimos os trabalhos que avaliaram grandes remanescentes tais como o Parque Estadual da Serra do Mar. Os resultados apontam para o efeito de muitos fatores sobre a ocorrência e abundância das espécies de mamíferos e aves cinegéticas, refletindo assim a complexidade destes sistemas naturais e a necessidade de estudos de longa duração para uma melhor compreensão de todos os processos envolvidos.

A falta de padronização e muitas vezes a não observância de premissas básicas das técnicas utilizadas dificultam as comparações de dados obtidos em diversos trabalhos ao longo deste bioma, o que atrasa possíveis avanços no conhecimento e até mesmo na implantação de ações efetivas de manejo nestas áreas.

Foi possível verificar diferenças marcantes na estrutura da vegetação entre áreas de floresta primária e vegetação secundária, bem como existem fortes indícios de variações sazonais, locais e possivelmente altitudinais na distribuição de palmeiras e na disponibilidade de frutos no norte da Serra do Mar no Estado de São Paulo. Não obstante estas diferenças naturais, foi possível constatar ainda a influência de fatores históricos e de ocupação e uso do solo sobre a vegetação atualmente presente nestas áreas. O corte raso das matas no passado, para uso como pastagens, leva a mudanças drásticas na estrutura da vegetação, disponibilidade de frutos em geral e também na densidade de palmeiras, e principalmente palmitos. Mesmo áreas que sofreram corte seletivo apresentam padrões de distribuição destas espécies vegetais diferentes de áreas 
pouco alteradas. Todos estes resultados corroboram o grande mosaico vegetacional hoje presente na região.

Para a fauna como um todo foi possível verificar a influência destes parâmetros da vegetação e também de fatores abióticos na abundância e ocorrência das espécies. A caça, histórica e atual, parece ser dentre os fatores externos aquele de maior importância, influenciando a densidade de muitas das espécies avaliadas e talvez responsável até mesmo por possíveis extinções locais.

A alteração na densidade destas espécies tem efeito não somente sobre suas populações como também podem influenciar outras espécies presentes na área, além de estarem intrinsecamente relacionados aos processos de herbivoria, predação e dispersão de muitas espécies vegetais. Indícios da ocorrência do fenômeno de compensação de densidades (“density compensation”) podem ser encontrados nas áreas, como também alterações populacionais devido à ausência de predadores de grande porte ou pelo aumento de espécies competidoras. Todos estes resultados reforçam a idéia de que nestes ambientes naturais todas as espécies estão fortemente correlacionadas e que alterações, mesmo que pequenas, em alguma delas podem levar a conseqüências para todo o sistema, conhecido como "efeito dominó".

Quanto às populações remanescentes maiores são as chances de manutenção quando maior é a área considerada, mesmo considerando-se diferentes números mínimos de indivíduos necessários. Vale ainda ressaltar que as áreas estudadas, se consideradas separadamente, não seriam capazes de manter populações viáveis para a maioria das espécies avaliadas, o que evidencia a importância da conectividade entre elas e, sobretudo, da manutenção de grandes blocos de mata contínua nesta região, o que garante a sobrevivência principalmente de espécies que apresentam, naturalmente ou não, baixas densidades, tais como predadores de topo, grandes primatas e espécies cinegéticas em geral.

Devemos lembrar ainda que estas avaliações de viabilidade não levam em conta fatores tais como o aumento ou continuidade da caça e alterações no ambiente (e.g. retirada de palmito), o que poderia levar a diminuição das populações hoje existentes, 
aumentando ainda mais as chances de extinção destas espécies.

$\mathrm{O}$ crescimento acelerado das cidades vizinhas próximas à Serra do Mar aumenta as pressões sobre estes remanescentes e colocam em risco o futuro destas espécies, o que pode comprometer a diversidade biológica na região. Uma das melhores maneiras de se combater uma ameaça deste tipo é obter o máximo possível de informações, através de estudos complementares, que nos permitam chamar a atenção da sociedade e traçar junto com os órgãos governamentais responsáveis estratégias para a conservação efetiva destas áreas, ampliando as parcerias e enfatizando a tomada de medidas enérgicas e imediatas para este fim, tais como o combate a caça e a retirada ilegal de palmito.

O Parque Estadual da Serra do Mar tem ao todo $3.150 \mathrm{~km}^{2}$ e é o maior remanescente de florestas contínuas de Mata Atlântica no Brasil, podendo ser considerado uma das mais importantes áreas para a preservação deste bioma, devido a sua riqueza faunística, qualidade dos remanescentes existentes, presença de espécies endêmicas, raras e/ou ameaçadas de extinção e também por sua localização biogeográfica. Além deste parque ser a maior Unidade de Conservação da Mata Atlântica, a região possui grande variação altitudinal e habitats pouco representados nas demais UCs deste bioma. O parque encontra-se próximo a áreas de elevada e crescente concentração humana, sendo ele cortado por diversas rodovias, oleodutos, gasodutos e estradas não pavimentadas, em uma área aonde o interesse turístico vem crescendo cada vez mais e junto com ele o interesse imobiliário, tendo em vista este cenário atual tornase imprescindível à inserção desta área como parte de uma estratégia mais ampla de criação de um corredor ecológico na região.

Apesar da proximidade da área estudada às grandes universidades do país, a maioria delas concentradas no sudeste brasileiro, pouco se conhece quanto ao status de grande parte das populações dos diferentes grupos de vertebrados no interior destes remanescentes, sendo que ainda existem muitas áreas cientificamente inexploradas, e que podem revelar a presença de espécies ainda não registradas e eventualmente até mesmo o aparecimento de novas. Portanto, dentre as ações prioritárias estariam também a realização de inventários e implantação de estudos de longa duração que, através do 
monitoramento dos indivíduos, contribuiriam para um melhor entendimento da dinâmica e dos efeitos dos fatores bióticos e abióticos nestas populações.

Por parte do órgão responsável pelas unidades avaliadas e das instituições governamentais relacionadas a conservação do bioma da Mata Atlântica no Estado de São Paulo, epsera-se a tomada de decisões mais práticas e de ações que visem a efetiva proteção destas áreas. Os baixos salários, a falta de capacitação e treinamento específicos, além do número reduzido de funcionários nas áreas avaliadas, situação essa, ao que parece, similar na maioria das unidades no estado, contribuem para o agravamento da situação. Mudanças são necessárias na política pública frente a estas ameaças e tanto o governo quanto a sociedade precisam se organizar e se estruturarem para defender este patrimônio. 
ANEXOS 
Anexo A. Dados populacionais para as cidades da macro-região do Vale do Paraíba Paulista e para as principais cidades do entorno das áreas amostradas

\begin{tabular}{|c|c|c|c|c|c|c|c|}
\hline \multirow{2}{*}{$\begin{array}{l}\text { Ano } \\
\text { Municípios/Região }\end{array}$} & \multirow[b]{2}{*}{$\begin{array}{l}\text { Área } \\
(\mathbf{k m 2})\end{array}$} & \multicolumn{2}{|l|}{1976} & \multicolumn{2}{|l|}{2000} & \multirow[b]{2}{*}{$\begin{array}{l}\text { Diferença } \\
\text { Densidade }\end{array}$} & \multirow[b]{2}{*}{$\begin{array}{l}\text { Taxa (\%) } \\
\text { Crescimento }\end{array}$} \\
\hline & & $\begin{array}{l}\text { Populaçãa } \\
\text { (hab) }\end{array}$ & $\begin{array}{l}\text { Densidade } \\
\text { (hab/km2) }\end{array}$ & $\begin{array}{l}\text { Populaçãa } \\
\text { (hab) }\end{array}$ & $\begin{array}{l}\text { Densidade } \\
\text { (hab/km2) }\end{array}$ & & \\
\hline Aparecida & 112 & 28.826 & 257,37 & 34.834 & 311,02 & 53,65 & 20,84 \\
\hline Caçapava & 365 & 35.880 & 98,30 & 75.813 & 207,71 & 109,41 & 111,30 \\
\hline Cachoeira Paulísta & 279 & 19.840 & 71,11 & 27.201 & 97,49 & 26,38 & 37,10 \\
\hline Campos do Jordão & 269 & 23.376 & 86,90 & 44.238 & 164,45 & 77,55 & 89,24 \\
\hline Cruzeiro & 331 & 52.609 & 158,94 & 73.469 & 221,96 & 63,02 & 39,65 \\
\hline Guaratinguetá & 825 & 79.986 & 96,95 & 104.022 & 126,09 & 29,14 & 30,05 \\
\hline Igaratá & 289 & 4.265 & 14,76 & 8.288 & 28,68 & 13,92 & 94,30 \\
\hline Jacareí & 463 & 70.628 & 152,54 & 191.358 & 413,30 & 260,76 & 170,95 \\
\hline Lavrinhas & 170 & 3.085 & 18,15 & 6.008 & 35,34 & 17,19 & 94,72 \\
\hline Lorena & 452 & 53.468 & 118,29 & 77.843 & 172,22 & 53,93 & 45,59 \\
\hline Monteiro Lobato & 327 & 3.091 & 9,45 & 3.592 & 10,98 & 1,53 & 16,24 \\
\hline Pindamonhangaba & 719 & 55.403 & 77,06 & 125.722 & 174,86 & 97,80 & 126,91 \\
\hline Piquete & 166 & 16.436 & 99,01 & 15.178 & 91,43 & $-7,58$ & $-7,65$ \\
\hline Queluz & 243 & 6.952 & 28,61 & 9.112 & 37,50 & 8,89 & 31,07 \\
\hline Roseira & 139 & 4.008 & 28,83 & 8.536 & 61,41 & 32,58 & 113,01 \\
\hline Santa Branca & 270 & 7.827 & 28,99 & 13.031 & 48,26 & 19,27 & 66,48 \\
\hline Santo Antônio do Pinhal & 97 & 6.265 & 64,59 & 6.311 & 65,06 & 0,47 & 0,73 \\
\hline São Bento do Sapucaí & 279 & 9.078 & 32,54 & 10.355 & 37,11 & 4,57 & 14,06 \\
\hline São José dos Campos & 1.118 & 190.300 & 170,21 & 538.909 & 482,03 & 311,82 & 183,20 \\
\hline Taubaté & 655 & 130.762 & 199,64 & 244.107 & 372,68 & 173,04 & 86,68 \\
\hline Tremembé & 174 & 13.381 & 76,90 & 34.807 & 200,04 & 123,14 & 160,13 \\
\hline Vale do Paraíba Paulista & 7.742 & 815.466 & 105,33 & 1.652 .734 & 213,48 & 108,15 & 102,67 \\
\hline Caraguatatuba & 391 & 18.064 & 46,20 & 78.836 & 201,63 & 155,43 & 336,42 \\
\hline Cunha & 1.339 & 22.620 & 16,89 & 23.062 & 17,22 & $\mathbf{0 , 3 3}$ & 1,97 \\
\hline
\end{tabular}


Anexo A. Dados populacionais para as cidades da macro-região do Vale do Paraíba Paulista e para as principais cidades do entorno das áreas amostradas nos anos de 1976, pouco antes da criação do PESM, e em 2000

\begin{tabular}{|c|c|c|c|c|c|c|c|}
\hline Ano & & 1976 & & 2000 & & & \\
\hline Municípios/Região & $\begin{array}{l}\text { Área } \\
(\mathbf{k m 2})\end{array}$ & $\begin{array}{l}\text { População } \\
\text { (hab) }\end{array}$ & $\begin{array}{l}\text { Densidade } \\
\text { (hab/km2) }\end{array}$ & $\begin{array}{l}\text { População } \\
\text { (hab) }\end{array}$ & $\begin{array}{l}\text { Densidade } \\
\text { (hab/km2) }\end{array}$ & $\begin{array}{l}\text { Diferença } \\
\text { Pop. (hab) }\end{array}$ & $\begin{array}{l}\text { Taxa (\%) } \\
\text { Crescimento }\end{array}$ \\
\hline Lagoinha & 251 & 5.799 & 23,10 & 4.958 & 19,75 & $-3,35$ & $-14,49$ \\
\hline Natividade da Serra & 848 & 9.517 & 11,22 & 6.944 & 8,19 & $-3,03$ & $-27,02$ \\
\hline Paraibuna & 714 & 13.160 & 18,43 & 16.992 & 23,80 & 5,37 & 29,13 \\
\hline São Luís do Paraitinga & 701 & 12.051 & 17,19 & 10.417 & 14,86 & $-2,33$ & $-13,55$ \\
\hline Ubatuba & 748 & 18.249 & 24,40 & 66.448 & $\mathbf{8 8 , 8 3}$ & 64,43 & 264,07 \\
\hline
\end{tabular}

Fonte: Anuário estatístico do Brasil 1976. Rio de Janeiro: IBGE, v.37, 1976 e IBGE, Departamento de População e Indicadores Sociais. 
Anexo B. Mapa do Núcleo Santa Virgínia do PESM. Trilhas de pesquisa, cobertura vegetal e uso do solo. Setas indicam os locais fonte de vetores de pressão antrópica: caça e retirada de palmito $\left({ }^{1}\right.$ Ubatuba, ${ }^{2}$ Natividade da Serra, ${ }^{3}$ São Luiz do Paraitinga e ${ }^{4}$ Rod. Oswaldo Cruz) (Mapa Fonte: SIGMA/ Giordano Bruno Automare)

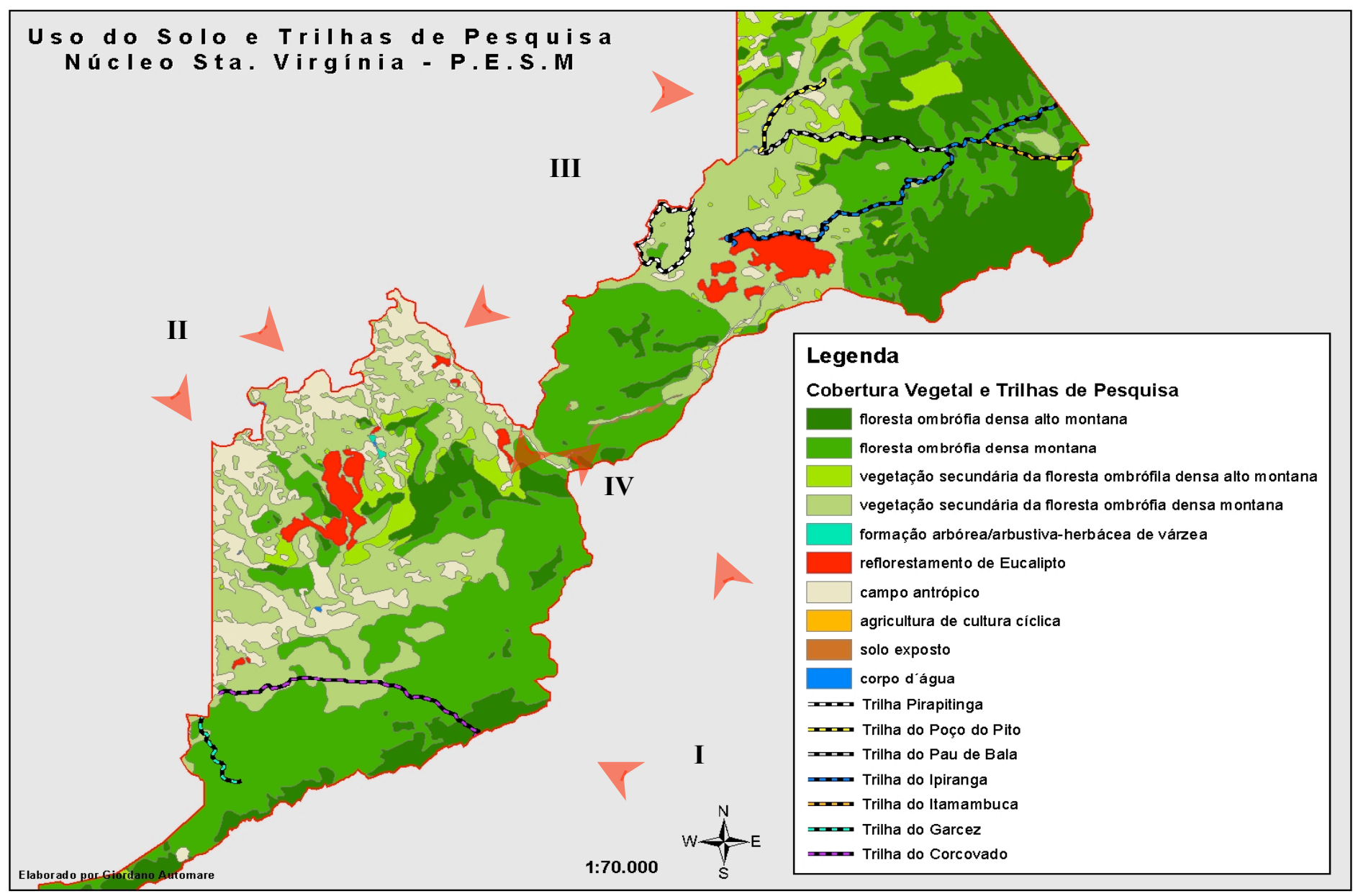


Anexo C. Mapa do Núcleo Cunha do PESM. Trilhas de pesquisa, cobertura vegetal e uso do solo. Setas indicam os locais fonte de vetores de pressão antrópica: caça e retirada de palmito $\left({ }^{1}\right.$ Ubatuba - menor intensidade que nas demais áreas, devido principalmente `as escarpas da Serra do Mar, ${ }^{2}$ Fazendas e Sítios Vizinhos ao NC, ${ }^{3}$ Bairro Palmital) (Mapa Fonte: SIGMA/ Giordano Bruno Automare)




Anexo D. Mapa do Núcleo Picinguaba do PESM. Trilhas de pesquisa, cobertura vegetacional e uso do solo. Setas indicam os locais fonte de vetores de pressão antrópica: caça e retirada de palmito $\left({ }^{1}\right.$ Vila Cambury, ${ }^{2}$ Vila Picinguaba, ${ }^{3}$ Rod. Rio Santos, ${ }^{4}$ Comunidades da Bocaina - RJ, ${ }^{5}$ Ubatuba, ${ }^{6}$ Vila Trindade - RJ, ${ }^{7}$ Sertão do Cubatã e ${ }^{8}$ Sertão da Fazenda) (Mapa Fonte: SIGMA/Giordano Bruno Automare)

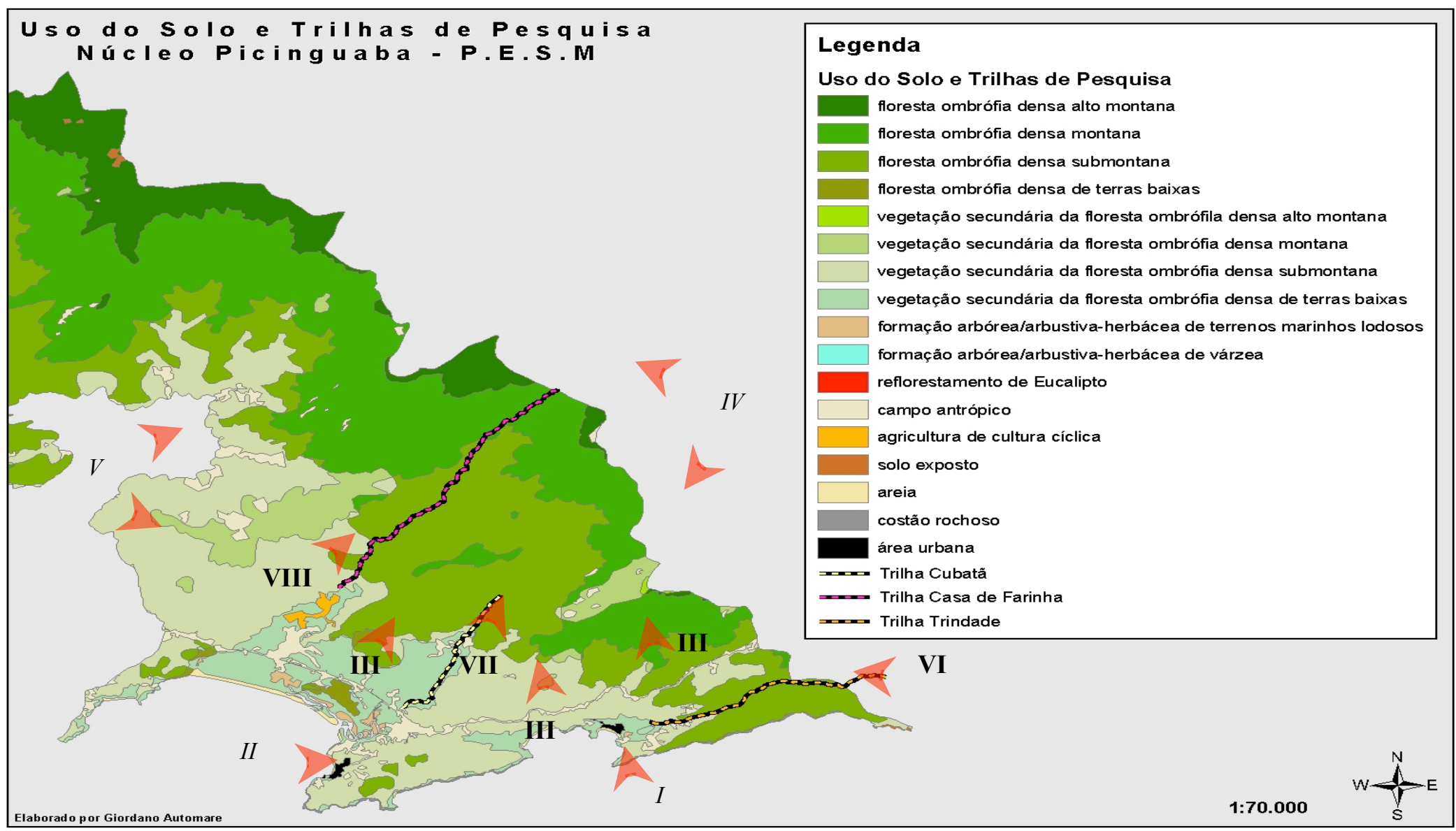


Anexo E. Temperaturas tomadas em três diferentes horários ao longo do dia nos meses típicos de inverno e verão. Dados primários da Estação Meteorológica localizada no NC/I

\begin{tabular}{|c|c|c|c|c|c|c|c|}
\hline Dia/Mês/Ano & 09h & $15 \mathrm{~h}$ & $18 \mathrm{~h}$ & Dia/Mês/Ano & 09h & $15 \mathrm{~h}$ & $18 \mathrm{~h}$ \\
\hline $1 / 7 / 2003$ & 13,10 & 20,80 & 10,70 & $1 / 1 / 2003$ & 15,50 & 27,00 & 24,90 \\
\hline $2 / 7 / 2003$ & 11,00 & 18,10 & 10,70 & $2 / 1 / 2003$ & 27,50 & 20,30 & 20,00 \\
\hline $3 / 7 / 2003$ & 9,20 & 13,60 & 11,50 & $3 / 1 / 2003$ & 21,70 & 26,20 & 24,10 \\
\hline $4 / 7 / 2003$ & 11,00 & 21,60 & 10,90 & $4 / 1 / 2003$ & 21,40 & 24,70 & 24,40 \\
\hline $5 / 7 / 2003$ & 17,90 & 23,60 & 12,40 & $5 / 1 / 2003$ & 22,60 & 22,30 & 23,20 \\
\hline $6 / 7 / 2003$ & 8,10 & 23,40 & 15,60 & $6 / 1 / 2003$ & 21,20 & 22,40 & 19,10 \\
\hline $7 / 7 / 2003$ & 18,00 & 16,40 & 14,40 & $7 / 1 / 2003$ & 19,50 & 23,10 & 17,50 \\
\hline $8 / 7 / 2003$ & 20,10 & 16,50 & 14,80 & $8 / 1 / 2003$ & 23,00 & 21,50 & 19,80 \\
\hline 9/7/2003 & 20,90 & 24,80 & 13,20 & $9 / 1 / 2003$ & 24,40 & 30,20 & 20,30 \\
\hline $10 / 7 / 2003$ & 13,50 & 15,50 & 15,60 & $10 / 1 / 2003$ & 27,80 & 25,90 & 22,30 \\
\hline $11 / 7 / 2003$ & 15,90 & 12,80 & 10,90 & $11 / 1 / 2003$ & 24,40 & 25,40 & 19,70 \\
\hline $12 / 7 / 2003$ & 7,80 & 8,60 & 8,40 & $12 / 1 / 2003$ & 17,50 & 19,00 & 17,40 \\
\hline $13 / 7 / 2003$ & 10,70 & 12,50 & 11,30 & $13 / 1 / 2003$ & 16,00 & 16,40 & 16,40 \\
\hline $14 / 7 / 2003$ & 14,10 & 14,40 & 10,10 & $14 / 1 / 2003$ & 17,40 & 10,00 & 6,00 \\
\hline $15 / 7 / 2003$ & 10,40 & 14,80 & 11,90 & $15 / 1 / 2003$ & 20,90 & 20,10 & 18,20 \\
\hline $16 / 7 / 2003$ & 13,60 & 19,20 & 13,60 & $16 / 1 / 2003$ & 21,70 & 19,50 & 19,20 \\
\hline $17 / 7 / 2003$ & 10,30 & 13,80 & 13,10 & $17 / 1 / 2003$ & 23,60 & 21,70 & 19,10 \\
\hline $18 / 7 / 2003$ & 10,00 & 20,50 & 13,00 & $18 / 1 / 2003$ & 22,00 & 22,50 & 21,30 \\
\hline $19 / 7 / 2003$ & 10,60 & 22,60 & 11,70 & $19 / 1 / 2003$ & 16,70 & 19,70 & 19,10 \\
\hline $20 / 7 / 2003$ & 4,70 & 20,60 & 12,30 & $20 / 1 / 2003$ & 23,20 & 24,40 & 20,80 \\
\hline $21 / 7 / 2003$ & 25,10 & 25,70 & 11,90 & $21 / 1 / 2003$ & 24,30 & 18,50 & 17,00 \\
\hline $22 / 7 / 2003$ & 11,60 & 23,60 & 13,20 & $22 / 1 / 2003$ & 23,00 & 21,90 & 21,20 \\
\hline $23 / 7 / 2003$ & 11,60 & 22,90 & 11,70 & $23 / 1 / 2003$ & 23,00 & 24,50 & 23,60 \\
\hline $24 / 7 / 2003$ & 13,60 & 22,90 & 12,10 & $24 / 1 / 2003$ & 22,60 & 21,80 & 20,30 \\
\hline $25 / 7 / 2003$ & 21,70 & 22,40 & 13,60 & $25 / 1 / 2003$ & 17,80 & 17,80 & 17,10 \\
\hline $26 / 7 / 2003$ & 11,30 & 15,60 & 13,20 & $26 / 1 / 2003$ & 20,40 & 18,80 & 18,50 \\
\hline $27 / 7 / 2003$ & 13,40 & 14,90 & 14,30 & $27 / 1 / 2003$ & 20,40 & 21,30 & 19,10 \\
\hline $28 / 7 / 2003$ & 14,40 & 15,10 & 14,20 & $28 / 1 / 2003$ & 20,30 & 23,10 & 20,00 \\
\hline $29 / 7 / 2003$ & 13,40 & 16,60 & 14,00 & $29 / 1 / 2003$ & 19,40 & 18,10 & 18,20 \\
\hline $30 / 7 / 2003$ & 16,10 & 16,30 & 16,00 & $30 / 1 / 2003$ & 20,50 & 20,60 & 18,90 \\
\hline $31 / 7 / 2003$ & 16,10 & 15,00 & 14,30 & $31 / 1 / 2003$ & 18,50 & 23,30 & 21,40 \\
\hline Médias & 13,52 & 18,23 & 12,73 & Médias & 21,23 & 21,68 & 19,62 \\
\hline
\end{tabular}


Anexo E. Temperaturas tomadas em três diferentes horários ao longo do dia nos meses típicos de inverno e verão. Dados primários da Estação Meteorológica localizada no NC/I

\begin{tabular}{|c|c|c|c|c|c|c|c|}
\hline Dia/Mês/Ano & 09h & $15 \mathrm{~h}$ & $18 \mathrm{~h}$ & Dia/Mês/Ano & 09h & $15 \mathrm{~h}$ & $18 \mathrm{~h}$ \\
\hline $1 / 6 / 2003$ & 15,10 & 21,20 & 12,80 & $1 / 2 / 2003$ & 25,40 & 25,20 & 22,40 \\
\hline $2 / 6 / 2003$ & 22,90 & 24,00 & 9,50 & $2 / 2 / 2003$ & 24,30 & 25,50 & 21,40 \\
\hline $3 / 6 / 2003$ & 10,20 & 20,40 & 15,40 & $3 / 2 / 2003$ & 25,00 & 25,20 & 23,60 \\
\hline $4 / 6 / 2003$ & 18,00 & 16,90 & 16,50 & $4 / 2 / 2003$ & 25,30 & 24,10 & 21,90 \\
\hline $5 / 6 / 2003$ & 15,50 & 19,20 & 15,70 & $5 / 2 / 2003$ & 25,30 & 25,10 & 17,30 \\
\hline $6 / 6 / 2003$ & 20,20 & 25,80 & 17,50 & $6 / 2 / 2003$ & 25,30 & 24,70 & 19,10 \\
\hline $7 / 6 / 2003$ & 22,50 & 21,80 & 17,00 & $7 / 2 / 2003$ & 25,50 & 27,10 & 23,70 \\
\hline $8 / 6 / 2003$ & 19,40 & 17,10 & 16,50 & $8 / 2 / 2003$ & 26,80 & 27,10 & 26,90 \\
\hline $9 / 6 / 2003$ & 16,30 & 17,90 & 16,90 & $9 / 2 / 2003$ & 22,70 & 27,80 & 25,30 \\
\hline $10 / 6 / 2003$ & 18,70 & 20,00 & 19,60 & $10 / 2 / 2003$ & 26,20 & 26,10 & 26,40 \\
\hline $11 / 6 / 2003$ & 19,70 & 24,40 & 18,30 & $11 / 2 / 2003$ & 25,40 & 27,90 & 26,10 \\
\hline $12 / 6 / 2003$ & - & 20,20 & 13,80 & $12 / 2 / 2003$ & 26,30 & 28,20 & 23,50 \\
\hline $13 / 6 / 2003$ & 14,90 & 23,60 & 14,30 & $13 / 2 / 2003$ & 25,00 & 25,30 & 22,30 \\
\hline $14 / 6 / 2003$ & 8,50 & 18,80 & 16,70 & $14 / 2 / 2003$ & 24,60 & 20,60 & 21,00 \\
\hline $15 / 6 / 2003$ & 12,30 & 19,90 & 15,70 & $15 / 2 / 2003$ & 20,00 & 23,70 & 19,10 \\
\hline $16 / 6 / 2003$ & 16,50 & 18,80 & 6,80 & $16 / 2 / 2003$ & 20,30 & 26,20 & 22,10 \\
\hline $17 / 6 / 2003$ & 12,20 & 18,50 & 11,20 & $17 / 2 / 2003$ & 22,70 & 19,00 & 19,30 \\
\hline $18 / 6 / 2003$ & 11,50 & 16,50 & 15,80 & $18 / 2 / 2003$ & 23,20 & 25,50 & 21,10 \\
\hline $19 / 6 / 2003$ & 17,70 & 22,90 & 16,20 & $19 / 2 / 2003$ & 23,20 & 20,80 & 18,60 \\
\hline $20 / 6 / 2003$ & 16,40 & 14,50 & 14,30 & $20 / 2 / 2003$ & 24,30 & 24,80 & 16,40 \\
\hline $21 / 6 / 2003$ & 15,50 & 22,20 & 13,30 & $21 / 2 / 2003$ & 25,40 & 22,40 & 21,60 \\
\hline $22 / 6 / 2003$ & 9,30 & 17,50 & 14,90 & $22 / 2 / 2003$ & 23,70 & 22,20 & 20,60 \\
\hline $23 / 6 / 2003$ & 6,70 & 18,80 & 5,80 & $23 / 2 / 2003$ & 22,80 & 23,70 & 22,10 \\
\hline $24 / 6 / 2003$ & 4,60 & 17,10 & 6,40 & $24 / 2 / 2003$ & 23,60 & 23,00 & 21,40 \\
\hline $25 / 6 / 2003$ & 9,60 & 15,30 & 11,20 & $25 / 2 / 2003$ & 24,60 & 23,70 & 21,90 \\
\hline $26 / 6 / 2003$ & 12,80 & 10,60 & 11,20 & $26 / 2 / 2003$ & 26,10 & 25,20 & 15,40 \\
\hline $27 / 6 / 2003$ & 12,80 & 10,60 & 12,30 & $27 / 2 / 2003$ & 24,50 & 24,60 & 13,40 \\
\hline $28 / 6 / 2003$ & 11,00 & 15,10 & 10,50 & $28 / 2 / 2003$ & 22,70 & 26,00 & 20,10 \\
\hline $29 / 6 / 2003$ & 12,20 & 14,00 & 11,00 & & & & \\
\hline $30 / 6 / 2003$ & 12,00 & 15,30 & 11,20 & & & & \\
\hline Médias & 14,31 & 18,63 & 13,61 & Médias & 24,29 & 24,67 & 21,21 \\
\hline
\end{tabular}


Anexo F. Valores de disponibilidade de frutos $\left(\mathrm{kg} / \mathrm{km}^{2}\right)$ no chão da mata para cada uma estações amostradas nas transecções utilizadas. Valores gerais e para as espécies com maior porcentagem de peso seco encontradas. Palmito (E. edulis), canela (C. moschata) e indaiá (A. dubia)

\begin{tabular}{|c|c|c|c|c|c|c|c|c|c|c|}
\hline & & & & Geral & & Palmito & & anela & & ndaía \\
\hline Transecções & $\begin{array}{c}\mathrm{N}^{\mathbf{0}} \\
\text { Plots } \\
\end{array}$ & $\begin{array}{l}\text { Área }\left(\mathrm{m}^{2}\right) \\
\text { Amostrada }\end{array}$ & $\begin{array}{c}\text { Verão } \\
\left(\mathbf{k g} / \mathbf{K m}^{2}\right) \\
\end{array}$ & $\begin{array}{l}\text { Inverno } \\
\left(\mathbf{k g} / \mathbf{K m}^{2}\right) \\
\end{array}$ & $\begin{array}{c}\text { Verão } \\
\left(\mathrm{kg} / \mathbf{K m}^{2}\right)\end{array}$ & $\begin{array}{r}\text { Inverno } \\
\left(\mathrm{kg} / \mathrm{Km}^{2}\right) \\
\end{array}$ & $\begin{array}{c}\text { Verão } \\
\left(\mathrm{kg} / \mathbf{K m}^{2}\right) \\
\end{array}$ & $\begin{array}{l}\text { Inverno } \\
\left(\mathbf{k g} / \mathbf{K m}^{2}\right) \\
\end{array}$ & $\begin{array}{c}\text { Verão } \\
\left(\mathbf{k g} / \mathbf{K m}^{2}\right) \\
\end{array}$ & $\begin{array}{r}\text { Inverno } \\
\left(\mathrm{kg} / \mathrm{Km}^{2}\right) \\
\end{array}$ \\
\hline Cacho & 11 & 220 & 64,09 & 0,00 & 26,36 & 0,00 & 0,00 & 0,00 & 0,00 & 0,00 \\
\hline RiBoA & 11 & 210 & 869,05 & 349,52 & 28,57 & 0,00 & 2,86 & 1,00 & 0,00 & 0,00 \\
\hline RiBoB & 36 & 710 & 588,17 & $2.293,80$ & 100,56 & 90,14 & 291,27 & $1.465,90$ & 0,00 & 0,00 \\
\hline GrMo & 85 & 1.690 & 799,94 & 578,88 & 303,02 & 38,11 & 73,43 & 288,70 & 0,00 & 0,00 \\
\hline Para & 15 & 300 & 17,00 & 0,00 & 0,00 & 0,00 & 0,00 & 0,00 & 0,00 & 0,00 \\
\hline $\mathrm{PaBaA}$ & 25 & 490 & $9.949,59$ & 44,69 & $8.197,55$ & 13,27 & 145,51 & 15,40 & 0,00 & 0,00 \\
\hline $\mathrm{PaBaB}$ & 29 & 580 & 17,59 & 48,79 & 17,59 & 48,79 & 0,00 & 0,00 & 0,00 & 0,00 \\
\hline PoPi & 25 & 490 & 9,18 & 0,00 & 7,35 & 0,00 & 0,00 & 0,00 & 0,00 & 0,00 \\
\hline Itam & 28 & 560 & $1.188,93$ & 32,32 & 846,07 & 32,32 & 115,71 & 0,00 & 0,00 & 0,00 \\
\hline CorcA & 36 & 720 & $2.012,92$ & $1.868,33$ & 930,14 & $1.535,83$ & 0,00 & 18,30 & $1.011,81$ & 63,61 \\
\hline CorcB & 13 & 250 & $2.908,00$ & $2.946,80$ & $2.871,60$ & $2.518,80$ & 0,00 & 0,00 & 0,00 & 81,20 \\
\hline $\mathrm{CaFa}$ & 50 & 1.000 & $1.496,20$ & $1.797,80$ & 64,50 & $1.236,00$ & 29,10 & 12,90 & 179,80 & 151,60 \\
\hline Cuba & 13 & 250 & $3.219,60$ & $5.090,00$ & 114,40 & $1.790,80$ & 0,00 & 0,00 & $1.673,20$ & $1.846,00$ \\
\hline Camb & 40 & 800 & 702,50 & 457,13 & 0,50 & 11,13 & 0,25 & 2,10 & 50,75 & 91,75 \\
\hline
\end{tabular}


Anexo G. Parâmetros de caracterização da vegetação obtidos a partir da análise dos dados obtidos na técnica de ponto quadrante e analisados no programa FITOPAC 2.0, e também das densidades de palmitos e palmeiras e disponibilidade de frutos e sementes no chão da mata calculados para cada uma das transeç̧ões utilizadas para o censo da fauna

\begin{tabular}{|c|c|c|c|c|c|c|c|c|c|c|c|c|c|}
\hline $\begin{array}{l}\text { Transecçõ } \\
\text { es }\end{array}$ & $\begin{array}{l}\mathrm{N}^{0} . \\
\text { Pts. }\end{array}$ & $\begin{array}{l}\mathrm{N}^{0} \text {. } \\
\text { Ind. }\end{array}$ & $\begin{array}{c}\text { D.Abs. } \\
\text { (ind./km²) }\end{array}$ & $\begin{array}{c}\text { Vol. } \\
\left(\mathrm{m}^{3} / \mathbf{k m}^{2}\right)\end{array}$ & $\begin{array}{c}\text { Cob.D. } \\
(\%)\end{array}$ & $\begin{array}{c}\text { DPA } \\
\text { (ind.//km²) }\end{array}$ & $\begin{array}{c}\text { DPJ } \\
\text { (ind.//km²) }\end{array}$ & $\begin{array}{c}\text { DPP } \\
\text { (ind.//km²) }\end{array}$ & $\begin{array}{c}\mathrm{DEA} \\
\text { (ind./km²) }\end{array}$ & $\begin{array}{c}\mathrm{DEJ} \\
\text { (ind.//km²) }\end{array}$ & $\begin{array}{c}\mathrm{DEP} \\
\text { (ind.//km²) }\end{array}$ & $\begin{array}{c}\text { PROD.F* } \\
\left(\mathrm{kg} / \mathbf{k m}^{2}\right)\end{array}$ & $\underset{\left(\mathrm{kg} / \mathbf{k m}^{2}\right)}{\text { PROD.P* }}$ \\
\hline NSVNCA & 16 & 64 & $1.990,00$ & $38.662,60$ & 92,43 & $3.980,89$ & $13.535,03$ & $13.535,03$ & 0,00 & $11.146,50$ & $27.866,24$ & 14,29 & 4,29 \\
\hline Cacho & 11 & 44 & $1.370,00$ & $12.223,30$ & 90,36 & 0,00 & $1.158,08$ & $1.158,08$ & $1.158,08$ & $34.742,33$ & $84.539,66$ & 32,05 & 13,18 \\
\hline RiBoA & 11 & 44 & $1.370,00$ & $45.554,00$ & 95,13 & $2.316,16$ & $41.690,79$ & $44.006,95$ & $2.316,16$ & $23.161,55$ & $62.536,19$ & 609,29 & 14,29 \\
\hline $\mathrm{RiBoB}$ & 35 & 140 & $4.350,00$ & $85.256,30$ & 94,56 & $8.007,28$ & $31.301,18$ & $50.955,41$ & $1.819,84$ & $55.323,02$ & $100.818,93$ & $1.440,99$ & 95,35 \\
\hline $\mathrm{RiBoC}$ & 13 & 52 & $1.620,00$ & $31.797,30$ & 96,80 & $4.899,56$ & $16.658,50$ & $7.839,29$ & $2.939,74$ & $54.875,06$ & $166.585,01$ & 140,71 & 52,50 \\
\hline GroMo & 80 & 320 & $9.940,00$ & $304.558,00$ & 95,35 & $20.700,64$ & $53.343,95$ & $70.063,69$ & $4.777,07$ & $43.152,87$ & $149.363,06$ & 689,41 & 170,56 \\
\hline Parai & 13 & 52 & $1.620,00$ & $35.995,60$ & 87,28 & 0,00 & $1.959,82$ & 0,00 & 0,00 & 979,91 & 0,00 & 8,50 & 0,00 \\
\hline $\mathrm{PaBaA}$ & 24 & 96 & $2.980,00$ & $86.400,50$ & 93,96 & $6.900,21$ & $18.577,49$ & $109.341,83$ & $14.331,21$ & $58.386,41$ & $306.263,27$ & $4.997,14$ & $4.105,41$ \\
\hline $\mathrm{PaBaB}$ & 28 & 112 & $3.480,00$ & $56.703,30$ & 79,65 & 0,00 & 454,96 & $3.184,71$ & 909,92 & $38.216,56$ & $99.636,03$ & 33,19 & 33,19 \\
\hline PoPit & 22 & 88 & $2.730,00$ & $69.142,40$ & 91,42 & 0,00 & $6.369,43$ & $66.589,46$ & $3.474,23$ & $20.266,36$ & $33.584,25$ & 4,59 & 3,67 \\
\hline Itama & 28 & 112 & $3.480,00$ & $128.702,40$ & 95,53 & $7.279,34$ & $20.473,16$ & $74.613,28$ & $13.648,77$ & $82.347,59$ & $460.418,56$ & 610,63 & 439,20 \\
\hline Pirap & 48 & 192 & $5.960,00$ & $126.514,50$ & 92,11 & $1.857,75$ & $20.966,03$ & $24.150,74$ & $6.104,03$ & $51.220,81$ & $219.214,44$ & 602,22 & 383,73 \\
\hline CorcA & 36 & 144 & $4.470,00$ & $69.333,50$ & 83,94 & $1.061,57$ & $1.061,57$ & $2.830,86$ & $15.215,85$ & $77.494,69$ & $589.525,83$ & $1.940,63$ & $1.232,99$ \\
\hline CorcB & 12 & 48 & $1.490,00$ & $68.872,10$ & 84,96 & $1.061,57$ & $2.123,14$ & $3.184,71$ & $45.647,56$ & $92.356,69$ & $2.393 .842,89$ & $2.927,40$ & $2.695,20$ \\
\hline CaFar & 50 & 200 & $6.210,00$ & $296.699,10$ & 86,57 & $2.802,55$ & $49.681,53$ & $55.796,18$ & $9.681,53$ & $98.598,73$ & $117.707,01$ & $1.647,00$ & 650,25 \\
\hline Cubat & 32 & 128 & $3.980,00$ & $84.434,80$ & 84,48 & $5.879,47$ & $112.689,86$ & $48.015,68$ & $11.758,94$ & $51.935,33$ & $11.758,94$ & $4.154,80$ & 952,60 \\
\hline Cambu & 35 & 140 & $4.350,00$ & $80.253,20$ & 82,31 & $2.183,80$ & $71.701,55$ & $82.620,56$ & 363,97 & $34.576,89$ & $13.102,82$ & 579,81 & 5,81 \\
\hline
\end{tabular}

* PROD.F inclui os valores de PROD.P, sendo que esta espécie foi também avaliada separadamente devido a sua reconhecida importância como espéciechave para frugívoros em geral. 
Anexo H. Uso histórico determinado para cada uma das transecções utilizadas. Categorias determinadas a partir da análise dos Planos de Gestão disponíveis para algumas das áreas (SMA, 1998a; SMA, 1998b) e de informações obtidas durante o levantamento de campo ${ }^{1}$

\begin{tabular}{lc}
\hline Transecções & Uso Histórico \\
\hline NSV-NC A & Uso intenso \\
Cacho & Corte seletivo \\
RiBoA & Corte seletivo \\
RiBoB & Corte seletivo \\
RiBoC & Corte seletivo \\
GroMo & Preservada \\
Parai & Uso intenso \\
PaBaA & Corte seletivo \\
PaBaB & Pastagem \\
PoPit & Pastagem \\
Itama & Corte seletivo \\
Pirap & Corte seletivo \\
CorcA & Uso intenso \\
CorcB & Corte seletivo \\
CaFar & Corte seletivo \\
Cubat & Corte seletivo \\
Cambu & Uso intenso \\
\hline
\end{tabular}

${ }^{1}$ Entrevistas não padronizadas com administradores, funcionários e moradores das unidades amostradas, incluindo ex-caçadores locais e moradores do entorno das unidades. Comunicação pessoal, 2003. 
Anexo I. Matriz secundária de abundância (indiv./10 km) das espécies ou grupos de fauna utilizadas para as análises de correspondência canônica (CCA) por meio do programa PCORD 4.0

\begin{tabular}{|c|c|c|c|c|c|c|c|c|}
\hline Transecções & $\begin{array}{c}\text { Abundância } \\
\text { C. } \text { aurita }\end{array}$ & $\begin{array}{c}\text { Abundância } \\
\text { T. pecari }\end{array}$ & $\begin{array}{l}\text { Abundância } \\
\text { S. aestuans }\end{array}$ & $\begin{array}{c}\text { Abundância } \\
\text { Mamíferos Geral* }\end{array}$ & $\begin{array}{l}\text { Abundância } \\
\text { Penelope sp. }\end{array}$ & $\begin{array}{l}\text { Abundância } \\
\text { O. capueira. }\end{array}$ & $\begin{array}{l}\text { Abundância } \\
T \text {. solitarius }\end{array}$ & $\begin{array}{l}\text { Abundância } \\
\text { Aves Geral** }\end{array}$ \\
\hline NSV-NC A & 2,86 & 0,57 & 0,00 & 22,37 & 2,55 & 0,00 & 0,00 & 3,87 \\
\hline Cacho & 0,00 & 0,00 & 0,00 & 0,00 & 1,01 & 0,00 & 0,00 & 1,54 \\
\hline RiBoA & 0,00 & 0,79 & 0,79 & 3,97 & 0,79 & 2,54 & 0,79 & 4,54 \\
\hline RiBoB & 0,00 & 0,00 & 0,00 & 2,99 & 0,95 & 0,76 & 0,24 & 2,45 \\
\hline RiBoC & 0,00 & 0,00 & 0,00 & 8,16 & 1,95 & 4,16 & 0,00 & 7,12 \\
\hline GrMo & 0,00 & 0,83 & 0,12 & 17,53 & 0,36 & 1,14 & 0,59 & 2,39 \\
\hline Para & 1,11 & 0,00 & 0,00 & 4,52 & 0,00 & 0,00 & 0,00 & 0,00 \\
\hline $\mathrm{PaBaA}$ & 0,00 & 0,00 & 0,88 & 0,88 & 0,00 & 11,33 & 0,00 & 11,33 \\
\hline $\mathrm{PaBaB}$ & 0,00 & 0,00 & 0,85 & 0,85 & 0,85 & 0,00 & 0,00 & 1,29 \\
\hline PoPi & 0,51 & 0,00 & 0,00 & 2,59 & 0,00 & 3,27 & 0,00 & 3,27 \\
\hline Itam & 0,89 & 0,89 & 2,23 & 16,58 & 1,79 & 1,43 & 0,89 & 5,04 \\
\hline Pira & 0,31 & 0,00 & 1,57 & 2,85 & 1,57 & 3,02 & 0,00 & 5,41 \\
\hline Garc & 0,00 & 0,00 & 0,00 & 0,00 & 1,11 & 0,00 & 1,11 & 2,80 \\
\hline CorcB & 0,00 & 0,00 & 8,86 & 10,13 & 2,53 & 0,00 & 0,00 & 3,85 \\
\hline $\mathrm{CaFa}$ & 0,00 & 0,09 & 0,26 & 2,55 & 0,95 & 0,83 & 0,26 & 2,52 \\
\hline Cuba & 0,00 & 0,00 & 0,00 & 0,47 & 1,89 & 3,02 & 0,47 & 6,36 \\
\hline Camb & 0,00 & 0,00 & 0,00 & 0,00 & 0,31 & 0,50 & 0,31 & 1,28 \\
\hline
\end{tabular}

* Abundância de todas as espécies de mamíferos cinegéticos visualizadas durante o censo.

** Abundância de todas as espécies de aves cinegéticas visualizadas durante o censo. 
Anexo J. Matriz principal de variáveis ambientais utilizadas para as análises de correspondência canônica (CCA) por meio do programa PCORD 4.0

\begin{tabular}{|c|c|c|c|c|c|c|c|}
\hline Transecções & $\begin{array}{c}\text { DABS } \\
\text { (ind.//km²) }\end{array}$ & $\begin{array}{c}\log \\
\text { COBD }(\%)\end{array}$ & $\begin{array}{c}\text { DPA } \\
\text { (ind./km²) }\end{array}$ & $\begin{array}{c}\text { DISPP } \\
\left(\mathrm{kg} / \mathrm{km}^{2}\right)\end{array}$ & $\begin{array}{r}\text { DISPO } \\
\left(\mathbf{k g} / \mathrm{km}^{2}\right)\end{array}$ & $\begin{array}{c}\text { CAÇA } \\
\text { (eventos/10km) }\end{array}$ & $\begin{array}{c}\text { TUR } \\
\text { (turistas/ano) }\end{array}$ \\
\hline NSV-NC A & $1.990,00$ & 1,97 & $3.980,89$ & 4,29 & 10,00 & 0,00 & $1.200,00$ \\
\hline Cacho & $1.370,00$ & 1,96 & 0,00 & 13,18 & 18,86 & 1,01 & $1.200,00$ \\
\hline RiBoA & $1.370,00$ & 1,98 & $2.316,16$ & 14,29 & 595,00 & 0,00 & $3.600,00$ \\
\hline RiBoB & $4.350,00$ & 1,98 & $8.007,28$ & 95,35 & $1.345,63$ & 0,00 & $3.600,00$ \\
\hline RiBoC & $1.620,00$ & 1,99 & $4.899,56$ & 52,50 & 88,21 & 0,00 & $3.600,00$ \\
\hline GroMo & $9.940,00$ & 1,98 & $20.700,64$ & 170,56 & 518,85 & 0,59 & 0,00 \\
\hline Parai & $1.620,00$ & 1,94 & 0,00 & 0,00 & 8,50 & 0,00 & $4.200,00$ \\
\hline $\mathrm{PaBaA}$ & $2.980,00$ & 1,97 & $6.900,21$ & $4.105,41$ & 891,73 & 2,65 & 0,00 \\
\hline $\mathrm{PaBaB}$ & $3.480,00$ & 1,90 & 0,00 & 33,19 & 0,00 & 0,00 & 0,00 \\
\hline PoPit & $2.730,00$ & 1,96 & 0,00 & 3,67 & 0,92 & 0,00 & 750,00 \\
\hline Itama & $3.480,00$ & 1,98 & $7.279,34$ & 439,20 & 171,43 & 1,34 & 0,00 \\
\hline Pirap & $5.960,00$ & 1,96 & $1.857,75$ & 383,73 & 218,49 & 0,00 & $3.500,00$ \\
\hline CorcA & $4.470,00$ & 1,92 & $1.061,57$ & $1.232,99$ & 707,64 & 0,39 & 380,00 \\
\hline CorcB & $1.490,00$ & 1,93 & $1.061,57$ & $2.695,20$ & 232,20 & 5,06 & 380,00 \\
\hline CaFar & $6.210,00$ & 1,94 & $2.802,55$ & 650,25 & 996,75 & 1,38 & 800,00 \\
\hline Cubat & $3.980,00$ & 1,93 & $5.879,47$ & 952,60 & $3.202,20$ & 2,82 & 0,00 \\
\hline Cambu & $4.350,00$ & 1,92 & $2.183,80$ & 5,81 & 574,00 & 1,55 & $1.200,00$ \\
\hline
\end{tabular}


Anexo K. Áreas de estudo utilizadas para comparações de densidade. Siglas utilizadas, tipo de floresta, nomes completos das áreas de estudo e demais informações geográficas. UF = unidade da federação, $\mathrm{X}=$ latitude e $\mathrm{Y}=$ longitude (coordenadas em graus)

\begin{tabular}{|c|c|c|c|c|c|}
\hline $\begin{array}{l}\text { Áreas de Estudo } \\
\text { (Siglas utilizadas) }\end{array}$ & $\begin{array}{l}\text { Tipo de } \\
\text { Floresta } \\
\end{array}$ & Nome Completo da Área de Estudo & UF & \multicolumn{2}{|c|}{ Coord enadas } \\
\hline PESM* $^{*}$ & Ombrófila & Parque Estadual da Serra do Mar & SP & $23^{\circ} 17^{\prime} \mathrm{S}$ & $43^{\circ} 03^{\prime} \mathrm{W}$ \\
\hline MDSP & Semidecídua & Parque Estadual Morro do Diabo & SP & $22^{\circ} 27^{\prime} \mathrm{S}$ & $52^{\circ} 10^{\prime} \mathrm{W}$ \\
\hline CES & Semidecídua & Estação Ecológica Caetetus & SP & $22^{\circ} 30^{\prime} \mathrm{S}$ & $49^{\circ} 45^{\prime} \mathrm{W}$ \\
\hline FM & Semidecídua & Fazenda Mosquito & SP & $22^{\circ} 44^{\prime} \mathrm{S}$ & $51^{\circ} 00^{\prime} \mathrm{W}$ \\
\hline FT & Semidecídua & Fazenda Tucano & SP & $22^{\circ} 30^{\prime} \mathrm{S}$ & $52^{\circ} 30^{\prime} \mathrm{W}$ \\
\hline FRC & Semidecídua & Fazenda Rio Claro & SP & $22^{\circ} 46^{\prime} \mathrm{S}$ & $48^{\circ} 55^{\prime} \mathrm{W}$ \\
\hline LFR & Tabuleiro & Reserva Florestal de Linhares & ES & $19^{\circ} 12^{\prime} \mathrm{S}$ & $40^{\circ} 02^{\prime} \mathrm{W}$ \\
\hline SBR & Tabuleiro & Reserva Biológica Sooretama & ES & $18^{\circ} 59^{\prime} \mathrm{S}$ & $40^{\circ} 05^{\prime} \mathrm{W}$ \\
\hline CVBR & Tabuleiro & Reserva Biológica Córrego do Veado & ES & $18^{\circ} 21^{\prime} \mathrm{S}$ & $40^{\circ} 09^{\prime} \mathrm{W}$ \\
\hline CGBR & Tabuleiro & Reserva Biológica Córrego Grande & ES & $18^{\circ} 15^{\prime} \mathrm{S}$ & $39^{\circ} 47^{\prime} \mathrm{W}$ \\
\hline M7 & Tabuleiro & Fragmento & ES & $19^{\circ} 48^{\prime} \mathrm{S}$ & $40^{\circ} 07^{\prime} \mathrm{W}$ \\
\hline Putiri & Tabuleiro & Fragmento & ES & $19^{\circ} 48^{\prime} \mathrm{S}$ & $40^{\circ} 07^{\prime} \mathrm{W}$ \\
\hline RBAR & Tabuleiro & Reserva Biológica Augusto Ruschi & ES & $19^{\circ} 45^{\prime} \mathrm{S}$ & $40^{\circ} 27^{\prime} \mathrm{W}$ \\
\hline RBSL & Tabuleiro & Reserva Biológica São Lourenço & ES & $19^{\circ} 56^{\prime} \mathrm{S}$ & $40^{\circ} 36^{\prime} \mathrm{W}$ \\
\hline RBSta. Lúcia & Tabuleiro & Reserva Biológica Santa Lucia & ES & $19^{\circ} 58^{\prime} \mathrm{S}$ & $40^{\circ} 32^{\prime} \mathrm{W}$ \\
\hline $\mathrm{EBC}$ & Semidecídua & Estação Biológica Caratinga & MG & $19^{\circ} 50^{\prime} \mathrm{S}$ & $41^{\circ} 50^{\prime} \mathrm{W}$ \\
\hline SB & Semidecídua & Serra do Brigadeiro & MG & $42^{\circ} 22^{\prime} \mathrm{S}$ & $20^{\circ} 34^{\prime} \mathrm{W}$ \\
\hline MSJ & Semidecídua & Mata São José & SP & $22^{\circ} 22^{\prime} \mathrm{S}$ & $47^{\circ} 28^{\prime} \mathrm{W}$ \\
\hline Água Sumida & Semidecídua & Fragmento & SP & $22^{\circ} 41^{\prime} \mathrm{S}$ & $48^{\circ} 06^{\prime} \mathrm{W}$ \\
\hline Sara & Semidecídua & Fragmento & SP & $22^{\circ} 41^{\prime} \mathrm{S}$ & $48^{\circ} 06^{\prime} \mathrm{W}$ \\
\hline Viraeiro & Semidecídua & Fragmento & SP & $22^{\circ} 41^{\prime} \mathrm{S}$ & $48^{\circ} 06^{\prime} \mathrm{W}$ \\
\hline Monal & Semidecídua & Fragmento & SP & $22^{\circ} 41^{\prime} \mathrm{S}$ & $48^{\circ} 06^{\prime} \mathrm{W}$ \\
\hline PEI & Ombrófila & Parque Estadual Intervales & SP & $24^{\circ} 12^{\prime} \mathrm{S}$ & $48^{\circ} 03^{\prime} \mathrm{W}$ \\
\hline SPP & Ombrófila & Serra de Paranapiacaba & SP & $24^{\circ} 20^{\prime} \mathrm{S}$ & $48^{\circ} 15^{\prime} \mathrm{W}$ \\
\hline PEIC & Ombrófila & Parque Estadual da Ilha do Cardoso & $\mathrm{SP}$ & $25^{\circ} 05^{\prime} \mathrm{S}$ & $47^{\circ} 53^{\prime} \mathrm{W}$ \\
\hline
\end{tabular}

* Corresponde a área amostrada no presente estudo; Núcleo Santa Virgínia/Natividade da Serra, Núcleo Cunha/Indaiá e Núcleo Picinguaba. 
Anexo L. Comparação de distâncias perpendiculares médias obtidas para algumas espécies em áreas de estudo onde foi utilizada a técnica de transecções lineares para a determinação das densidades. Referência (Ref.) 1 = Presente estudo, 2 = Chiarello, 1997, 3 = Guix et al., 1997, 4 = Sanchez-Alonzo et al., 2002, 5 = Galetti et al., em preparação

\begin{tabular}{|c|c|c|c|c|c|c|c|}
\hline Área de Estudo & Bioma/Tipo Florestal* & C. aurita** & C. apella & S. aestuans & Mamíferos & Penelope sp *** & Ref. \\
\hline PESM & MA - Ombrófila & 5,67 & 9,54 & 4,15 & 4,65 & 4,94 & 1 \\
\hline LFR & MA - Tabuleiro & 9,00 & 17,20 & 8,00 & 10,88 & & 2 \\
\hline SBR & MA - Tabuleiro & 11,60 & 21,60 & 8,18 & 15,52 & & 2 \\
\hline CVBR & MA - Tabuleiro & 4,20 & 18,10 & 6,70 & 8,34 & & 2 \\
\hline CGBR & MA - Tabuleiro & & 10,40 & 8,70 & 16,98 & & 2 \\
\hline M7 & MA - Tabuleiro & & 17,60 & 6,60 & 13,53 & & 2 \\
\hline Putiri & MA - Tabuleiro & & 23,10 & 5,50 & 17,45 & & 2 \\
\hline PEI & MA - Ombrófila & & & & & 29,00 & 3 \\
\hline $\mathrm{PEI}<400$ & MA - Ombrófila & & & & & 17,00 & 4 \\
\hline $\mathrm{PEI}>500$ & MA - Ombrófila & & & & & 6,00 & 4 \\
\hline PPF & MA - Ombrófila & & & & & 12,00 & 4 \\
\hline FRN & Pantanal - Cordilheiras & & & & 17,15 & 23,35 & 5 \\
\hline FRN & Pantanal - Mata Ciliar & & & & 12,12 & 22,20 & 5 \\
\hline
\end{tabular}

* MA - Mata Atlântica

** Para as áreas de Chiarello (1997) a comparação foi realizada com C. geoffroyi.

*** Para as áreas de Galleti et al. (em prep.) a comparação foi realizada com Pipile pipile 
Anexo M. Lista de ocorrência das espécies para as áreas estudadas do PESM. Legenda: Dieta (modificado de Fonseca et al., 1996 \& Sick, 1997): herbívoro podador (HB), herbívoro pastador (HG), insetívoro voador (IA), nectarívoro (NE), hematófago (HE), frugívoro/onívoro (FO), frugívoro/herbívoro $(\mathrm{FH})$, frugívoro/granívoro $(\mathrm{FG})$, piscívoro (PS), carnívoro (CA), insetívoro/onívoro (IO), gomívoro/onívoro (GO) e mimercófago (MY). Peso: peso médio em gramas de um adulto (retirado de Fonseca et al. 1996 \& Sick, 1997). Status: segundo Lista de Fauna Ameaçada do Estado de São Paulo (Decreto n. 42.838 de 4 fev. de 1998), onde CP - Criticamente em perigo, EP - Em perigo, VU Vulnerável, PA - Provavelmente ameaçada e A - Ameaçada . Tipo de registro durante o presente estudo: avistado $(A)$, câmeras automáticas $(C)$, vocalização $(V)$, captura $(P)$, rastros $(R)$, fezes $(F)$, carcaças/ind. atropelados $(E)$, registrados por outros pesquisadores $(O X-$ onde $\mathrm{X}$ é a referência do estudo ou pesquisador consultado - veja ao final da tabela). Provav. indica quando uma espécie foi registrada em duas das três unidades e por isso foi considerada com ocorrência provável para a terceira área. Prov. Extinta indica quando já existiram registros confiáveis na área, mas a espécie não foi registrada nos últimos 8 anos, sendo considerada como provavelmente extinta. ? indica ausência de informações para aquela espécie

\begin{tabular}{|c|c|c|c|c|c|c|c|}
\hline MAMÍFEROS & Dieta & Status & Peso (g) & Nome Comum & NSV/NS & $\mathrm{NC} / \mathrm{I}$ & NP \\
\hline \multicolumn{8}{|l|}{ 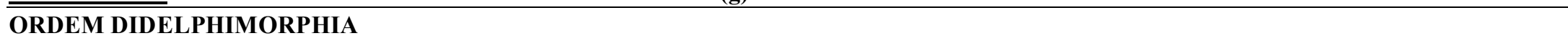 } \\
\hline Caluromys philander (Linnaeus, 1758) & FO & & 170 & Cuíca-lanosa & $?$ & $?$ & O6 \\
\hline Didelphis aurita (Wied-Neuwied, 1826) & FO & & 985 & Guambá-de-orelha-preta & $C, A, O 6$ & $A$ & A, O6 \\
\hline Gracilinanus microtarsus (Wagner, 1842) & $\mathrm{IO}$ & $\mathrm{PA}$ & 31 & Catita, Guaiquica & 01,06 & $?$ & $?$ \\
\hline Marmosa murina (Linnaeus, 1758) & $\mathrm{IO}$ & & 52 & Catita, Guaiquica & $O 1$ & $?$ & $?$ \\
\hline Marmosops incanus (Lund, 1840) & $\mathrm{IO}$ & PA & 64 & Cuíca & $01,02,06,07$ & Provav. & O6 \\
\hline Metachirus nudicaudatus (Desmarest, 1817) & $\mathrm{IO}$ & & 280 & Cuíca-de-quatro-olhos & $?$ & $?$ & O6 \\
\hline Micoureus travassosi & $?$ & & $?$ & & $?$ & $?$ & O6 \\
\hline Micoreus demerarea (Thomas, 1905) & $\mathrm{IO}$ & & 105 & Cuíca & O7 & $?$ & $?$ \\
\hline Monodelphis americana (Muller, 1776) & IO & & 29 & Cuíca-de-três-listras & O7 & Provav. & O6 \\
\hline Monodelphis domestica (Wagner, 1842) & $\mathrm{IO}$ & & 67 & Catita & O7 & & \\
\hline Monodelphis scalops (Thomas, 1888) & IO & PA & 74 & Catita & O2 & $?$ & $?$ \\
\hline
\end{tabular}


Anexo M. Lista de ocorrência das espécies para as áreas estudadas do PESM

\begin{tabular}{|c|c|c|c|c|c|c|c|}
\hline MAMÍFEROS & Dieta & Status & Peso (g) & Nome Comum & NSV/NS & $\mathrm{NC} / \mathrm{I}$ & NP \\
\hline \multicolumn{8}{|l|}{ 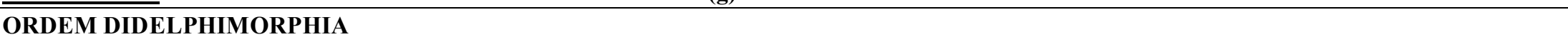 } \\
\hline Monodelphis theresa (Thomas, 1921) & $\mathrm{IO}$ & & 25 & Catita & $O 2$ & $?$ & $?$ \\
\hline Philander frenata (Olfers, 1818) & IO & & 360 & Cuíca & $?$ & $?$ & O6 \\
\hline Philander opossum (Linnaeus, 1758) & IO & & 369 & Cuíca & O7 & $?$ & $?$ \\
\hline \multicolumn{8}{|l|}{ ORDEM EDENTATA } \\
\hline Bradypus variegatus (Schinz, 1825) & $\mathrm{HB}$ & & 3900 & Preguiça comum & $A, O 1$ & Provav. & $A, O 5$ \\
\hline Dasypus novemcinctus (Linnaeus, 1758) & $\mathrm{IO}$ & & 3650 & Tatu-galinha & $E, C, R, O l$ & $A, C, R$ & $E, R, O 5$ \\
\hline Tamamdua tetradactyla (Linnaeus, 1758) & MY & PA & 5200 & Tamamduá-mirim & $?$ & $?$ & O5 \\
\hline \multicolumn{8}{|l|}{ ORDEM CHIROPTERA } \\
\hline Anoura caudifer (E. Geoffroy, 1847) & $\mathrm{NE}$ & & 10 & Morcego & O3 & $?$ & $?$ \\
\hline Anoura geoffroy (Gray, 1838) & $\mathrm{NE}$ & & 15 & Morcego & O3 & $?$ & $?$ \\
\hline Artibeus (c.f.) fimbriatus (Gray, 1838) & FO & & 54 & Morcego & O3 & $?$ & $?$ \\
\hline Carollia perpiscillata (Linnaeus, 1758) & FO & & 17 & Morcego & O3 & $?$ & $?$ \\
\hline Desmodus rotundos (E. Geoffroy, 1810) & $\mathrm{HE}$ & & 30 & Morcego-vampiro & O3 & $?$ & $?$ \\
\hline Lonchorhina aurita (Tomes, 1863) & IA & & 15 & Morcego & O3 & $?$ & $?$ \\
\hline Micronycteris sp. & IA & & $?$ & Morcego & O3 & $?$ & $?$ \\
\hline Sturnira (c.f.) lilium (E. Geoffroy, 1810) & FO & & 19 & Morcego & O3 & $?$ & $?$ \\
\hline Eptesicus sp. & IA & & $?$ & Morcego & O3 & $?$ & $?$ \\
\hline Myotis sp. & IA & & $?$ & Morcego & O3 & $?$ & $?$ \\
\hline Myotis (c.f.) nigricans (Schinz, 1821) & IA & & 5 & Morcego & O3 & $?$ & $?$ \\
\hline
\end{tabular}


Anexo M. Lista de ocorrência das espécies para as áreas estudadas do PESM

\begin{tabular}{|c|c|c|c|c|c|c|c|}
\hline MAMÍFEROS & Dieta & Status & Peso (g) & Nome Comum & NSV/NS & $\mathrm{NC} / \mathrm{I}$ & NP \\
\hline \multicolumn{8}{|l|}{ ORDEM PRIMATES } \\
\hline Callithrix aurita (É. Geoffroy, 1812) & GO & A-EP & 290 & Sagui-da-serra-escuro & $\mathbf{A}, \mathbf{V}$ & $A, V$ & $O 5^{1}$ \\
\hline Alouatta guariba (É. Geoffroy, 1812) & FH & $\mathrm{A}-\mathrm{VU}$ & 5650 & Bugio, Guariba, Barbado & $A, V$ & $A, V$ & $V$ \\
\hline Brachyteles arachnoides (É. Geoffroy, 1806) & FH & $\mathrm{A}-\mathrm{CP}$ & 13500 & Muriqui, Mono-carvoeiro & Provav. & $A$ & $A^{2}$ \\
\hline Cebus nigritus (Linnaeus, 1758) & FO & & 2500 & Macaco-prego & $A, O 1$ & $A$ & $O 5^{1}$ \\
\hline \multicolumn{8}{|l|}{ ORDEM CARNIVORA } \\
\hline Cerdocyon thous (Linnaeus, 1766) & IO & \multirow{3}{*}{$\mathrm{C}-\mathrm{CP}$} & 6500 & Cachorro-do-mato & $A, C, R$ & $R$ & $E, R$ \\
\hline Speothos venaticus (Lund, 1842) & CA & & 6000 & Cachorro-vinagre & $?$ & 5 & $?$ \\
\hline Nasua nasua (Linnaeus, 1766) & FO & & 5100 & Quati & $R, O 1$ & $A$ & $A, O 5$ \\
\hline Procyon cancrivorus (G. Cuvier, 1798) & FO & \multirow[t]{3}{*}{$\mathrm{PA}$} & 5400 & Mão-pelada, Guaxinim & $R, C$ & $R$ & $R, O 5$ \\
\hline Eira barbara (Linnaeus, 1758) & $\mathrm{CA}$ & & 4850 & Irara, Papa-mel & $R, F$ & $C$ & $R, O 5$ \\
\hline Galictis cuja (Molina, 1782) & $\mathrm{CA}$ & & 1580 & Furão & $A, O 1$ & Provav. & E, O5 \\
\hline Lontra longicaudis (Olfers, 1818) & PS & $\mathrm{A}-\mathrm{VU}$ & 5800 & Lontra & $A, F$ & $A, F$ & $R, F$ \\
\hline Herpailurus yaguaroundi (Lacép`ede, 1809) & $\mathrm{CA}$ & $\mathrm{PA}$ & 5000 & Jaguarundi & $E, R, O 1$ & $R$ & $R$ \\
\hline Leopardus pardalis (Linnaeus, 1758) & $\mathrm{CA}$ & $\mathrm{A}-\mathrm{VU}$ & 10000 & Jaguatirica & $R, F, C, O 1$ & $\mathbf{R}, \mathbf{F}, \mathbf{C}$ & $R, O 5$ \\
\hline Leopardus tigrina (Schreber, 1775) & $\mathrm{CA}$ & $\mathrm{A}-\mathrm{VU}$ & 2250 & Gato-do-mato pequeno & $R^{3}, F^{3}, C, O 1$ & $R^{3}, F^{3}, C$ & $R^{3}, F^{3}$ \\
\hline Leopardus wiedii (Schinz, 1821) & $\mathrm{CA}$ & A-EP & 3220 & Gato-maracajá & $R^{3}, F^{3}, C, O 1$ & $R^{3}, F^{3}$ & $R^{3}, F^{3}$ \\
\hline Puma concolor (Linnaeus, 1771) & $\mathrm{CA}$ & $\mathrm{A}-\mathrm{VU}$ & 74500 & Onça parda, Suçuarana & $R, F, C$ & $R, F, C$ & $R, F$ \\
\hline Panthera onca (Linnaeus, 1758) & $\mathrm{CA}$ & $\mathrm{A}-\mathrm{CP}$ & 94500 & Onça-pintada & Prov. Extinta & Prov. Extinta & Prov. Extinta \\
\hline
\end{tabular}

${ }^{1}$ Ocorrência prevista somente acima de 150-200 m de altitude segundo Auricchio (1995) e Cerqueira, Marroig \& Pinder (1998).

${ }^{2}$ Este espécie deve ocorrer somente para as áreas elevadas deste núcleo. Foi registrada em um único evento, acima dos $400 \mathrm{~m}$ de altitude (Observ. Pessoal).

${ }^{3}$ A diferenciação destas espécies de felinos unicamente por rastro e/ou morfologia de fezes não é segura (em $O 1$ a identificação foi por pêlos).

${ }^{4}$ Registros geralmente para a parte alta do núcleo, acima de 400 metros de altitude (Observação pessoal).

${ }^{5}$ Durante entrevistas não padronizadas funcionário da unidade, ex-caçador local, descreveu a visualização de um grupo de indivíduos com características comportamentais e morfológicas que coincidem com S. venaticus. Porém, devido a natureza do registro deve ser considerado com cautela. 
Anexo M. Lista de ocorrência das espécies para as áreas estudadas do PESM

\begin{tabular}{|c|c|c|c|c|c|c|c|}
\hline MAMÍFEROS & Dieta & Status & Peso (g) & Nome Comum & $\mathbf{N S V} / \mathbf{N S}$ & $\mathrm{NC} / \mathrm{I}$ & $\mathbf{N P}$ \\
\hline \multicolumn{8}{|l|}{$\overline{\overline{O R D E M ~ P E R I S S O D A C T Y L A ~}}$} \\
\hline Tapirus terrestris (Linnaeus, 1758) & $\mathrm{FH}$ & A-EP & 239000 & Anta & $R, F$ & $R, F$ & $R, F^{4}$ \\
\hline \multicolumn{8}{|l|}{ ORDEM ARTIODACTYLA } \\
\hline Pecari tajacu (Linnaeus, 1758) & $\mathrm{FH}$ & $\mathrm{A}-\mathrm{VU}$ & 19000 & Caititú, Cateto & $A, R, C, E, O 1$ & $A, R, C$ & $R^{4}$ \\
\hline Tayassu pecari (Link, 1795) & $\mathrm{FH}$ & A-EP & 30000 & Queixada, Porco-do-mato & $A, R, C$ & $A, R, C$ & $A, R, V^{4}$ \\
\hline Mazama americana (Erxleben, 1777) & FH & & 29000 & Veado-mateiro & $R, O 1$ & $R, C, E$ & $R$ \\
\hline \multicolumn{8}{|l|}{ ORDEM RODENTIA } \\
\hline Sciurus aestuans (Linnaeus, 1766 & FO & & 189 & Esquilo, caxinguelê & $A, V, O 1$ & $A, V$ & $A, V, O 5$ \\
\hline Akodon montensis (Thomas, 1902) & $\mathrm{IO}$ & & 25 & Rato-do-chão & O6 & $?$ & $?$ \\
\hline Akodon nigrita & $\mathrm{IO}$ & & $?$ & Rato-do-chão & O6 & $?$ & $?$ \\
\hline Akodon cursor (Winge, 1887) & $\mathrm{IO}$ & & 38 & Rato-do-chão & $?$ & $?$ & O5 \\
\hline Delomys dorsalis(Hensel, 1872) & $?$ & & 50 & Rato-do-mato & O6 & $?$ & $?$ \\
\hline Nectomys squamipes (Brants, 1827) & FO & & 249 & Rato-d'água & $01,06,07$ & Provav. & O5 \\
\hline Oecomys sp. & $?$ & & $?$ & Rato-do-mato & $?$ & $?$ & O5 \\
\hline Oligoryzomys spp. & FG & & $10-29$ & Rato-do-mato & $O 1$ & & \\
\hline Oligoryzomys nigripes (Olfers, 1818) & FG & & 21 & Rato-do-mato & 07,06 & Provav. & O5 \\
\hline Oryzomys intermedius (Leche, 1886) & FG & & 59 & Rato-do-mato & 01,06 & $?$ & $?$ \\
\hline Oryzomys ratticeps (Hensel, 1873) & FG & & 144 & Rato-do-mato & $O 1$ & Provav. & O5 \\
\hline Orizomys russatus & $?$ & & $?$ & Rato-do-mato & O6 & $?$ & 05 \\
\hline Oxymycterus iheringi (Thomas, 1896) & $\mathrm{IO}$ & & 43 & Rato-do-brejo & 01,07 & $?$ & $?$ \\
\hline Oxymycterus sp. & $?$ & & $?$ & Rato-do-brejo & 06,07 & $?$ & $?$ \\
\hline Oxymycterus dasytrichus (Schinz, 1821) & $?$ & & $?$ & Rato-do-brejo & $?$ & $?$ & O5 \\
\hline
\end{tabular}


Anexo M. Lista de ocorrência das espécies para as áreas estudadas do PESM

\begin{tabular}{|c|c|c|c|c|c|c|c|}
\hline MAMÍFEROS & Dieta & Status & Peso (g) & Nome Comum & $\mathbf{N S V / N S}$ & $\mathrm{NC} / \mathrm{I}$ & $\mathbf{N P}$ \\
\hline \multicolumn{8}{|l|}{ ORDEM RODENTIA } \\
\hline Rhagomys rufescens (Thomas, 1886) & $?$ & & 15 & Rato-do-mato-vermelho & $?$ & $?$ & O5 \\
\hline Rhipidomys sp. & $?$ & & $?$ & Rato-da-árvore & $?$ & $?$ & O5 \\
\hline Thaptomys nigrita (Lichtenstein, 1829) & $\mathrm{IO}$ & & 20 & Rato-do-chão & $O 1$ & $?$ & $?$ \\
\hline Wilfredomys oenax (Thomas, 1828) & $?$ & & 48 & Rato-do-mato & $O 1$ & Provav. & O5 \\
\hline Coendou prehensilis(Linnaeus, 1758) & FG & & 3360 & Ouriço-cacheiro & $E$ & $E$ & $A, E$ \\
\hline Sphiggurus villosus (F. Cuvier, 1823) & FH & & 1300 & Ouriço-cacheiro & $?$ & $?$ & O5 \\
\hline Sphiggurus insidiosus (F. Cuvier, 1823) & FH & & 800 & Ouriço-cacheiro & $?$ & $?$ & O5 \\
\hline Cavia aperea (Erxleben, 1777) & HG & & 549 & Preá & $?$ & $?$ & O5 \\
\hline Hidrochaeris hidrochaeris (Linnaeus, 1766) & HB & & 50000 & Capivara & $R, F, C$ & $A, R, F, C$ & $A, R, F$ \\
\hline Agouti paca (Linnaeus, 1766) & FH & A-VU & 8227 & Paca & $R, C, O 1$ & $R, C$ & $R$ \\
\hline Dasyprocta leporina (Linnaeus, 1758) & FH & & 2167 & Cutia & $A, O 1$ & Provav. & O5 \\
\hline Euryzygomatomys guiara (spinosus???) & & & & & $?$ & $?$ & O5 \\
\hline Kannabateomys amblyonyx (Wagner, 1845) & $\mathrm{HB}$ & & 460 & Rato-da-taquara & $F, O 4$ & $A$ & O5 \\
\hline Trinomys dimidiatus (Gunther, 1877) & FG & & 181 & Rato-de-espinho & $?$ & $?$ & O5 \\
\hline Trinomys iheringi (Thomas, 1911) & $\mathrm{FG}$ & & 200 & Rato-de-espinho & 08 & Provav & O5 \\
\hline Echimys nigrispinus (Wagner, 1842) & FG & & 250 & Rato-da-árvore & $?$ & $?$ & O5 \\
\hline \multicolumn{8}{|l|}{ ORDEM LAGOMORPHA } \\
\hline Sylvilagus brasiliensis (Linnaeus, 1758) & FH & & 339 & Coelho, Tapetí & $A, O 1$ & Provav. & $A$ \\
\hline
\end{tabular}


Anexo M. Lista de ocorrência das espécies para as áreas estudadas do PESM

\begin{tabular}{|c|c|c|c|c|c|c|c|}
\hline$\underline{\text { AVES }}$ & Dieta & Status & $\operatorname{Peso}(\mathrm{g})$ & Nome Comum & $\mathbf{N S V} / \mathbf{N S}$ & NC/I & NP \\
\hline \multicolumn{8}{|l|}{ ORDEM GALLIFORMES } \\
\hline Pipile jacutinga (Spix, 1825) & $\mathrm{FH}$ & $\mathrm{A}-\mathrm{CP}$ & 1250 & Jacutinga & $A^{6}$ & $A^{7}$ & Prov. Extinta \\
\hline Penelope obscura (Temminck, 1815) & $\mathrm{FH}$ & & 850 & Jacuaçu & $A^{8}, E, C$ & $A^{8}, C$ & $A^{8}$ \\
\hline Penelope superciliares (Temminck, 1815) & $\mathrm{FH}$ & & 1200 & Jacupemba & $?$ & $?$ & Provav. ${ }^{8}$ \\
\hline Odontophorus capueira (Spix, 1825) & FG & & $315^{*}$ & Uru, Uru-capoeira & $A, V$ & $A, V$ & $A, V$ \\
\hline \multicolumn{8}{|l|}{ ORDEM TINAMIFORMES } \\
\hline Tinamus solitarius (Vieillot, 1819) & FG & $\mathrm{A}-\mathrm{VU}$ & 1450 & Macuco & $A, V, C$ & $A, V$ & $A, V$ \\
\hline \multicolumn{8}{|l|}{ ORDEM PICIFORMES } \\
\hline Ramphastos toco (Muller, 1776) & FO & & 540 & Tucano Toco & $V$ & $A$ & $A, V$ \\
\hline Ramphastos vitellinus (Lichtenstein, 1823) & $\mathrm{FO}$ & & $?$ & Tucano-de-bico preto & $A, V$ & $V$ & $A$ \\
\hline Ramphastos dicolorus (Linnaeus, 1766) & $\mathrm{FO}$ & & $?$ & Tucano-de-bico-verde & $V$ & $A$ & $A$ \\
\hline
\end{tabular}

${ }^{6}$ Reintrodução de indivíduos na área. Avistado uma única vez, fora do censo, um casal voando sobre a rodovia, provavelmente reintroduzidos.

${ }^{7}$ Foi avistado um indivíduo uma única vez durante o censo. Nenhum outro registro foi realizado.

${ }^{8}$ A diferenciação destas espécies de cracídeos em campo é muito difícil devido à similaridade morfológica das espécies. Segundo Guix (1997) o NP é área provável de ocorrência de ambas espécies, enquanto que nas áreas situadas na parte elevada da Serra do Mar, deve ocorrer exclusivamente $P$. obcura.

Sub-total de espécies de mamíferos registrados para toda a área (incluíndo Provav.):

Sub-total de espécies de aves registradas para toda a área (incluíndo Provav.)

Número total de espécies registradas para toda a área (incluíndo Provav.)

7

70

20

53

Número de espécies em alguma das categorias de ameaçadas:

18

$O 1=$ Wang, 1999; O2 = Camardella et al., 2000; O3 = Neto, A. C.(Comum. pessoal , 2004); O4 = Nobre, R. A. (Comum. pessoal , 2004);

O5 = Pinheiro \& Geise, 2003; O6= Voltollini, 2003 e O7 = Briani, D. C. (Comum. pessoal , 2004). 


\section{REFERÊNCIAS BIBLIOGRÁFICAS}

ALEIXO, A; GALETTI, M. The conservation of the avifauna in a lowland Atlantic forest in southeast Brazil. Bird Conservation International, v.7, p.235-261, 1997.

ALTRICHTER, M.; DREWS, C.; SÁENZ, J.; CARRILLO, E. Sex ratio and breeding of white-lipped peccary (Tayassu pecari) in a Costa Rican rain forest. Biología Tropical, v.49, p.383-389, 2001.

ASQUITH, N. M.; WRIGHT, S. J.; CLAUSS, M. J. Does mammal community composition control recruitment in neotropical forests? Evidence from Panama. Ecology, v. 78, p.941-946, 1997.

AUGUST, P. V. The role of habitat complexity and heterogeneity in structuring tropical mammal communities. Ecology, v. 64,n.6, p.1495-1507, 1983.

AURICCHIO, P. Primatas do Brasil. São Paulo: Terra Brasilis, 1995. 167p.

ÁVILA-PIRES, F.D.; GOUVÊA, E. Mamíferos do parque nacional de itatiaia. Boletim do Museu Nacional, n.291, p.1-29, 1977.

AYRES, J.M.; FONSECA, G.A.B.; RYLANDS, A.B.; QUEIROZ, H.L.; PINTO, L.P.S.; MASTERSON, D.; CAVALCANTI, R. Abordagens inovadoras para conservação da biodiversidade do Brasil: os corredores ecológicos das florestas neotropicais do Brasil. Versão 3.0. Programa piloto para a proteção de florestas neotropicais, projeto parques e reservas. Brasília: Ministério do Meio Ambiente, Recursos Hídricos e da Amazônia Legal (MMA)/ Instituto Brasileiro do Meio Ambiente e dos Recursos Naturais Renováveis (IBAMA), 1997. 64p.

BARROSO, G. M.; MORIM, M. P.; PEIXOTO, A. L.; ICHASO, C. L. F. Frutos e sementes: morfologia aplicada à sistemática de dicotiledôneas. Viçosa: UFV, 1999. $443 p$.

BAZZAZ, F. A. The physiological ecology of plant sucession. Annual Review of Ecology and Systematics, v. 10, p. 351-371,1979.

BECKER, M.; DALPONTE, J. C. Rastros de mamíferos silvestres brasileiros. Brasília: Editora da Universidade de Brasília, 1991. 61p. 
BERGALLO, H.G.; VERA, Y.; CONDE, C.F.; BITTENCOURT, E.B.; BOSSI, D.E.P.; ROCHA, C.F.D. As similaridades nos parâmetros comunitários de pequenos mamíferos de duas áreas de mata atlântica do sul de São Paulo, Sudeste do Brasil. In: SEMINÁRIO REGIONAL DE ECOLOGIA, 8., Rio de Janeiro, 1998. Anais. Rio de Janeiro: UFRJ, 1998. p.939-949.

BLAKE, J. G.; LOISELLE, B. A.; MOERMOND, T. C.; LEVEY, D. J.; DENSLOW, J. S. Quantifying abundance of fruits for birds in tropical habitats. Studies in Avian Biology, v.13, p.73-79, 1990.

BODMER, R. E; EISENBERG, J. F.; K. H. REDFORD. Hunting and the likelihood of extinction of amazonian mammals. Conservation Biology, v. 11, p. 460-466, 1997.

BODMER, R.E.; FANG, T.G.; MOYA, L. Primates and ungulates: a comparison of suscetibility to hunting. Primate Conservation, v.9, p.79- 83, 1988.

BRANDÃO, L.D.; DEVELEY, P.F. Distribution and conservation of the buffy tuftedear marmoset, Callithrix aurita, in lowland coastal atlantic forest, south-east Brazil. Neotropical Primates, v. 6, n. 3, p. 86-88, 1998.

BRITO, D.; FIGUEIREDO, M.S.L. Minimum viable population and conservation status of the Atlantic forest spiny rat Trinomys eliasi. Biological Conservation, v.112, p.153-158, 2003.

BRITO, D.; GRELLE, C.E.V. Effectiveness of a reserve network for the conservation of the endemic marsupial Micoureus travassosi in Atlantic Forest remnants in southeastern Brazil. Biodiversity and Conservation, v.1, n.1, p.1- 18, 2003.

BROWN, A.; S. CHALUKIAN; MALMIERCA, L. Habitat y alimentacion de Cebus nigritus en N.O. argentino y la disponibilidad de frutos en al dossel arboreo. Revista Museo Argentino Ciências Naturais Bernardino Rivadavia, v.13, p. 273-280, 1984.

BROWN, A. D.; ZUNINO, G. E. Dietary variability in Cebus nigritus in extreme habitats: evidence for adaptability. Folia Primatologica, v. 54, p. 187-195, 1990.

BROWN JUNIOR., K. S.; BROWN, G. G. Habitat alteration and species loss in Brazilian forests. In T. C. WHITMORE; J. A. SAYER (Ed). Tropical deforestation and species extinctions. London: Chapman \& Hall Books, 1992. p.119-142.

BROWN, S; LUGO, A.E. Tropical secondary forests. Journal of Tropical Ecology, v.6, p.1-32, 1990. 
BUCKLAND, S.T.; ANDERSON, D.R.; BURNHAM, K.P.; LAAKE, J.L. Distance sampling. Estimating abundance of biological populations. London: Chapman \& Hall, 1993. 432p.

BUCKLAND, S.T.; ANDERSON, D.R.; BURNHAM, K.P.; LAAKE， J.L.; BORCHERS, D.L.; THOMAS, L.. Introduction to distance sampling. Oxford, Oxford University Press, 2001. 568p.

BURNHAM, K.P.; ANDERSON, D.R.; LAAKE, J.L. Estimation of density from line transect sampling of biological populations. Wildlife Monographs, v.72, p.1-202, 1980.

CABS (CENTER FOR APPLIED BIODIVERSITY SCIENCE). Biodiversity conservation corridors: planning, implementing, and monitoring sustainable landscapes. By SANDERSON, J.; ALGER, K.; FONSECA, G.A.B.; GALINDOLEAL, C.; INCHAUSTRY, V. H.; MORRISON, K. Washington: Conservation International, 2003. 41p.

CAMPASSI, F. Síndromes de dispersão das espécies arbóreas da Mata Atlântica. Rio Claro, 2002. 101p. Monografia (Graduação)-Instituto de Biociências, Universidade Estadual Paulista "Júlio de Mesquita Filho".

CARBONE, C. S.; CHRISTIE; K.; CONFORTI, T.; COULSON, J. R.; GINSBERG, M.; GRIFFITHS, J.; HOLDEN, K.; KAWANISHI, M. F.; KINNAIRD, R.; LAIDLAW, A.; LYNAM, D. W.; MACDONALD, D.; MARTYR, C.; MCDOUGAL, L; NATH, T.; O'BRIEN, J.; SEIDENSTICKER, D. J.; SMITH, M.; SUNQUIST, R. L.; TILSON; W. N.; WAN SHAHRUDDIN. The use of photographic rate to estimate densities of tigers and other cryptic mammals. Animal Conservation, v.4, p. 81-88, 2001.

CASSEY, P.; MCARDLE, B.H. An assessment of distance sampling techniques for estimating animal abundance. Environmetrics, v.10, p.261- 278, 1999.

CASTRO, C.S.S. Tamanho da área de vida e padrão de uso do espaço em grupos de sagüis, Callithix jacchus (Linnaeus) (Primates, Callitrichidae). Revista Brasileira de Zoologia, v. 20, n. 1, p. 91-96, 2003.

CERQUEIRA, R.; FREITAS, S.R. A new study of microhabitat structure of samall mammals. Revista Brasileira de Biologia, v. 59, n. 1, p. 219-223, 1999.

CERQUEIRA, R., MARROIG, G.; PINDER, L.. Marmosets and lion-tamarins distribution (Callitrichidae, Primates) in Rio de Janeiro State, southeastern Brazil. Mammalia, v. 62, p. 213-226, 1998. 
CHAPMAN, C. A.; CHAPMAN, L.; WRANGHAM, R. W.; HUNT, K.; GEBO, D.; GARDNER, L. Estimators of fruit abundance of tropical trees. Biotropica, v. 24, p.527-531, 1992.

CHAZDON, R. L. Light variation and carbon gain in rainforest understory palms. Journal of Ecology, v. 74, p. 995-1012, 1986.

CHAZDON, R. L.; FETCHER, N. Photosynthetic responses of Pisum sativum to an increase in irradiance during growth I. Photosynthetic activities. Australian Journal of Plant Physiology,v. 14, p.1-18, 1984.

CHIARELLO, A.G. Home range of the brown howler monkey, Alouatta fusca, in a forest fragment of southeastern Brazil. Folia Primatologica, v.601, p.73-175, 1993.

CHIARELLO, A.G. Mammalian community and vegetation structure of Atlantic forest fragments in southeastern Brazil. Cambridge, 1997. 120p. Thesis (Ph.D.) Cambridge University.

CHIARELLO, A.G. Effects of fragmentation of the Atlantic forest on mammal communities in South-eastern Brazil. Biological Conservation, v.89, p.71-82, 1999.

CHIARELLO, A.G. Influência da caça ilegal sobre mamíferos e aves das matas de tabuleiro do norte do Estado do Espírito Santo. Boletim do Museu de Biologia Mello Leitão, v.11/12, p.229-247, 2000a.

CHIARELLO, A.G. Density and populations size of mammals in remnants of Brazilian Atlantic Forest. Conservation Biology, v.14, p.1649-1657, 2000 b.

CHIARELLO, A.G.; MELO, F.R. de. Primate population densities and sizes in Atlantic forest remnants of northern Espirito Santo, Brazil. International Journal of Primatology, v.22, n.3, p.379-396, 2001.

COLLAR, N.J.;GONZAGA, L.P.; KRABBE, N.; MADROÑO-NIETO, A.; NARANJO, L.G.; PARKER, T.A.; WEGE, D.C. Threatened birds of the Americas. Cambridge: International council for bird preservation (ICBP)/IUCN, 1992. 1100p.

CONTE, R.; REIS, M. S.; REIS, A.; MANTOVANI, A.; MARIOT, A.; FANTINI, R. C.; NODARI, R. O. Dinâmica da regeneração natural de Euterpe edulis. In REIS, M. S.; REIS, A. Euterpe edulis Martius - (Palmiteiro): Biologia, conservação e manejo. Itajaí: Herbário Barbosa Rodrigues, 2000. p. 106-130.

CORREA, H. K. M.; COUTINHO, P. E. G.; FERRARI, S. F.. Between-year differences in the feeding ecology of highland marmosets (Callithrix aurita \& Callithrix flaviceps) in southeastern Brazil. Journal of Zoology, v.252, p. 421-427, 2000. 
COSENZA, B.A.P.; MELO, F.R. Primates of the Serra do Brigadeiro State Park, Minas Gerais, Brazil. Neotropical Primates,v.6, n.1, p.18-20, 1998.

CULLEN JÚNIOR, L. Hunting and biodiversity in Atlantic forest fragments, São Paulo, Brazil. Florida, 1997. 134p. Dissertation (M.S.) - University of Florida.

CULLEN JÚNIOR, L.; RUDRAN, R. Transectos lineares na estimativa de densidade de mamíferos e aves de médio e grande porte. In: CULLEN JÚNIOR., L.; RUDRAN, R.; VALLADARES-PADUA, C. (Ed.). Métodos de estudos em biologia da conservação e manejo da vida silvestre. Curitiba: Ed. UFPR/ FBPN, 2003. p.169179.

CULLEN JÚNIOR, L.; BODMER R.E.; PÁDUA, C.V. Caça e biodiversidade nos fragmentos florestais da Mata Atlântica, São Paulo, Brazil. In: FANG, T.G., MONTENEGRO, O.L.; BODMER, R.E. (Ed.). Manejo y conservación de fauna silvestre en America Latina. Florida: WCS, University of Florida, 1999, p.125-139.

CULLEN JÚNIOR, L.; BODMER, R.E.; PADUA, C.V. Effects of hunting in habitat fragments of the Atlantic forests, Brazil. Biological Conservation, v.95, p.49-56, 2000 .

CULLEN JÚNIOR, L.; BODMER, R.E.; PÁDUA, C.V. Ecological consequences of hunting in Atlantic forest patches, São Paulo, Brazil. Oryx, v.35, p.137-144, 2001.

DEAN, W. A ferro e fogo: a história e a devastação da Mata Atlântica brasileira. São Paulo: Companhia das Letras, 1996. 261 p.

DE LA TORRE, SNOWDON, C. T.; BEJARANO, M. Effects of human activities on wild pygmy marmosets in ecuadorian amazonia. Biological Conservation, v. 94, p.153-163, 2000.

DEVELEY, P.F; ENDRIGO, E. Aves da grande São Paulo: guia de campo. São Paulo: Aves Fotos Editora, 2004. 295 p.

EISENBERG, J. F.; K. H. REDFORD. Mammals of the Neotropics: The Central Neotropics; Equador, Peru, Bolivia, Brazil. Chicago: The University of Chicago Press, 1999. 609 p.

EMMONS, L.H. Neotropical rainforest mammals: a field guide. Chicago: The University of Chicago Press, 1990. 281p. 
ESTRADA, A., R. COATES-ESTRADA, D. MERITT, S. MONTIEL; D. CURIEL. Patterns of frugivore species richness and abundance in forest islands and in agricultural habitats at Los Tuxtlas, Mexico. In: FLEMING, T.H.; ESTRADA, A. (Ed.). Frugivory and seed dispersal: ecological and evolutionary aspects. London: Kluwer Academic Publishe, 1993. p.436 - 545.

FERRARI, S.F. The behaviour and ecology of the buffy-headed marmoset Callithrix flaviceps (O. Thomas, 1903). London, 1988. 100p. Thesis (Ph.D.) - University College London.

FERRARI, S.F. Multiple transects or multiple walks? A response to Magnusson (2001). Neotropical Primates, v.10, n.3, p.131- 132, 2002.

FERRARI, S.F.; K.M. CORRÊA; P.E.G. COUTINHO. Ecology of the "southern" marmosets (Calithrix aurita and Callithrix flaviceps): How different, how similar? In: NORCONCK et al. (Ed.). Adaptative radiations of neotropical pimates. New York: Plenum Press, 1996, p.157-171.

FONSECA, G. A. B. Small mammal species diversity in brazilian tropical primary \& secondary forests of different sizes. Revista Brasileira de Zoologia, v. 6, p. 381$422,1989$.

FONSECA, G.A.B.; HERRMANN, G.; LEITE, Y.L.R; MITTERMEIER, R.A.; RYLANDS, A.B.; PATTON, J.L. Lista anotada dos mamíferos do Brasil. Occasional Papers Conservation International, n. 4, 38p, 1996.

FONSECA, G.A.B.; PINTO, L.P.S.; RYLANDS, A.B. Biodiversidade e unidades de conservação. In: CONGRESSO BRASILEIRO DE UNIDADES DE CONSERVAÇÃO, Curitiba, 1997. Anais. Curitiba: Universidade Livre do Meio Ambiente/ Rede Nacional Pró-Unidades de Conservação/ Instituto Ambiental do Paraná, 1997. p.189-209.

FRANKHAM, R. Effective population size/ adult population size ratios in wildlife: a review. Genetical Research, v.66, p.95-107, 1995.

GALETTI, M. Fruits and frugivores in a brazilian atlantic forest. Cambridge, 1996. 242p. Thesis (Ph.D.) - University of Cambridge.

GALETTI, M.; PERES, C.A. Plantas-chave em florestas tropicais. Ciência Hoje, v.95, p.57- 58, 1993.

GALETTI, M.; ALEIXO, A. Effects of palm heart harvesting on frugivores in the Atlantic forest of Brazil. Journal of Applied Ecology, v.35, p. 286-293, 1998.a 
GALETTI, M.; PEDRONI, F. Diet of capuchin monkeys (Cebus apella) in a semideciduous forest. South-east Brazilian Journal of Tropical Ecology, v. 10, p.27-33, 1994.

GALETTI, M.; FERNANDEZ, J.C. Palm harvesting in the brazilian atlantic forest: changes in industry structure and the illegal trade. Journal of Applied Ecology, v.35, p.294-301, 1998.b

GALETTI, M.; PASCHOAL, M.; F. PEDRONI. Predation on palm nuts (Syagrus romanzoffiana) by squirrels (Sciurus ingrami). South-East Brazilian Journal of Tropical Ecology, v. 8, p.121-123, 1992.

GALETTI, M.; LAPA, R.; PIZO, M.A. Frugivory by toucans (Ramphastidae) at two altitudes in the Atlantic Forest of Brazil. Biotropica, v.32, n.4b, p.842-850, 2000.

GALETTI, M.; MARTUSCELli, P.; OLMOS, F.; ALEIXO, A. Ecology and conservation of the pipin-guan Pipile jacutinga in southeasthern Brazil. Biological Conservation, v.82, p.31-39, 1997.

GARGAGLIONI, L.H.; BATALHÃO, M.E.; LAPENTA, M.J.; CARVALHO, M.F.; ROSSI, R.V.; VERULLI, V.P. Mamíferos da estação ecológica de Jataí, Luis Antônio, São Paulo. Papéis Avulsos de Zoologia, v.40, n.17, p.267-287, 1998.

GENTRY, A H.; DODSON, C. Contribution of nontrees to specis richness of a tropical rain forest. Biotropica, v. 19, p. 149-156, 1987.

GIBBS P.E.; LEITÃO- FILHO H.F.; ABBOTT, R.J. Application of the point-centred quarter method in a floristic survey of na área of gallery Forest at Mogi-Guaçu, SP, Brazil. Revista Brasileira de Botânica, v.3, p.17-22, 1980.

GILPIN, M.E.; SOULÉ, M.E. Minimum viable populations: processes of species extinction. In: SOULÉ, M.E. (Ed.). Conservation Biology, the science of scarcity and diversity. Sundeland: Sinauer Associates, 1986, p.19- 34.

GLANZ, W.E. The terrestrial mammal fauna of Barro Colorado Island: censuses and long-term changes. In: LEIGH JUNIOR.; E.G.; RAND, A.S.; WINDSOR, D.M. (Ed.). The ecology of a tropical forest: seasonal rhythms and long-therm changes. Washington, D.C.: Smithsonian Institution Press, 1996. p.455-466.

GONZÁLEZ-SÓLIS, J.; GUIX, J.C.; MATEOS, E.; LLORENS, L. Density estimates, group size and habitat use of monkeys (mammals:cebidae). In: MATEOS, E.; GUIX, J.C.; SERRA, A.; PISCIOTTA, K. (Ed.). Censuses of vertebrates in a Brazilian Atlantic rainforest area: The Paranapiacaba fragment. Barcelona: Universitat de Barcelona, 2002, p.111- 125. 
GRIFFITHS, M.; C. P. SCHAIK. Camera-trapping: a new tool for the study of elusive rain forest animals. Tropical Biodiversity, v. 2, p.131-139, 1993

GUARIGUATA, M.R.; DUPUY, J. M.. Forest regeneration in abondoned logging roads in lowland Costa Rica. Biotropica, v. 29, p. 15-28, 1997.

GUIX,J.C. Exclusão geográfica e ecológica de Penelope obscura, Penelope superciliaris e Pipile jacutinga (Galliformes: Cracidae). Ararajuba, v. 5, p.195-202, 1997.

GUIX, J.C.; MAÑOSA, S.; PEDROCCHI, V.; VARGAS, M.J.; SOUZA, F.L. Census of three frugivorous birds in an Atlantic rainforest area of southeastern Brazil. Ardeola, v.44, n.2, p.229- 233, 1997.

HARCOURT, A. H. Empirical estimates of minimum viable population sizes for primates: tens to tens of thousands? Animal Conservation, v. 5, p. 237-244, 2002.

HEIDUCK, S. The use of disturbed and undisturbed forest by masked-titi monkeys Callicebus personatus melanochir is proportional to food availability. Oryx, v.36, n.2, p.133-139, 2002.

HENRIQUES, R.P.B.; ALHO, C.J.R. Microhabitat selection by two rodent species in the cerrado of Central Brazil. Mammalia, v. 55, n. 1, p. 49-56, 1991.

HERNÁNDEZ, A.; MARTÍN, M.; SERRA, A.; GUIX, J.C. Density estimates of syntopic species of toucans (Aves: Ramphastidae). In: MATEOS, E.; GUIX, J.C.; SERRA, A.; PISCIOTTA, A. (Ed.). Censuses of vertebrates in a Brazilian Atlantic rainforest area: The Paranapiacaba fragment. Barcelona: Universidade de Barcelona, p.79- 95, 2002.

HODGES, K.M.; CHAMBERLA, M.J.; LEOPOLD, B.D. Effects of summer hunting on ranging behavior of adult raccons in central mississippi. Journal of Wildlife Management, v.64, n.1, p.194-198, 2000.

HORINO, S.; MIURA, S. Population viability analysis of a japanese black bear population. Population Ecology, v.42, p.37-44, 2000.

INSTITUTO BRASILEIRO DE GEOGRAFIA ESTATISTICA Anuário estatístico do Brasil 1976-2000, Rio de Janeiro: IBGE (www.ibge.gov.br.)(20/05/2004).

JANSON, C.H.; TERBORGH, J. Censo de primates en selva humeda tropical. Publicación del Museu de Historia Natural Javier Prado, Serie A, Zoologia, n.28, p.3-38, 1980. 
JANSON, C.H.; EMMONS, L.H. Ecological structure of the nonflying mammal community at Cocha Cashu Biological Station, Manu National Park, Peru. In: GENTRY, A.H. (Ed.). Four neotropical rainforests. New Haven: Yale University Press, 1990. p.314-338.

JONES, L.L.C.; RAPHAEL, M.G. Inexpensive camera systems for detecting martens, fishers, and other animals: guidelines for use and standardization. Washington: Department of Agriculture, 1993.320p.

KARANTH, K.U.; NICHOLS, J.D.. Camera trapping bif cats: some questions that should be asked frequently. Unpublished manuscript, 2000.

KENT, M.; COKER, P. Vegetation description and analysis, a practical approach. London: Belhaven Press, 1992. 363 p.

KEUROGHLIAN, A.; EATON, D.P.; LONGLAND, W.S. Area use by white-lipped and collared peccaries (Tayassu pecari and Tayassu tajacu) in a tropical forest fragment. Biological Conservation. 2004. /No prelo/

KIERULFF, M.C.M.;. RYLANDS, A.B. Census and distribution of the golden lion tamarin (Leontopithecus rosalia). American Journal of Primatology, v. 59, p. 2944, 2003.

KILGO, J.C.; LABISKY, R.F.; FRITZEN, D.E. Influences of hunting on the behavior of white-tailed deer: implications for conservation of the florida panther. Conservation Biology, v.12, n.6, p.1359-1364, 1998.

KILTIE, R. Stomach contents of rain forest peccaries (Tayassy tajacu and T. pecari). Biotropica, v.13, n.3, p.234-236, 1981 a.

KILTIE, R. Distribution of palm fruits on a rain forest floor: why white - lipped peccaries forage near objects. Biotropica, v.13, n.2, p.141-145, $1981 \mathrm{~b}$.

LAAKE, J.L.; BUCKLAND, S.T.; ANDERSON, D.R.; BURNHAM, K.P. DISTANCE user's guide. Fort Collins: Colorado State University, 1994. 84p.

LEMOS DE SÁ, R.M. Manejo de fauna na reserva Xavante Rio das Mortes, MT: cultura indígena e método científico integrados para a conservação. Brasília: WWF, 2000. 68p. (Série técnica, 4)

LORENZI, H. Árvores brasileiras: manual de identificação e cultivo de plantas arbóreas nativas do Brasil. Nova Odessa: Ed. Plantarum, 1992. 384p. 
LORENZI, H. Árvores brasileiras: manual de identificação e cultivo de plantas arbóreas nativas do Brasil. Nova Odessa: Ed. Plantarum, 1998. v.2, 384p.

LORENZI. H.; SOUZA.H.M.; MEDEIROS-COSTA, J.T.; CERQUEIRA, L.S.C.; VON BEHR, N. Palmeiras no Brasil - Nativas e Exóticas. Nova Odessa: Ed. Plantarum, 1996. 303p.

LOVEJOY, T.E.J.; BIERREGAARD, R. O.; RYLANDS, A.B.; MALCOLM, J.R.; QUINTELA, L.H.; HARPER, K. S.; BROWN JUNIOR., K.S.; POWELL, A.H.; POWELL, G.V.N.; SCHUBART,H.O.R.; HAYS, M.B. Edge and other effects of isolation on Amazon forest fragments. In SOULÉ, M.E. (Ed). Conservation Biology- The science of scarcity and diversity. Sunderland, Massachusetts: Sinauer Associates, 1986. p. 257-285.

LYNCH, M.; LANDE, R. The critical effective size for a genetically secure population. Animal Conservation, v.1, p.70-72, 1998.

MACARTHUR, R.H.; DIAMOND, J.M.; KARR, J.R. Density compensation in island faunas. Ecology, v.53, n.2, p.330- 342, 1972.

MAEHR, D.S.; LACY, R.C.; LAND, E.D.; BASS, O.L.; HOCTOR, T.S. Evolution of population viability assesment for the Florida panther: a multiperspective approach. In: BEISSINGER, S.R.; MCCULLOUGH, D.R. (Ed.). Population viability analysis. Chicago: The University of Chicago Press, 2002. p.284-310.

MAGNUSSON, W.E. Standard errors of survey estimates: what do they mean? Neotropical Primates, v.9, n.2, p.53- 54, 2001.

MALCOLM, J. R. Estimation of mammalian densities in continuous forest north Manaus. In: GENTRY, A.H. (Ed.). Four neotropical rainforests. New Haven: Yale University Press, 1990. p. 339-357.

MANTOVANI, W. Estrutura e dinâmica da floresta atlântica na Juréia, Iguape, SP. São Paulo, 1993. 179p. Tese (Livre-docência) - Instituto de Biociências, Universidade de São Paulo.

MARINHO-FILHO, J. S.; REIS, M. L. A fauna de mamíferos associada às matas de galeria. In: SIMPÓSIO SOBRE MATA CILIAR. Anais. Campinas: Fundação Cargill, 1989. p. 46-60.

MARSDEN, S. The status and ecology of parrots and other birds in and around the Sooretama/Linhares and Porto Seguro atlantic forest reserves, Brazil. Manchester, 1999. 100 p. Thesis (Ph.D.) - Manchester Metropolitan University. 
MARTIN, M. Estima de la densidad poblacional de tucán de pico verde (Ramphastos dicolorus) en una isla del sudeste de Brasil. Grupo de Estudos Ecológicos, v. 6, p.1-9, 2000.

MARTINS, M. M.; E. Z. F. SETZ. Diet of buffy tufted-eared marmosets (Callithrix aurita) in a forest fragment in southeastern Brazil. International Journal of Primatology, v. 21, p.467-476, 2000.

MARTUSCELLI, P.; OLMOS, F. Cracid conservation in São Paulo state, southeastern Brazil. In: STRAHL, S.D.; BEAUJON, S.; BROOKS, D.M.; BEGAZO, A.J.; SEDAGHATKIH, G.; OLMOS, F. (Ed.). The Cracidae. Their biology an conservation. São Paulo: Surrey and Blaine/ Hancock House Publ., 1997. p.482491.

MCARDLE, B. H.; GASTON, K.J.; LAWTON, J.H. Variation in the size of animal populations: patterns, problems and artefacts. Journal of Animal Ecology, v.3, p.145-153, 1990.

MINISTÉRIO DO MEIO AMBIENTE/ SECRETARIA DE BIODIVERSIDADE E FLORESTAS. Avaliação e ações prioritárias para a conservação da biodiversidade da Mata Attântica e Campos Sulinos. Brasília: Conservation International do Brasil; Fundação SOS Mata Atlântica; Fundação Biodiversitas; Instituto de Pesquisas Ecológicas; Secretaria do Meio Ambiente do Estado de São Paulo; Instituto Estadual de Florestas-MG, 2000. 40p.

MINISTÉRIO DO MEIO AMBIENTE. Primeiro relatório nacional para a convenção sobre diversidade biológica. Brasília: Ministério do Meio Ambiente, dos Recursos Hídricos e da Amazônia Legal, 1998. 283p.

MORELLATO, L.P.C.; HADDAD, C. Introduction: The brazilian atlantic forest. Biotropica, v. 32, n. 4b, p. 786-792, 2000.

MORELLATO, P. C; LEITÃO-FILHO, H.F. Reproductive phenology of climbers in a southeastern Brazilian forest. Biotropica,v. 28, p. 180-191, 1996.

MUELLER-DOMBOIS, D.; ELLENBERG, H.. Aims and methods of vegetation ecology. New York: John Willey and Sons, 1974. 547 p.

MUSKIN, A. Field notes and geographic distribution of Callithrix aurita in eastern Brazil. American Journal of Primatology, v. 7, p. 377-380, 1984.

MYERS, N.; MITTERMEIER, R.A.; MITTERMEIER, C.G.; FONSECA, G.A.B.; KENT, J. Biodiversity hotspots for conservation priorities. Nature, v.403, p.853$858,2000$. 
NEWMARK, W. D. Species area relationship and its determinants for mammals in western north-american national-parks. Biological Journal of the Linnean Society, v. 28, p. 83-98, 1986.

NEWMARK, W. D. A land-bridge island perspective on mammalian extinctions in western north-american parks. Nature, v. 325, p. 430-432, 1987.

NEWMARK, W. D. Tropical forest fragmentation and the local extinction of understory birds in the eastern usambara mountains, Tanzania. Conservation Biology, v. 5, p. 67-78, 1991.

NEWMARK, W. D. The role and design of wildlife corridors with examples from Tanzania. Ambio, v. 22, p.500-504,1993.

NEWMARK, W. D. Extinction of mammal populations in western north-american national-parks. Conservation Biology, v. 9, p. 512-526, 1995.

NEWMARK, W. D. Insularization of Tanzanian parks and the local extinction of large mammals. Conservation Biology, v. 10, p.1549-1556, 1996.

OLIVEIRA-FILHO, A.T.; FONTES, M.A.L. Patterns of floristic differentiation among atlantic forest in southeastern Brazil and the influence of climate. Biotropica, v. 32, n. 4b., p. 793-810, 2000.

OLMOS, F.; GALETTI, M. A conservação e o futuro da Juréia: isolamento ecológico e impacto humano. In: MARQUES, O.A.V.; DULEBA, W. (Ed.). Estação Ecológica Juréia - Itatins: ambiente físico, flora e fauna. Ribeirão Preto: Holos Editora, 2004. p.360- 377.

OLMOS, F.; ALBUQUERQUE, J.L.B.; GALETTI, M.; MILANO, M.S.; CÂMARA, I.G.; COIMBRA-FILHO, A.F.; PACHECO, J.F.; BAUER, C.; PENA, C.G.; FREITAS, T.R.O.; PIZO, M.A.; ALEIXO, A. Correção política e biodiversidade: a ameaça das "populações tradicionais" à Mata Atlântica. In: ALBUQUERQUE, J.L.B. (Ed.). Ornitologia e conservação: da ciência às estratégias. Tubarão: UNISUL, 2002. 150p.

PARDINI, R; DEVELEY, P.F. Mamíferos de médio e grande porte na Estação Juréia Itatins. In: MARQUES, O.A.V.; DULEBA, W. (Ed.). Estação ecológica JuréiaItatins; ambiente físico, flora e fauna. Ribeirão Preto: Ed. Holos. 2004 p. 296-303

PASCHOAL, M.; GALETTI, M. Seasonal food use by the neotropical squirrel Sciurus ingrami in southeastern Brazil. Biotropica, v. 27, n. 2, p. 268-273, 1995. 
PASSAMANI, M.; MENDES, S.L.; CHIARELLO, A.G. Non-volant mammals of the Estação biológica de Santa Lúcia and adjacent areas of Santa teresa, Espírito Santo, Brazil. Boletim do Museu de Biologia Mello Leitão, v.11/12, p.201-214, 2000.

PAULILO, M. T. Ecofisiologia de plântulas e plantas jovens de Euterpe edulis: comportamente em relação a variação de luz. In: REIS, M.S; REIS, A. (Ed.). Euterpe edulis Martius - (Palmiteiro): Biologia, conservação e manejo. Itajaí: Herbário Barbosa Rodrigues, 2000. p. 93-105.

PERES, C.A. Effects of hunting on western amazonian primate communities. Biological Conservation, v.54, n.1, p.47-59, 1990.

PERES, C. A. Indigenous reserves and nature conservation in amazonian forests. Conservation Biology, v.8, p.586-589, 1994.

PERES, C.A. Population status of white-lipped Tayassu pecari and collared peccaries $T$. tajacu in hunted and unhunted amazonian forests. Biological Conservation, v.77, p115-123, 1996.

PERES, C. A. Effects of habitat quality and hunting pressure on arboreal folivore densities in neotropical forests: A case study of howler monkeys (Alouatta spp.). Folia Primatologica, v.68, p.199-222, 1997.

PERES, C.A. General guidelines for standardizing line-transect surveys of tropical forest primates. Neotropical Primates, v.7, n.1, p.11-16, 1999.

PERES, C.A. Evaluating the impact and sustainability of subsistence hunting at multiple Amazonian forest sites. In: ROBINSON, J.G.; BENNETT, E.L. (Ed.). Hunting for sustainability in tropical forests. New York: Columbia University Press, 2000. p.83-115.

PERES, C.A. Synergistic effects of subsistence hunting and habitat fragmentation on amazonian forest vertebrates. Conservation Biology, v.15, n.6, p.1490-1505, 2001.

PERES, C.A.; DOLMAN, P.M. Density compensation in neotropical primate communities: evidence from 56 hunted and nonhunted Amazonian forests of varying productivity. Oecologia, v.122, p.175-189, 2000.

PICKETT, S.T.A. Differential adaptation of tropical tree species to canopy gaps and its role in community dynamics. Tropical Ecology, v. 24, p. 68-84, 1983.

PINHEIRO, P. S.; GEISE, L. Mamíferos não-voadores do núcleo Picinguaba (Ubatuba, SP). In: CONGRESSO BRASILEIRO DE MASTOZOOLOGIA, 2. Livro de resumos. Belo Horizonte: PUC-MG, 2003. p.133. 
PINTO, L.P.; COSTA, C.M.R.; STRIER, K.B.; FONSECA, G.A.B. Habitat density and group size of primates in a Brazilian tropical forest. Folia Primatologica, v.61, p.135-143, 1993.

PIRES, A. M. Z.; SANTOS, J.E.; PIRES, J. S. Conservação da biodiversidade: análise da situação de unidades de conservação de proteção integral (parques estaduais e estações ecológicas) do Estado de São Paulo. In: MILANO, M.S.; THEULEN, V. (Ed). CONGRESSO BRASILEIRO DE UNIDADES DE CONSERVAÇÃO, 2. Anais. Campo Grande: Rede Nacional Pró-Unidades de Conservação/FBPN, 2000. p. 618-627.

PONTES, A. R. M. Environmental determinants of primate abundance in Maracá Island, Roraima, brazilian amazonia. Journal of Zoology of London, v. 247, p. 189-199, 1999.

PRICE, E. C.; PIEDADE, H. M.; WORMELL, D. Population densities of primates in a brazilian atlantic forest. Folia Primatologica, v. 73, p. 54-56, 2002.

RALLS, K.; HARVEY, P.H.; LYLES, A.M. Inbreeding in natural populations of birds and mammals. In: SOULÉ, M.E. (Ed.). Conservation biology, the science of scarcity and diversity. Sunderland: Sinauer Associates, 1986. p.35-56.

RALLS, K.; BEISSINGER, S.F.; COCHRANE, J.F. Guidelines for using population viability analysis in endangered species management. In: BEISSINGER, S.R.; MCCUlloUgh, D.R. (Ed.). Population viability analysis. Chicago: The University of Chicago Press, 2002. p.521- 550.

REDFORD, K.H. The empty forest. Bioscience, v.42, n.6, p.412-422, 1992.

REDFORD, K.H. Hunting in neotropical forests: a subsidy from nature. In: HLADIK, C.M.; HLADIK, A.; LINARES, O.F.; PAGEZY, H., UNESCO (Ed.). Tropical forests, people and food: biocultural interactions and applications to development. Portland: Book News, 1993. 852 p. (man and biosphere, 13).

REDFORD, K.H.; ROBINSON, J.G. The game of choice: patterns of indian and colonist hunting in the neotropics. American Anthropologist, v.89, p.650-667, 1987.

REDFORD, K.H.; ROBINSON, J.G. Park size and the conservation of forest mammals in Latin America. In: MARES, M.A; SCHMIDLY, D.J. (Ed.). Latin American Mammalogy: history, biodiversity and conservation. Oklahoma: University of Oklahoma Press, 1991. p.277-234. 
REED, D.H.; O'GRADY, J.J.; BROOK, B.W.; BALLOU, J.D.; FRANKHAM, R. Estimates of minimum viable population sizes for vertebrates and factors influencing those estimates. Biological Conservation, v.113, p. 23-34, 2003.

REIS, M.S.; FANTINI, A.C.; NODARI, R.O.; REIS, A.; GUERRA, M.P.; MANTOVANI, A. Management and conservation of natural populations in Atlantic rain forest: The case study of palm heart (Euterpe edulis Martius). Biotropica, v.32, p.894-902, 2000.

ROBINSON, J.G.; REDFORD, K.H. Body size, diet and population density of neotropical forest mammals. The American Naturalist, v.128, n.5, p.665-680, 1986.

ROBINSON, J.G.; BENNETT, E.L. Carrying capacity limits to sustainable hunting in tropical forests. In: ROBINSON, J.G.; BENNETT, E.L. (Ed.). Hunting for sustainability in tropical forests. New York: Columbia University Press, 2000. p.13-30.

RYLANDS, AB. The behaviour and ecology of three species of marmosets and tamarins (Callithrichidae: primates) in Brazil. Cambridge, 1982. 100p. Thesis (Ph.D.) University of Cambridge.

SÁNCHEZ-ALONSO, C.; OLIVERAS, I.; MARTIN, M. Density estimates of guans (Aves: Cracidae): Pipile jacutinga and Penelope obscura. In: MATEOS, E.; GUIX, J.C.; SERRA, A.; PISCIOTA, K. (Ed.). Censuses of vertebrates in a brazilian atlantic forest area: the Paranapiacaba fragment. Barcelona: Universitat de Barcelona, 2002. p. 67-78.

SÃO BERNARDO, C.S. Abundância, densidade e tamanho populacional de aves e mamíferos cinegéticos no Parque Estadual da Ilha do Cardoso. Piracicaba, 2004. 154p. Dissertação (Mestrado) - Escola Superior de Agricultura "Luiz de Queiroz", Universidade de São Paulo.

SÃO BERNARDO, C.S.; GALETTI, M. Densidade e tamanho populacional de primatas em um fragmento florestal no sudeste do Brasil. Revista Brasileira de Zoologia. 2004/no prelo/.

SCHWARZKOPF, L.; RYLANDS, A.B. Primates species richness in relation to habitat structure in amazonian rainforest fragments. Biological Conservation, v.48, p.1-12, 1989.

SECRETARIA DO MEIO AMBIENTE. Fauna ameaçada no Estado de São Paulo. São Paulo: Governo do Estado de São Paulo, 1998. 60p. (Série documentos ambientais) 
SECRETARIA DO MEIO AMBIENTE. Paisagem paulista: áreas protegidas. São Paulo: Empresa das Artes, 1999. 146 p.

SECRETARIA DO MEIO AMBIENTE. Plano de manejo das unidades de conservação- Parque Estadual da Serra do Mar Núcleo Santa Virgínia/Natividade da Serra. Plano de gestão ambiental.- fase 1. São Paulo: Projeto de preservação da mata atlântica (PPMA)/ coordenadoria de informações técnicas/ documentação e pesquisa ambiental (CINP)/ Instituto Florestal (IF)/ Fundação Florestal (FF), 1998. 174 p.

SECRETARIA DO MEIO AMBIENTE. Plano de manejo das unidades de conservação- Parque Estadual da Serra do Mar Núcleo Picinguaba. Plano de gestão ambiental.- fase 1. São Paulo: Projeto de preservação da mata atlântica (PPMA); coordenadoria de informações técnicas; documentação e pesquisa ambiental (CINP); Instituto Florestal (IF); Fundação Florestal (FF), 1998. 191 p.

SHAFFER, M.L. Minimum population sizes for species conservation. Bioscience, v.31, p.131-134, 1981.

SHAFFER, M. L.; SAMSON, F. B. Population size and extinction: a note on detemninig critical population size. American Naturalist, v.125, p.144-152, 1985.

SHAFFER, M.L.; WATCHMAN, L.H.; SNAPE, W.J.; LATCHIS, I.K. Population viability analysis and conservation policy. In: BEISSINGER, S.R.; MCCUllOUGH, D.R. (Ed.). Population viability analysis. Chicago: The University of Chicago Press, 2002. p.123-142.

SHEPHERD, G.J. FITOPAC: Manual do usuário. Campinas: Unicamp, Departamento de Botânica, 1995. 72p.

SICK, H. Birds in Brazil. Princeton: Princeton University Press, 1993. 932p.

SICK, H. Ornitologia brasileira. Rio de Janeiro: Editora Nova Fronteira, 1997. 862p.

SILVA, A. F.; LEITÃO-FILHO, E.H.F. Composição florística e estrutura de um trecho de mata atlântica de encosta no município de Ubatuba (São Paulo). Revista Brasileira de Biologia, v. 5, p. 43-52, 1982.

SOKAL,R.R.; ROHLF, F.J. Biometry: the principles and practice of statistics in biological research. 3.Ed. New York: W.H. Freeman, 1995. 887 p.

SOMMER, S.; VOLAHY, T.; SEAL, U.S. A population and habitat viability assessment for the higly endangered giant jumping rat (Hypogeomys antimena), the largest extant endemic rodent of Madagascar. Animal Conservation, v.5, p.263-273, 2002. 
SOS MATA ATLANTICA; INPE. Atlas da evolução dos remanescentes florestais e ecossistemas associados do domínio da Mata Atlântica no período de 1985-1990. São Paulo: Fundação SOS Mata Atlântica, 1992. 120 p.

SOULÉ, M.E. Conservation biology, the science of scarcity and diversity. Sunderland: Sinauer Associates, 1986. 584p.

SPIRONELO, W.R. Importância dos frutos de palmeiras (Palmae) na dieta de um grupo de Cebus apella (Cebidae, Primates) na Amazônia Central. In: RYLANDS, AB.; BERNARDES, A.T. (Ed.). A primatologia no Brasil. 3ed. Belo Horizonte: Ed. UFMG, 1991. p.285-296.

STALLINGS, J.R.; FONSECA, G.A.B.; PINTO, L.P.S.; AGUIAR, L.M.S.; SÁBATO, E.L. Mamíferos do parque florestal Estadual do Rio Doce, Minas Gerais, Brasil. Revista Brasileira de Zoologia, v.7, n.4, p.663-677, 1991.

STEVENSON, PR. The relashionship between fruit production and primate abundance in neotropical communities. Biological Journal of the Linnean Society, v.72, p.161-178, 2001.

STRIER, K. B. Viability analyses of na isolated population of muriqui monkeys (Brachyteles arachnoides): implications for primate conservation and demography. Primate Conservation, v. 14, p.43-52, 1993.

STRIER, K. B. Population viabilities and conservation implications for muriquis (Brachyteles arachnoides) in Brazil's Atlantic forest. Biotropica, v.32, n.4b, p.903913, 2002.

TABARELLI, M.; MANTOVANI, W. A regeneração de uma floresta tropical montana após corte e queima (São Paulo-Brasil). Revista Brasileira de Biologia, v. 59, n. 2, p. 239-250, 1999.

TABARELLI, M., MANTOVANI, W., PERES, C.A. Effects of habitat fragmentation on plant guild structure in the montane Atlantic forest of sotheastern Brazil.

Biological Conservation, v. 91, p. 119-127, 1999.

TABARELLI, M., SILVA, J.M.C., GASCON, C. Forest fragmentation, synergism and the impoverishment of neotropical forests. Biodiversity and Conservation, $v .13$, p.1419-1425, 2004. 
TEAR, T.; SCOTT, J.M.; HAYWORD, P.H.; GRIFFITH, B. Status and prospectus for success of the endangered species act: a look at recovery plans. Science, v.262, p.976-977, 1993.

TERBORGH, J. Keystone plant resources in the tropical forests. In: SOULÉ, M.E. (Ed.). Conservation biology, the science of scarcity and diversity. Sunderland: Sinauer Associates, 1986. p.330-344.

TER BRAAK, C.J.F. Cannonical correspondence analysis: a new eigenvector technique for multivariate direct gradient analysis. Ecology, v. 67, p. 1167-1179, 1986.

TER BRAAK, C.J.F. The analysis of vegetation environment relationships by canonical correspondence analysis. Vegetatio, v. 69, p. 69-77, 1987.

TER BRAAK, C.J.F. CANOCO - a FORTRAN program for canonical community ordination by (partial) (detrended) (canonical) correspondence analysis, principal componente analysis. Version 2.1. Wageningen: Institute of Applied Computer, Science, 1988. 71p.(Technical report LWA-88-02, TNO)

TIEPOLO, L.M.; FERNADEZ, F.A.S.; TOMAS, W.M. A conservação da população de cervo-do-pantanal Blastocerus dichotomus (Illiger, 1815) (Mammalia, Cervidae) no Parque Nacional de Ilha Grande e entorno. Natureza e Conservação, v.2, n.1, p.5666, 2004.

TORRES DE ASSUMPÇÃO, C. An ecological study of the primates of southeastern Brazil, with a reappraisal of Cebus apella races. Edinburgh, 1983. 283p. Thesis (Ph.D.) - University of Edinburgh.

TURNBULL, M. H. Effectof light quantity and quality during development of the photosynthetic characteristics of six Australian rainforest tree species. Oecologia, v.87, p. 110-117, 1991.

VANDERMEER, J.; DE LA CERDA, I. G.; BOUCHER, D. Contrasting growth rate patterns in eighteen tree species from a post-hurricane forest in Nicaragua. Biotropica, v. 29, p. 151-161, 1997.

VAN SCHAIK, C.P.; TERBORGH, J.W.; WRIGHT, S.J. The phenology of tropical forests: adaptive significance and consequences for primary consumers. Annual Review of Ecology and Systematics, v. 24, p. 353-377, 1993

VIEIRA, E. M. Occurence and prevalece of bot flies, Metacuterebra apicalis (Diptera : Cuterebridae), in rodents of cerrado from central Brazil. Journal of Parasitology,.v.79, p. 792-795, 1993. 
VIEIRA, E. M. Estudo comparativo de comunidades de pequenos mamíferos em duas áreas de Mata Atlântica situadas a diferentes altitudes no sudeste do Brasil. Campinas, 1999. 129p. Tese (Doutorado) - Instituto de Biociências, Universidade de Campinas.

VIEIRA, E. M.; MARINHO-FILHO, J. S. Pre and post-fire habitat utilization by rodents of cerrado from central Brazil. Biotropica, v. 30, p. 491-496, 1998.

WANG, E. O que comem os felídeos em uma área de mata atlântica. Rio Claro, 1999. 50p. Dissertação (Mestrado) - Instituto de Biociências, Universidade Estadual Paulista "Júlio de Mesquita Filho".

WHITMORE, T. C. An introdcution to tropical rain forest. London: Blackwell, 1990. $215 p$.

WILLIS, E.O. The composition of avian communities in remanescent woodlots in southern Brazil. Papéis Avulsos de Zoologia, v.33, p.1-25, 1979.

WILliS, E.O.; ONIKI, Y. Aves do Estado de São Paulo. Rio Claro: Divisa, 2003. $398 p$.

WILSON, D.E.; COLE, F.R.; NICHOLS, J.D., RUDRAN, R.; FOSTER, M.S. Measuring and monitoring biological diversity: Standard methods for mammals.Washington: Smithsonian Institution Press, 1996. 316 p.

WORLD WILDLIFE FUNDATION. Áreas protegidas ou espaços ameaçados? Brasília/DF: WWF Brasil. 1999. 96p

WRIGHT, S.J. The myriad consequences of hunting for vertebrates and plants in tropical forests. Perspectives in Plant Ecology, Evolution and Systematics, v.6, p.73- 86, 2003.

WRIGHT, S.J.; CARRASCO, C.; CALDERÓN, O.; PATON, S. The El Niño southern oscillation variable fruti production, and famine in tropical forest. Ecology, v.80, p.1632-1647, 1999.

WRIGHT, S.J.; ZEBALLOS, H.; DOMINGUEZ, I.; GALLARDO, M.M.; MORENO, M.C.; IBANEZ, R. Poachers alter mammal abundance, seed dispersal and seed predation in a neotropical forest. Conservation Biology, v.14, n.1, p.227- 239, 2000.

ZAR, J. H. Biostatistical Analysis. London: Prentice-Hall International, 1996. 96 p. 